DÉBORA COTING BRAGA

\title{
AVALIAÇÃO DE MÉTODOS NUMÉRICOS DE ANÁLISE LINEAR DE ESTABILIDADE PARA PERFIS DE AÇO FORMADOS À FRIO
}

Dissertação apresentada à Escola Politécnica da Universidade de São Paulo para obtenção do título de Mestre em Engenharia.

Área de concentração: Engenharia de Estruturas e Geotécnica.

Orientador: Eduardo M. B. Campello.

São Paulo

2015 
Este exemplar foi revisado e corrigido em relação à versão original, sob responsabilidade única do autor e com a anuência de seu orientador.

São Paulo, de de

Assinatura do autor:

Assinatura do orientador:

\section{FICHA CATALOGRÁFICA}

\section{Braga, Débora Coting}

Avaliação de métodos numéricos de análise linear de estabilidade para perfis de aço formados à frio / D. C. Braga -- versão corr. -- São Paulo, 2015. $121 \mathrm{p}$.

Dissertação (Mestrado) - Escola Politécnica da Universidade de São Paulo. Departamento de Engenharia de Estruturas e Geotécnica.

1.Estabilidade 2.Método dos elementos finitos 3.Flambagem I.Universidade de São Paulo. Escola Politécnica. Departamento de Engenharia de Estruturas e Geotécnica II.t. 


\section{AGRADECIMENTOS}

Ao meu orientador Eduardo M. B. Campello, por toda a dedicação a elaboração deste trabalho.

Aos meus pais, pelo amor, incentivo e apoio incondicional.

Aos colegas de trabalho Daniel Lepikson, Flavio Rubin e Jacques Raigorodsky, pela compreensão e apoio.

Aos colegas do LMC, Eduardo Simões, Paulo Nigro, Jorge Costa, Ricardo Lahuerta, ao professor Ruy Pauletti e ao professor Miguel Bucalem pelas inúmeras discussões sobre modelagem em elementos finitos.

Ao meu professor e amigo Januário Pellegrino Neto, pela motivação a ingressar no mestrado.

A todos que direta ou indiretamente fizeram parte da minha formação, o meu muito obrigado. 
"Tudo o que temos de decidir é o que fazer com o tempo que nos é dado.”

Gandalf, J. R. R. Tolkien 


\section{RESUMO}

Para o projeto de estruturas com perfis de aço formados a frio, é fundamental a compreensão dos fenômenos da instabilidade local e global, uma vez que estes apresentam alta esbeltez e baixa rigidez à torção. A determinação do carregamento crítico e a identificação do modo de instabilidade contribuem para o entendimento do comportamento dessas estruturas. Este trabalho avalia três metodologias para a análise linear de estabilidade de perfis de aço formados a frio isolados, com o objetivo de determinar os carregamentos críticos elásticos de bifurcação e os modos de instabilidade associados. Estritamente, analisase perfis de seção $\mathrm{U}$ enrijecido e $\mathrm{Z}$ enrijecido isolados, de diversos comprimentos e diferentes condições de vinculação e carregamento. Determinam-se os carregamentos críticos elásticos de bifurcação e os modos de instabilidade globais e locais por meio de: (i) análise com o Método das Faixas Finitas (MFF), através do uso do programa computacional CUFSM; (ii) análise com elementos finitos de barra baseados na Teoria Generalizada de Vigas (MEFGBT), via uso do programa GBTUL; e (iii) análise com elementos finitos de casca (MEFcascas) por meio do uso do programa ABAQUS. Algumas restrições e ressalvas com relação ao uso do MFF são apresentadas, assim como limitações da Teoria Generalizada de Viga e precauções a serem tomadas nos modelos de cascas. Analisa-se também a influência do grau de discretização da seção transversal. No entanto, não é feita avaliação em relação aos procedimentos normativos e tampouco análises não lineares, considerando as imperfeições geométricas iniciais, tensões residuais e o comportamento elastoplástico do material.

Palavras-chave: Análise linear de estabilidade, Perfis formados a frio, Método das faixas finitas, Teoria generalizada de viga, Método dos elementos finitos. 


\begin{abstract}
For the design of cold formed steel members, it is essential to understand the effects of local and global instability, since these members typically have a high slenderness and low torsion stiffness. The determination of critical loads and the associated buckling modes contribute to understand the behavior of these members. This work performs a evaluation of three methods for linear stability analysis of isolated cold-formed steel members in order to determine the elastic critical loads and the corresponding buckling modes. Specifically, Ue and Ze shape members were studied with various length, different boundary conditions and loads. The elastic critical loads and buckling modes are determined by means of: (i) analysis with the Finite Strip Method (FSM), by the computer program CUFSM, (ii) beam finite element analysis based on the Generalized Beam Theory (FEM-GBT), by GBTUL program, and (iii) Finite Element Method with shell analysis using ABAQUS program. Some restrictions and warnings regarding the use of the FSM are presented, as well as limitations of the Generalized Beam Theory and precautions to be taken in the shell models. It is also analyzed the influence of the degree of discretization of the cross section. In the present study, no evaluation was made with respect to normative procedures neither nonlinear analyses considering the initial geometric imperfections, residual stresses and elastoplastic behavior of the material.
\end{abstract}

Keywords: Linear stability analysis, Cold formed members, Finite strip method, Generalized beam theory, Finite element method. 


\section{SUMÁRIO}

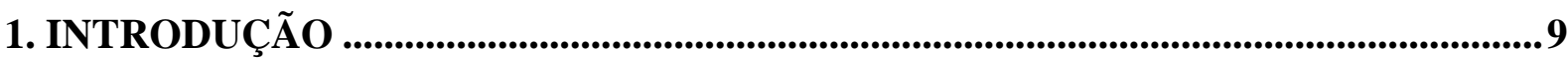

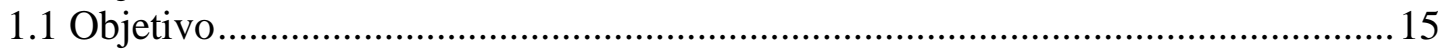

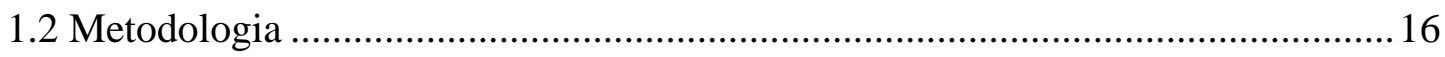

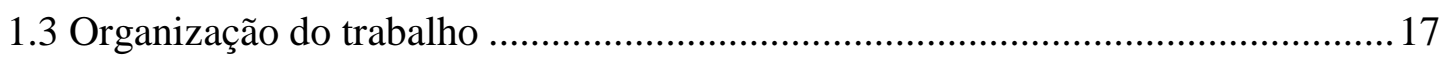

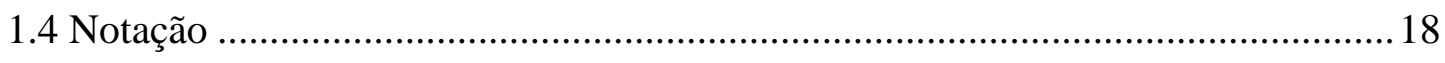

2. TEORIA DA ESTABILIDADE ELÁSTICA APLICADA À ANÁliSE DE PERFIS

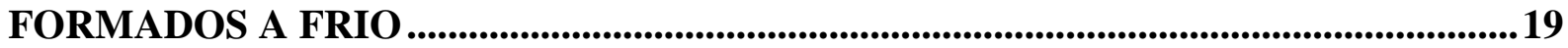

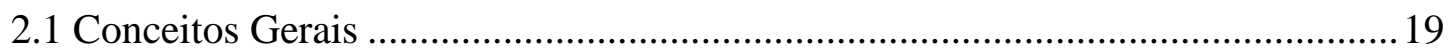

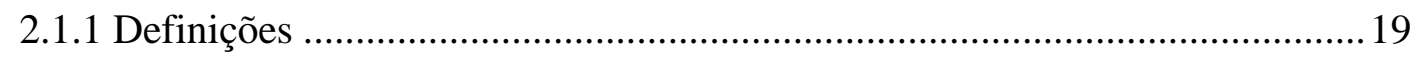

2.1.2 Tipos de Instabilidade Elástica............................................................... 21

2.1.3 Tipos de Instabilidade Bifurcacional .................................................... 24

2.1.4 Métodos de determinação dos Pontos de Bifurcação.....................................26

2.2 Instabilidade global de barras de seção transversal delgada .................................. 34

2.2.1 Instabilidade global por flexão: força crítica de Euler .................................. 36

2.2.2 Instabilidade global por torção e flexotorção: força crítica de Vlasov ........... 38

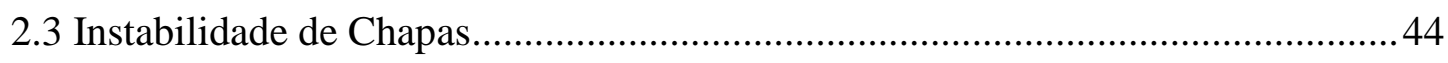

3. MÉTODOS NÚMERICOS DE ANÁLISE LINEAR DE ESTABILIDADE .................53

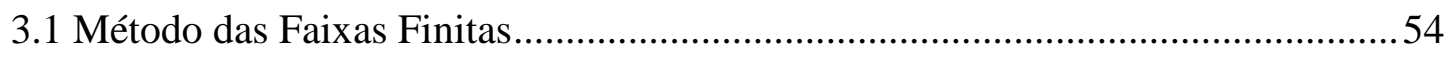

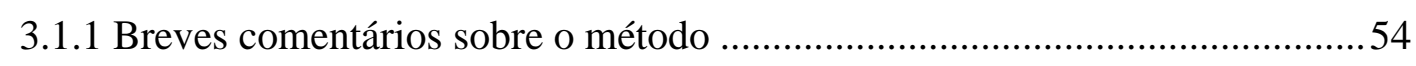

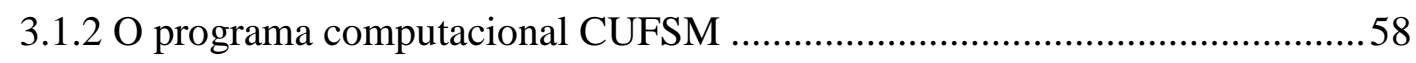

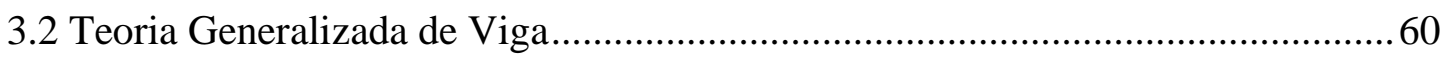

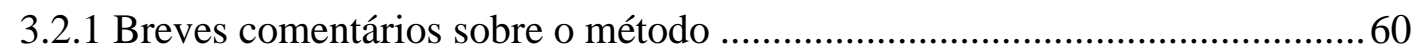

3.2.2 O programa computacional GBTUL................................................... 61

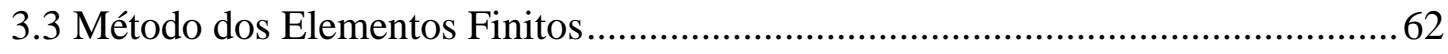

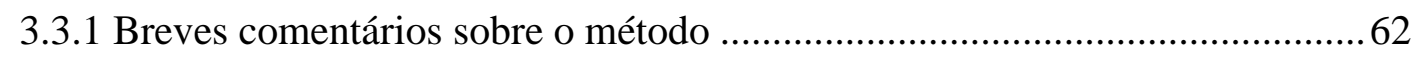

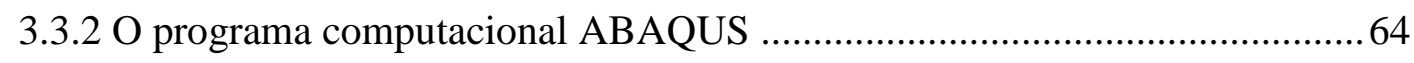


4. APLICAÇÃO: ANÁLISE DE PERFIS Ue E Ze ...................................................................66

4.1 Barra biarticulada submetida a compressão uniforme ........................................ 67

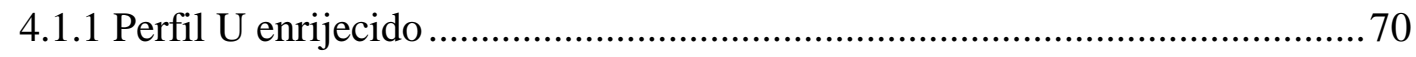

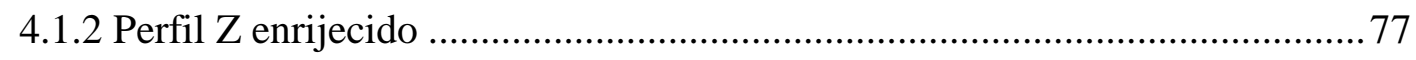

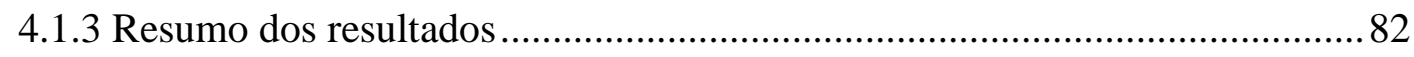

4.2 Barra biarticulada submetida à flexão pura.................................................... 83

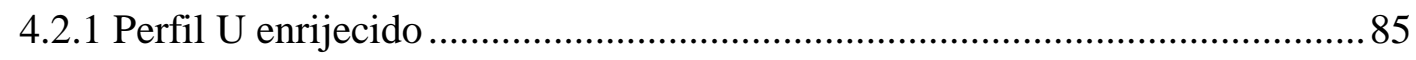

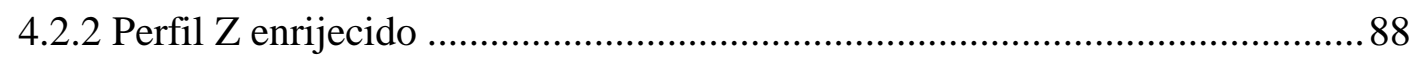

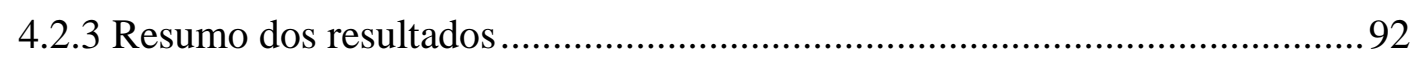

4.3 Barra biarticulada submetida à flexão simples.................................................. 93

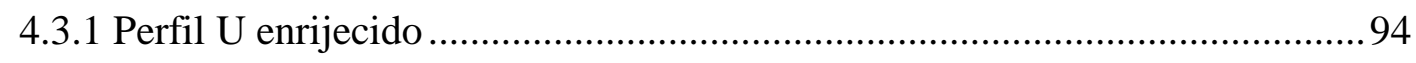

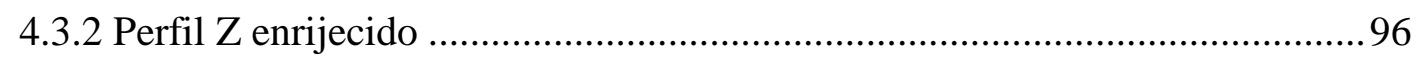

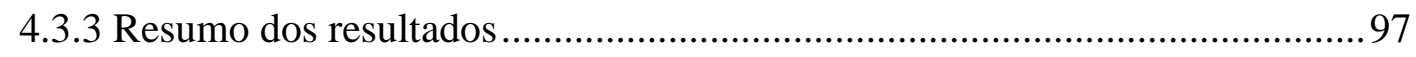

4.4 Barra engastada submetida à flexão simples................................................... 98

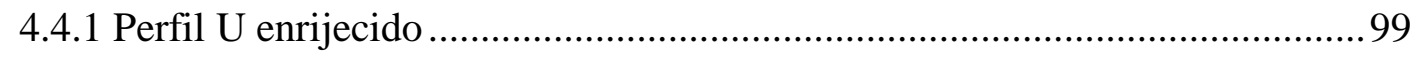

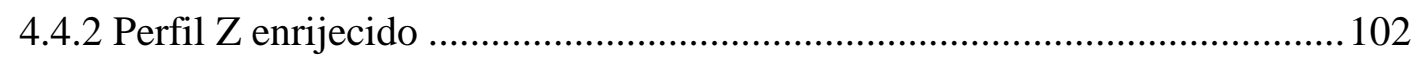

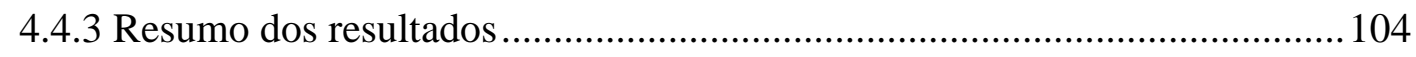

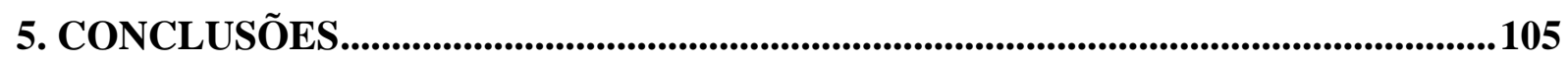

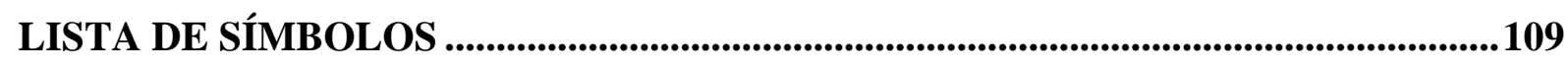

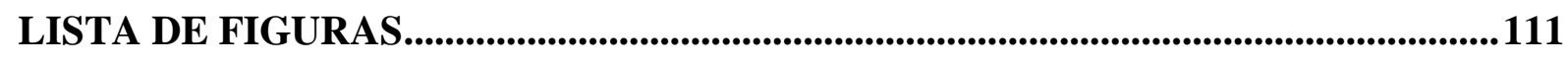

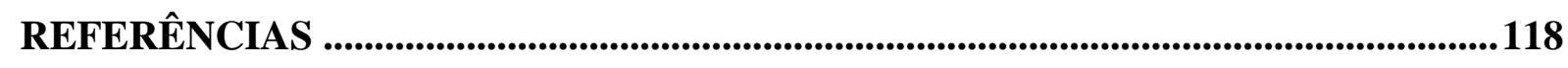




\section{Capítulo 1}

\section{INTRODUÇÃO}

Os perfis de aço formados a frio, ou perfis de chapas dobradas, são amplamente empregados em diversos segmentos da construção civil. O êxito em sua difusão está diretamente relacionado ao bom padrão construtivo, à facilidade de fabricação, à economia no manuseio e na montagem, além de sua demasiada versatilidade. $\mathrm{O}$ aproveitamento desses perfis é motivado também por sua leveza, alta esbeltez e elevada eficiência estrutural. No entanto, tais aspectos corroboram para o surgimento de complicações: a perda de estabilidade passa a ser um aspecto importante no projeto.

Os fenômenos de instabilidade manifestam-se repentina e violentamente, ou seja, as ruínas produzidas por instabilidade ocorrem sem aviso e, quase sempre, produzem grandes danos à estrutura (ZAGOTTIS, 1980). Nesse contexto, o projeto de uma estrutura ou de um elemento estrutural não pode basear-se unicamente em conceitos de segurança relacionados a esforços resistentes e a deformações.

No âmbito da engenharia de estruturas, estabilidade é a tendência de um sistema equilibrado permanecer próximo à sua configuração original quando pequenas perturbações encorajam o sistema a abandoná-la. Considera-se que a estrutura está em equilíbrio estável, estático ou dinâmico, se pequenas perturbações (deslocamentos, impulsos, acelerações) causam pequenos efeitos sobre a configuração original, ou seja, se a estrutura "acomoda" as perturbações impostas, permanecendo próxima ao estado inicial. Entretanto, se pequenas perturbações promovem a busca do equilíbrio em uma configuração distante da original, afirma-se que a estrutura está em equilíbrio instável.

Neste trabalho, é relevante o estudo do comportamento das estruturas em equilíbrio estático, uma vez que é do domínio da engenharia civil - entende-se como 
equilíbrio estático aquele em que o sistema está em repouso ou livre de forças de inércia em sua posição de equilíbrio -. No contexto analisado, a instabilidade pode ocorrer por (i) bifurcação ou (ii) ponto limite, sendo que a primeira contextualiza a instabilidade de barras esbeltas, quando consideradas peças ideais (sem imperfeições geométricas e sem tensões residuais) e de material infinitamente elástico.

A instabilidade bifurcacional é o objeto principal deste estudo e pode ser dividida em (i) simétrica estável, (ii) simétrica instável e (ii) assimétrica. A figura abaixo ilustra o contexto teórico no qual se insere esse trabalho.

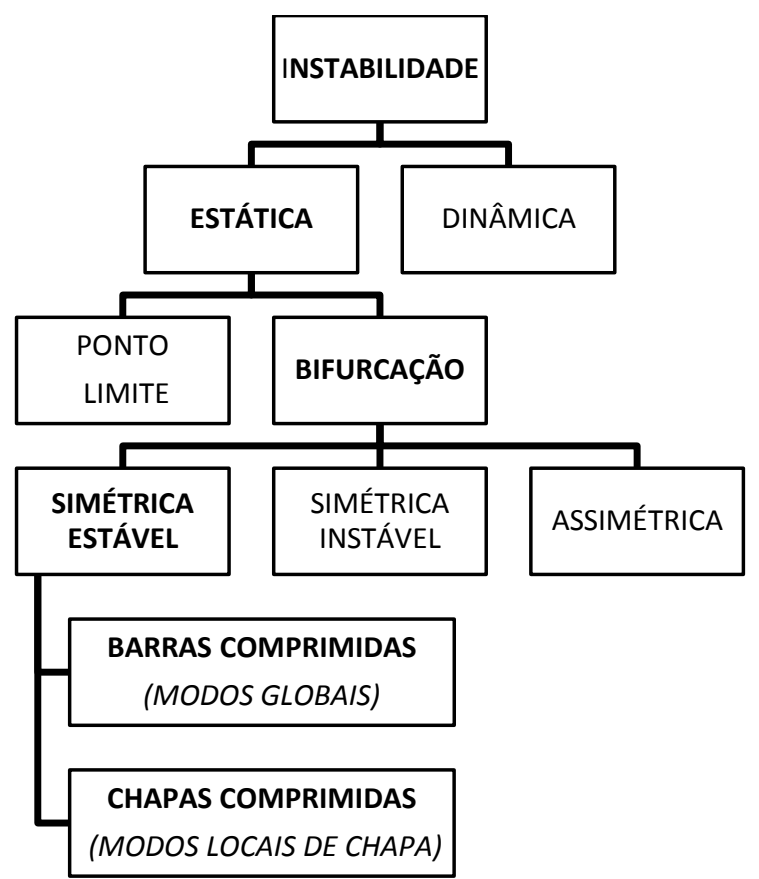

Figura 1.1 - Contextualização da instabilidade de perfis formados a frio.

Nesse ponto, é importante fazer uma observação acerca do uso da palavra "flambagem", que é controverso na literatura técnica nacional. Para muitos, flambagem designa qualquer tipo de instabilidade (i.e., tanto bifurcação quanto ponto limite) e pode ser entendida como a tradução de "buckling". Para outros, designa apenas a instabilidade pelo aparecimento de qualquer ponto de bifurcação, definição defendida por Zagottis (1980) (nessa referência, pode-se ler à página 10.6 que "tal fenômeno será denominado flambagem, ou instabilidade pelo aparecimento de um ponto de bifurcação do equilíbrio"). Finalmente, há aqueles que defendem que a flambagem designa somente a instabilidade por bifurcação simétrica estável, uma das três classificações da instabilidade bifurcacional (curiosamente, muitos creditam essa última definição a Zagottis (1980); contudo, não é isso o que se lê na referida bibliografia). No presente 
trabalho, adotar-se-á o termo "instabilidade" para o caso geral e "flambagem" para o caso específico de bifurcação, conforme a designação dada por Zagottis (1980), fazendo-se menção a "bifurcação simétrica estável” quando necessário.

Os fenômenos de instabilidade são comumente classificados como de natureza global ou local. Os modos de instabilidade globais em barras comprimidas são caracterizados por não envolverem deformação significativa das seções transversais em seu plano, provocando nas seções deslocamentos quase que exclusivamente de corpo rígido. Dessa maneira, são normalmente classificados pelo meio técnico (sobretudo aquele ligado às estruturas de aço) em três possíveis modos: (i) modo global por flexão $(\mathrm{MGF})^{1}$, que ocorre em barras com seções duplamente simétricas ou com simetria em relação a um ponto; (ii) modo global por flexotorção (MGFT) ${ }^{2}$, que ocorre em barras com seções com um ou nenhum eixo de simetria; e (iii) modo global por torção $(\mathrm{MGT})^{3}$, que ocorre por exemplo em barras curtas e de baixa rigidez à torção.

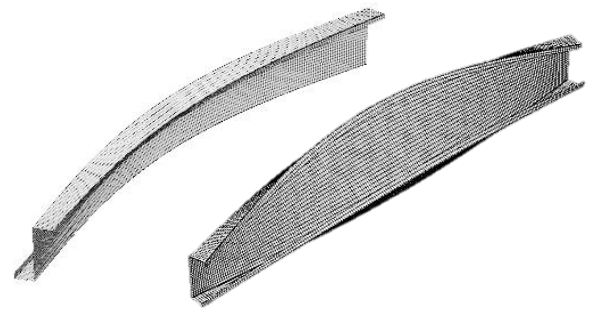

MGF

(a)

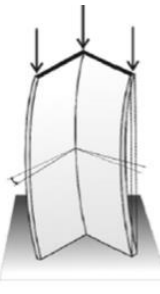

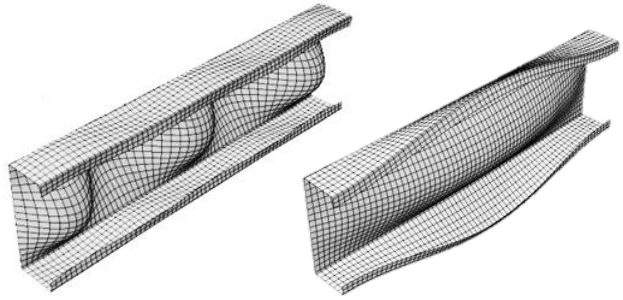

MLC

(d) (e)

Figura 1.2 -Modos de instabilidade classificados em:(a) modo global por flexão, (b) modo global por flexotorção, (c) modo global por torção, (d) modo local de chapa e (e) modo distorcional.

Já os modos de instabilidade locais são aqueles que não envolvem deslocamentos significativos do eixo da barra, mas induzem deformações localizadas, mantendo a barra como um todo em sua posição retilínea original. A maior parte dos perfis de aço formados a frio tem seção aberta formada por paredes muito esbeltas, o que os torna bastante suscetíveis a esses fenômenos de instabilidade localizados.

Os modos locais são convencionalmente divididos em modo local de chapa (MLC) e modo distorcional (MD), como ilustra a Figura 1.2d e Figura 1.2e respectivamente. Por definição, o modo local de chapa caracteriza-se pela conservação

\footnotetext{
${ }^{1}$ Figura 1.2a

${ }^{2}$ Figura 1.2b

${ }^{3}$ Figura 1.2c
} 
da posição original dos cantos dobrados da seção, isto é, as arestas permanecem retas ao longo do comprimento do perfil, apresentando somente deslocamentos de flexão das paredes que constituem o perfil; enquanto que o modo distorcional caracteriza-se pela rotação e possível translação do conjunto formado pela mesa comprimida e seu enrijecedor de borda, com grandes mudanças na forma da seção transversal e nas arestas originalmente retas.

Mesmo que os modos globais, locais de chapa e distorcionais sejam fenômenos aceitos e tratados nas normas de projeto, não existem definições únicas para esses três tipos de instabilidade elástica. Considerando ainda que esses modos puros podem interagir, afirma-se que a análise do comportamento de perfis formados a frio é complexa.

Essas análises de estabilidade costumam ser divididas em dois tipos: (i) análise linear, que permite identificar apenas os modos de instabilidade bifurcacional e o valor dos carregamentos críticos correspondentes a estruturas ideais ${ }^{4}$; e (ii) análise não linear, que permite obter a trajetória de equilíbrio completa da estrutura e, logo, identificar qualquer tipo de ponto crítico (bifurcacional ou por ponto limite), além de avaliar seu comportamento antes e após o(s) ponto(s) crítico(s). Somente na análise não linear, pode-se considerar grandes deslocamentos e rotações, a plastificação do material e a presença de imperfeições geométricas.

As normas de projeto de estruturas em todo o mundo, no que se refere ao cálculo do esforço resistente de perfis formados a frio, baseiam-se, mesmo que indiretamente, na determinação dos carregamentos críticos elásticos de bifurcação associados a cada tipo de instabilidade do perfil. O chamado Método da Resistência Direta (MRD) foi criado por Schafer e Peköz (1998) com a intenção de contornar os problemas encontrados no Método de Largura Efetiva (MLE), para que o processo de dimensionamento não recorresse a cálculos iterativos. O MRD foi incluído em 2004 na norma norte-americana - "North American specification for the design of cold-formed steel structural members" - (AMERICAN IRON STEEL INSTITUTE, 2004) e no anexo C da ABNT NBR 14762 (2010) - "Dimensionamento de estruturas de aço constituídas por perfis formados a frio" - (ASSOCIAÇÃO BRASILEIRA DE

\footnotetext{
${ }^{4}$ Sob elasticidade linear e sem imperfeições geométricas.
} 
NORMAS TECNICAS, 2010). Dessa forma, é muito importante a adequada determinação dos carregamentos críticos elásticos para os diferentes modos de instabilidade desses perfis.

Pesquisas teóricas e experimentais, realizadas em décadas recentes, têm o objetivo de analisar, caracterizar e descrever o comportamento dos perfis formados a frio no que concerne às suas instabilidades. Citam-se nos parágrafos subsequentes alguns trabalhos de referência.

Mulligan e Peköz (1984) procuraram estabelecer uma formulação para descrever satisfatoriamente o comportamento pós-critico até a ruína de chapas esbeltas simplesmente apoiadas e sob compressão centrada, de modo a gerar um modelo de comportamento aproximado do comportamento real. Suas expressões foram desenvolvidas a partir de equações polinomiais para representar a largura efetiva da placa. Mais tarde, Schafer e Peköz (1998) estudaram o efeito das imperfeições geométricas iniciais e as tensões residuais.

No Brasil, Pimenta e Yojo (1993) desenvolveram a base da teoria não linear de barras que possibilitou a implementação do PEFSYS, programa computacional de elementos finitos desenvolvido no Laboratório de Mecânica Computacional da Escola Politécnica da USP. Essa teoria, geometricamente exata, foi complementada posteriormente por Júlio Fruchtengarten (1995), Campello (2000) e Campello e Pimenta (2003), permitindo efetuarem-se análises não lineares em perfis formados a frio considerando de maneira consistente os efeitos do empenamento não uniforme da seção transversal. Mais tarde, Jairo Fruchtengarten (2005) estudou a flambagem lateral de vigas de aço de seção I, comparando os carregamentos críticos obtidos com a teoria não linear geometricamente exata do PEFSYS e as normas de projeto. Jairo concluiu que em geral as recomendações de norma estavam demasiadamente a favor da segurança e que as considerações em relação à restrição ao empenamento eram impostas de maneira inadequada. Fora do âmbito de barras, Campello, Pimenta e Wriggers (2003) formularam um elemento de casca triangular com base na teoria não linear geometricamente exata para a análise não linear de estruturas com materiais em regime elástico e elastoplástico.

Nagahama (2003) contemplou, através do Método dos Elementos Finitos (MEF) e utilizando o programa ABAQUS, análises lineares e não lineares de instabilidade de perfis formados a frio de seção U enrijecido e "rack". Concluiu-se nas análises lineares que a 
restrição ao empenamento não altera os valores do carregamento crítico nos modos locais de placa, no entanto, essa restrição aumenta a rigidez do elemento estrutural no modo distorcional. Nas análises não lineares, observou que as imperfeições geométricas não têm influência significativa na configuração pós-critica de modos locais de placa e modos distorcionais desses perfis; e por fim, que o efeito da plasticidade é especialmente mais importante sobre o modo distorcional do que sobre o modo local de placa. No mesmo ano, Sarawit et al (2003) elaboraram uma síntese da utilização dos programas baseados no MEF para a resolução de problemas de estabilidade de perfis de paredes finas.

Ao mesmo tempo, Chodraui (2003) estudou a abordagem dos procedimentos normativos para a avaliação da flambagem por distorção em barras submetidas à compressão centrada e à flexão. Posteriormente, Chodraui (2006) apresentou análises experimentais de diversos perfis de aço (U, Ue, cantoneira simples e dupla) e comparou-as com o resultado de análises não lineares considerando imperfeições geométricas e tensões residuais no ANSYS e procedimentos normativos. Concluiu que as tensões residuais têm pouca influência na determinação do carregamento crítico desses perfis e que o modelo numérico e as curvas de resistência da ABNT NBR 14762:2010 estão em conformidade com as análises experimentais.

Após alguns anos, Pinto (2010) e Castelani (2012) estudaram o Método da Resistência Direta (MRD) com auxilio do CUFSM. Ainda no âmbito de procedimentos normativos, Silva (2006) realizou diversas análises paramétricas de perfis de aço formados a frio e desenvolveu o programa DIMPERFIL para facilitar a determinação dos esforços resistentes conforme os procedimentos de largura efetiva da norma brasileira ABNT NBR 14762:2010 e da norma americana AISI (2001).

Pierin (2011) desenvolveu ferramentas computacionais para avaliar o comportamento estrutural de pilares ${ }^{5}$ de aço formados a frio em situação de incêndio. $\mathrm{O}$ programa computacional INSTAB foi elaborado para realizar análises lineares e não lineares de estabilidade de perfis formados a frio, empregando o método das faixas finitas confinadas, cFSM, para material elastofrágil, considerando a redução das

\footnotetext{
${ }^{5}$ Barras simplesmente apoiadas submetidas a compressão uniforme.
} 
propriedades mecânicas devido à temperatura. Os resultados foram validados com os obtidos na literatura cientifica e por meio de análises numéricas no ANSYS.

No mesmo ano, com o uso do CUFSM, Barreta (2011) selecionou perfis de chapas dobradas de seção Z com dimensões tais que originassem apenas a bifurcação de MLC e MD na condição simplesmente apoiados e submetidos à compressão uniforme. Em seguida, através de análises não lineares no ABAQUS, concluiu que as imperfeições geométricas de modos distorcionais são mais desfavoráveis no comportamento póscrítico em regime elástico e elastoplástico dos perfis selecionados.

Posteriormente, Mezzomo (2012) estudou a decomposição modal de perfis U enrijecidos biarticulados e biengastados submetidos à compressão pura e à flexão pura. O cálculo de modos de flambagem puros e a quantificação da interação de modos globais e locais foram obtidos através do uso de modelos de elementos finitos restringidos desenvolvidos no MATLAB e comparados com os resultados do cFSM e do GBTUL.

No cenário internacional, recentemente Schafer e Camotim (2013) sumarizaram os trabalhos mais atuais no que concerne os perfis de aço formados a frio.

\subsection{Objetivo}

No contexto da análise linear de estabilidade, o objetivo deste trabalho é avaliar três diferentes métodos numéricos de obtenção dos carregamentos críticos elásticos e seus correspondentes modos de instabilidade, quando aplicados a perfis de chapas dobradas de seção U enrijecido e Z enrijecido (comercialmente denominado "Ue" e "Ze"), para barras isoladas sem restrição ao empenamento e (i) biarticuladas submetidas à compressão uniforme, conforme Figura 1.3a; (ii) biarticuladas submetidas à flexão pura, conforme Figura 1.3b; (iii) biarticuladas submetidas à flexão simples, conforme Figura $1.3 \mathrm{c}$ e (iii) engastadas submetida à flexão simples, conforme Figura 1.3d. Avalia-se também a influência do grau de discretização da seção transversal.

Esse trabalho não tem, por ora, a intenção de estudar os efeitos das tensões residuais e nem das imperfeições iniciais sobre a estabilidade dos perfis. Restringe-se somente a uma avaliação dos métodos numéricos de análise linear de estabilidade, isto é, aqueles que fornecem os carregamentos críticos elásticos. Formalmente, conforme será explicitado nos capítulos subsequentes, a análise consiste na resolução de um 
problema de autovalores e autovetores associado às matrizes de rigidez elástica e geométrica do perfil discretizado (qualquer que seja o método numérico empregado).

(a)

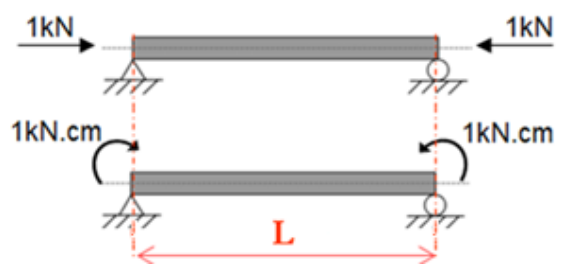

(c)

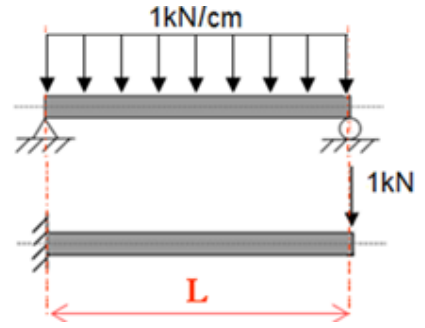

Figura 1.3 - Condições de vinculação e carregamento para a barra: (a) biarticulada submetida a compressão uniforme, (b) biarticulada submetida a flexão pura, (c) biarticulada submetida a carregamento distribuído e (d) engastada submetida a flexão simples.

\subsection{Metodologia}

Tratando-se de análises lineares de estabilidade, citam-se as três metodologias mais consagradas na literatura e no meio técnico para a determinação dos carregamentos críticos de perfis formados a frio:

a) Aquela baseada no uso do Método das Faixas Finitas (MFF), que tira proveito da natureza prismática dos perfis e discretiza a seção transversal em finitos segmentos, sendo que cada um dá origem a uma faixa com uma dimensão longitudinal igual à do comprimento total do perfil conforme a Figura 1.4a;

b) Aquela baseada no uso do Método dos Elementos Finitos em conjunto com a Teoria Generalizada de Vigas (MEF-GBT), desenvolvida por Richard Schardt em 1966, que decorre de uma teoria de elementos finitos de barra enriquecida com a introdução de nós ao longo da seção transversal, permitindo a consideração dos efeitos locais conforme a Figura 1.4b;

c) Aquela baseada no uso do Método dos Elementos Finitos com elementos de casca (MEF-cascas), que é o método numérico mais amplo e popular, e discretiza tanto a seção transversal quanto o eixo longitudinal em finitos elementos conforme a Figura 1.4c. 


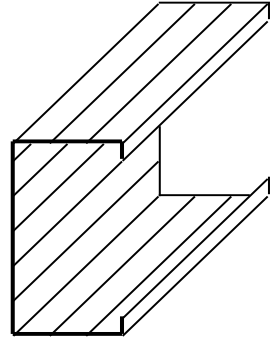

(a)

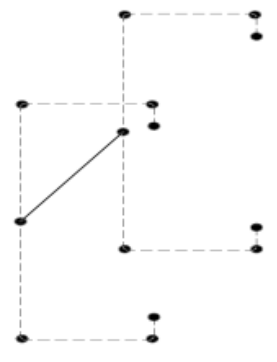

(b)

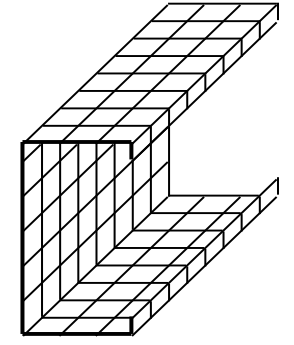

(c)

Figura 1.4 - Apresentação esquemática do (a) MFF, (b) MEF-GBT e (c) MEF-cascas

Essas são as três metodologias a serem avaliadas neste trabalho. Para as três, respectivamente, os seguintes programas computacionais são utilizados nesse trabalho: (i) CUFSM (SCHAFER; ÁDÁNY, 2006), desenvolvido na Universidade Johns Hopkins de Baltimore, Estados Unidos; (ii) GBTul (BEBIANO, et al., 2008), desenvolvido na Universidade Técnica de Lisboa; e (iii) ABAQus (ABAQUS, 2010), comercializado pela Dassault Systemes Simulia Corporation.

\subsection{Organização do trabalho}

Além desse capítulo, no qual foi apresentada a introdução da dissertação, o texto apresenta mais quatro capítulos que são brevemente descritos nos parágrafos a seguir.

O capítulo 2 elucida os conceitos gerais mais importantes para a compreensão da teoria de estabilidade elástica quando aplicada a perfis formados a frio. Apresentam-se algumas definições importantes tais como as de equilíbrio estável e instável; ponto crítico e carregamento crítico; os tipos de instabilidade elástica; as classificações da instabilidade bifurcacional e os métodos mais difundidos para a determinação dos pontos de bifurcação. Aborda-se também a determinação da força crítica de Euler e da força crítica de Vlasov para instabilidade global de barras comprimidas de seção transversal de paredes delgadas. A instabilidade local é abordada no contexto da instabilidade de elementos bidimensionais e os carregamentos críticos referentes aos modos locais de chapa são obtidos através da teoria de instabilidade de placas.

O capítulo 3 está segmentado em três itens dedicados a (i) apresentar brevemente o Método das Faixas Finitas e mostrar os aspectos mais relevantes do programa computacional CUFSM; (ii) abordar brevemente a Teoria Generalizada de Viga e ressaltar os aspectos mais relevantes do programa computacional GBTUL, além de (iii) apontar brevemente o Método dos Elementos Finitos e mostrar os aspectos mais relevantes do programa computacional ABAQUS. 
O capítulo 4 apresenta exemplos de aplicação das três metodologias acima. São mostrados resultados obtidos nas análises lineares de estabilidade para barras isoladas (i) biarticuladas e submetidas à compressão uniforme, (ii) biarticuladas submetidas à flexão pura, (iii) biarticuladas e submetidas à flexão simples e (iv) engastadas e submetidas à flexão simples. Para todas as condições de carregamento e vinculação, são analisados perfis com duas seções transversais distintas: $\mathrm{U}$ enrijecido e $\mathrm{Z}$ enrijecido.

O capítulo 5 apresenta as conclusões obtidas a partir das análises realizadas, a comparação dos métodos empregados e suas vantagens e desvantagens.

Ao final do texto, apresentam-se as listas de símbolos e figuras e são listadas as referências bibliográficas utilizadas durante a elaboração desse trabalho.

\subsection{Notação}

Ao longo de todo o texto, as grandezas vetoriais serão representadas por letras minúsculas em negrito $(\mathbf{u}, \boldsymbol{\varphi}, \ldots)$ e as matrizes por letras maiúsculas também em negrito $(\mathbf{U}, \boldsymbol{\Phi}, \ldots)$. As grandezas escalares serão representadas por letras maiúsculas e minúsculas, porém em estilo normal, ou seja, sem ser negrito, exemplo: a, $P, \lambda, \Pi, \ldots$ 


\section{Capítulo 2}

\section{TEORIA DA ESTABILIDADE ELÁSTICA APLICADA À ANÁLISE DE PERFIS FORMADOS A FRIO}

\subsection{Conceitos Gerais}

Os perfis de aço formados a frio apresentam, em geral, maior esbeltez local (relação entre a largura e a espessura dos elementos) em relação aos clássicos perfis soldados e laminados. Além disso, os perfis de seções abertas com paredes muito delgadas possuem baixa rigidez à torção, tornando-os mais suscetíveis a instabilidades globais.

Neste capítulo serão apresentados alguns conceitos fundamentais sobre a teoria da estabilidade aplicada a estruturas de barras, e os diferentes tipos de instabilidade elástica que podem ocorrer, tais como bifurcação, ponto limite e instabilidade dinâmica. No contexto de instabilidade bifurcacional, serão abordados os diferentes tipos de bifurcação, a saber, (i) simétrica estável, (ii) simétrica instável e (iii) assimétrica, além das metodologias de análise mais empregadas para a determinação do carregamento crítico elástico.

\subsubsection{Definições}

Estabilidade e instabilidade são atributos a fenômenos que estão associados a vários sistemas físicos e químicos. Ao se referir a esses fenômenos, sempre temos em mente algum estado ou comportamento do sistema, que é denominado configuração do sistema. Assim, a estabilidade e a instabilidade são atributos relacionados a estados 
particulares do sistema. Nesse contexto, propõem-se nos parágrafos a seguir as definições com base nas referências (TIMOSHENKO; GERE, 1961), (THOMPSON; HUNT, 1973), (SIMITSES, 1976), (ZAGOTTIS, 1980), (THOMPSON, 1982), (FARSHAD, 1994), (WASZCZYSZYN; CICHÓN; RADWANSKA, 1994), (GAMBHIR, 2004), (PIMENTA, 2006) e (GALAMBOS; SUROVEK, 2008).

Diz-se que uma configuração do sistema está em equilíbrio estável em qualquer instante de tempo se pequenas perturbações nos parâmetros do sistema ou nas condições externas provocam pequenas alterações na configuração original. Em outras palavras, modificações pequenas, por exemplo, na geometria do sistema, ou em suas condições de contorno, ou a imposição de pequenas velocidades iniciais, conduzirão a movimentos pouco afastados da configuração de equilíbrio em que o sistema se encontrava anteriormente às modificações. Diz-se ainda que a configuração de equilíbrio é assintoticamente estável se, para o tempo tendendo a infinito, a configuração do sistema perturbado tender, em termos de posições e velocidades, à configuração de equilíbrio original.

Afirma-se também que a configuração do sistema está em equilíbrio instável se pequenas perturbações nos parâmetros do sistema ou nas condições externas provocam grandes alterações na configuração original, ou seja, modificações pequenas, por exemplo, na geometria do sistema ou em suas condições de contorno, ou a imposição de pequenas velocidades iniciais, conduzirão a movimentos progressivamente mais afastados da configuração de equilíbrio em que o sistema se encontrava anteriormente às modificações.

Finalmente, se a perturbação for exclusivamente de posição, sem a imposição de velocidades, e o sistema permanecer em equilíbrio na posição perturbada, mostra-se que sua configuração é de equilíbrio indiferente ou neutro, o que pode ser considerado um caso particular do equilíbrio instável.

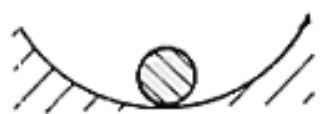

Estável

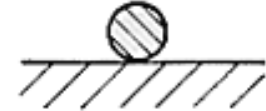

Indiferente

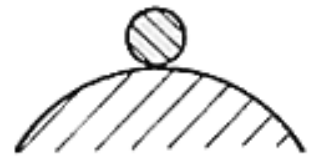

Instável

(a)

(b)

(c)

Figura 2.1 - Estados de equilíbrio (a) estável, (b) indiferente ou neutro e (c) instável. 
Resumidamente, o conceito fundamental de equilíbrio estável, indiferente e instável é ilustrado na Figura 2.1. Essa figura é clássica na literatura e ilustra de maneira simplificada esses conceitos.

A estabilidade e a instabilidade podem ser melhores definidas, de modo geral, utilizando conceitos da dinâmica. No entanto, para sistemas estáticos, isto é, sistemas onde as forças de inércia são desprezáveis frente às demais forças e os carregamentos e vinculações não variam com o tempo, as definições propostas anteriormente são comumente aceitas.

Faz-se necessária também a definição de carregamento crítico, que é o carregamento (seja ele uma força, um conjunto de forças ou momentos) correspondente a um ponto crítico, i.e. um ponto em que a estrutura pode se tornar instável. Um ponto crítico, por sua vez, pode ser de dois tipos: (i) estático, podendo ser classificado como ponto de bifurcação ou ponto limite (ambos caracterizam a perda de estabilidade através de uma mudança brusca do sistema, com o mesmo saltando para uma nova configuração estática de equilíbrio, sendo esse fenômeno conhecido como "buckling" na língua inglesa), ou (ii) dinâmico, caracterizado por induzir movimentos oscilatórios. Essas classificações são abordadas detalhadamente nos itens a seguir.

\subsubsection{Tipos de Instabilidade Elástica}

Entende-se por instabilidade elástica aquela que se processa com o material trabalhando em seu regime elástico. Estruturas elásticas em equilíbrio estável podem perder a estabilidade de diversas maneiras. Os tipos de perda de estabilidade elástica dependem do sistema e das condições externas, incluindo as forças externas e condições de contorno. Distinguem-se aqui a instabilidade elástica (i) bifurcacional, associada a um ponto de bifurcação - este fenômeno é nomeado também como flambagem, e na literatura de língua inglesa como "linear buckling"; (ii) de ponto limite, com reversão da configuração (chamado de "snap-trough") ou sem reversão - sendo chamado também de nonlinear buckling na literatura de língua inglesa; e (iii) dinâmica (como, por exemplo, "flutter" ou drapejamento).

Nos sistemas estruturais, flambagem, ou instabilidade pelo aparecimento de um ponto de bifurcação, é um dos tipos mais comuns de perda de estabilidade e objeto de estudo desde o século XVIII. Uma das primeiras análises de problemas de bifurcação foi apresentada para barras retas isoladas comprimidas em 1744, pelo matemático suíço 
Leonard Euler (THOMPSON, 1982). Em um determinado estágio de carregamento, a trajetória de equilíbrio da barra (curva força externa versus deslocamento de um ponto da estrutura) tem a tendência a se aproximar de um ponto de divergência, ou ponto de bifurcação, a partir do qual dois caminhos passam a ser possíveis. O ponto de bifurcação é a intersecção desses dois caminhos e denota uma possível alteração no comportamento do sistema, uma vez que a partir de tal ponto o mesmo pode seguir dois estados de equilíbrio distintos. Adiante do ponto de bifurcação, o sistema pode: (i) permanecer ao longo da sua trajetória original, a chamada trajetória primária ou trajetória fundamental (correspondente à forma retilínea original da barra), ou (ii) divergir da trajetória original e seguir uma nova trajetória, nomeada de trajetória secundária (correspondente a uma forma em que a barra adquire curvatura), sendo a primeira alternativa instável e a segunda estável. A Figura 2.2 ilustra o carregamento crítico, designado como $\mathrm{P}_{\text {cr. }}$
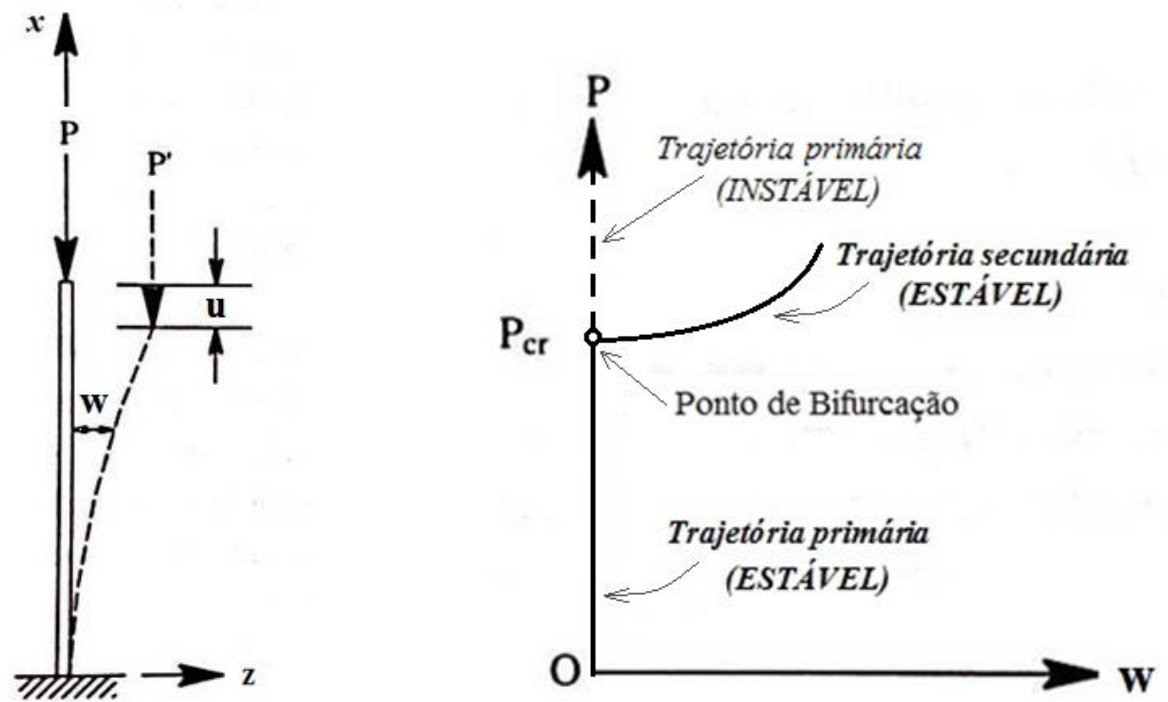

Figura 2.2 -Instabilidade bifurcacional de uma barra comprimida. Adaptado de (GAMBHIR, 2004).

A instabilidade pelo aparecimento de um ponto limite caracteriza-se quando o carregamento atinge um valor crítico associado a um ponto de máximo (local) da trajetória de equilíbrio a partir do qual a estrutura torna-se instável. Em outras palavras, fazendo o carregamento $\mathrm{P}$ crescer a partir de zero, ao atingir o ponto crítico por ponto limite, designado de $\mathrm{P}_{\mathrm{cr}, \mathrm{L}}$, o sistema passa a ter equilíbrio instável, sem ter outra configuração de equilíbrio possível nas proximidades da configuração crítica e sem poder suportar acréscimos de $\mathrm{P}$ a partir de $\mathrm{P}_{\mathrm{cr}, \mathrm{L}}$ sem mudança radical da configuração do sistema. Não há, portanto, bifurcação do equilíbrio; há instabilidade, mas não flambagem. 
Para determinar o carregamento crítico correspondente a uma perda de estabilidade da estrutura por ponto limite, deve-se determinar a trajetória de equilíbrio completa, o que muitas vezes requer a solução do problema estático não linear. Essa, por sua vez, deve ser obtida por meio de métodos iterativos, usando uma estratégia de carregamento incremental, por exemplo, o método de Newton-Raphson. Problemas que apresentam esse tipo de instabilidade possuem grande dificuldade numérica, pois uma vez que a rigidez do sistema torna-se negativa após o ponto limite, o algoritmo deve realizar um decréscimo da força para aumentar os deslocamentos. Nessas situações, deve-se trabalhar com técnicas de continuação para controle do tamanho e direção do incremento, como a técnica do comprimento da corda ou do comprimento de arco.

Um dos casos mais afamados de instabilidade por ponto limite é o fenômeno denominado de snap-through ou reversão da configuração. Como não existe estado de equilíbrio estável possível para valores de carregamento acima do ponto limite nas suas imediações, a reversão da configuração pode ocorrer, que é a busca por uma nova configuração de equilíbrio distante da configuração original. O fenômeno ilustrado na Figura 2.3 é observado, por exemplo, em arcos abatidos e calotas esféricas.
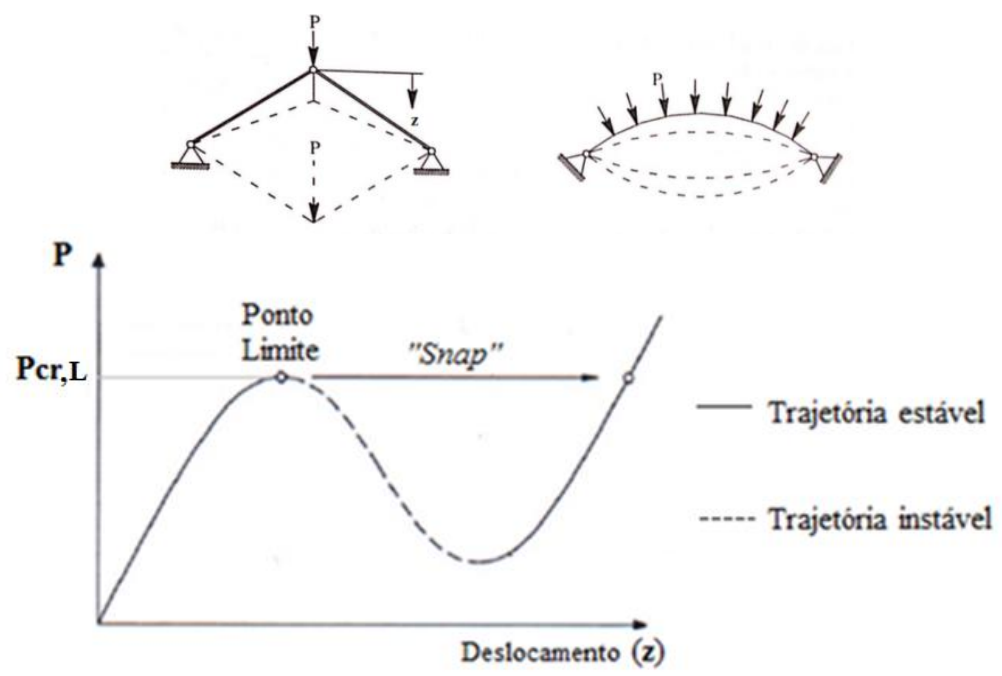

Figura 2.3 -Instabilidade por Ponto Limite. Adaptado de (REIS; DINAR, 2012).

A instabilidade dinâmica, por sua vez, é aquela em que o sistema, ao se tornar instável, passa a sofrer oscilações com aumento da amplitude. A instabilidade dinâmica de sistemas elásticos pode ocorrer, por exemplo, quando as forças aplicadas não são conservativas. Flutter ou drapejamento é o tipo de instabilidade dinâmica ligada à ação de fluidos sobre estruturas ou sólidos deformáveis, onde passam a existir movimentos cíclicos rápidos em que a estrutura ou o sólido absorve energia mecânica do meio, 
consequentemente amplificando a amplitude e a velocidade de seu movimento com o tempo. Quando a velocidade do fluido em relação à estrutura ou ao sólido atinge o valor crítico a partir do qual tais movimentos se tornam possíveis, eles se iniciam bruscamente e acabam em geral conduzindo à ruína da estrutura ou sólido.

O escopo deste trabalho se restringe exclusivamente ao estudo da instabilidade elástica bifurcacional, a qual será mais extensivamente abordada nas seções a seguir.

\subsubsection{Tipos de Instabilidade Bifurcacional}

A instabilidade bifurcacional é dividida em simétrica estável, simétrica instável e assimétrica. A simétrica estável é caracteriza por apresentar duas trajetórias de equilíbrio estáveis e simétricas após atingido o ponto de bifurcação - podem apresentar esse comportamento, por exemplo, chapas e barras esbeltas ideais comprimidas que possuem alguma simetria (geométrica ou de carregamento e vinculação). A simétrica instável é caracterizada por apresentar duas trajetórias de equilíbrio instáveis e simétricas entre si após atingido o ponto de bifurcação - é o caso de estruturas formadas por cascas ou arcos abatidos ideais. Por fim, a assimétrica é caracterizada por apresentar duas trajetórias de equilíbrio, uma estável e outra instável, após a bifurcação - trata-se de cascas cilíndricas ideais.

Os sistemas ideais, ou perfeitos, são idealizações que visam simplificar o comportamento das estruturas, desconsiderando qualquer imperfeição seja essa geométrica, do material ou da forma de aplicação do carregamento. Essa simplificação permite a obtenção do carregamento crítico de bifurcação por meio de análises lineares de estabilidade, i.e. análises de estabilidade por autovalores e autovetores, comumente denominada análise de flambagem ou linear buckling analysis na literatura de língua inglesa.

Os sistemas imperfeitos, i.e. com imperfeições, não apresentam ponto de bifurcação mas podem apresentar pontos limites. Esses sistemas exibem um comportamento não linear cuja trajetória de equilíbrio pode ser determinada através de teorias não lineares (aproximadas ou geometricamente exatas), com processos iterativos de análises incrementais, algoritmos de alto nível de controle, tal como método da corda, que permitam traçar toda a trajetória do sistema. 
Em geral o ponto crítico representa uma situação de colapso para a estrutura e sua estimativa rigorosa requer o uso de teorias não lineares. No caso de pontos de bifurcação, a estimativa por meio de análise linear é apenas uma primeira aproximação que pode ser favorável ou desfavorável à segurança, a depender da sensibilidade da estrutura a imperfeições.

Na Figura 2.4 os sistemas perfeitos são representados por linhas grossas, pretas para trajetórias primárias e azuis para secundárias, enquanto que os sistemas imperfeitos são representados por linhas finas cinzas.

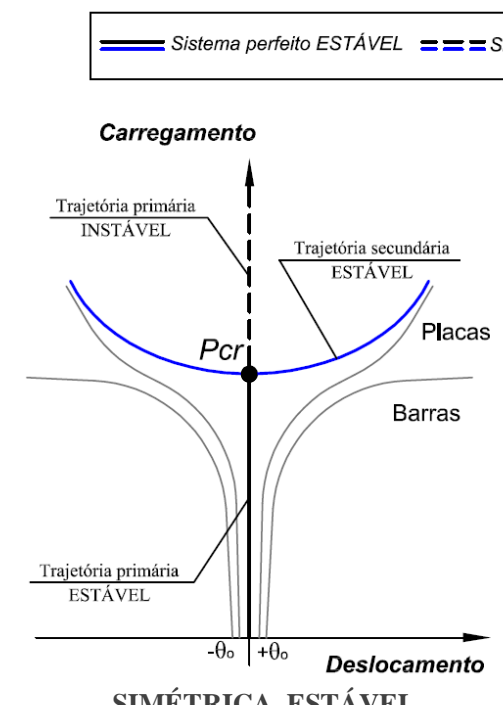

(a)

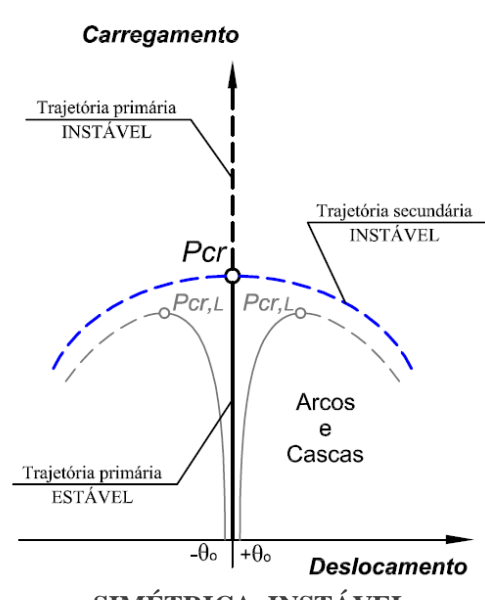

SIMÉTRICA INSTÁVEL

(b)

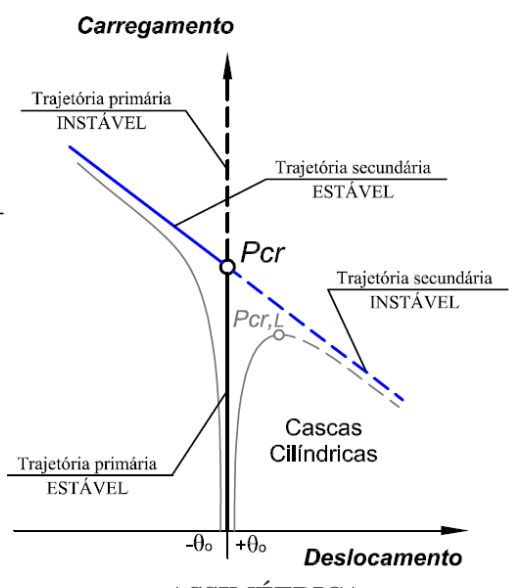

ASSIMÉTRICA

(c)

Figura 2.4 - Instabilidade bifurcacional do tipo (a) simétrica estável, (b) simétrica instável e (c) assimétrica de sistemas perfeitos e imperfeitos; identificação de pontos de bifurcação e carregamentos críticos por bifurcação, $\mathbf{P}_{\mathrm{cr}} \mathbf{e}$ por ponto limite, $\mathbf{P}_{\mathrm{cr}, \mathrm{L}}$.

Tratando-se de placas, Figura 2.4a, o comportamento pós-crítico é estável e à medida que a placa evolui na trajetória pós-crítica, as deformações fora do seu plano causam tensões de tração de membrana que aumentam a rigidez da placa (a rigor, a placa transforma-se em uma casca). Dessa maneira, afirma-se que as placas possuem uma reserva de capacidade no comportamento pós-crítico. Adotar o carregamento crítico de bifurcação, $\mathrm{P}_{\mathrm{cr}}$, para o dimensionamento da placa, neste caso, está a favor da segurança. Por outro lado, não considerar a reserva de capacidade pode acarretar no superdimensionamento da mesma, ou seja, desperdício de recursos.

Ainda na Figura 2.4a, para o caso de barras, há pouco ganho adicional de rigidez, por consequência, nas imediações do ponto crítico, os deslocamentos são muito grandes. Sendo assim, Pcr é uma boa estimativa para o colapso de barras. 
Ao contrário das placas, adotar o carregamento crítico, $\mathrm{P}_{\mathrm{cr}}$, para $\mathrm{o}$ dimensionamento de arcos abatidos e cascas abatidas, está contra a segurança, conforme ilustrado na Figura 2.4b. Falhas catastróficas podem ocorrer, por exemplo, em estruturas de cascas que forem projetadas para carregamentos críticos provenientes de análises lineares. Em alguns casos o carregamento máximo suportado em situações reais (com imperfeições seja na fabricação, seja na aplicação do carregamento) é cerca de $30 \%$ menor do que ao predito para o sistema perfeito, $\mathrm{P}_{\mathrm{cr}}$ (GAY NETO, 2012).

Os sistemas perfeitos ou ideais caracterizados por uma bifurcação assimétrica, por sua vez, são extremamente sensíveis a imperfeições, pois dada uma imperfeição inicial $\left(+\theta_{0}\right.$ ou $\left.-\theta_{0}\right)$, ela causa uma preferência do sistema para uma das trajetórias secundárias, as quais são completamente distintas entre si (podem ser estável ou instável). Em sistemas perfeitos se esta preferência indicar uma configuração desestabilizante é possível que ocorra a ruína da estrutura, como é o caso, por exemplo, de cascas cilíndricas com imperfeições $+\theta_{0}$ conforme a Figura 2.4c.

Conclui-se que, no caso geral, a simplificação do problema de instabilidade através de análises lineares que determinam apenas o ponto de bifurcação é válida somente para sistemas cuja trajetória pós-crítica seja simétrica e estável, ou seja, placas e barras.

\subsubsection{Métodos de determinação dos Pontos de Bifurcação}

Há três metodologias estabelecidas que possibilitam a determinação dos carregamentos críticos, i.e. pontos críticos, para estruturas sujeitas ao fenômeno da instabilidade elástica: (i) o método direto ou do equilíbrio, (ii) o método energético e (iii) o método dinâmico. No âmbito da engenharia civil, cujas estruturas são projetadas para permanecer em equilíbrio estático e estão nas situações mais usuais sob a ação de forças conservativas, as duas primeiras podem ser amplamente empregadas. Embora o método dinâmico seja mais completo, aborda situações que fogem ao escopo desse trabalho e, portanto não será abordado nesse texto.

Apresentam-se a seguir modelos simplificados que abordam as metodologias aplicadas a sistemas conservativos de estruturas de barras em equilíbrio estático. 


\section{- Método Direto ou do Equilíbrio}

Considere o sistema mecânico da Figura 2.5 composto por duas barras infinitamente rígidas $\mathrm{AB}$ e $\mathrm{BC}$ de comprimento $\mathrm{L}$ cada, conectadas entre si no ponto $\mathrm{B}$ por uma mola de rotação de rigidez constante $\mathrm{k}_{\mathrm{m}}$ e articuladas em A e C. As duas barras estão originalmente orientadas ao longo da linha reta $\mathrm{ABC}$. Admite-se que não existem imperfeições geométricas nesse sistema, que o peso próprio das barras é desprezável e que o único carregamento atuante no sistema é a força axial centrada, $\mathrm{P}$, na direção de $\mathrm{ABC}$. Todas as equações de equilíbrio são satisfeitas na configuração retilínea ABC.

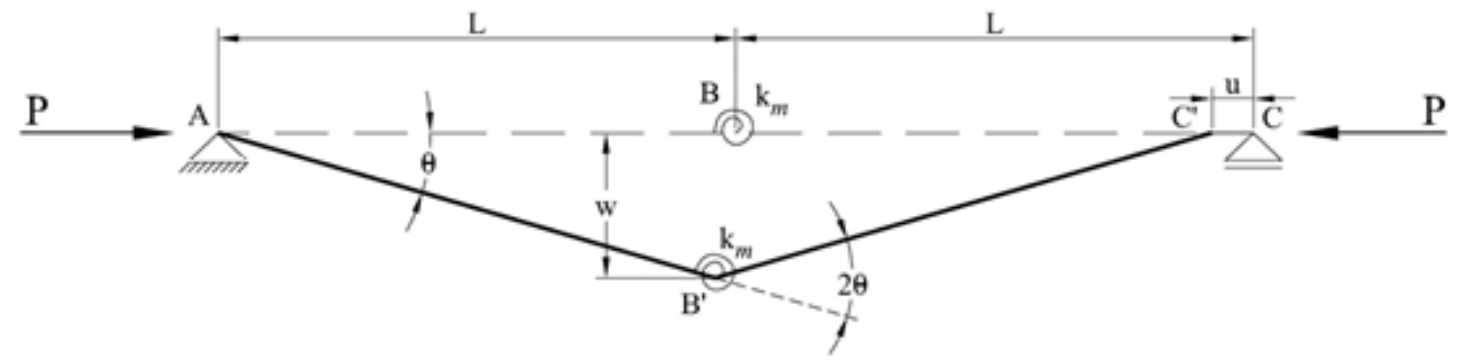

Figura 2.5 - Barras biarticuladas sob compressão.

O parâmetro $\theta$ descreve uma configuração alternativa $A B^{\prime} C^{\prime}$ nas imediações da configuração retilínea (por vezes chamada de "configuração perturbada"), e para que tal configuração possa ser considerada um estado de equilíbrio, as equações de equilíbrio devem ser satisfeitas para a mesma. Para tanto, pode-se escrever o equilíbrio de momentos em torno do ponto B' através da equação simplificada:

$$
2 \mathrm{k}_{m} \theta-\operatorname{PLsen} \theta=0
$$

Define-se um parâmetro adimensional, $p$, denominado fator de carregamento conforme a Eq. (2.2) abaixo:

$$
p=\frac{\mathrm{PL}}{2 \mathrm{k}_{m}}=\frac{\theta}{\operatorname{sen} \theta} .
$$

Esta é uma relação não linear entre o carregamento e a rotação $\theta$ referente à configuração perturbada. A Figura 2.6 mostra a variação do fator de carregamento com o ângulo $\theta$. Linearizando a Eq. (2.1), isto é, considerando apenas os termos de primeira ordem da expansão de senos, obtém-se a seguinte equação de equilíbrio linearizada:

$$
\left(2 k_{m}-\mathrm{PL}\right) \theta=0 \text {. }
$$

Do ponto de vista formal, a Eq. (2.3) pode ser entendida como aquela que conduz a um problema de autovalores para um sistema de dimensão unitária. No caso geral, em 
que o sistema tem $n$ dimensões, o problema de autovalores e autovetores correspondente é apresentado a seguir.

Seja A uma matriz coeficiente quadrada de dimensão $n \times n$ e $\lambda$ um escalar. Se existir um vetor $\boldsymbol{\Phi}$ tal que $\mathbf{A} \boldsymbol{\Phi}=\lambda \boldsymbol{\Phi}$, então diz-se que $\lambda$ é um autovalor de $\mathbf{A}$ e $\boldsymbol{\Phi}$ é o autovetor correspondente. De outra maneira, pode-se escrever a expressão anterior como:

$$
\left[\begin{array}{cccc}
\mathrm{a}_{11} & \mathrm{a}_{12} & \ldots & \mathrm{a}_{1 n} \\
\mathrm{a}_{21} & \mathrm{a}_{22} & \ldots & \mathrm{a}_{2 n} \\
\vdots & \vdots & \ddots & \vdots \\
\mathrm{a}_{n 1} & \mathrm{a}_{n 2} & \ldots & \mathrm{a}_{n n}
\end{array}\right]\left\{\begin{array}{c}
\Phi_{1} \\
\Phi_{2} \\
\vdots \\
\Phi_{\mathrm{n}}
\end{array}\right\}=\lambda\left\{\begin{array}{c}
\Phi_{1} \\
\Phi_{2} \\
\vdots \\
\Phi_{\mathrm{n}}
\end{array}\right\} .
$$

A Eq. (2.4) é equivalente ao seguinte sistema homogêneo:

$$
\left[\begin{array}{cccc}
\mathrm{a}_{11}-\lambda & \mathrm{a}_{12} & \ldots & \mathrm{a}_{1 n} \\
\mathrm{a}_{21} & \mathrm{a}_{22}-\lambda & \ldots & \mathrm{a}_{2 n} \\
\vdots & \vdots & \ddots & \vdots \\
\mathrm{a}_{n 1} & \mathrm{a}_{n 2} & \ldots & \mathrm{a}_{n n}-\lambda
\end{array}\right]\left\{\begin{array}{c}
\Phi_{1} \\
\Phi_{2} \\
\vdots \\
\Phi_{\mathrm{n}}
\end{array}\right\}=\left\{\begin{array}{c}
0 \\
0 \\
\vdots \\
0
\end{array}\right\} .
$$

A forma compacta da Eq. (2.5) pode ser escrita conforme a Eq.(2.6), onde I é a matriz identidade:

$$
(\mathbf{A}-\lambda \mathbf{I}) \Phi=0 .
$$

O sistema de equações lineares tem soluções não triviais, i.e. soluções diferentes do vetor nulo, se o determinante abaixo for nulo:

$$
\operatorname{det}(\mathbf{A}-\lambda \mathbf{I})=\left|\begin{array}{cccc}
\mathrm{a}_{11}-\lambda & \mathrm{a}_{12} & \ldots & \mathrm{a}_{1 n} \\
\mathrm{a}_{21} & \mathrm{a}_{22}-\lambda & \ldots & \mathrm{a}_{2 n} \\
\vdots & \vdots & \ddots & \vdots \\
\mathrm{a}_{n 1} & \mathrm{a}_{n 2} & \ldots & \mathrm{a}_{n n}-\lambda
\end{array}\right|=0
$$

A solução da Eq. (2.7) resulta num polinômio de grau $n$ na variável $\lambda$, chamado de polinômio característico de A. As $n$ raízes da Eq. (2.7) são os autovalores e para cada raiz $\lambda$ há um vetor $\boldsymbol{\Phi}$, não nulo, correspondente que satisfaz a Eq. (2.4). A menor das raízes no contexto da instabilidade bifurcacional está associada ao menor carregamento crítico.

Retomando o caso em estudo, como visto acima a Eq. (2.3) pode ser entendida como um problema de autovalores para um sistema de dimensão unitária e o polinômio resultante é de grau 1, ou seja, para que o sistema tenha solução não trivial a equação abaixo deve ser satisfeita:

$$
2 \mathrm{k}_{m}-\mathrm{PL}=0 .
$$


Na Eq.(2.8), $2 \mathrm{k}_{m}$ representa o termo $a_{11}$ da matriz A da Eq. (2.7) e o termo PL atua como o autovalor $\lambda$. Devido ao fato de o comprimento da barra ser conhecido, o único parâmetro livre é o carregamento $\mathrm{P}$, de forma que há um valor de $\mathrm{P}$ tal que a Eq. (2.3) seja válida para valores não nulos de $\theta$. Tal valor de $\mathrm{P}$ é o carregamento crítico, $\mathrm{P}_{\mathrm{cr}}$ :

$$
\mathrm{P}_{\mathrm{cr}}=\frac{2 \mathrm{k}_{m}}{\mathrm{~L}} .
$$

Este valor corresponde à magnitude de $p=1$, conforme a relação abaixo:

$$
\frac{\mathrm{P}}{\mathrm{P}_{\mathrm{cr}}}=\frac{\mathrm{PL}}{2 \mathrm{k}_{m}}=p
$$

Na Figura 2.6 nota-se que conforme há acréscimo de $p$, a trajetória primária se aproxima de um ponto de bifurcação, indicado pela letra A. A partir desse ponto a trajetória $\mathrm{OA}$ se divide em duas ramificações (i) configuração retilínea $(\theta=0)$, que é instável a partir do ponto $\mathrm{A}$ e (ii) configuração não retilínea $(\theta \neq 0)$, trecho $\mathrm{AE}$, que é estável.

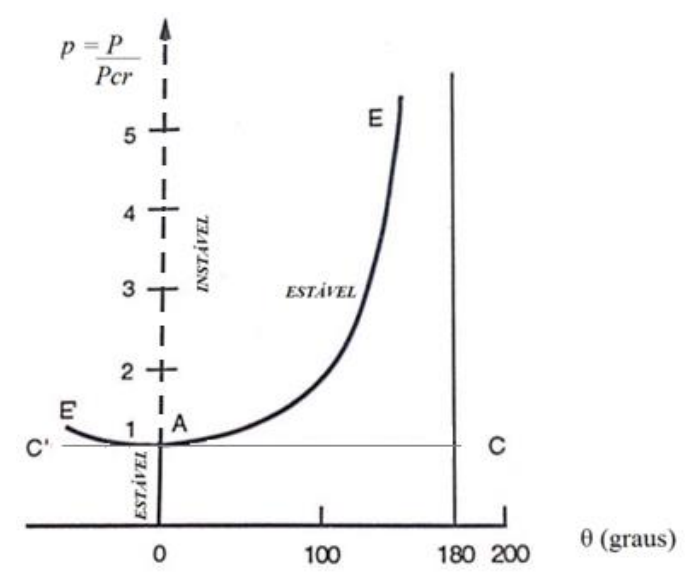

Figura 2.6 - Razão de carregamento, $p$, versus rotação o. Adaptado de (FARSHAD, 1994).

Como mencionado, a versão linearizada da equação de equilíbrio conduz a um problema de autovalor, cujo carregamento crítico é o autovalor e o modo de deformação é o autovetor da estrutura. No problema de autovalor linearizado, a magnitude dos deslocamentos na configuração pós-crítica permanece indefinida. A determinação dos deslocamentos só pode ser estudada satisfatoriamente com a formulação não linear do problema, i.e. por meio da Eq. (2.1), ou seja, à luz de um modelo que acomode (seja de forma aproximada ou de forma geometricamente exata) deslocamentos ou rotações de magnitude moderada ou grande. 
A utilização do Método Direto ou do Equilíbrio no exemplo considerado foi possível sem grandes dificuldades matemáticas, devido à simplicidade do sistema estrutural apresentado. Em sistemas mais complexos, o método não apresenta dificuldades conceituais novas, mas torna-se, de forma geral, bastante trabalhoso quando não impossível de ser resolvido analiticamente. Por esse motivo, é comum recorrer-se ao método energético, que envolve indiretamente o equacionamento do equilíbrio do sistema ao mesmo tempo em que permite mais facilmente o uso de técnicas numéricas para a solução das equações correspondentes. Esse método é o objeto do próximo tópico.

\section{- Método Energético}

O Método Energético constitui uma ferramenta poderosa para a análise de estabilidade. Para demonstrar suas características principais, considera-se novamente o modelo simplificado da Figura 2.5. A energia potencial total é a soma algébrica do trabalho realizado pelas forças externas e o trabalho realizado pelas forças internas, ou energia de deformação.

O trabalho realizado pelas forças internas, i.e. a energia de deformação, contém contribuição apenas da mola (pois as barras AB e BC são admitidas indeformáveis), sendo dado por:

$$
\mathrm{U}=\frac{1}{2} \mathrm{k}_{m}(2 \theta)^{2} .
$$

E o trabalho realizado pelas forças externas é dado por:

$$
\mathrm{W}=-\mathrm{Pu}=-\mathrm{P} 2 \mathrm{~L}(1-\cos \theta) \text {. }
$$

Portanto a energia potencial total é expressa pela seguinte equação:

$$
\Pi=\mathrm{U}+\mathrm{W}=2 \mathrm{k}_{m} \theta^{2}-2 \mathrm{PL}(1-\cos \theta) .
$$

De acordo com os princípios variacionais da mecânica dos sólidos deformáveis, a condição de estacionariedade da energia potencial total garante que, para sistemas conservativos, o sistema estará em equilíbrio estático. Portanto, impondo a condição de estacionariedade, i.e. igualando a zero a primeira variação de П (variação que, neste caso, coincide com o diferencial da primeira derivada) em relação a $\theta$, obtém-se a seguinte equação de equilíbrio:

$$
\frac{\mathrm{d} \Pi}{\mathrm{d} \theta}=4 \mathrm{k}_{m} \theta-2 \mathrm{PL} \operatorname{sen} \theta=0 \text {. }
$$


Nota-se que esta relação é idêntica à Eq. (2.1) obtida para o método do equilíbrio e o processo para a determinação do carregamento crítico a partir da Eq. (2.14) recai no clássico problema de autovalores como visto no método anterior.

De acordo com o Teorema de Lagrange-Dirichlet, uma condição de equilíbrio de um sólido conservativo seja estável é que a segunda variação da energia potencial seja positivo-definida nesta configuração. O equilíbrio será estável para todos os casos em que a configuração corresponder a um ponto de mínimo da energia potencial, e instável se corresponder a um ponto de máximo, conforme ilustrado na Figura 2.7. Neste caso, tem-se:

$\frac{\mathrm{d}^{2} \Pi}{\mathrm{d} \theta^{2}}=4 \mathrm{k}_{m}-2 \mathrm{PLcos} \theta=4 \mathrm{k}_{m}(1-p \cos \theta)$.

Em particular, para a condição $\theta=0$ :

$\frac{\mathrm{d}^{2} \Pi}{\mathrm{d} \theta^{2}}=4 \mathrm{k}_{m}(1-p)$.

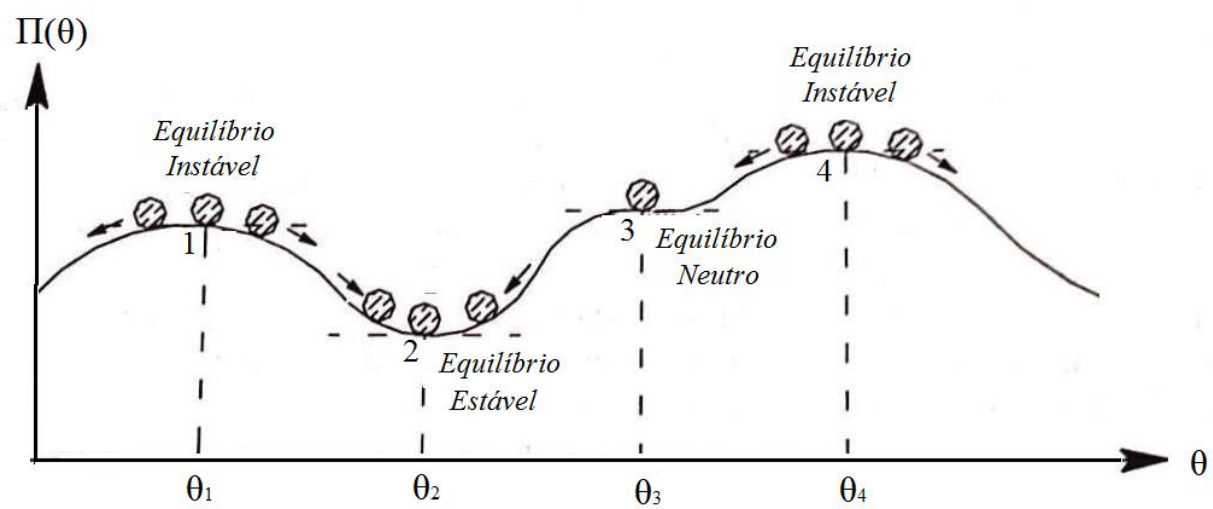

Figura 2.7 - Variação da energia potencial total, П. Adaptado (GAMBHIR, 2004).

Através da investigação do sinal da segunda variação de П, pode-se afirmar que:

- Para valores de $p<1$, tem-se $\mathrm{d}^{2} \Pi / \mathrm{d} \theta^{2}>0$, o que representa um ponto de mínimo, consequentemente o equilíbrio é estável;

- Para valores de $p>1$, tem-se $\mathrm{d}^{2} \Pi / \mathrm{d} \theta^{2}<0$, o que representa um ponto de máximo, consequentemente o equilíbrio é instável;

- Para valores de $p=1$, tem-se $\mathrm{d}^{2} \Pi / \mathrm{d} \theta^{2}=0$, não há mudança nos níveis da energia potencial total, consequentemente o equilíbrio é neutro, ou indiferente.

O sistema tem a tendência natural de procurar um nível de energia mais baixo. Em alguns casos esse nível de energia inferior exige outra configuração do sistema, o que 
no caso da Figura 2.5 leva a estrutura a abandonar a configuração retilínea e encontrar um estado de equilíbrio correspondente a um mínimo da energia potencial, tornando-se por sua vez uma configuração de equilíbrio estável.

Em muitos casos não é possível determinar a solução analítica do problema associado ao método energético devido às complexidades da geometria, carregamentos e condições de contorno; para isso utiliza-se de métodos numéricos. O método de Rayleigh-Ritz, por exemplo, foi muito utilizado no passado (e ainda até hoje, como ponto de partida de muitos procedimentos numéricos) e faz uso de funções de aproximação geralmente sob a forma polinômios ou funções trigonométricas. As funções de aproximação devem satisfazer as condições de contorno e contêm coeficientes a serem determinados através da minimização da energia potencial.

Por exemplo, seja w o deslocamento aproximado de uma barra sem peso conforme a Figura 2.8, expresso em termos de uma soma de funções de aproximação conhecidas $\Psi_{i}(\mathrm{x})(\mathrm{i}=1, \ldots, \mathrm{n})$, também chamadas funções de forma, que variam em $\mathrm{x}$, e de coeficientes a serem determinados $\mathrm{a}_{i}(\mathrm{i}=1, \ldots, \mathrm{n})$, conforme a Eq. (2.17).

$$
\mathrm{w}=\sum_{i=1}^{n} \mathrm{a}_{i} \Psi_{i}(x)
$$

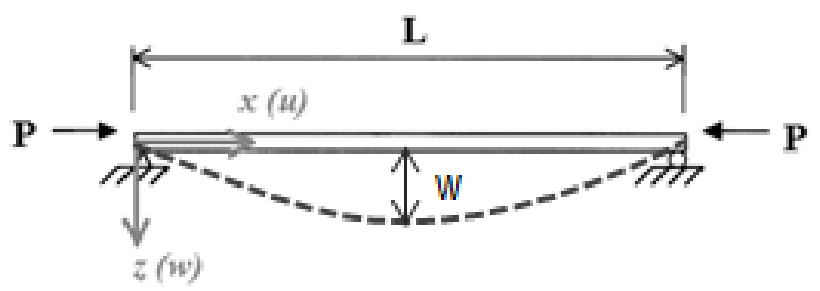

Figura 2.8 - Deflexão de uma barra comprimida simplesmente apoiada de comprimento $L$ e produto de rigidez à flexão EI constante.

Inserindo um escalar $\lambda$ para parametrizar o carregamento, a energia potencial total devido à flexão causada pelo carregamento $\lambda \mathrm{P}$ é definida como:

$$
\Pi=\mathrm{U}+\mathrm{W}=\frac{1}{2} \mathrm{EI} \int_{0}^{\mathrm{L}}\left(\mathrm{w}^{\prime \prime}\right)^{2} \mathrm{dx}-\frac{1}{2} \lambda \int_{0}^{\mathrm{L}} \mathrm{P}\left(\mathrm{w}^{\prime}\right)^{2} \mathrm{dx} .
$$

Substituindo a Eq. (2.17) na expressão do funcional da energia potencial total e realizando a integração no espaço das variáveis, o funcional torna-se uma função de coeficientes indeterminados $\mathrm{a}_{i}$, como segue:

$$
\Pi=\mathrm{F}_{U}\left(\mathrm{a}_{1}, \mathrm{a}_{2}, \ldots, \mathrm{a}_{n}\right)-\lambda \mathrm{F}_{W}\left(\mathrm{a}_{1}, \mathrm{a}_{2}, \ldots, \mathrm{a}_{n}\right) .
$$


$\mathrm{F}_{U}$ e $\mathrm{F}_{W}$ são neste caso funções quadráticas que representam a energia de deformação e o trabalho das forças externas, em função dos coeficientes arbitrários $\mathrm{a}_{i}$. Impondo a condição de estacionariedade, isto é, $\delta \Pi=0$, é possível determinar cada um dos coeficientes da soma através da seguinte equação:

$$
\frac{\partial \Pi}{\partial \mathrm{a}_{i}}=0 \quad i=1,2, \ldots, n .
$$

Como a primeira derivada de funções quadráticas são funções lineares, a Eq. (2.20) representa um conjunto de $n$ equações lineares homogêneas em termos das variáveis independentes $\mathrm{a}_{1}, \mathrm{a}_{2}, \ldots, \mathrm{a}_{n}$, que pode ser escrito da seguinte maneira:

$$
\begin{gathered}
\frac{\partial \mathrm{F}_{U}}{\partial \mathrm{a}_{1}}-\lambda \frac{\partial \mathrm{F}_{W}}{\partial \mathrm{a}_{1}}=0 \\
\frac{\partial \mathrm{F}_{U}}{\partial \mathrm{a}_{2}}-\lambda \frac{\partial \mathrm{F}_{W}}{\partial \mathrm{a}_{2}}=0 \\
\vdots \\
\frac{\partial \mathrm{F}_{U}}{\partial \mathrm{a}_{\mathrm{n}}}-\lambda \frac{\partial \mathrm{F}_{W}}{\partial \mathrm{a}_{\mathrm{n}}}=0
\end{gathered}
$$

Para existir soluções não triviais, i.e. outras configurações de equilíbrio que não sejam a retilínea, o determinante do sistema de equações acima deve ser zero. Isso resulta em uma equação polinomial de grau $n$, cujas raízes são os autovalores. A princípio as $n$ raízes são de interesse, porém, muitas vezes, o mais importante é o menor dos autovalores, pois é aquele que pode ser atingido primeiro.

De maneira alternativa, porém equivalente, pode-se definir o chamado quociente de Rayleigh, conforme:

$$
\rho=\frac{\mathrm{F}_{U}\left(\mathrm{a}_{1}, \mathrm{a}_{2}, \ldots, \mathrm{a}_{n}\right)}{\mathrm{F}_{W}\left(\mathrm{a}_{1}, \mathrm{a}_{2}, \ldots, \mathrm{a}_{n}\right)} .
$$

Em que a minimização do quociente fornece o seguinte conjunto de equações lineares:

$$
\frac{\partial \rho}{\partial \mathbf{a}_{i}}=0 \quad i=1,2, \ldots, n
$$

Atualmente, muitos métodos numéricos utilizados para a análise linear de estabilidade, como por exemplo, o método dos elementos finitos, podem ser vistos como uma generalização das ideias do método de Rayleigh-Ritz. Nesse caso, à parte das especificidades acerca das funções de aproximação de cada método, incide-se invariavelmente em um problema de autovalores exatamente análogo ao apresentado 
acima, cuja solução fornece o valor dos carregamentos críticos e os correspondentes modos de instabilidade.

Nas próximas duas seções serão abordadas as particularidades da instabilidade de barras e de chapas comprimidas. Essas últimas, por sua vez, são de grande importância para o entendimento da estabilidade de perfis formados a frio.

\subsection{Instabilidade global de barras de seção transversal delgada}

A instabilidade global de barras de seção transversal de paredes delgadas, no caso de barras comprimidas ou fletidas, é caracterizada pela ocorrência preponderante de deformação do eixo da barra, sendo que a sua seção transversal apresenta quase que exclusivamente deslocamentos de corpo rígido, i.e. translações e rotações sem deformação em seu plano.

A tendência em reduzir o peso das estruturas produz barras com paredes cada vez mais delgadas, tornando os elementos estruturais suscetíveis aos fenômenos de instabilidade, conforme citado anteriormente.

Convencionalmente, uma barra é considerada de seção delgada quando suas dimensões relativas satisfazem a seguinte ordem de grandeza:

$$
\frac{\mathrm{t}}{\mathrm{d}} \leq 0,1
$$

Na relação acima, t é a espessura da parede e d representa uma dada dimensão de interesse da seção (por exemplo, a largura de uma parede).

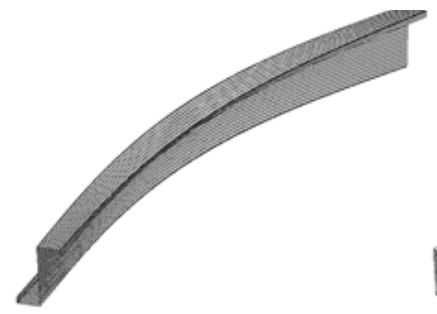

(a)

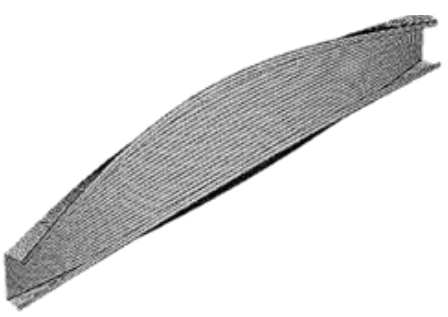

(b)

Figura 2.9 - Modos de instabilidade globais (a) por flexão, e (b) por flexotorção.

Conforme já mencionado, a instabilidade global dessas barras pode ocorrer de três maneiras: (i) modo global por flexão, MGF - ocorre em barras com seção duplamente simétrica ou seção com um ponto de simetria conforme Figura 2.9a, (ii) modo global 
por torção, MGT - ocorre em especial em barras curtas com seção cruciforme e com baixa rigidez a torção e (iii) modo global por flexotorção, MGFT - ocorre em barras com seção com um ou nenhum eixo de simetria, conforme Figura 2.9b.

Ressalta-se que tanto a instabilidade por flexão como a instabilidade por torção são casos particulares do caso geral de instabilidade por flexotorção (FARSHAD, 1994), este caracterizado pela mudança de posição do centro de cisalhamento, ou centro de torção, ocorrendo na seção transversal translações e rotações de corpo rígido. Se acontecerem somente as translações o fenômeno é devido à flexão, ao passo que se ocorrerem somente rotações o fenômeno é devido à torção.

Conforme referido no capítulo 1, no âmbito da mecânica das estruturas a teoria linear de estabilidade elástica teve seu início com os trabalhos de Euler, em 1744, sobre a instabilidade global por flexão de barras comprimidas simplesmente apoiadas. Durante muitas décadas, esse foi o único fenômeno de instabilidade estudado. No final do século XIX, Prandtl e Michell revisitaram o problema e estudaram a instabilidade de vigas de seção transversal retangular em regime elástico para determinar as equações diferenciais que regem o fenômeno, utilizando a teoria de torção uniforme de SaintVenant (1855). Posteriormente, por volta de 1910, Wagner e Timoshenko (separadamente) estudaram o efeito do empenamento em vigas com seção transversal de seção I.

A determinação dos pontos de bifurcação de barras, associados à instabilidade global, ao longo de anos foi alvo de estudo de muitos engenheiros e pesquisadores. Em meados de 1960, a resistência dos materiais recebeu um considerável avanço com a teoria proposta por Vasilii Zakharovich Vlasov, para barras com paredes abertas e seção delgada (MORI; NETO, 2009). Inicialmente, a teoria foi aplicada a problemas relativamente simples, os quais não demandavam grandes esforços para a obtenção da solução analítica. Entre as décadas de 1960 e 1970, a evolução dos métodos de resolução com o uso de técnicas computacionais possibilitou a análise de problemas mais complexos. Diversas teorias de barras (incorporando, por exemplo, grandes deslocamentos e grandes rotações, descrições mais detalhadas do empenamento, entre outros) sugiram desde então, fazendo uso, sobretudo, do método dos elementos finitos para a solução de suas equações. 
Nas seções a seguir serão apresentadas algumas das metodologias empregadas para a determinação do carregamento crítico, i.e. pontos críticos, para barras comprimidas suscetíveis a instabilidade global por flexão, torção e flexotorção.

\subsubsection{Instabilidade global por flexão: força crítica de Euler}

Esta seção está inserida na teoria clássica de barras, denominada teoria de Bernoulli-Euler, onde se supõe que as seções transversais permanecem planas e ortogonais a um determinado eixo da barra, portanto não sendo considerados o empenamento e a distorção por força cortante.

Seja uma barra ideal, sem peso, simplesmente apoiada e submetida a uma força concentrada P, conforme a Figura 2.8 (página 32), cujo deslocamento na direção do eixo vertical z é representado por "w". Para a barra de comprimento L e produto de rigidez à flexão EI constante, admitindo válidas as hipóteses da teoria de Bernoulli-Euler, tem-se a equação diferencial conforme Eq. (2.24).

$$
\mathrm{EI} w^{i v}+\mathrm{P} w^{\prime \prime}=0,
$$

cuja solução geral é apresentada na Eq. (2.25), sendo $\lambda^{2}=$ P/EI.

$$
w(x)=a_{1}+a_{2} x+a_{3} \operatorname{sen}(\lambda x)+a_{4} \cos (\lambda x) .
$$

Impondo as condições de contorno para barras biarticulada, ou seja, $w=w^{\prime \prime}=0$ para $\mathrm{x}=0$ e $\mathrm{x}=\mathrm{L}$, pode ser escrever as seguintes relações:

$$
\begin{aligned}
& \mathrm{w}(0)=0=a_{1}+a_{4}, \\
& \mathrm{w}^{\prime \prime}(0)=0=-a_{4} \lambda^{2}, \\
& \mathrm{w}(L)=0=a_{1}+a_{2} L+a_{3} \operatorname{sen}(\lambda L)+a_{4} \cos (\lambda L), \\
& \mathrm{w}^{\prime \prime}(L)=0=-a_{3} \lambda^{2} \operatorname{sen}(\lambda L)-a_{4} \lambda^{2} \cos (\lambda L) .
\end{aligned}
$$

Estas relações podem ser reescritas de forma matricial, como apresentado abaixo:

$$
\left[\begin{array}{cccc}
1 & 0 & 0 & 1 \\
0 & 0 & 0 & -\lambda^{2} \\
1 & L & \operatorname{sen}(\lambda L) & \cos (\lambda L) \\
0 & 0 & -\lambda^{2} \operatorname{sen}(\lambda L) & -\lambda^{2} \cos (\lambda L)
\end{array}\right]\left\{\begin{array}{l}
a_{1} \\
a_{2} \\
a_{3} \\
a_{4}
\end{array}\right\}=0
$$

Os coeficientes $a_{\mathrm{i}}$ definem a linha elástica da barra e, na configuração pós-crítica (admitida muito próxima da configuração original para que continuem válidas as hipóteses de pequenos deslocamentos e pequenas rotações - o que é uma inconsistência, 
já que a instabilidade provoca um salto para uma configuração distante), pelo menos um deve ser diferente de zero para que ela não seja igual à configuração retilínea. Assim, para que a Eq. (2.26) admita solução não trivial, o determinante abaixo deve ser nulo:

$$
\left|\begin{array}{cccc}
1 & 0 & 0 & 1 \\
0 & 0 & 0 & -\lambda^{2} \\
1 & L & \operatorname{sen}(\lambda L) & \cos (\lambda L) \\
0 & 0 & -\lambda^{2} \operatorname{sen}(\lambda L) & -\lambda^{2} \cos (\lambda L)
\end{array}\right|=0
$$

A solução da Eq. (2.27) leva à seguinte equação característica:

$$
\lambda^{4} L \operatorname{sen}(\lambda L)=0
$$

Para que existam soluções não triviais a equação abaixo deve ser satisfeita.

$$
\operatorname{sen}(\lambda L)=0 \rightarrow \lambda \mathrm{L}=\mathrm{n} \pi, \quad \mathrm{n}=1,2,3 \ldots
$$

A Eq. (2.29) implica a existência de infinitas raízes, i.e. infinitos pontos de bifurcação. De outra maneira, pode-se escrever a Eq. (2.29) em função dos parâmetros P, E e I, tal que:

$$
\lambda \mathrm{L}=\sqrt{\frac{P L^{2}}{E I}}=n \pi, \quad \mathrm{n}=1,2,3 \ldots
$$

Como se admitiu inicialmente que a rigidez a flexão EI é constante ao longo do comprimento L, o único parâmetro livre é o carregamento aplicado, P. Este, por sua vez, recebe o título de carregamento crítico, $\mathrm{P}_{\mathrm{cr}}$, por estar associado a um ponto crítico.

$$
\mathrm{P}_{c r}=\frac{n^{2} \pi^{2} E I}{L^{2}}, \quad \mathrm{n}=1,2,3 \ldots
$$

Substituindo a Eq.(2.30) na Eq.(2.26), os coeficientes $a_{1}, a_{2}$ e $a_{4}$ resultam nulos e, portanto, a Eq.(2.25) pode ser reescrita na forma:

$$
w(x)=a_{3} \operatorname{sen}\left(\frac{\mathrm{n} \pi}{L} x\right), \quad \mathrm{n}=1,2,3 \ldots
$$

$\mathrm{O}$ valor do coeficiente $a_{3}$ não pode ser obtido nesta análise, porém ele representa simplesmente a amplitude da onda senoidal descrita pela linha elástica na configuração pós-crítica, i.e. o modo de instabilidade da barra. Na Figura 2.10 estão representados os três primeiros modos $(n=1,2$ e 3). O menor dos carregamentos críticos corresponde a $\mathrm{n}=1$, sendo ele comumente designado por força ou carregamento crítico de Euler, $\mathrm{P}_{\mathrm{E}}$ :

$$
\mathrm{P}_{c r}=\mathrm{P}_{E}=\frac{\pi^{2} E I}{L^{2}}
$$




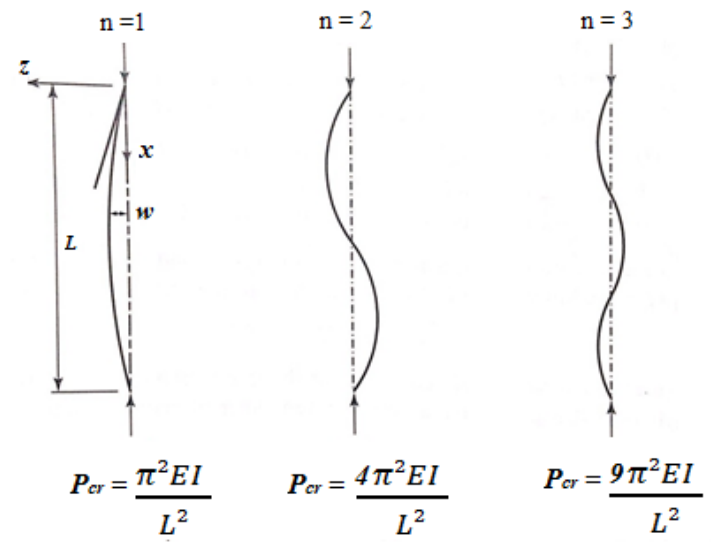

Figura 2.10 - Carregamentos críticos e modos de instabilidade (n=1,2 e 3) para barras comprimidas simplesmente apoiadas. Adaptado de (GALAMBOS; SUROVEK, 2008).

O mesmo procedimento pode ser empregado para outras condições de vinculação. As novas condições de contorno, compatíveis com a nova condição de vinculação, levarão a determinantes diferentes do apresentado na Eq. (2.27) e novamente as raízes na equação polinomial serão os pontos de bifurcação e os autovetores os modos de instabilidade. É possível escrever uma solução geral para barras comprimidas em regime elástico conforme a equação abaixo:

$$
\mathrm{P}_{c r}=\mathrm{P}_{E}=\frac{\pi^{2} E I}{L e^{2}},
$$

sendo $L_{e} \mathrm{o}$ chamado comprimento efetivo da barra, dado em função das vinculações nas extremidades da barra. Para os casos fundamentais apresentados na Figura 2.11 os comprimentos efetivos da barra são: (I) apoiado-apoiado $\mathrm{L}_{\mathrm{e}}=1,0 \mathrm{~L}$; (II) engastadoapoiado $\mathrm{L}_{\mathrm{e}}=0,7 \mathrm{~L}$; (III) engastado-engastado $\mathrm{L}_{\mathrm{e}}=0,5 \mathrm{~L}$ e (IV) engastado-livre $\mathrm{L}_{\mathrm{e}}=2,0 \mathrm{~L}$ e (V) engastado-engastado com recalque de apoio $\mathrm{L}_{\mathrm{e}}=1,0 \mathrm{~L}$;

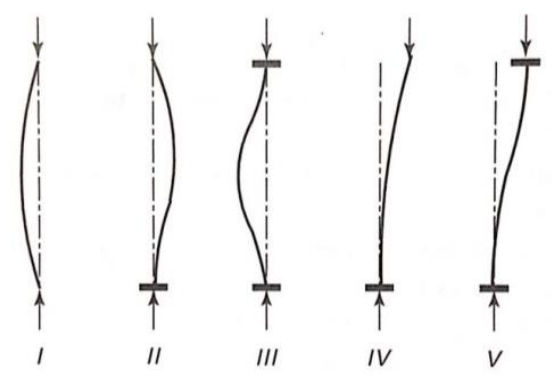

Figura 2.11 - Casos fundamentais de barras comprimidas (GALAMBOS; SUROVEK, 2008).

\subsubsection{Instabilidade global por torção e flexotorção: força crítica de Vlasov}

$\mathrm{Na}$ teoria de (VLASOV, 1961) o empenamento da seções transversais é considerado e as seguintes hipóteses são adotadas: (i) a forma da seção transversal não 
se altera, ou seja, não se considera a distorção da seção em seu próprio plano; (ii) as deformações por cisalhamento da seção em relação ao eixo da barra podem ser desprezadas; (iii) o empenamento da seção transversal é constante ao longo da espessura t das paredes.

Toma-se como ponto de partida a Eq. (2.35), que permite obter de modo aproximado, porém sem perda significativa do resultado, o deslocamento longitudinal (na direção $\mathrm{x}$ ) de um ponto da seção transversal, definido como empenamento:

$$
\overline{\mathrm{u}}=\omega \varphi^{\prime} .
$$

A área setorial ${ }^{6}, \omega$, nas seções abertas de paredes delgadas, corresponde à função empenamento de Saint-Venant quando esta é calculada na linha média de cada parede, sendo usualmente representada por um diagrama traçado ao longo da linha média das paredes. Nota-se que, para uma mesma barra, a forma do empenamento é a mesma para todas as suas seções, mas a intensidade difere de uma seção para outra, sendo proporcional à rotação específica, $\varphi^{\prime}$, definida como a taxa de variação da rotação de torção $\varphi$ ao longo do eixo x (conforme apresentado na Figura 2.12) e obtida através da equação:

$$
\varphi^{\prime}=\frac{\mathrm{d} \varphi}{\mathrm{dx}}=\frac{M_{t}}{G I_{t}},
$$

sendo $\mathrm{M}_{\mathrm{t}} \mathrm{o}$ momento de torção uniforme, $\mathrm{G}$ o modulo de elasticidade transversal do material e $\mathrm{I}_{\mathrm{t}} \mathrm{o}$ momento de inércia a torção, ou a constante de torção de Saint-Venant.

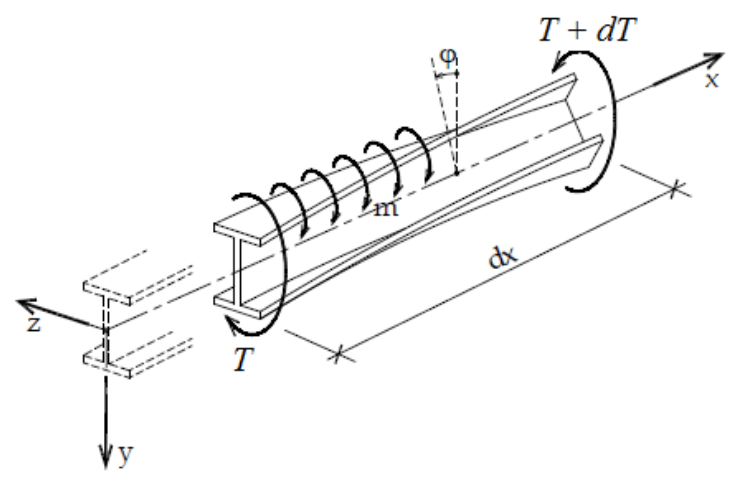

Figura 2.12 - Empenamento e rotação $\varphi$ da barra submetida ao momento de torção T e momento de torção distribuído m. Adaptado de (MORI; NETO, 2009).

${ }^{6}$ Será considerada sempre a área setorial principal, ou seja, aquela cujo polo está localizado no centro de torção. Para os leitores interessados no cálculo da área setorial, ver, por exemplo, (MORI; NETO, 2009) e (FRUCHTENGARTEN, 2003). 
O momento de torção, $\mathrm{T}$, é composto de duas parcelas distintas correspondentes a momento de (i) torção uniforme, $\mathrm{M}_{\mathrm{t}}$, obtido através da Eq. (2.36), e (ii) torção nãouniforme ou flexotorção, $\mathrm{M}_{\mathrm{ft}}$, obtido através da Eq. (2.37).

$$
M_{\mathrm{ft}}=-\mathrm{EI}_{\omega} \varphi^{\prime \prime \prime}
$$

$\mathrm{Na}$ relação (2.37), E é o modulo de elasticidade do material e $\mathrm{I}_{\omega}$ é o chamado momento de inércia setorial, ou constante de empenamento, definido por:

$$
\mathrm{I}_{\omega}=\int_{A} \omega^{2} d A
$$

Portanto, o momento de torção é obtido através da equação:

$$
T=M_{\mathrm{t}}+M_{\mathrm{ft}}=\mathrm{G} I_{t} \varphi^{\prime}-\mathrm{EI}_{\omega} \varphi^{\prime \prime \prime} .
$$

A resultante das tensões de cisalhamento, $\tau_{t}$, devido ao momento de torção uniforme, as tensões de cisalhamento, $\tau_{\omega}$, e as tensões normais, $\sigma_{\omega}$, devido ao momento de flexotorção, são apresentadas abaixo e ilustradas na Figura 2.13.

$$
\begin{aligned}
\tau_{t} & =\frac{M_{\mathrm{t}}}{I_{t}} t \\
\tau_{\omega} & =-\frac{M_{\mathrm{ft}} \mathrm{S}_{\omega}}{t \mathrm{I}_{\omega}} \\
\sigma_{\omega} & =\frac{B}{\mathrm{I}_{\omega}} \omega
\end{aligned}
$$

Sendo $\mathrm{S}_{\omega}$ o momento estático setorial, definido pela integral (na área da seção transversal) da função empenamento e B é o bimomento, um novo esforço solicitante, autoequilibrado e que foi apresentado por Vlasov em 1961 como sendo:

$$
B=E \mathrm{I}_{\omega} \varphi^{\prime \prime}
$$

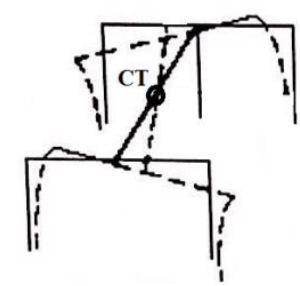

(a)

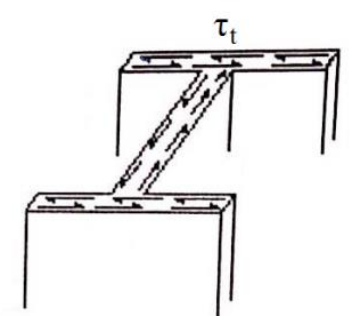

(b)

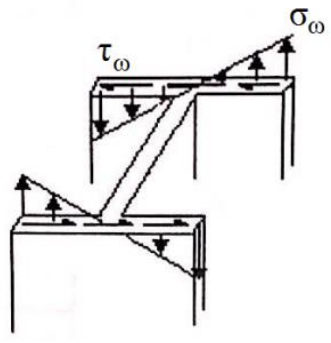

(c)

Figura 2.13 - (a) barra deformada e localização do centro de torção CT, (b) tensões de cisalhamento devido ao momento de torção uniforme $M_{t} e(c)$ tensões normais e de cisalhamento devido ao momento de flexotorção $M_{\mathrm{ft}}$. Adaptado de (FRUCHTENGARTEN, 2003) 
Existe um ponto pertencente ao plano da seção transversal, coincidente ou não com o centro geométrico da seção, denominado centro de torção ou centro de cisalhamento, pelo qual deve passar o plano de aplicação da resultante das cargas transversais e, consequentemente, das forças cortantes, de modo que não ocorra torção, e sim, apenas flexão. O centro de torção é uma propriedade geométrica da seção transversal e será aqui representado pela sigla CT.

Tomando-se o eixo $x$ como o eixo longitudinal de uma barra e os eixos $y$ e $z$ os eixos principais de inércia com origem no centro de gravidade, $\mathrm{CG}$, e as propriedades setoriais calculadas em relação ao centro de torção, cujas coordenadas são $y_{0}$ e $z_{0} \mathrm{em}$ relação ao CG, e considerando-se ainda que as forças externas são compostas apenas pelas forças distribuídas $\mathrm{f}_{x}, \mathrm{f}_{y}, \mathrm{f}_{z}$, e pelo momento externo de torção distribuído, $m$, as equações de equilíbrio passam a ser escritas como:

$$
\begin{aligned}
\mathrm{f}_{x} & =-\mathrm{EA} u^{\prime \prime} \\
\mathrm{f}_{y} & =\mathrm{E} I_{z} v^{i v} \\
\mathrm{f}_{z} & =\mathrm{E} I_{y} w^{i v} \\
m & =\mathrm{G} I_{t} \varphi^{\prime \prime}-\mathrm{EI}_{\omega} \varphi^{i v}
\end{aligned}
$$

sendo $u, v, w$ os deslocamentos nos eixos $x, y, z, \varphi$ a rotação de torção da seção transversal e $I_{y}$ e $I_{z}$ são os momentos de inércia em relação aos eixos principais de inércia $y$ e $z$, respectivamente.

A teoria clássica de estabilidade elástica objetiva determinar a intensidade do carregamento a partir do qual a configuração inicial deixa de ser estável. Ao atingir o carregamento crítico, a barra passa da configuração de equilíbrio original para uma nova configuração, denominada "pós-crítica". As novas equações de equilíbrio são determinadas, na teoria de Vlasov, para uma configuração pós-crítica próxima da inicial, de modo que os incrementos dos deslocamentos e das tensões sejam pequenos de tal forma que possam ser consideradas desprezáveis as mudanças nos esforços solicitantes (ou, em outras palavras, de tal forma que a hipótese de linearidade geométrica possa ser mantida).

Assim, para os deslocamentos adicionais resultantes da perda de estabilidade da barra, considera-se que o incremento de tensões está em equilíbrio com um carregamento externo fictício, a ser determinado. 
Admitem-se válidas, para a configuração pós-crítica, as equações de equilíbrio deduzidas para a configuração original, Eqs. (2.44) - (2.47), mas desprezam-se os deslocamentos anteriores à perda de estabilidade e admite-se que $u, v, w$ e $\varphi$ são os incrementos dos deslocamentos devidos à mudança de configuração de equilíbrio.

Impondo as condições de contorno e as forças fictícias deduzidas a partir do equilíbrio de um elemento da barra na configuração deformada, é possível reescrever as equações diferenciais para a configuração pós-crítica. As equações para os casos mais gerais são apresentadas em (FRUCHTENGARTEN, 1995) e neste texto, a título de ilustração, será apresentado a seguir apenas o caso específico ilustrado na Figura 2.14.
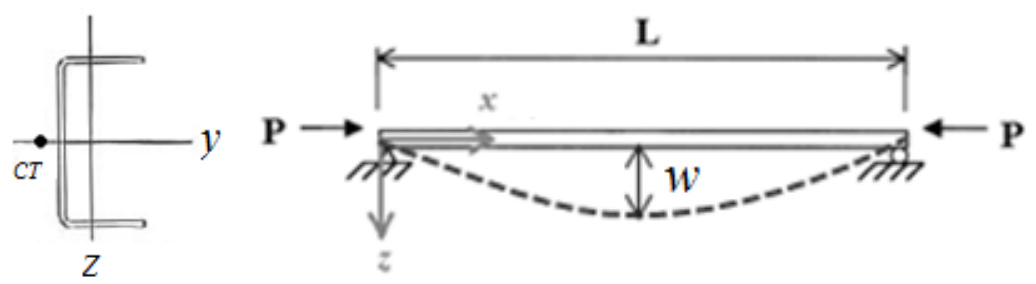

Figura 2.14 - Barra comprimida simplesmente apoiada.

Seja a barra ideal simplesmente apoiada de comprimento L submetida à compressão uniforme $\mathrm{P}$ conforme a Figura 2.14, indeformável axialmente e com empenamento não inibido nas extremidades. As equações diferencias para a configuração pós-crítica são:

$$
\begin{aligned}
& \mathrm{E} I_{z} v^{i v}-P\left(v^{\prime \prime}-z_{0} \varphi^{\prime \prime}\right)=0, \\
& \mathrm{E} I_{y} w^{i v}-P\left(w^{\prime \prime}+y_{0} \varphi^{\prime \prime}\right)=0, \\
& \mathrm{EI}_{\omega} \varphi^{i v}-G I_{t} \varphi^{\prime \prime}-P\left(r_{0}^{2} \varphi^{\prime \prime}-y_{0} w^{\prime \prime}+z_{0} v^{\prime \prime}\right)=0 .
\end{aligned}
$$

onde $y_{0}$ e $z_{0}$ são as coordenadas do centro de torção na direção dos eixos principais de inércia $y$ e $z$ em relação ao centro geométrico da seção transversal e $r_{0}$ é o raio de giração polar dado pela Eq.(2.51), onde $r_{y}$ e $r_{z}$ são os raios de giração em relação aos eixos principais de inércia $y$ e $z$ respectivamente:

$$
r_{0}^{2}=r_{y}^{2}+r_{z}^{2}+y_{0}^{2}+z_{0}^{2} .
$$

Lembrando que as equações diferenciais (2.48), (2.49) e (2.50) são válidas somente para barras biarticuladas e com compressão perfeitamente centrada.

As condições de contorno para o caso de barras simplesmente apoiadas nas direções $y$ e $z$ e cujos apoios impedem a rotação de torção, mas permitem o empenamento da seção, são apresentadas a seguir: 


$$
\begin{aligned}
& v(0)=v(L)=w(0)=w(L)=0 \\
& v^{\prime \prime}(0)=v^{\prime \prime}(L)=w^{\prime \prime}(0)=w^{\prime \prime}(L)=0 \\
& \varphi(0)=\varphi(L)=\varphi^{\prime \prime}(0)=\varphi^{\prime \prime}(L)=0
\end{aligned}
$$

Inserindo as condições acima nas equações (2.48), (2.49) e (2.50), pode-se determinar a seguinte solução geral para o sistema:

$$
\begin{aligned}
v & =a_{1} \operatorname{sen} \frac{\pi x}{L} \\
w & =a_{2} \operatorname{sen} \frac{\pi x}{L} \\
\varphi & =a_{3} \operatorname{sen} \frac{\pi x}{L}
\end{aligned}
$$

sendo $a_{1}, a_{2}$ e $a_{3}$ constantes a serem determinadas.

Substituindo as Eq. (2.52) e (2.53) nas equações diferenciais de equilíbrio (2.48), (2.49) e (2.50) chega-se ao seguinte sistema de equações lineares no formato matricial:

$$
\left[\begin{array}{ccc}
P-P_{E z} & 0 & P z_{0} \\
0 & P-P_{E y} & -P y_{0} \\
P z_{0} & -P y_{0} & r_{0}^{2}\left(P-P_{\omega}\right)
\end{array}\right]\left\{\begin{array}{l}
a_{1} \\
a_{2} \\
a_{3}
\end{array}\right\}=0
$$

sendo:

- $P_{E y}$ o carregamento crítico de Euler devido à instabilidade elástica por flexão em relação ao eixo principal y e é fornecido pela Eq. (2.55):

$P_{E y}=\frac{\pi^{2} E I_{y}}{L^{2}}$

- $P_{E z}$ o carregamento crítico de Euler devido à instabilidade elástica por flexão em relação ao eixo principal $z$ e é fornecido pela Eq. (2.56):

$P_{E z}=\frac{\pi^{2} E I_{z}}{L^{2}}$

- $P_{\omega}$ o carregamento crítico de Vlasov devido à instabilidade elástica por torção em relação ao eixo longitudinal $x$ e é fornecido pela Eq. (2.57):

$$
P_{\omega}=\frac{1}{r_{0}^{2}}\left(G I_{t}+\frac{\pi^{2} E C_{w}}{L^{2}}\right) \text {. }
$$

A solução não trivial do sistema de equações lineares (2.54) é fornecida impondo que o determinante da matriz do sistema seja nulo, o que gera a equação cúbica (2.58):

$$
r_{0}^{2}\left(P-P_{E y}\right)\left(P-P_{E z}\right)\left(P-P_{\omega}\right)-P^{2} z_{0}^{2}\left(P-P_{E y}\right)-P^{2} y_{0}^{2}\left(P-P_{E z}\right)=0
$$


$\mathrm{O}$ carregamento crítico, $\mathrm{P}_{\mathrm{cr}}$ será igual à menor das raízes, $\mathrm{P}$, da Eq. (2.58). Para as barras em que o centro de torção coincide com o centro geométrico da seção transversal, i.e., barras em que $y_{0}=z_{0}=0$, o modo de instabilidade global será de flexão se uma das forças de bifurcação de Euler, Eq. (2.55) e (2.56), for menor do que a força de bifurcação de torção, Eq. (2.57), ao passo que o modo de instabilidade global será de torção se esta última for inferior às de Euler. Para todos os outros casos, a instabilidade global ocorrerá devido ao modo de flexotorção, MGFT.

\subsection{Instabilidade de Chapas}

A instabilidade de uma chapa é um fenômeno que quase sempre mobiliza a sua flexão. Esse aspecto acaba por transformar a chapa em uma placa ou até mesmo em um casca, sendo essa flexão quase sempre acompanhada de deformações no plano médio da mesma.

Por definição, a terminologia chapa refere-se a um elemento bidimensional plano com carregamentos na direção do plano médio que podem estar associados à flexão apenas no próprio plano da superfície da chapa ${ }^{7}$. As placas e cascas, por sua vez, podem estar submetidas a carregamentos perpendiculares à sua superfície média, que podem mobilizar a flexão transversal, possibilitando deslocamentos transversalmente a esta superfície $^{8}$. As cascas, mais especificamente, referem-se a elementos bidimensionais cuja superfície média não é plana 9 .

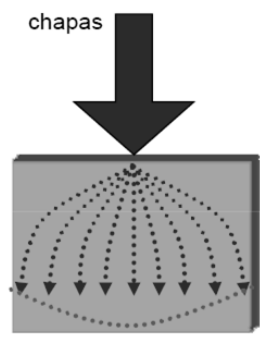

(a)

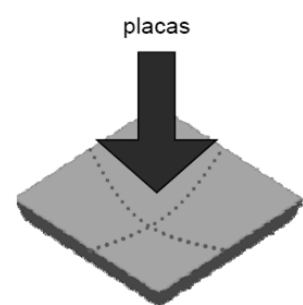

(b)

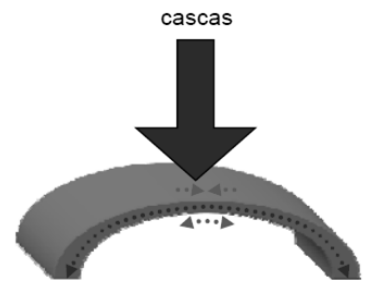

(c)

Figura 2.15 - Elementos estruturais bidimensionais (a) chapas (b) placas e (c) cascas.

As barras que possuem seção transversal de paredes delgadas, como é o caso dos perfis formados a frio, podem ser entendidas como um conjunto de elementos

\footnotetext{
${ }^{7}$ Figura 2.15a

${ }^{8}$ Figura 2.15b

${ }^{9}$ Figura 2.15c
} 
bidimensionais, conectados entre si ao longo dos respectivos bordos longitudinais. $\mathrm{Na}$ configuração indeformada, i.e. quando a estrutura está na sua forma plana e sem carregamentos perpendiculares, esses elementos se comportam como chapa. Atingido o ponto crítico, surgem deslocamentos fora do plano, o que requer que os mesmos sejam classificados como placa ou casca. Na grande maioria das vezes, na configuração póscrítica o elemento não está mais na sua forma plana e surgem esforços de membrana que caracterizam um comportamento semelhante ao das cascas.

Do ponto de vista estrutural, os modos de instabilidade local de perfis formados a frio, como já descrito no capítulo 1, podem ser entendidos com um problema de instabilidade de chapas isoladas. Isso permite que se determinem os carregamentos críticos devidos ao modo local de chapa, MLC. A terminologia MLC será aqui utilizada mesmo que, como já dito, os elementos tenham se tornado placas ou cascas após ultrapassar o ponto crítico.

O estudo das placas é uma atividade clássica da Mecânica e remonta aos trabalhos de Mlle. Sophie Germain, de G. R. Kirchhoff, de Lord Kelvin e de von Kármann ainda no século XIX (CAMPELLO, 2005). Os trabalhos iniciais sobre a estabilidade elástica de placas e chapas datam do século XVIII, devendo-se inicialmente a (i) Saint-Venant, a determinação da equação diferencial de equilíbrio, (ii) G. H. Bryan, a determinação da solução dessa equação para chapas simplesmente apoiadas e (iii) H. Reissner e S. P. Timoshenko, a solução para chapas com outras condições de vinculação.

A equação diferencial de equilíbrio de uma chapa na configuração pós-crítica em regime elástico é obtida admitindo-se que a configuração pós-crítica é muito próxima da configuração plana original, da mesma forma como é feito na teoria de Vlasov no item anterior, ou seja, presume-se pequenos deslocamentos e pequenas rotações, sendo descrita abaixo ${ }^{10}$ :

$$
\nabla^{4} w=\frac{\partial^{4} w}{\partial x^{4}}+2 \frac{\partial^{4} w}{\partial x^{2} \partial y^{2}}+\frac{\partial^{4} w}{\partial y^{4}}=\frac{1}{D}\left(P_{x} \frac{\partial^{2} w}{\partial x^{2}}+2 P_{x y} \frac{\partial^{2} w}{\partial x \partial y}+P_{y} \frac{\partial^{2} w}{\partial y^{2}}\right)
$$

onde $\nabla^{4}$ é o operador diferencial de quarta ordem, $w$ é o deslocamento fora do plano e os esforços de membrana por unidade de comprimento são representados por $P_{x}, P_{y} \mathrm{e}$ $P_{x y}$ e ilustrados na Figura 2.16. A rigidez à flexão, $D$, é dada pela equação:

\footnotetext{
${ }^{10}$ Equação diferencial de Saint-Venant. O carregamento perpendicular ao plano e as forças de volume não são consideradas (TIMOSHENKO; GERE, 1961).
} 


$$
D=\frac{E t^{3}}{12\left(1-\nu^{2}\right)}
$$

em que $E$ e $v$ são o módulo de elasticidade e o coeficiente de Poisson do material e $t$ a espessura da chapa respectivamente.

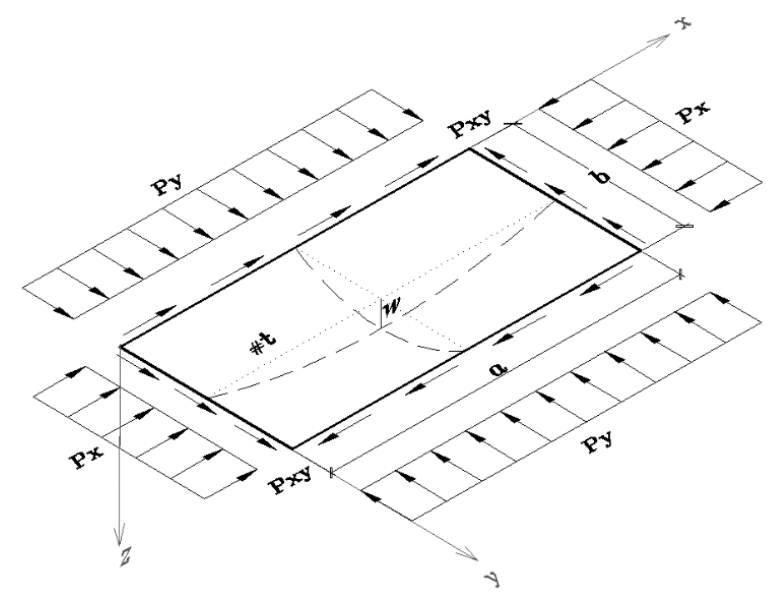

Figura 2.16 - Chapa retangular simplesmente apoiada.

O Método do Equilíbrio consiste em resolver a Eq. (2.59), impondo as condições de contorno da e determinando o menor valor de carregamento que satisfaça a equação de equilíbrio. Como mencionado no item 2.1.4 esse processo pode ser muito trabalhoso ou até inviável para alguns casos, como por exemplo, placas enrijecidas ou com geometria complexa; nesses casos, o Método Energético pode ser empregado com facilidade para a determinação aproximada do carregamento crítico que condiciona o surgimento de um deslocamento fora do plano da chapa.

O método energético aplicado a chapas retangulares é semelhante ao aplicado a barras comprimidas, ou seja, uma configuração é de equilíbrio se e somente se a energia potencial total for estacionária para essa configuração. Denotando por $U$, a energia potencial das forças internas e por $\mathrm{W}$, a energia potencial das forças externas, a energia potencial total, П, pode ser escrita como:

$$
\Pi=\mathrm{U}+\mathrm{W}
$$

sendo U representado pela Eq. (2.62) e W pela Eq (2.63).

$$
\begin{aligned}
& U=\frac{1}{2} D \int_{0}^{a} \int_{0}^{b}\left\{\left(\frac{\partial^{2} w}{\partial x^{2}}+\frac{\partial^{2} w}{\partial y^{2}}\right)^{2}-2(1-\nu)\left[\frac{\partial^{2} w}{\partial x^{2}} \frac{\partial^{2} w}{\partial y^{2}}-\left(\frac{\partial^{2} w}{\partial x \partial y}\right)^{2}\right]\right\} d x d y, \\
& W=-\frac{1}{2} \int_{0}^{a} \int_{0}^{b}\left[P_{x}\left(\frac{\partial w}{\partial x}\right)^{2}+P_{y}\left(\frac{\partial w}{\partial y}\right)^{2}+2 P_{x y} \frac{\partial w}{\partial x} \frac{\partial w}{\partial y}\right] d x d y .
\end{aligned}
$$


Admitindo-se que os carregamentos $P_{x}, P_{y}$ e $P_{x y}$ são proporcionais, ou seja, podem ser escritos como funções monoparamétricas de um fator de carregamento $\lambda$, tal que:

$$
P_{x}=\lambda \bar{P}_{x} ; \quad P_{y}=\lambda \bar{P}_{y} \quad ; \quad P_{x y}=\lambda \bar{P}_{x y}
$$

Com o aumento gradual da magnitude de $\lambda$, chega-se a uma condição cuja forma plana de equilíbrio torna-se instável, ou seja, qualquer perturbação introduzida no sistema fará com que, de maneira súbita, a chapa busque outra forma de manter-se em equilíbrio, i.e. ocorrem deslocamentos fora do plano da chapa. Conforme apresentado no item 2.1.4, isso equivale a dizer que, para um determinado valor de $\lambda$, o sinal da segunda derivada da energia potencial total deixa de ser positivo.

Para sistemas em equilíbrio, a energia potencial das forças externas é igual a energia potencial das forças internas. Utilizando-se desse artifício e das equações (2.62), (2.63) e (2.64), pode-se obter a seguinte relação, se o equilíbrio for garantido:

$$
\lambda=\frac{D \int_{0}^{a} \int_{0}^{b}\left\{\left(\frac{\partial^{2} w}{\partial x^{2}}+\frac{\partial^{2} w}{\partial y^{2}}\right)^{2}-2(1-\nu)\left[\frac{\partial^{2} w}{\partial x^{2}} \frac{\partial^{2} w}{\partial y^{2}}-\left(\frac{\partial^{2} w}{\partial x \partial y}\right)^{2}\right]\right\} d x d y}{-\int_{0}^{a} \int_{0}^{b}\left[\bar{P}_{x}\left(\frac{\partial w}{\partial x}\right)^{2}+\bar{P}_{y}\left(\frac{\partial w}{\partial y}\right)^{2}+2 \bar{P}_{x y} \frac{\partial w}{\partial x} \frac{\partial w}{\partial y}\right] d x d y}=\frac{F_{U}}{F_{W}} .
$$

Todavia, para que o equilíbrio seja garantido, deve-se assegurar a condição de estacionariedade da energia potencial total $(\delta \Pi=0)$. Dessa forma, impõe-se a condição de mínimo à Eq. (2.65), tal que:

$$
\delta \lambda=\frac{F_{W} \delta F_{U}-F_{U} \delta F_{W}}{F_{W}{ }^{2}}=0 .
$$

Simplificando e utilizando a relação que $\lambda=F_{U} / F_{W}$, obtém-se:

$$
\frac{1}{F_{W}}\left(\delta F_{U}-\lambda \delta F_{W}\right)=0
$$

A expressão de $w$ deve satisfazer as condições de contorno e, quando aproximada por funções de interpolação (ou de aproximação) e introduzida na equação acima, conduz a um sistema de equações algébricas. Tal sistema contém uma matriz associada e que só admite solução não trivial quando o determinante dessa matriz for nulo. De $\delta F_{U}$ decorre a chamada matriz de rigidez elástica $\boldsymbol{K}_{e}$, e de $\delta F_{W}$ a chamada matriz de rigidez geométrica $\boldsymbol{K}_{g}$, de onde se pode reescrever a equação anterior como:

$$
\left|\boldsymbol{K}_{e}-\lambda \boldsymbol{K}_{g}\right|=0
$$


O problema (2.68) é denominado Análise de Euler ou Análise Linear de Estabilidade ou, ainda, Análise Linear de Flambagem ${ }^{11}$ e a determinação de $\lambda$ fornece uma aproximação do carregamento crítico, conforme as relações da Eq. (2.64) e, consequentemente do modo crítico. Esta aproximação é tão boa quanto melhor forem atendidas as hipóteses acima.

As almas de perfis de seção Ue biarticulados e sob compressão uniforme, por exemplo, podem ser representadas por chapas retangulares simplesmente apoiadas, conforme ilustrado na Figura 2.16, tomando-se como nulo os valores de $P_{y}$ e $P_{x y}{ }^{12}$. Para chapas simplesmente apoiadas, conforme a Figura 2.16, o deslocamento fora do plano da chapa, $w$, pode ser representado pela seguinte dupla série de senos:

$$
w=\sum_{m=1}^{\infty} \sum_{n=1}^{\infty} \mathrm{a}_{m n} \operatorname{sen}\left(\frac{m \pi x}{a}\right) \operatorname{sen}\left(\frac{n \pi y}{b}\right),
$$

sendo $\mathrm{a}_{m n}$ um conjunto de coeficientes a serem determinados, considerando " $n$ " $\mathrm{o}$ número de ondas na direção perpendicular ao carregamento e " $m$ " o número de ondas paralelas ao carregamento.

Substituindo a expressão de $w$ na Eq. (2.62), a energia de deformação pode ser escrita como:

$$
U=\frac{1}{2} D \int_{0}^{a} \int_{0}^{b}\left\{\sum_{m=1}^{\infty} \sum_{n=1}^{\infty} \mathrm{a}_{m n}\left(\frac{m^{2} \pi^{2}}{a^{2}}+\frac{n^{2} \pi^{2}}{b^{2}}\right) \operatorname{sen}\left(\frac{m \pi x}{a}\right) \operatorname{sen}\left(\frac{n \pi y}{b}\right)\right\}^{2} d x d y .
$$

$\mathrm{Na}$ Eq. (2.70), apenas os termos quadráticos da série infinita resultam em integrais não nulas. Observando a equação (2.71), pode-se simplificar a expressão da energia de deformação para a Eq. (2.72).

$$
\begin{aligned}
& \int_{0}^{a} \int_{0}^{b} \operatorname{sen}^{2}\left(\frac{m \pi x}{a}\right) \operatorname{sen}^{2}\left(\frac{n \pi y}{b}\right) d x d y=\frac{a b}{4}, \\
& U=\frac{\pi^{4} a b}{8} D \sum_{m=1}^{\infty} \sum_{n=1}^{\infty} \mathrm{a}_{m n} 2\left(\frac{m^{2}}{a^{2}}+\frac{n^{2}}{b^{2}}\right)^{2} .
\end{aligned}
$$

11 "Linear buckling analysis" em inglês (PIMENTA, 2006).

${ }^{12}$ Esta hipótese não é válida para os casos em que ocorre o efeito "shear lag", como por exemplo, quando as abas do perfil também estão comprimidas mas as vinculações nas extremidades só são introduzidas pela alma, provocando cisalhamento nas junções entre as abas e a alma. 
Por sua vez, substituindo a Eq. (2.69) na Eq. (2.63), a energia potencial das forças externas é expressa por:

$$
W=\frac{\pi^{2} b}{8 a} P_{x} \sum_{m=1 n=1}^{\infty} \sum_{m n}^{\infty} \mathrm{a}^{2} m^{2} .
$$

Portanto, a Eq. (2.65) para a determinação do carregamento crítico das almas desses tipos de perfil torna-se:

$$
P_{x}=\frac{\pi^{2} a^{2} D \sum_{m=1}^{\infty} \sum_{n=1}^{\infty} \mathrm{a}_{m n}{ }^{2}\left(\frac{m^{2}}{a^{2}}+\frac{n^{2}}{b^{2}}\right)^{2}}{\sum_{m=1}^{\infty} \sum_{n=1}^{\infty} \mathrm{a}_{m n}{ }^{2} m^{2}} .
$$

A Eq. (2.74) só será um mínimo se todos os coeficientes $\mathrm{a}_{m n}$, exceto um, forem iguais à zero. Assim sendo:

$$
P_{x}=\frac{\pi^{2} a^{2} \mathrm{D}}{m^{2}}\left(\frac{m^{2}}{a^{2}}+\frac{n^{2}}{b^{2}}\right)^{2} .
$$

Podem ocorrer várias ondas na direção da compressão, porém para obter-se o menor valor de $P_{x}$, deve ocorrer apenas uma onda perpendicular ao carregamento, ou seja, $n=1$. Dessa maneira é possível determinar a equação do carregamento crítico para chapas retangulares simplesmente apoiadas e comprimidas em uma direção:

$$
P_{c r}=\frac{\pi^{2} \mathrm{D}}{a^{2}}\left(m+\frac{1}{m} \frac{a^{2}}{b^{2}}\right)^{2} .
$$

$\mathrm{O}$ primeiro fator do termo à direita da Eq. (2.76) está relacionado com a força crítica de Euler para barras comprimidas. Trata-se de uma faixa por unidade de largura e de altura " $a$ ". O segundo fator indica a proporção entre a perda de estabilidade de uma chapa em relação à perda de estabilidade de uma faixa de altura "a". Esta relação depende da proporção entre a altura e largura da chapa, a relação " $a / b$ " e do número de ondas " $m$ ", uma vez que já foi estabelecido que $n=1$.

A equação anterior pode ser reescrita em função do chamado parâmetro k, conforme abaixo:

$$
P_{c r}=\frac{\pi^{2} \mathrm{D}}{\mathrm{b}^{2}}\left(m \frac{\mathrm{b}}{a}+\frac{1}{m} \frac{a}{\mathrm{~b}}\right)^{2}=k \frac{\pi^{2} \mathrm{D}}{b^{2}} .
$$

Finalmente, o carregamento crítico para $m=1$ é determinado por:

$$
P_{c r}=\frac{\pi^{2} \mathrm{D}}{b^{2}}\left(\frac{\mathrm{b}}{a}+\frac{a}{\mathrm{~b}}\right)^{2} .
$$


Se a largura " $b$ " da chapa for mantida constante e se comprimento " $a$ " da chapa for aumentado gradualmente, o parâmetro fora dos parênteses na Eq. (2.78) permanecerá constante e o parâmetro dentro dos parênteses irá variar conforme a variação da relação $a / b$. É possível observar que é estabelecido um mínimo para $a=b$, i.e. para chapas quadradas o carregamento crítico é o menor possível. Para esse caso, tem-se:

$$
P_{c r}=4 \frac{\pi^{2} \mathrm{D}}{b^{2}}
$$

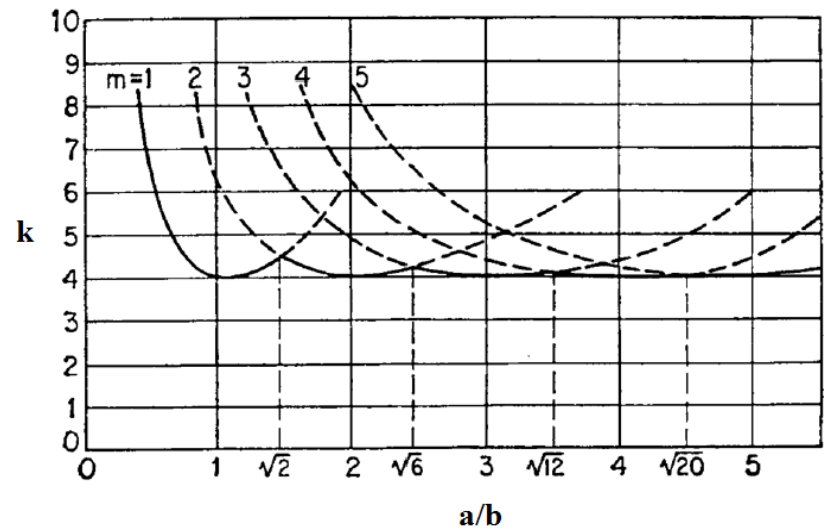

Figura 2.17 - Chapa retangular simplesmente apoiada sob compressão em uma direção (TIMOSHENKO; GERE, 1961).

Variando o número de ondas na direção do carregamento e a relação $a / b$, é possível determinar as curvas apresentadas na Figura 2.17. Tendo essas curvas fica evidente a determinação do carregamento crítico através do parâmetro k.

Nota-se que para chapas curtas a curva $m=1$ apresenta os menores valores de $\mathrm{k}$, i.e. a chapa flete em uma onda; após a intersecção com a curva $m=2$, a segunda curva apresenta os menores valores de $\mathrm{k}$, i.e. a chapa flete em duas ondas e assim sucessivamente. A transição da curva $m$ para a curva $m+1$ ocorre para mesmos valores de k, partindo do termo dentro dos parênteses da Eq. (2.77) pode-se escrever:

$$
\frac{m b}{a}+\frac{a}{m b}=\frac{(m+1) b}{a}+\frac{a}{(m+1) b}
$$

Da equação anterior, obtém-se de maneira simplificada a expressão que fornece os pontos onde as curvas de diferentes ondas se interceptam:

$$
\frac{a}{b}=\sqrt{m(m+1)}
$$


Através da Eq. (2.81), é possível determinar quantas ondas longitudinais a chapa com a relação $a / b$ irá formar sob a ação do carregamento crítico (i.e. do menor carregamento que conduza ao deslocamento fora do plano):

$$
\begin{array}{r}
a / b<1,41: m=1 \\
1,41<a / b<2,45: m=2 \\
2,45<a / b<3,46: m=3 \\
3,46<a / b<4,47: m=4 \\
4,47<a / b<5,48: m=5
\end{array}
$$

Nota-se que para chapas alongadas, cuja relação a/b é alta, têm-se:

$a / b \approx m$.

Pode-se concluir que para chapas alongadas há uma tendência de que a chapa perca estabilidade dividindo-se em " $m$ " chapas quadradas, i.e. $\mathrm{k}=4$ para quaisquer valores de $a / b$ contanto que o comprimento da chapa seja muito maior do que a largura.

Por exemplo, seja uma chapa simplesmente apoiada de dimensões " $a$ " $\mathrm{e}$ $b=100 \mathrm{~cm}$, espessura $\mathrm{t}=1 \mathrm{~cm}$, módulo de elasticidade $\mathrm{E}=21000 \mathrm{kN} / \mathrm{cm}^{2}$, coeficiente de Poisson $v=0,30$ e uniformemente comprimida de $P x$ conforme a Figura 2.16. O carregamento crítico em função do comprimento da chapa e do número de ondas é:

$$
P_{x, c r}=\frac{\pi^{2} 21000}{12\left(1-0,3^{2}\right)} \frac{1^{3}}{100^{2}}\left(m \frac{100}{a}+\frac{1}{m} \frac{a}{100}\right)^{2}=1,90\left(m \frac{100}{a}+\frac{1}{m} \frac{a}{100}\right)^{2} \mathrm{kN} / \mathrm{cm}
$$

Para uma chapa quadrada, $a=100 \mathrm{~cm}$ e $m=1$, o carregamento crítico será $\mathrm{P}_{\mathrm{cr}}=7,59 \mathrm{kN} / \mathrm{cm}$, com tensão crítica $\sigma_{\mathrm{cr}}=75,9 \mathrm{MPa}$ dada conforme relação abaixo:

$$
\sigma_{c r}=\frac{P_{c r}}{\mathrm{t}}
$$

O modo de instabilidade da chapa quadrada é ilustrado na Figura 2.18a. Variando o comprimento da chapa para $a=150 \mathrm{~cm}$, para $m=1$ obtém-se $\mathrm{P}_{\mathrm{x}}=8,91 \mathrm{kN} / \mathrm{cm}$, porém para $m=2$ é possível alcançar um valor ainda menor para o carregamento, sendo este o verdadeiro carregamento crítico da chapa de relação $a / b=1,5$ :

$$
P_{c r}=1,90\left(2 \frac{100}{150}+\frac{1}{2} \frac{150}{100}\right)^{2}=8,24 \mathrm{kN} / \mathrm{cm}
$$

Para valores de $a=300 \mathrm{~cm}$ e $a=500 \mathrm{~cm}$, o mesmo cálculo pode ser empregado e o menor carregamento para ocorrer a perda da estabilidade se dará para $m=3$ e $m=5$ respectivamente, resultando ambos em $\mathrm{P}_{\mathrm{cr}}=7,59 \mathrm{kN} / \mathrm{cm}$, mesmo valor obtido para a chapa quadrada. 
Com o auxílio do programa computacional EBPlate (Elastic Buckling of Plates) do CTICM (Centro Tecnológico Industrial da Construção Metálica da França), é possível determinar o carregamento crítico para (i) diversas condições de contorno dos bordos da chapa, (ii) chapas enrijecidas transversalmente e longitudinalmente, (iii) outras condições de carregamento tais como flexão e cisalhamento e (iv) chapas ortótropas.

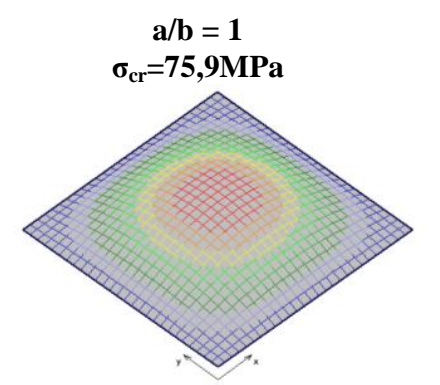

(a)

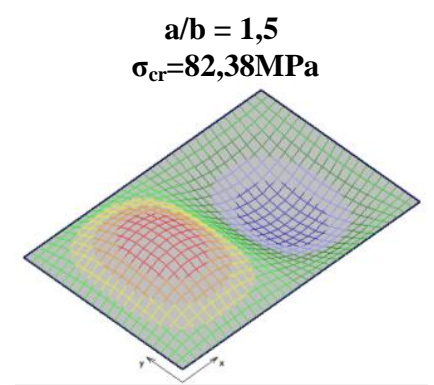

(b)

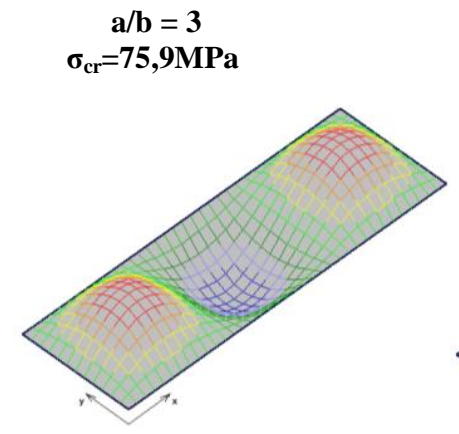

(c)

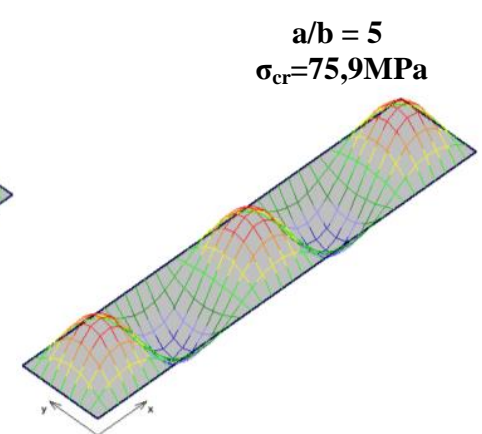

(d)

Figura 2.18 - Tensões críticas em MPa e modos de instabilidade para (a) a=100cm, $m=1$ e n=1; (b) $a=150 \mathrm{~cm}, \mathrm{~m}=2$ e $n=1 ;(c) a=300 \mathrm{~cm}, \mathrm{~m}=3$ e $n=1 ;(d) a=500 \mathrm{~cm}, m=5$ e $n=1$.

O programa é gratuito e encontra-se disponível no site oficial do CTICM ${ }^{13}$.

\footnotetext{
${ }^{13}$ http://www.cticm.com/content/ebplate-version-201-0 (acessado em janeiro de 2014).
} 


\section{Capítulo 3}

\section{MÉTODOS NUMÉRICOS DE ANÁLISE LINEAR DE ESTABILIDADE}

Os métodos numéricos de análise linear de estabilidade são aqueles que fornecem os carregamentos críticos elásticos de bifurcação por meio de técnicas de aproximação numérica das equações de equilíbrio, sendo essas em geral formuladas por meio do método energético. Formalmente, consistem na resolução de um problema de autovalores e autovetores associados às matrizes de rigidez elástica e geométrica da estrutura discretizada (qualquer que seja o método de discretização empregado).

Esse capítulo apresenta os aspectos relevantes (i) da metodologia baseada no uso do método das faixas finitas (MFF), e do programa computacional CUFSM, utilizando os métodos de solução "signature curve" e "general boundary condition"; (ii) da metodologia baseada no uso do método dos elementos finitos com a teoria generalizada de viga (MEF-GBT), com uso do programa GBTUL; e por fim, (iii) da metodologia baseada no método dos elementos finitos com uso de elementos de casca (MEF-cascas), com o programa ABAQUS.

Tanto o CUFSM quanto o GBTUL são programas gratuitos e disponíveis na internet. Essa característica, aliada à interface gráfica simples, torna-os atrativos em relação ao ABAQUS, ou quaisquer outros programas consagrados que exijam um investimento considerável e um período de familiarização com a ferramenta. 


\subsection{Método das Faixas Finitas}

\subsubsection{Breves comentários sobre o método}

Apesar do enorme desenvolvimento da última década em termos computacionais, o Método das Faixas Finitas, MFF, em alguns casos ainda pode ser uma alternativa bastante vantajosa em relação ao Método dos Elementos Finitos. Embora seja uma visão controversa, esse método muitas vezes é entendido como uma "simplificação" do MEF quando este usa elementos de superfície, tendo sido desenvolvido de modo a superar os problemas relacionados aos elevados esforços computacionais de uma discretização bidimensional.

Para a análise de perfis, o MFF tira proveito da natureza prismática dos perfis e discretiza a linha média da seção transversal (em relação à espessura) em finitos segmentos. Na direção longitudinal do perfil, cada um desses segmentos dá origem a uma faixa com uma dimensão longitudinal igual a do comprimento total do perfil, denominado de "L" na Figura 3.1a. Cada faixa finita é representada por quatro nós, tendo cada nó quatro graus de liberdade $(u, v, w, \theta)$ associados ao sistema de coordenas local $(x, y, z)$. O campo de deslocamentos $\mathbf{u}=[u v w \theta]^{T}$ é obtido por interpolação dos deslocamentos nodais $\mathbf{d}=\left[\begin{array}{llll}u_{1} & v_{1} & u_{2} & v_{2}\end{array} \mid w_{1} \theta_{1} w_{2} \theta_{2}\right]^{T}$, apresentados na Figura 3.1b, através das funções de forma, agrupadas na matriz $\boldsymbol{\Psi}$.

Os deslocamentos no plano da faixa $(u, v)$, ou deslocamentos de membrana, variam linearmente na direção transversal $x$, enquanto que na direção longitudinal $y$ o deslocamento $u$, obedece a um componente harmônico da função de forma longitudinal $\Psi(\mathrm{y})$, e $v$ varia segundo a derivada desta. Os deslocamentos fora do plano da faixa, $w$, ou deslocamentos de flexão, variam segundo um polinômio cúbico na direção transversal $x$ e acompanham a função de forma $\Psi(y)$ na direção longitudinal $y$. As funções de forma longitudinais devem ser escolhidas de acordo com as condições de contorno do problema. No caso de um perfil biarticulado, é possível fazer $\Psi(\mathrm{y})=$ $\operatorname{sen}(\mathrm{m} \pi \mathrm{y} / \mathrm{L})$, sendo que a constante "m" denota o número de semiondas esperado para a configuração deformada ao longo do comprimento da faixa ("m" é um número que deve ser assumido a priori; normalmente, adota-se $\mathrm{m}=1$ ). 


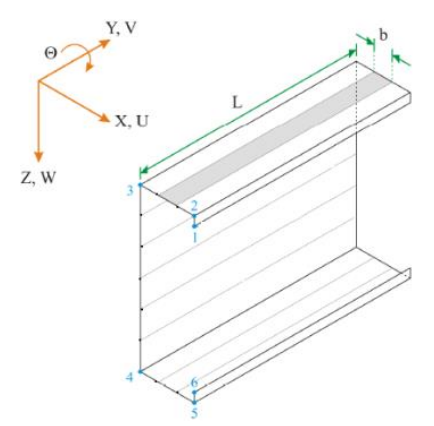

(a)

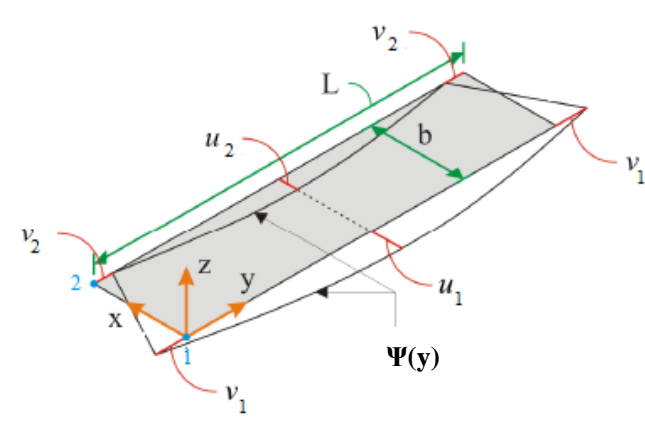

(b)

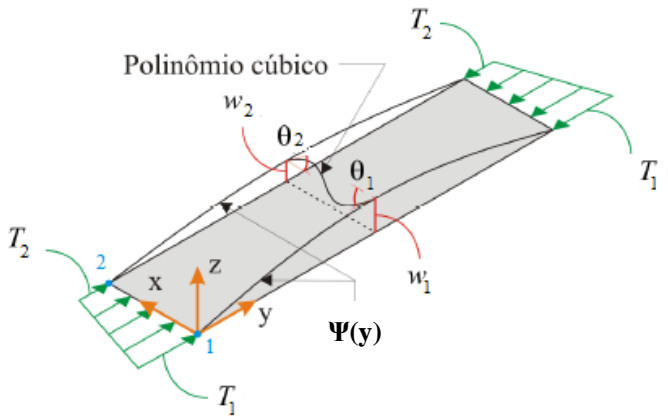

(c)

Figura 3.1 - MFF utilizado no programa CUFSM. (a) Discretização do perfil (b) deslocamentos nodais de membrana (c) deslocamentos nodais de flexão e distribuição do carregamento longitudinal numa faixa Adaptado (MEZZOMO, 2012).

De maneira geral, os campos de deslocamentos de uma faixa finita, $u, v$ e $w$, aproximados pelos deslocamentos dos nós e pelas funções de forma, são escritos matematicamente pelas seguintes equações ${ }^{14}$ :

$$
\begin{aligned}
& u=\left[\left(1-\frac{x}{b}\right) \quad \frac{x}{b}\right]\left[\begin{array}{l}
u_{1} \\
u_{2}
\end{array}\right\} \Psi(y), \\
& v=\left[\left(1-\frac{x}{b}\right) \frac{x}{b}\right]\left[\begin{array}{l}
v_{1} \\
v_{2}
\end{array}\right\} \Psi^{\prime}(y), \\
& w=\left[\left(1-\frac{3 x^{2}}{b^{2}}+\frac{2 x^{3}}{b^{3}}\right)\left(x-\frac{2 x^{2}}{b}+\frac{x^{3}}{b^{2}}\right)\left(\frac{3 x^{2}}{b^{2}}-\frac{2 x^{3}}{b^{3}}\right)\left(\frac{x^{3}}{b^{2}}-\frac{x^{2}}{b}\right)\right]\left\{\begin{array}{c}
w_{1} \\
\theta_{1} \\
w_{2} \\
\theta_{2}
\end{array}\right\} \Psi(y) .
\end{aligned}
$$

\section{- Matrizes de Rigidez}

A deformação na faixa é composta pelas parcelas de membrana e flexão. A deformação de membrana, $\boldsymbol{\varepsilon}_{\mathbf{m}}$, está na linha de centro da faixa e é governada pela hipótese de estado plano de tensão. A deformação por flexão, $\boldsymbol{\varepsilon}_{\mathbf{f}}$, segue a teoria clássica

\footnotetext{
${ }^{14}$ Ver por exemplo (LI; SCHAFER, 2010).
} 
de placas finas de Kirchhoff onde se admite que a deformação é nula no plano médio da placa. As deformações também podem ser escritas em função das derivadas das funções de forma, representadas pela matriz $\mathbf{B}$ e os deslocamentos nodais $\mathbf{d}$, conforme Eq. (3.4).

$$
\varepsilon=\varepsilon_{\mathbf{m}}+\varepsilon_{\mathbf{f}}=\left\{\begin{array}{c}
\varepsilon_{x} \\
\varepsilon_{y} \\
\gamma_{x y}
\end{array}\right\}_{m}+\left\{\begin{array}{c}
\varepsilon_{x} \\
\varepsilon_{y} \\
\gamma_{x y}
\end{array}\right\}_{b}=\left\{\begin{array}{c}
\partial u / \partial x \\
\partial v / \partial y \\
\partial u / \partial y+\partial v / \partial x
\end{array}\right\}+\left\{\begin{array}{c}
-z \partial^{2} w / \partial x^{2} \\
-z \partial^{2} w / \partial y^{2} \\
2 z \partial^{2} w / \partial x \partial y
\end{array}\right\}=\mathbf{B d} \cdot
$$

Admitindo-se que as faixas finitas representam estruturas constituídas por materiais elásticos lineares, as relações tensões-deformações serão lineares e expressas pela Eq. (3.5), sendo as tensões de membrana $\boldsymbol{\sigma}_{\mathbf{m}}$ e as tensões de flexão $\boldsymbol{\sigma}_{\mathbf{f}}$, tal que:

$$
\sigma=\sigma_{\mathrm{m}}+\sigma_{\mathrm{f}}=\mathbf{D} \varepsilon
$$

A matriz das constantes elásticas $\mathbf{D}$ é definida pelas grandezas $E_{x}, E_{y}, G_{x y}, v_{x}, v_{y}$ e t, que são respectivamente o módulo de deformação longitudinal, o módulo de deformação transversal, o módulo de cisalhamento, os coeficientes de Poisson e a espessura (admitida uniforme) da faixa finita.

Por sua vez, a energia de deformação interna é definida pela Eq. (3.6), como segue:

$$
U=\frac{1}{2} \int \sigma^{\mathrm{T}} \varepsilon \mathrm{dV}=\frac{1}{2} \int \varepsilon^{\mathrm{T}} \mathbf{D} \varepsilon \mathrm{dV}=\frac{1}{2} \mathbf{d}^{\mathrm{T}} \int \mathbf{B}^{\mathrm{T}} \mathbf{D B} \mathrm{dVd}=\frac{1}{2} \mathbf{d}^{\mathrm{T}} \mathbf{k}_{\mathbf{e}} \mathbf{d} .
$$

Nota-se que a equação constitutiva apresentada na Eq. (3.5) foi imposta na Eq. (3.6), obtendo-se então a matriz de rigidez elástica, $\mathbf{k}_{\mathbf{e}}$, definida abaixo:

$$
\mathbf{k}_{\mathbf{e}}=\int \mathbf{B}^{\mathrm{T}} \mathbf{D B} \mathrm{dV} \text {. }
$$

Considerando o carregamento aplicado na Figura 3.1, a matriz de rigidez geométrica é obtida através do trabalho realizado pelas forças externas $\left(T_{1}, T_{2}\right)$, definido como:

$$
W=\frac{1}{2} \int_{0}^{\mathrm{a}} \int_{0}^{\mathrm{b}}\left[\mathrm{T}_{1}-\frac{\left(\mathrm{T}_{1}-\mathrm{T}_{2}\right) x}{\mathrm{~b}}\right]\left[\left(\frac{d u}{d y}\right)^{2}+\left(\frac{d v}{d y}\right)^{2}+\left(\frac{d w}{d y}\right)^{2}\right] d x d y .
$$

As derivadas de segunda ordem do campo dos deslocamentos podem ser expressas em função das funções de forma, $\boldsymbol{\Psi}$, e dos deslocamentos nodais, $\mathbf{d}$, conforme as equações:

$$
\left(\frac{d u}{d y}\right)^{2}+\left(\frac{d v}{d y}\right)^{2}+\left(\frac{d w}{d y}\right)^{2}=\mathbf{d}^{T} \Psi^{\prime} T \Psi^{\prime} \mathbf{d}=\mathbf{d}^{T} \mathbf{G}^{T} \mathbf{G d}
$$


Introduzindo esta notação é possível reescrever a Eq. (3.8) na forma:

$$
W=\frac{1}{2} \mathbf{d}^{\mathrm{T}} \int_{0}^{\mathrm{a}} \int_{0}^{\mathrm{b}}\left[\mathrm{T}_{1}-\frac{\left(\mathrm{T}_{1}-\mathrm{T}_{2}\right) x}{\mathrm{~b}}\right] \mathbf{G}^{\mathrm{T}} \mathbf{G} d x d y \mathbf{d}=\frac{1}{2} \mathbf{d}^{\mathrm{T}} \mathbf{k}_{\mathrm{g}} \mathbf{d},
$$

onde $\mathbf{k}_{\mathbf{g}}$ é a matriz de rigidez geométrica dada conforme a Eq. (3.11).

$$
\mathbf{k}_{\mathbf{g}}=\int_{0}^{\mathrm{a}} \int_{0}^{\mathrm{b}}\left[\mathrm{T}_{1}-\frac{\left(\mathrm{T}_{1}-\mathrm{T}_{2}\right) x}{\mathrm{~b}}\right] \mathbf{G}^{\mathrm{T}} \mathbf{G} d x d y .
$$

As equações anteriores foram estabelecidas em relação a um referencial local, ao qual corresponde o sistema de coordenadas locais (x, y, z). Para escrever as equações globais, em relação a um referencial global é necessário efetuar a transformação de coordenadas, i.e. escrever as equações relativas ao comportamento de cada faixa finita no sistema de coordenadas globais $(\mathrm{X}, \mathrm{Y}, \mathrm{Z})$. Esta transformação pode ser facilmente obtida recorrendo a relações trigonométricas que compõe uma matriz transformação.

Com todos os graus de liberdade expressos em coordenadas globais, as matrizes de rigidez elástica e geométrica globais, $\mathbf{K}_{\mathbf{e}}$ e $\mathbf{K}_{\mathbf{g}}$ respectivamente, serão expressas pelo somatório da contribuição de cada faixa finita “j”, tal como segue abaixo.

$$
\mathbf{K}_{\mathbf{e}}=\sum_{\mathbf{n}}^{\mathrm{j}=1} \mathbf{K}_{\mathbf{e}}{ }^{\mathrm{j}} ; \mathbf{K}_{\mathbf{g}}=\sum_{\mathbf{n}}^{\mathrm{j}=1} \mathbf{K}_{\mathbf{g}}{ }^{\mathrm{j}}
$$

\section{- Estabilidade Elástica Linear}

Utilizando as matrizes acima, a análise linear de estabilidade por meio do MFF compreende em resolver o seguinte problema generalizado de autovalores:

$$
\mathbf{K}_{\mathbf{e}} \Phi=\Lambda \mathbf{K}_{\mathbf{g}} \Phi
$$

Existe um fator multiplicativo do carregamento externo tal que exista solução não trivial. A solução da Eq. (3.13) resulta na matriz diagonal $\Lambda=\operatorname{diag}\left[\lambda_{1}, \lambda_{2}, \ldots, \lambda_{n}\right]$, cujo autovalor $\lambda$ representa um possível fator multiplicativo para determinar o carregamento crítico. $\boldsymbol{\Phi}$ é a matriz de autovetores, que representam os modos de instabilidade para cada autovalor.

A precisão dos resultados obtidos por este método depende de o quão o MFF consegue reproduzir as reais condições de contorno nas extremidades do perfil e do nível de discretização da seção transversal, i.e., do número de faixas, e da "qualidade" das funções de forma $\boldsymbol{\Psi}$ que originam as matrizes de rigidez elástica e geométrica, conforme brevemente demostrado anteriormente. 
No âmbito da análise de estabilidade elástica de barras (prismáticas), submetidas a carregamentos simples (e.g., compressão, flexão uniformes) por meio do MFF, refere-se a dois programas de cálculo de fácil utilização: (i) THIN-WALL, desenvolvido na Universidade de Sydney, e (ii) CufSM, elaborado na Universidade Johns Hopkins de Baltimore, sendo o segundo empregado neste trabalho e apresentado brevemente no item a seguir.

\subsubsection{O programa computacional CUFSM}

O CuFsm é um programa elaborado por Benjamim W. Schafer e Teoman Peköz (SCHAFER E PEKÖZ, 1998) que utiliza o MFF, conforme descrito acima, para calcular os carregamentos críticos elásticos de bifurcação de um perfil isolado de seção transversal definida, de diversos comprimentos. O programa fornece o modo e o carregamento crítico correspondente para diferentes comprimentos arbitrários da barra.

O CUFSM, apesar de ser uma alternativa de baixo custo computacional em relação a programas de MEF, apresenta algumas restrições: (i) as barras devem ser obrigatoriamente prismáticas (isto é, de seção transversal constante ao longo do eixo); (ii) o método só permite barras isoladas; (iii) não há restrição ao empenamento; e (iv) por existir nós somente nas extremidades da barra, o carregamento só pode ser aplicado nessas seções.

Implementações recentes possibilitaram o desenvolvimento do Método das Faixas Finitas Confinadas (Constrained Finite Strip Method), denominado cFSM, (LI, SCHAFER, 2010). Através de ideias semelhantes às da teoria generalizada de viga (a qual será abordada no próximo item), o método possibilitou a identificação e decomposição dos modos elásticos de instabilidade. As versões CUFSM 3.12 (e em diante) do programa contêm tanto o método convencional quanto o método modificado.

Embora o método das faixas finitas possibilite a solução de uma grande variedade de problemas, as versões CUFSM 3.13 (e anteriores) utilizam funções de forma longitudinais que permitem a análise apenas de barras biarticuladas (identificadas no programa como S-S, ou "simply supported"). A solução fornecida nessa condição é denominada "signature curve", por apresentar os resultados em forma de curva do fator de carregamento versus diversos comprimentos da barra - fornecendo, assim, uma espécie de panorama do comportamento do perfil para diferentes comprimentos. Além disso, na solução "signature curve" o CUFSM fixa o número de ondas longitudinais "m" 
em 1, não permitindo a análise de situações com $m \neq 1$ (esse aspecto é informado ao usuário de forma muito discreta, como pode ser observado na interface do programa ilustrada na Figura 3.2 - o valor $\mathrm{m}=1$ aparece em vermelho, porém em caracteres pequenos e num local de pouco destaque; o usuário tampouco é advertido sobre o que isso significa e quais as consequências que implica).

O mesmo grupo de pesquisadores Li e Schafer (2010) implementou novas funções de forma longitudinais tanto para o método convencional quanto para o método modificado, possibilitando assim a análise de estabilidade de perfis com várias condições de contorno: S-S (articulação nas duas extremidades), C-C (engaste nas duas extremidades), S-C (articulação-engaste) e C-F (engaste-livre), porém sem a apresentação dos resultados em forma de curvas. A variante do método no programa foi denominada de "general boundary condition". As versões CUFSM 4.0 em diante permitem a solução tanto pelo "signature curve" - que, enfatiza-se, fixa "m" em 1 e só permite a condição S-S - quanto pela "general boundary condition". Neste trabalho, no Capítulo 4 todos os resultados obtidos com a opção "signature curve" serão referenciados como CUFSM-SC, enquanto que os resultados obtidos com a variante "general boundary condition" serão apresentados como CUFSM-GBC. Salienta-se que todos se referem ao método convencional (i.e., o cFSM não foi utilizado).

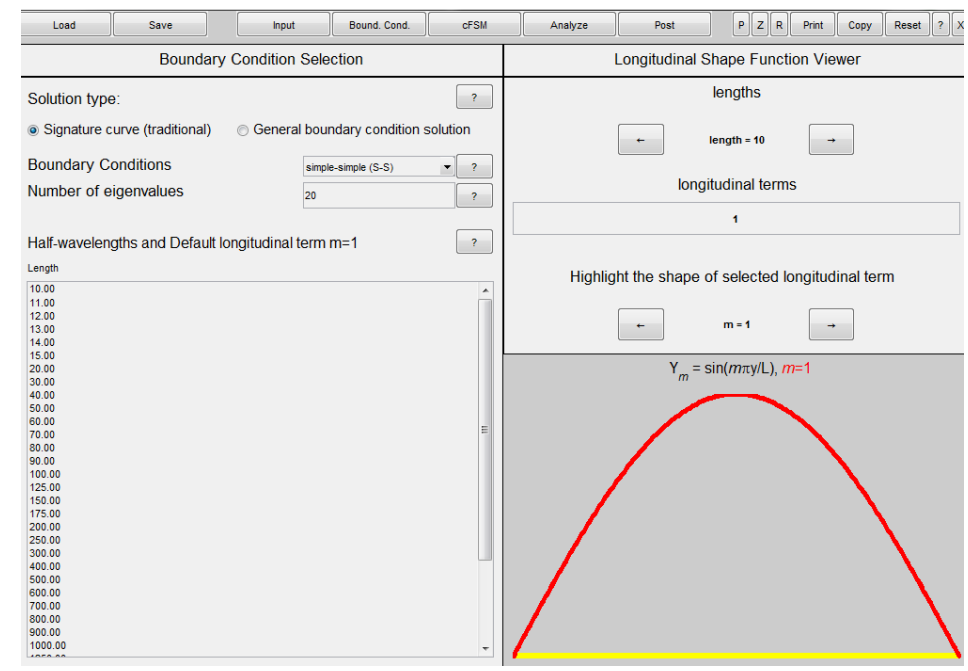

Figura 3.2 - Interface do CUFSM 4.03 para a opção "signature curve".

Neste trabalho utilizou-se a versão CUFSM 4.03. O programa é gratuito e encontra-se disponível na página da internet ${ }^{15}$ dos pesquisadores Li e Schafer, (2010).

\footnotetext{
${ }^{15}$ http://www.ce.jhu.edu/bschafer/cufsm (acessado em junho 2013).
} 


\subsection{Teoria Generalizada de Viga}

\subsubsection{Breves comentários sobre o método}

A Teoria Generalizada de Vigas, denominada GBT (Generalized Beam Theory) foi desenvolvida por Richard Schardt em 1966 na Alemanha (CAMOTIM, et al., 2006), porém esta teoria permaneceu exclusiva ao país de origem até meados da década de 80, quando J. M. Davies disseminou-a entre a comunidade científica de língua inglesa. Davies (Some applications of generalized beam theory, 1992) aplicou a GBT para investigar a estabilidade elástica linear de perfis formados a frio e verificou o enorme potencial dessa teoria, resultando em um método mais robusto do que aquele baseado nas faixas finitas e mais econômico computacionalmente do que aquele baseado no uso de elementos finitos de casca - ainda que não tão geral quanto esse último.

Atualmente, a GBT tem atraído a atenção de muitos pesquisadores, especialmente na Universidade Técnica de Lisboa, onde o programa GBTUL foi desenvolvido. A GBT trabalha diretamente com os modos elásticos de instabilidade desacoplados. No entanto, uma limitação importante para o uso mais generalizado da GBT por meio da comunidade técnica e profissional é a falta de um programa computacional com a formulação facilmente acessível e documentada.

A GBT apresenta uma formulação baseada em uma teoria de vigas, isto é, ela idealiza o perfil como sendo um objeto unidimensional representado por sua linha de eixo, dotado de uma seção transversal. O eixo pode experimentar deslocamentos e rotações de magnitude moderada (embora seja possível a extensão da teoria para incluir grandes deslocamentos e rotações finitas), e a descrição cinemática é enriquecida com a inclusão de graus de liberdade adicionais pertencentes às seções transversais (e não ao eixo). Em outras palavras, introduzem-se nós nas seções transversais, o que permite a consideração dos efeitos locais, i.e. das deformações da seção.

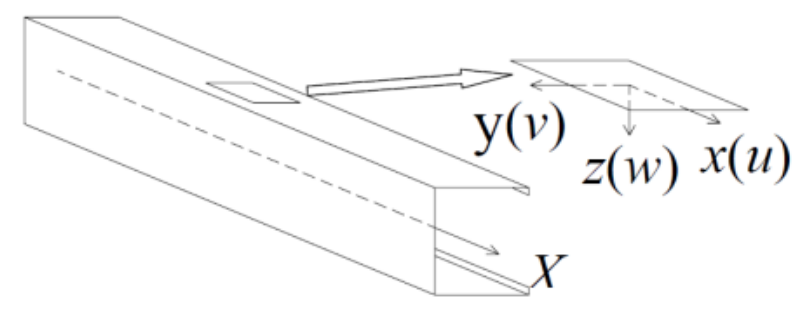

Figura 3.3 - Eixos locais e deslocamentos referenciados. Adaptado (BEBIANO, et al., 2008). 
A análise linear de estabilidade via GBT passa por três etapas: (i) análise da seção transversal, (ii) definição dos modos de deformação da seção que se supõe relevantes ao perfil em estudo, (iii) análise da barra ou solução modal (problema de autovalores e autovetores).

A análise da seção transversal consiste em definir o campo dos deslocamentos $(u$, $v, w)$, referentes aos eixos $x, y$ e $z$, conforme a Figura 3.3, através dos deslocamentos modais definidos ao longo da linha média da seção transversal e das chamadas funções de amplitude longitudinais $\boldsymbol{\Psi}_{k}(x)$.

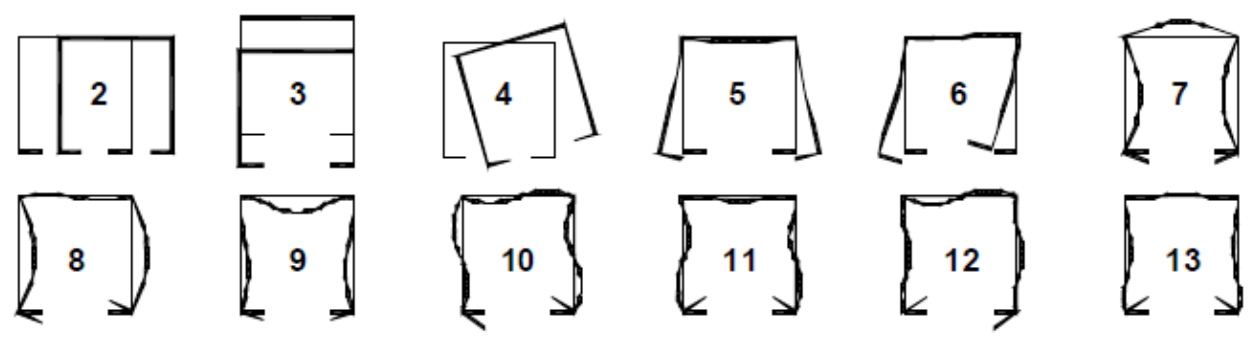

Figura 3.4 - Modos de deformação no plano da seção transversal (BEBIANO, et al., 2008).

A definição dos modos de deformação da seção transversal depende da forma da seção e de sua discretização. A Figura 3.4 ilustra exemplos de modos de deformação para uma seção transversal formada por um perfil U enrijecido.

A análise da barra consiste em resolver um problema de autovalores e autovetores formalmente idêntico ao apresentado no subitem 3.1.1, cuja solução é (i) analítica para os casos em que o perfil é biarticulado e está sob carregamento uniforme, e (ii) numérica, baseada em elementos finitos (de barra), para todos os outros casos. O método se propõe a resolver o sistema:

$$
\left[\mathbf{K}_{\mathrm{e}}-\lambda \mathbf{K}_{\mathrm{g}}\right] \Phi_{k}(x)=0,
$$

sendo $\mathbf{K}_{\mathrm{e}}$ a matriz de rigidez elástica, $\mathbf{K}_{\mathrm{g}}$ a matriz de rigidez geométrica e $\lambda$ o fator multiplicador do carregamento aplicado. Uma vez que a dimensão desse sistema é relativamente baixa, pouco ou moderado esforço computacional é necessário para obter a solução.

\subsubsection{O programa computacional GBTUL}

O GBTUl é uma ferramenta para a análise de estruturas constituídas de barras prismáticas de paredes finas baseado na GBT. Nos últimos anos, Camotim e seus colegas da Universidade Técnica de Lisboa desenvolveram e implementaram, no 
GBTUL, diversas formulações com base na GBT para realizar (i) análises lineares de estabilidade e pós-críticas, e (ii) análises dinâmicas e de vibração de peças de paredes finas com material isótropo e ortótropo.

Para a estabilidade de barras isoladas, o programa permite visualizar as contribuições de cada modo de deformação nos diversos modos de instabilidade. Esse aspecto às vezes é útil na interpretação da resposta estrutural sob consideração.

Como resposta nas análises de estabilidade, o GBTUL exibe os modos de instabilidade e os correspondentes carregamentos críticos para diversos comprimentos do perfil (o comprimento é admitido como uma variável livre: apenas as dimensões da seção transversal são fixas e fornecidas nos dados de entrada), semelhantemente ao CuFsm.

O programa é gratuito e encontra-se disponível no website dos pesquisadores (BEBIANO, et al., 2008). Neste trabalho utilizou-se a versão 1.0b.

\subsection{Método dos Elementos Finitos}

\subsubsection{Breves comentários sobre o método}

A grande maioria das análises estruturais atualmente efetuadas pela comunidade técnico-científica ligada às estruturas de aço é estabelecida por meio de programas que, de alguma forma, utilizam o Método dos Elementos Finitos (MEF). Recorre-se a um dos diversos programas comerciais existentes no mercado, como o ABAQUS, o ANSYS, o SAP2000, o NASTRAN, dentre outros.

De fato, devido à sólida fundamentação matemática do MEF, aliado à sua versatilidade, eficácia e generalidade, programas como esses tornaram-se instrumentos inestimáveis na análise de estruturas, especialmente quando é preciso considerar o comportamento não linear da geometria e do material.

No caso da análise de estabilidade de perfis formados a frio, o uso do MEF geralmente consiste em discretizar a geometria do perfil, utilizando elementos de casca. Com esses elementos, os deslocamentos e as rotações em um ponto qualquer do perfil são aproximados por funções de forma polinomiais cujos coeficientes são os deslocamentos generalizados, ou seja, os graus de liberdade nodais. A necessidade de 
capturar adequadamente as deformações da seção transversal nos diversos modos de instabilidade (cujas formas são inicialmente desconhecidas) faz com que sejam utilizadas malhas razoavelmente refinadas.

A introdução dos carregamentos e das condições de contorno nos nós das seções transversais extremas deve ser feita minuciosamente, a fim de representar adequadamente a solicitação externa e a condição de vínculo desejada. Esse aspecto parece evidente, porém é o momento em que muitos modelos incorrem em erro e fornecem resultados completamente inesperados ou sem nenhuma utilidade.

Simular, por exemplo, uma condição de articulação em uma extremidade de um perfil requer que o analista compreenda quais são os deslocamentos e rotações nodais que devem ser restritos em cada nó da seção considerada, e quais os que devem ser liberados. Restringir deslocamentos axiais (i.e. na direção do eixo do perfil), por exemplo, afeta diretamente o empenamento da seção e, por conseguinte, tem efeito sobre o carregamento crítico do perfil; além de modificar o giro de corpo rígido que a seção eventualmente teria (por flexão), se o perfil fosse articulado nessa extremidade. A compressão uniforme só será corretamente representada se todos os nós da seção estiverem axialmente restritos, porém esta pode ter efeitos indesejados sobre o empenamento e sobre o giro de flexão da seção.

A análise linear de estabilidade por meio do MEF consiste na solução de um problema de autovalores e autovetores envolvendo a matriz de rigidez tangente do perfil discretizado, de forma totalmente análoga ao problema apresentado nos subitens anteriores. Trata-se de determinar o carregamento para que a matriz de rigidez tangente torne-se singular, de modo que o problema tenha soluções não triviais.

$$
\mathbf{K}_{\mathbf{t}} \Phi=0
$$

$\mathrm{Na}$ equação acima $\Phi$ é a solução não trivial dos deslocamentos e $\mathbf{K}_{\boldsymbol{t}}$ é matriz de rigidez tangente, composta pela matriz de rigidez elástica $\mathbf{K}_{\mathbf{e}}$ e a matriz de rigidez geométrica $\mathbf{K}_{\mathbf{g}}$, que por sua vez contém os carregamentos aplicados.

A Eq. (3.15) conduz a Eq. (3.16), que permite obter os autovalores $\lambda_{i}$ e os autovetores $\boldsymbol{\Phi}_{i}$ de cada modo " $i$ ":

$$
\left[\mathbf{K}_{\mathrm{e}}-\lambda_{i} \mathbf{K}_{\mathrm{g}}\right] \Phi_{i}=0 .
$$

A Eq. (3.16) é resolvida por meio de métodos iterativos de solução, como por exemplo, o método dos subespaços ou o método de Lanczos. 


\subsubsection{O programa computacional ABAQUS}

A escolha do tipo de elemento de casca mais apropriado é essencial para a confiabilidade dos resultados, pois as especificidades de cada elemento (grau das funções de forma, ordem de integração de Gauss, suscetibilidade ou não ao fenômeno de travamento numérico, entre outros) podem afetar drasticamente os resultados.

Na biblioteca de elementos do ABAQUS existem três elementos de casca de quatro nós, designados por S4R5, S4R e S4, esses elementos são os mais empregados em análises lineares de estabilidade (SARAWIT, et al., 2003). Diferem-se no número de graus de liberdade por nó e no número de pontos de integração.

O elemento S4R5, e todos os outros elementos do ABAQUS que terminam com o número "5", possuem cinco graus de liberdade por nó: três translações e duas rotações, essas referentes a eixos contidos no plano do elemento, ou seja, não há rotação em torno do eixo normal ao plano do elemento. Entretanto, todos os outros elementos, inclusive o S4R e o S4, possuem seis graus de liberdade por nó: três translações e três rotações.

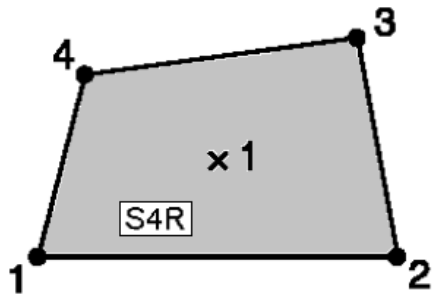

(a)

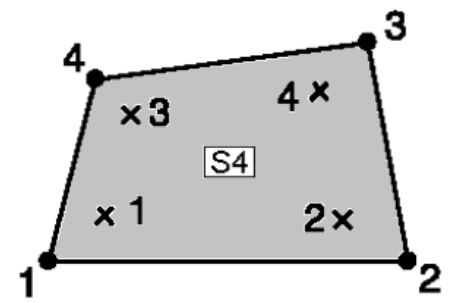

(b)

Figura 3.5 - Pontos de integração dos elementos finitos de (a) integração reduzida: S4R e (b) integração completa: S4. Adaptado de (ABAQUS, 2010).

Os elementos da biblioteca do ABAQUS que contém a letra "R", por exemplo, $\mathrm{S} 4 \mathrm{R}^{16}$ e S4R5, possuem integração reduzida. A integração numérica de ordem reduzida é atraente por acarretar economia computacional, uma vez que utiliza menos pontos de Gauss do que um esquema com integração completa, por exemplo, o $\mathrm{S} 4^{17}$. Por outro lado, pode induzir os chamados modos espúrios de deformação, exigindo algum esquema de estabilização para evitar matrizes de rigidez artificialmente singulares.

\footnotetext{
${ }^{16}$ Figura 3.5a.

${ }^{17}$ Figura 3.5b.
} 
Em todos os modelos deste trabalho, utilizou-se o elemento o S4R, elemento de quatro nós, com 6 graus de liberdade por nó, integração reduzida e com a estabilização chamada de "hourglass control".

Nas análises com o ABAQUS, diferentemente do CUFSM e do GBTUL, o comprimento do perfil, denominado de "L" na Figura 3.6, precisa ser definido previamente, ou seja, é um dado fixo do problema. Portanto, para cada seção transversal e para cada caso de carregamento e vinculação há um modelo com um comprimento longitudinal definido previamente.

Subdivide-se a barra na direção longitudinal e transversal, de tal maneira que os elementos possuam a melhor razão de aspecto possível, i.e. relação entre o comprimento e a largura do elemento próxima a 1.

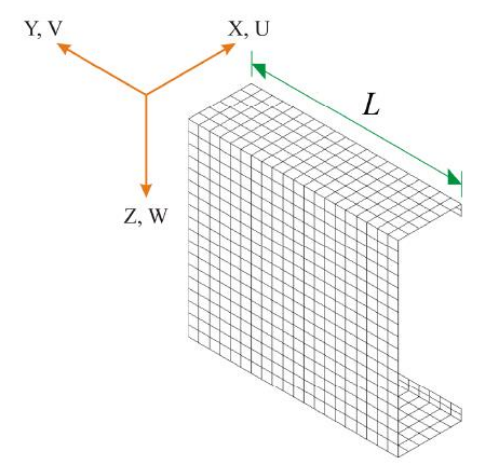

Figura 3.6 - Exemplo de malha de elementos finitos para o perfil $U$ enrijecido de comprimento $L$. 


\section{Capítulo 4}

\section{APLICAÇÃO: ANÁLISE DE PERFIS Ue E Ze}

Este capítulo é dedicado à obtenção dos carregamentos críticos elásticos bifurcacionais e seus correspondentes modos de instabilidade, através do (i) MFF, (ii) MEF-GBT e (iii) MEF-cascas, quando aplicados à análise de perfis de chapa dobrada para os comprimentos, L, de $15 \mathrm{~cm}, 70 \mathrm{~cm}, 150 \mathrm{~cm}, 200 \mathrm{~cm}, 300 \mathrm{~cm}$ e $400 \mathrm{~cm}$. As condições de carregamento e vinculação analisadas são: (i) barra biarticulada submetida à compressão uniforme, conforme Figura 4.1a, (ii) barra biarticulada submetida a flexão pura, conforme Figura 4.1b, (iii) barra biarticulada submetida a carregamento distribuído conforme Figura 4.1c e (iv) barra engastada em uma extremidade e livre na outra, submetida à flexão simples, conforme Figura 4.1d.

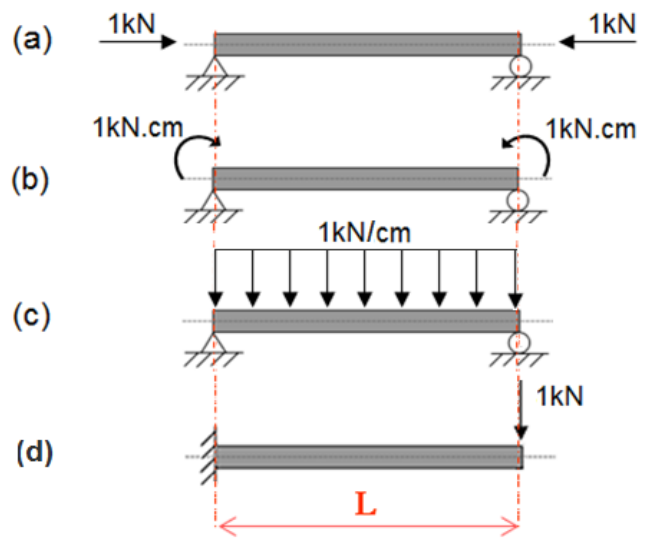

Figura 4.1 - Condições de vinculação e carregamento: (a) barra biarticulada submetida a compressão uniforme, (b) barra biarticulada submetida a flexão pura, (c) barra biarticulada submetida a carregamento distribuído e (d) barra engastada submetida a flexão simples.

As seções transversais analisadas são (i) U enrijecido (comercialmente denominado "Ue") cujas dimensões em milímetros são 200x75x20x2, sendo essas a 
altura total da alma, a largura da mesa, a largura do enrijecedor e a espessura das paredes respectivamente, conforme ilustrado na Figura 4.2a; e (ii) $\mathrm{Z}$ enrijecido (comercialmente denominado "Ze") cujas dimensões em milímetros também são $200 \times 75 \times 20 \times 2$, conforme ilustrado na Figura 4.3a. Avalia-se também a influência do grau de discretização da seção transversal, conforme apresentado na Figura 4.2b, Figura 4.2c e Figura 4.2d para o perfil Ue e na Figura 4.3b, Figura 4.3c e Figura 4.3d para o perfil Ze.

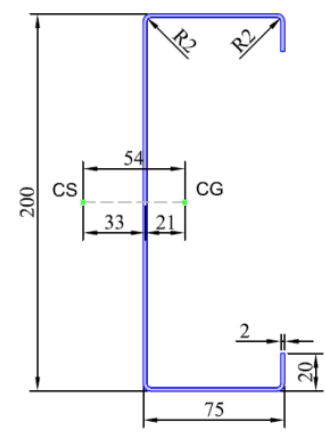

(a)

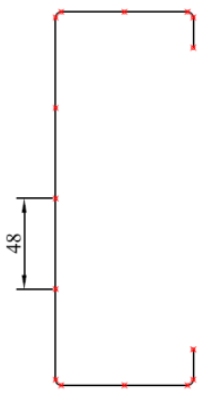

(b)

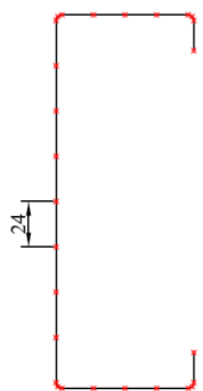

(c)

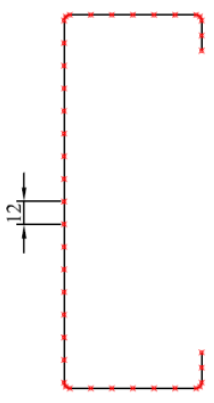

(d)

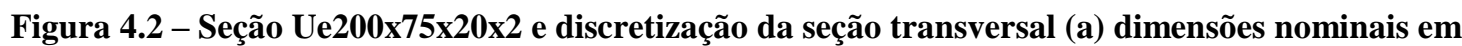
mm, (b) malha tipo 1, (c) malha tipo 2 e (d) malha tipo 3.

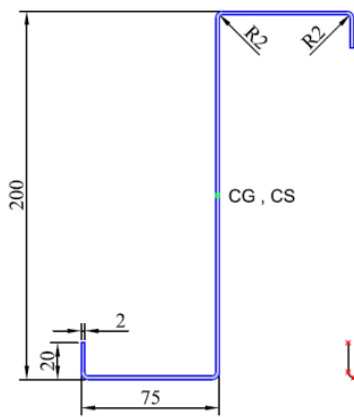

(a)

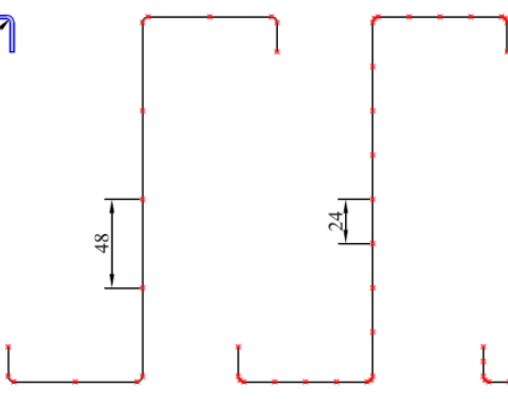

(c)

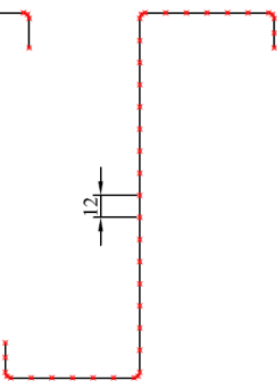

(d)

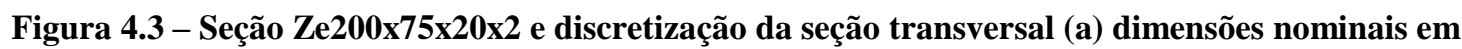
mm, (b) malha tipo 1, (c) malha tipo 2 e (d) malha tipo 3.

\subsection{Barra biarticulada submetida a compressão uniforme}

Conforme apresentado na Figura 4.1a, Figura 4.2 e Figura 4.3, os perfis em

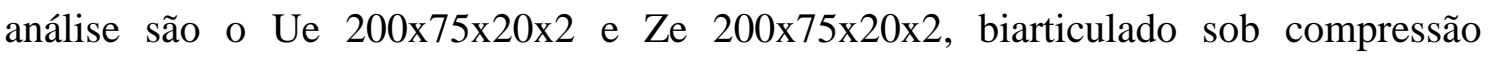
uniforme $\mathrm{P}$ de valor igual a $1 \mathrm{kN}$, com empenamento livre e distorção restringida nas extremidades.

Utilizaram-se três diferentes discretizações das seções transversais, conforme ilustrado na Figura 4.2 e Figura 4.3, nomeadas de tipo 1, tipo 2 e tipo 3, sendo 1 a seção menos refinada e 3 a seção mais refinada. 
Aborda-se aqui a comparação das diferenças de modelagem entre o MFF, MEFGBT e o MEF-cascas através dos programas CUFSM, GBTUl e ABAQUS.

No CUFSM, o carregamento pode ser aplicado como uma tensão uniforme, $\sigma$ (força $\mathrm{P}$ atuando na área da seção transversal, A) ao longo de todo o comprimento do perfil - ver Figura 4.5a para Ue e Figura 4.6a para Ze - ou como uma força P, nesse caso unitária, aplicada no centro de torção da seção transversal, exatamente como é aplicado no GBTUL e ilustrado na Figura 4.5b e Figura 4.6b respectivamente, para os perfis Ue e Ze.

No ABAQUS, a princípio aplicou-se um carregamento linear na linha média da alma nas seções extremas. As condições de apoio simples e empenamento livre foram simuladas conforme uma ligação com tala simples de alma, como ilustrado na Figura 4.4a. Sendo assim, as seguintes restrições foram aplicadas: (i) fixou-se a translação na direção do eixo longitudinal do perfil em apenas um ponto, que é o ponto médio da alma na seção do meio do vão (esse vínculo tem reação nula devido ao fato de o carregamento ser autoequilibrado, porém é necessário para evitar deslocamento de corpo rígido) e (ii) chamando de $\mathrm{x}$ e $\mathrm{y}$ as direções da seção transversal, paralelas respectivamente à mesa e à alma da seção, restringiu-se a translação nas direções x e y em todos os nós da alma nas seções extremas (os vínculos na direção x apresentam reação nula, porém são necessários para garantir o impedimento à rotação de corpo rígido), conforme Figura 4.4b.

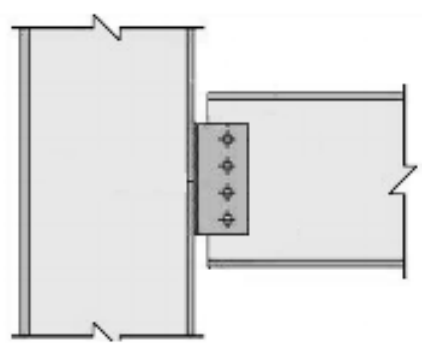

(a)

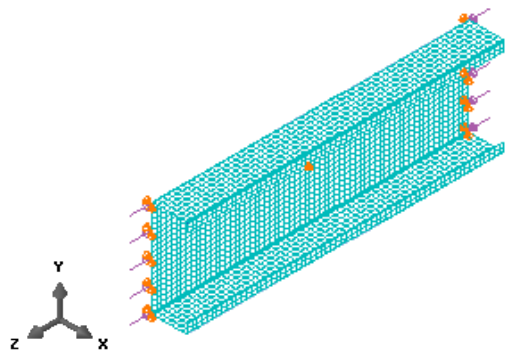

(b)

Figura 4.4 - (a) Ligação viga-pilar com tala simples de alma e (b) modelo estrutural para perfil Ue.

No entanto, para alguns comprimentos L, o ABAQUS obteve carregamentos críticos correspondentes a modos distorcionais nas seções extremas. Esse resultado não foi encontrado em nenhuma análise feita no CUFSM e no GBTUL, o que permitiu concluir que tais programas simulam a condição de apoio simples e empenamento livre restringindo a distorção nas extremidades. No modelo de cascas, essa condição só é 
reproduzida se os nós da alma e das mesas forem impedidos de se deslocarem nas direções x e y.

Embora o modelo ilustrado na Figura 4.4b represente melhor uma ligação típica entre peças e forneça menores valores de carregamento crítico para alguns casos de comprimento, optou-se aqui por alterar as condições de contorno dos modelos de casca de modo que os resultados obtidos com o ABAQUS possam ser comparados com os correspondentes obtidos por meio do CUFSM e do GBTUL.

Portanto, para as barras biarticuladas, além de se fixar a translação na direção z no ponto médio da alma, restringiu-se a translação nas direções $\mathrm{x}$ e y em todos os nós das seções transversais extremas (incluindo alma, mesas e enrijecedores), de forma a impedir a distorção das mesmas.

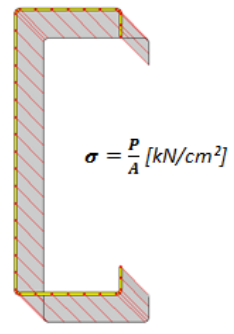

(a)

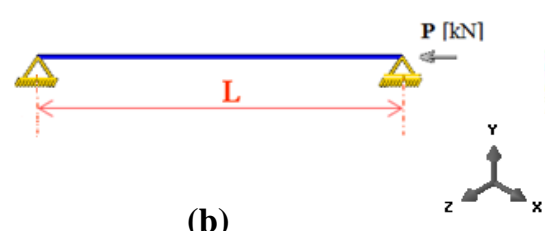

(b)

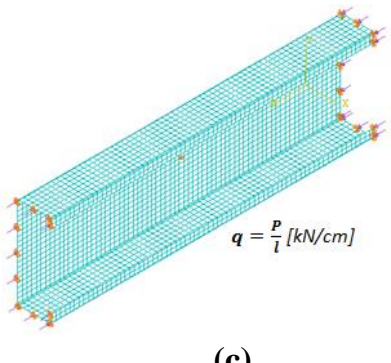

(c)

Figura 4.5 - Modelo estrutural do perfil Ue para (a) CUFSM, (b) GbTUL e (c) ABAQuS.

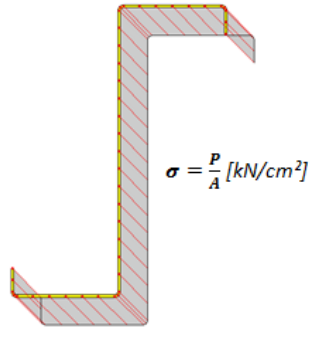

(a)

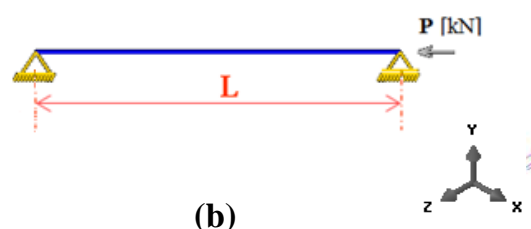

(b)

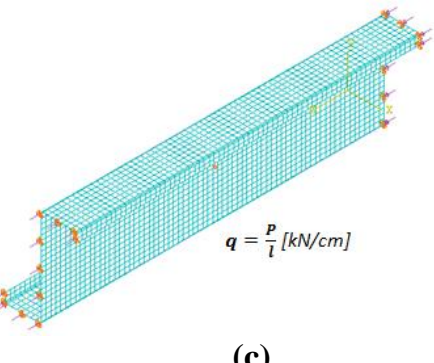

(c)

Figura 4.6 - Modelo estrutural do perfil Ze para (a) CUFSM, (b) GbTUl e (c) AbaQUS.

Para os perfis mais longos ( $\mathrm{L}=400 \mathrm{~cm}$ ), em que se espera que os modos globais sejam preponderantes, calculou-se também, a título de comparação, o carregamento crítico por meio da teoria de Vlasov apresentada no Capítulo 2 (nesse caso, apenas a barra biarticulada sob compressão uniforme). As características das seções transversais estão apresentadas na Figura 4.7 (perfil Ue) e na Figura 4.8 (perfil Ze), e os carregamentos críticos globais $P_{E y}, P_{E z}$ e $P_{\omega}$ foram obtidos conforme apresentado nas Eq. (2.55), Eq. (2.56) e Eq. (2.57), respectivamente. Impondo esses carregamentos críticos globais e as características da seção transversal na equação cúbica (2.58) e 
determinando as três raízes, obteve-se o carregamento crítico mínimo para o modo global, que resultou em:

$$
P_{c r}=65,2 \mathrm{kN} \text {, }
$$

para o perfil Ue e em:

$$
P_{c r}=47,0 \mathrm{kN} \text {, }
$$

para o perfil Ze.
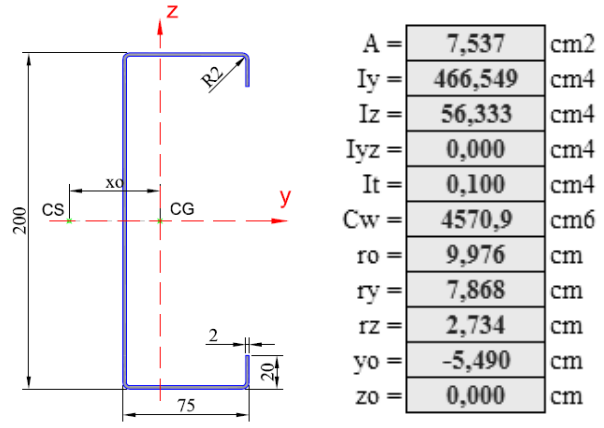

$\begin{array}{rl}\mathrm{L} & =400 \mathrm{~cm} \\ \text { PEy } & =604,4 \\ \mathrm{PEz} & =73,0 \\ \mathrm{P} \omega & \mathrm{kN} \\ \mathrm{PN} & \mathrm{k7}, 6\end{array}$

Figura 4.7 - Características geométricas da seção transversal U enrijecido.

\begin{tabular}{|c|c|}
\hline$A=$ & 7,537 \\
\hline $\mathrm{Iy}=$ & 519,839 \\
\hline $\mathrm{Iz}=$ & 36,290 \\
\hline $\mathrm{Iyz}=$ & 0,000 \\
\hline$\theta=$ & $-19,4$ \\
\hline $\mathrm{It}=$ & 0,100 \\
\hline $\mathrm{Cw}=$ & 6269,5 \\
\hline ro $=$ & 8,590 \\
\hline $\mathrm{ry}=$ & 8,305 \\
\hline $\mathrm{rz}=$ & 2,194 \\
\hline yo $=$ & 0,000 \\
\hline$z_{0}=$ & 0,000 \\
\hline
\end{tabular}
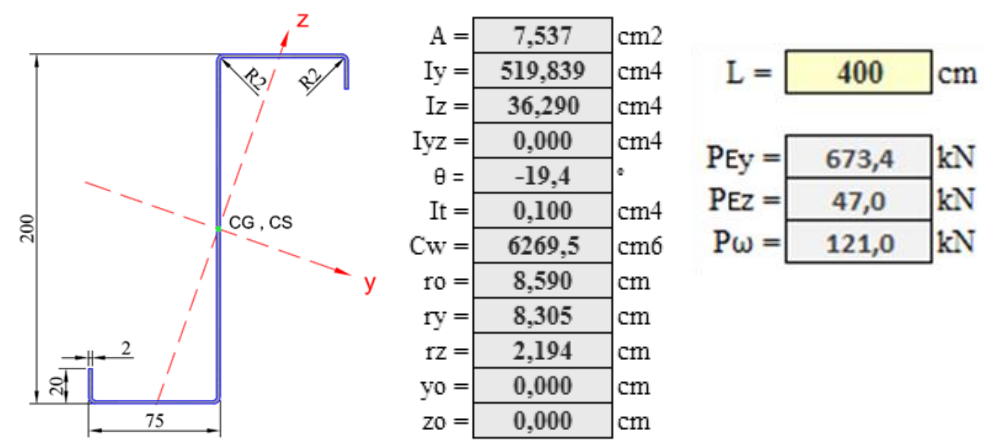

PEy $=673,4 \mathrm{kN}$

$\mathrm{PEz}=47,0 \mathrm{kN}$

$\mathrm{P} \omega=121,0 \mathrm{kN}$

Figura 4.8 - Características geométricas da seção transversal $Z$ enrijecido.

Na sequência, são apresentados os modos de instabilidade e os carregamentos críticos obtidos nas análises numéricas para os perfis Ue e Ze via CUFSM (os resultados com a opção "signature curve" são denominados CUFSM-SC e os resultados com a opção "general boundary condition” são denominadas CUFSM-GBC), GBTUL e ABAQUS.

\subsubsection{Perfil $U$ enrijecido}

\subsubsection{Análise com o método das faixas finitas via CUFSM}

A Figura 4.9 apresenta a curva obtida com o uso do CUSFM-SC, cuja abscissa representa o comprimento do perfil em milímetros (escala logarítmica) e a ordenada 
representa o fator de carregamento, $p^{18}$. Os seis pontos marcados representam o carregamento crítico para os comprimentos L, de $15 \mathrm{~cm}, 70 \mathrm{~cm}, 150 \mathrm{~cm}, 200 \mathrm{~cm}, 300 \mathrm{~cm}$ e $400 \mathrm{~cm}$. Os respectivos modos de instabilidade são apresentados na Figura 4.10.

Nota-se que os casos de comprimentos $15 \mathrm{~cm} \mathrm{e} 70 \mathrm{~cm}$, aparentemente correspondem a pontos de mínimo locais na curva da Figura 4.9, essa imagem da à falsa impressão que o perfil de $\mathrm{L}=150 \mathrm{~cm}$ tem força crítica maior do que, por exemplo, o perfil de $\mathrm{L}=15 \mathrm{~cm}$. Os carregamentos críticos obtidos com os três graus de refinamento da seção transversal estão apresentados na Tabela 4.1.

Tabela 4.1. Valores dos carregamentos críticos $(\mathrm{kN})$ obtidos com o CUFSM-SC para os graus de refinamento (Gr) tipo 1, 2 e 3 da seção transversal.

\begin{tabular}{ccccccc}
\hline & \multicolumn{5}{c}{$\mathrm{L}(\mathrm{cm})$} \\
\cline { 2 - 7 } Gr. & 15,0 & 70,0 & 150,0 & 200,0 & 300,0 & 400,0 \\
\hline 1 & 82,15 & 155,58 & 271,73 & 232,84 & 109,06 & 64,84 \\
2 & 82,08 & 155,34 & 271,25 & 231,54 & 108,48 & 64,51 \\
3 & 82,07 & 154,36 & 271,04 & 231,19 & 108,32 & 64,43 \\
\hline
\end{tabular}

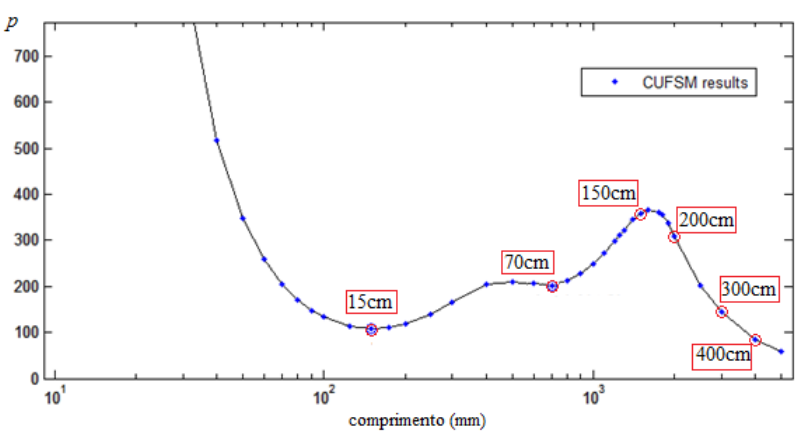

Figura 4.9 - Determinação da curva do fator de carregamento, $p$, em função do comprimento do perfil em mm, com o CUFSM-SC.

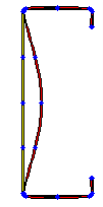

(a) $\mathrm{L}=15 \mathrm{~cm}$
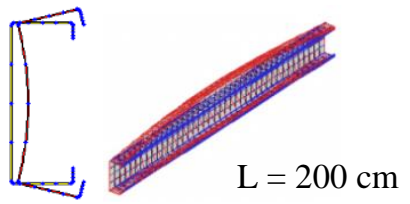

(d)

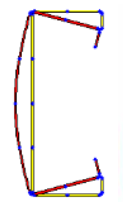

(b)

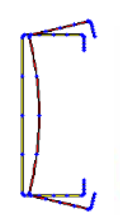

(c)

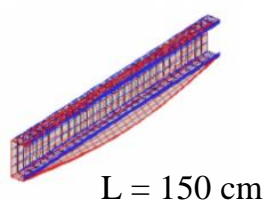

)

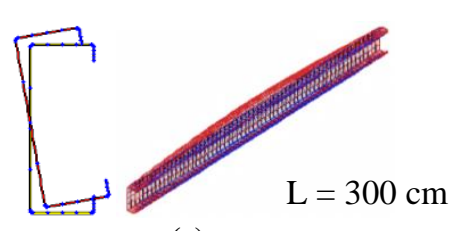

(e)

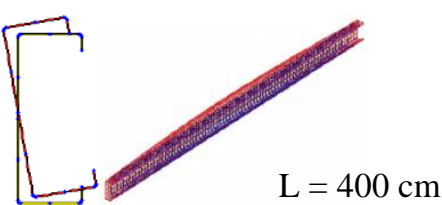

(f)

Figura 4.10 - Modos de instabilidade obtidos com o CUFSM-SC para a discretização tipo 1 da seção transversal para comprimento de (a) $15 \mathrm{~cm}$, (b) $70 \mathrm{~cm}$, (c) $150 \mathrm{~cm}$, (d) $200 \mathrm{~cm}$, (e) $300 \mathrm{~cm}$ e (f) 400

cm. 4.1).

${ }^{18}$ Relação entre o carregamento crítico, Pcr, e o carregamento unitário aplicado, P (ver Figura 
Convém destacar que para o comprimento de $15 \mathrm{~cm}$ o CUFSM-SC fornece como resultado um modo local de chapa (MLC), para os comprimentos $70 \mathrm{~cm}, 150 \mathrm{~cm}$ e 200 cm o modo de instabilidade é distorcional (MD) e finalmente para os comprimentos 300 $\mathrm{cm}$ e $400 \mathrm{~cm}$ o resultado é um modo global de flexotorção (MGFT). No caso específico do comprimento de $400 \mathrm{~cm}$, os resultados da Tabela 4.1 estão em excelente concordância com a solução analítica obtida com a teoria de Vlasov.

Utilizando a opção "general boundary condition", obtêm-se resultados diferentes para os comprimentos de 70 a $300 \mathrm{~cm}$ : o carregamento crítico passa a ser aproximadamente $\mathrm{P}_{\mathrm{cr}}=82 \mathrm{kN}$ para todos os comprimentos indicados na figura abaixo e todos correspondem a um modo local de chapa (MLC) com mais de uma semionda longitudinal, conforme ilustrado na Figura 4.11. Nessa opção de solução o CUFSM-GBC apenas ilustra os modos de instabilidade e apresenta os carregamentos críticos correspondentes, ou seja, não há a exibição da curva de fator de carregamento em função do comprimento do perfil como na opção CUFSM-SC.
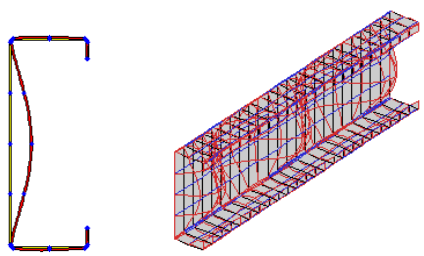

(a)

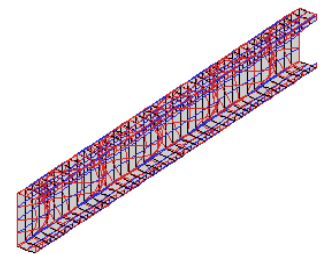

(b)

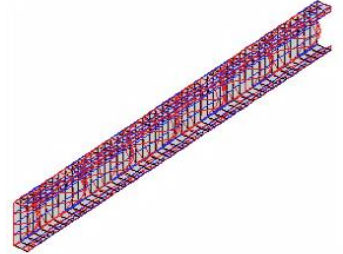

(c)

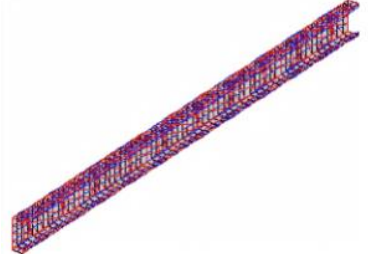

(d)

Figura 4.11 - Modo de instabilidade local de chapa obtido via CUFSM-GBC, para comprimentos de (a) $70 \mathrm{~cm}$, (b) $150 \mathrm{~cm}$, (c) $200 \mathrm{~cm}$ e (d) $300 \mathrm{~cm}$.

Observa-se que o programa CUFSM, utilizando o "signature curve", não toma conhecimento do MLC com mais de uma semionda. Para esses casos, o programa só captura pontos críticos em níveis de carregamento superiores ao mínimo, correspondentes a modos distorcionais ou globais de flexotorção.

\subsubsection{Análise com a teoria generalizada de viga via GBTUL}

A Figura 4.12 apresenta a curva obtida com o uso do programa computacional GBTUL, cujo eixo das abscissas representa o comprimento da barra em centímetros (escala logarítmica) e o eixo das ordenadas representa o carregamento crítico em kN. Os pontos destacados em vermelho indicam as barras de comprimentos iguais a $15 \mathrm{~cm}, 70$ $\mathrm{cm}, 200 \mathrm{~cm}, 300 \mathrm{~cm}$ e $400 \mathrm{~cm}$. Os modos de instabilidade referentes aos pontos destacados são apresentados na Figura 4.13, enquanto que os carregamentos críticos para os três graus de refinamento são apresentados na Tabela 4.2. 
Tabela 4.2. Valores dos carregamentos críticos $(\mathrm{kN})$ obtidos com o GBTUL para os graus de refinamento (Gr) tipo 1,2 e 3.

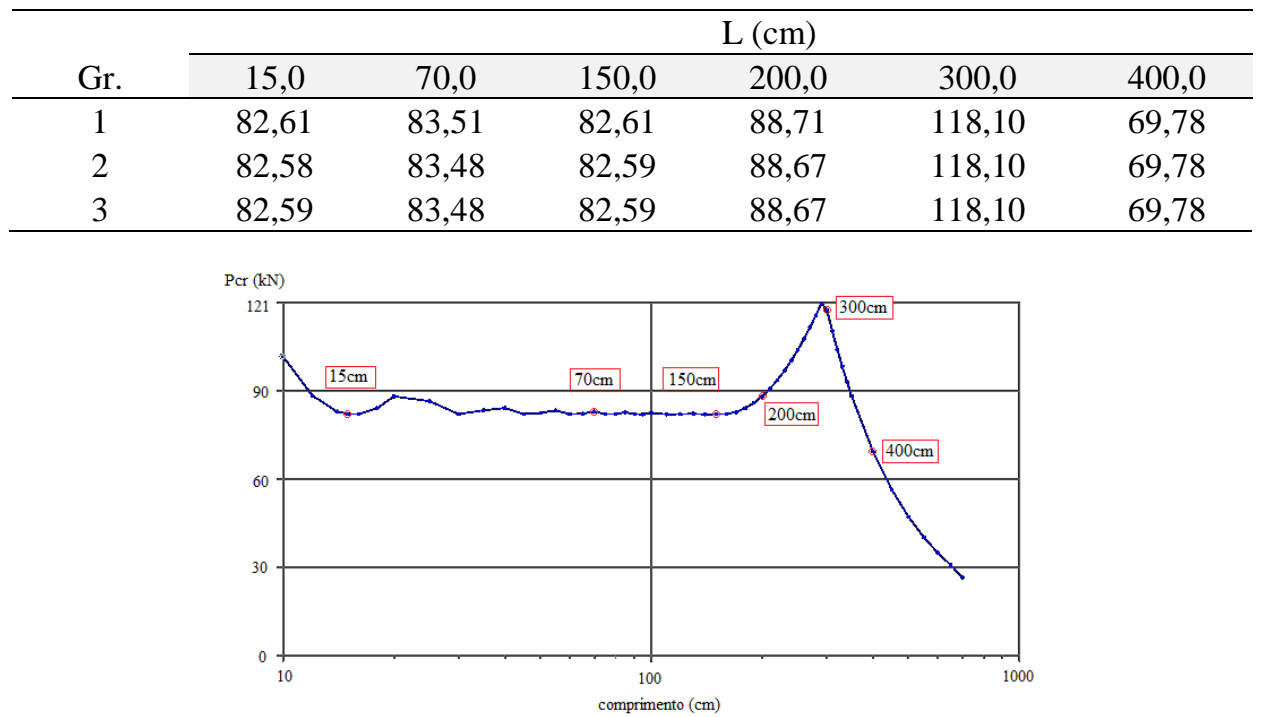

Figura 4.12 - Determinação da curva carregamento crítico, $\operatorname{Pcr}(\mathrm{kN})$ em função do comprimento (cm) com o GBTUL.

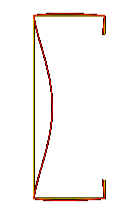

$\mathrm{L}=15 \mathrm{~cm}$

(a)

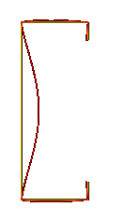

$\mathrm{L}=70 \mathrm{~cm}$

(b)

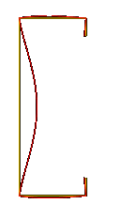

$=150 \mathrm{~cm}$

(c)

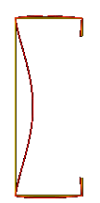

$\mathrm{L}=200 \mathrm{~cm}$

(d)

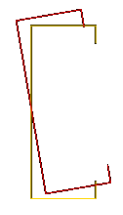

$\mathrm{L}=300 \mathrm{~cm}$

(e)

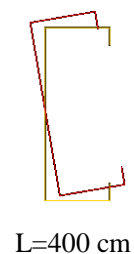

(f)

Figura 4.13 - Seção transversal no meio do vão obtida com o GBTUL para os modos de instabilidade de comprimento igual a: (a) $15 \mathrm{~cm}$, (b) $70 \mathrm{~cm}$, (c) $150 \mathrm{~cm}$, (d) $200 \mathrm{~cm}$, (d) $300 \mathrm{~cm}$ e (f) $400 \mathrm{~cm}$.

Os resultados para o comprimento de $15 \mathrm{~cm}$ estão em boa concordância com os do item anterior. Porém, para os comprimentos de $70 \mathrm{~cm}, 150 \mathrm{~cm}$ e $200 \mathrm{~cm}$ o GbTUL-SC fornece como modo de instabilidade o modo local de chapa (MLC), sendo esse com a ocorrência de mais de um harmônico longitudinal (i.e., o número de semiondas longitudinais pode ser maior do que 1), e com carregamento crítico da ordem de $83 \mathrm{kN}$ $(\mathrm{L}=70 \mathrm{~cm}$ e $\mathrm{L}=150 \mathrm{~cm})$ ou $88 \mathrm{kN}(\mathrm{L}=200 \mathrm{~cm})$. Essa resposta é diferente daquela obtida com o uso do método das faixas finitas com a opção "signature curve", onde se obtém um modo distorcional (MD) com quase o dobro $(\mathrm{L}=70 \mathrm{~cm}$ e $\mathrm{L}=150 \mathrm{~cm}$ ) ou o triplo $(\mathrm{L}=200 \mathrm{~cm})$ do carregamento crítico, conforme apresentado na Tabela 4.1, mas próxima daquela obtida com o uso do CUFSM com a opção "general boundary condition" (à exceção do perfil com $300 \mathrm{~cm}$ de comprimento).

Por outro lado, para os comprimentos de $300 \mathrm{~cm}$ e $400 \mathrm{~cm}$, o GBTUL fornece carregamentos e modos críticos que concordam com os resultados do CUFSM-SC, sendo os modos de instabilidade por flexotorção global (MGFT) em ambos os casos. Para o 
perfil com $400 \mathrm{~cm}$, a resposta também está em boa concordância com a solução analítica de Vlasov.

Cabe observar que, analisando a Figura 4.12, temos a falsa impressão de que, para uma faixa de comprimentos entre $200 \mathrm{~cm}$ e $300 \mathrm{~cm}$ há um acréscimo do carregamento crítico. Isso ocorre em virtude de o número máximo de semiondas permitido no programa GBTUL ser igual, por default, a 10 harmônicos longitudinais.

Quando se altera o valor de "m" para, por exemplo, 20 harmônicos longitudinais, obtêm-se a curva ilustrada na Figura 4.14 e os valores das cargas críticas para $200 \mathrm{~cm}$ e $300 \mathrm{~cm}$ são alterados conforme a Tabela 4.3. Observa-se que para o comprimento de $300 \mathrm{~cm}$ o modo deixa de ser global de flexotorção (MGFT) e passa a ser um modo local de chapa (MLC) - da mesma forma como predito pelo CUFSM-GBC.

Tabela 4.3 Valores dos carregamentos críticos $(\mathrm{kN})$ para os graus de refinamento (Gr) tipo 1, 2 e 3 .

\begin{tabular}{ccc}
\hline & \multicolumn{2}{c}{$\mathrm{L}(\mathrm{cm})$} \\
\cline { 2 - 3 } Gr. & 200,0 & 300,0 \\
\hline 1 & 82,52 & 82,55 \\
2 & 82,49 & 82,52 \\
3 & 82,49 & 82,52 \\
\hline
\end{tabular}

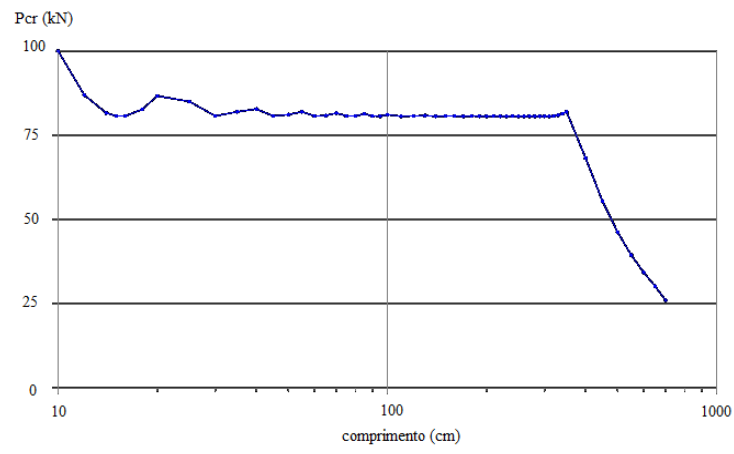

Figura 4.14 - Determinação da curva comprimento (cm) vs. carga crítica, Pcr (kN).

Esse resultado indica que, para uma determinada faixa de comprimentos, o carregamento crítico independe do comprimento do perfil, pois passa a ser comandado por modos locais, para os quais a largura das paredes da seção é mais relevante do que o comprimento do perfil. Assim a diferença entre cada uma das barras está somente na quantidade de harmônicos ${ }^{19}$ dos respectivos modos críticos. Nota-se que, nessa faixa de comprimentos, os modos de instabilidade mínimos correspondem sempre a modos locais de chapa, MLC.

\footnotetext{
${ }^{19}$ Semiondas longitudinais “ $m$ ”.
} 


\subsubsection{Análise com o método dos elementos finitos via ABAQUS}

Definido o S4R como o elemento a ser utilizado, conforme pronunciado anteriormente, discretizou-se o perfil seguindo os graus de discretização tipo 1, 2 e 3 já apresentados na Figura 4.2.

A Figura 4.15 e Figura 4.16 apresentam o primeiro modo de instabilidade obtido através do ABAQUS para cada um dos comprimentos analisados nos itens anteriores, considerando que as faixas de cores se referem ao valor do deslocamento normalizado: máximo na cor vermelha e nulo na cor azul escura. Os carregamentos críticos para os três graus de refinamento estão apresentados na Tabela 4.4.

Tabela 4.4. Valores dos carregamentos críticos $(\mathrm{kN})$ obtidos com o MEF-cascas para os graus de refinamento $(\mathrm{Gr})$ tipo 1,2 e 3.

\begin{tabular}{ccccccc}
\hline & \multicolumn{7}{c}{$\mathrm{L}(\mathrm{cm})$} \\
\cline { 2 - 6 } Gr. & 15,0 & 70,0 & 150,0 & 200,0 & 300,0 & 400,0 \\
\hline 1 & 87,70 & 90,76 & 85,82 & 85,89 & 85,97 & 60,12 \\
2 & 82,57 & 83,98 & 83,31 & 83,37 & 83,44 & 62,86 \\
3 & 80,26 & 82,28 & 80,87 & 80,93 & 80,98 & 63,95 \\
\hline
\end{tabular}

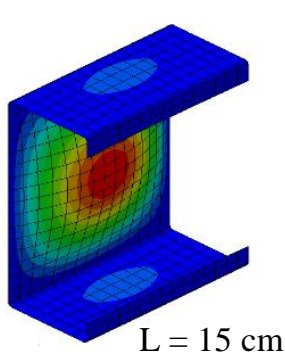

(a)

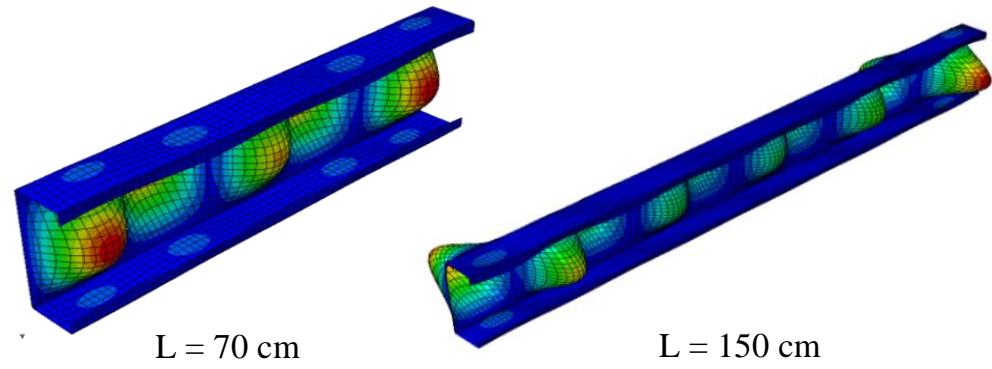

(c)

Figura 4.15 - Modos de instabilidade obtidos com o ABAQUS para a discretização tipo 3 da seção transversal para comprimento de (a) $15 \mathrm{~cm}$, (b) $70 \mathrm{~cm}$ e (c) $150 \mathrm{~cm}$

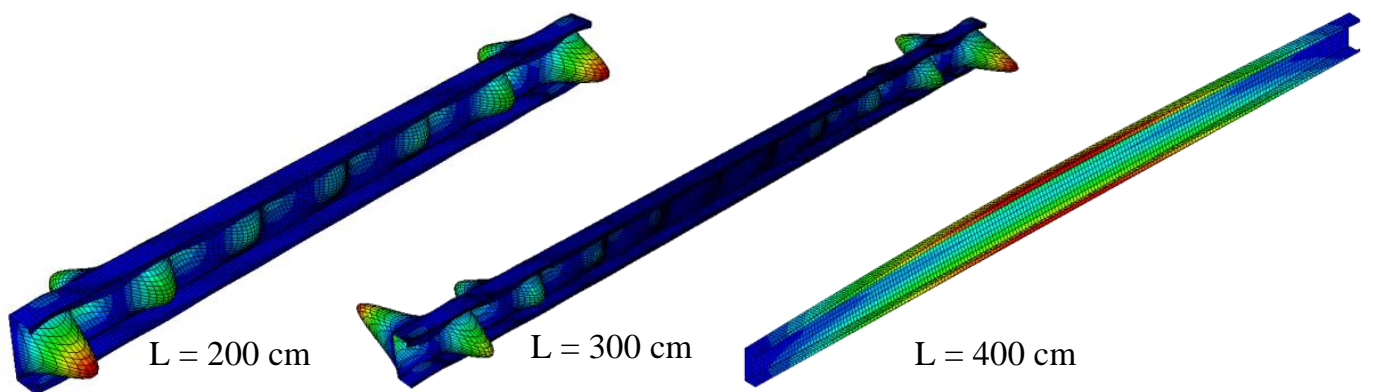

(a) (b) (c)

Figura 4.16 - Modos de instabilidade obtidos com o ABAQUS para a discretização tipo 3 da seção transversal para comprimento de (a) $200 \mathrm{~cm}$, (b) $300 \mathrm{~cm}$ e (c) $400 \mathrm{~cm}$.

É importante observar que os casos para comprimentos de $15 \mathrm{~cm}, 70 \mathrm{~cm}, 150 \mathrm{~cm}$, $200 \mathrm{~cm}$ e $300 \mathrm{~cm}$ resultaram em modos locais de chapa (MLC), o primeiro com uma 
onda longitudinal, o segundo com cinco semiondas longitudinais, o terceiro com dez semiondas longitudinais, o quarto com treze semiondas longitudinais e por fim, o quinto com vinte semiondas longitudinais. Esses resultados estão em ótima concordância com aqueles obtidos com o GBTUL (MEF-GBT), caso nesse último o número de semiondas permitido for suficientemente grande ( $\mathrm{m}=20$ ou maior), mas diferem bastante daqueles do CUFSM-SC (signature curve).

Para os casos de comprimento de $70 \mathrm{~cm}, 150 \mathrm{~cm}$ e $200 \mathrm{~cm}$, a Figura 4.17a, Figura 4.17b e Figura 4.18a apresentam o primeiro dos modos distorcionais (MD), dentre todos os modos obtidos para esses perfis. Para esses comprimentos, respectivamente, tem-se: (a) o MD é o vigésimo modo, com $\mathrm{Pcr}=156,1 \mathrm{kN}$, (b) o MD é o trigésimo primeiro modo, com Pcr=269,9 kN e (c) o MD é o décimo sétimo modo, com Pcr = 234,1 kN. Convém destacar que esses são os modos que a análise via CUFSM com a opção "signature curve" captura como sendo o primeiro modo de instabilidade para as barras de $70 \mathrm{~cm}, 150 \mathrm{~cm}$ e $200 \mathrm{~cm}$ de comprimento, respectivamente.

Ainda para a barra de $200 \mathrm{~cm}$, nota-se que o modo de instabilidade da Figura 4.18b ilustra o primeiro modo de instabilidade apresentado pelo GBTUL (MEF-GBT) quando o número de semiondas máximo é fixado em 10, conforme o default do programa.

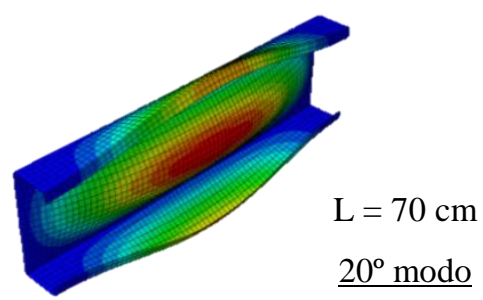

$\mathrm{Pcr}=156 \mathrm{kN}$

(a)

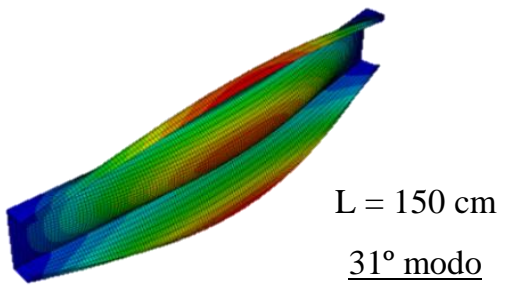

$\mathrm{Pcr}=270 \mathrm{kN}$

(b)

Figura 4.17 - Primeiro dos modos de instabilidade distorcional, MD: (a) vigésimo modo de instabilidade para $L=70 \mathrm{~cm}$ e (b) trigésimo primeiro modo de instabilidade para $\mathrm{L}=150 \mathrm{~cm}$.

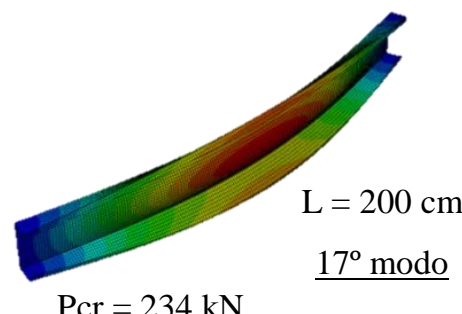

(a)

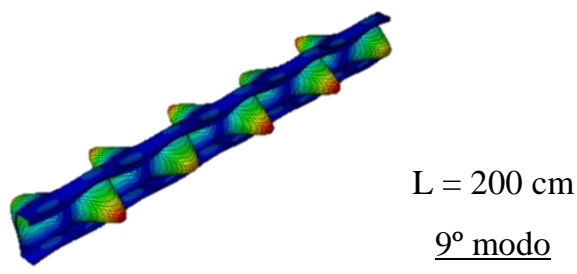

Pcr $=88 \mathrm{kN}$

(b)

Figura 4.18 - Carregamentos críticos e modos de instabilidade para $\mathrm{L}=\mathbf{2 0 0} \mathrm{cm}$, considerando até: (a) uma semionda longitudinal e (b) dez semiondas longitudinais

Para o caso da barra de $300 \mathrm{~cm}$ de comprimento, a Figura 4.19 apresenta o primeiro dos modos globais, dentre todos os modos obtidos para esses perfis. Para esse 
comprimento tem-se o MGFT como o vigésimo segundo modo, com Pcr=107,0 kN. Esse é o modo que a análise via CUFSM com a opção "signature curve" captura como sendo o primeiro modo de instabilidade, ou seja, um carregamento crítico superior ao que de fato o ABAQUS obteve na Tabela 4.4.

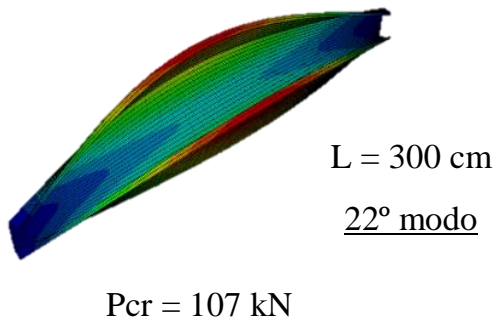

Figura 4.19 - Modo global de flexotorção, MGFT para $L=300 \mathrm{~cm}$ : vigésimo segundo modo de instabilidade.

Já para o caso da barra de $400 \mathrm{~cm}$ de comprimento, os resultados estão em ótima concordância com a solução analítica de Vlasov, da mesma forma que se observou com os demais programas. Cabe aqui, contudo, um breve comentário. Os carregamentos críticos obtidos com o CUFSM-SC estão em conformidade com o obtido pelo ABAQUS para a malha tipo 3. Em ambos os programas, o valor do carregamento crítico é aproximadamente $\operatorname{Pcr}=64 \mathrm{kN}$, bem próximo do valor teórico de Pcr=65,2 kN apresentado na Eq. (4.1). Já o GBTUL forneceu um carregamento crítico levemente superior ao teórico, de Pcr=69,8kN. Isso pode ser explicado pela simplificação da seção transversal, pois o GBTUL não considera os cantos arredondados do perfil, o que altera ligeiramente as características da seção transversal e consequentemente os valores dos carregamentos críticos.

Em todos os casos estudados, nota-se que o nível de discretização da seção transversal tem influência (embora não determinante) no valor dos carregamentos críticos. Esses diferem entre si de (i) $6 \%$ a $10 \%$ entre os tipos 1 e 3, (ii) $3 \%$ a $8 \%$ entre os tipos 1 e 2 , e (iii) $2 \%$ a $3 \%$ entre os tipos 2 e 3 .

\subsubsection{Perfil $Z$ enrijecido}

\subsubsection{Análise com o método das faixas finitas via CUFSM}

A Figura 4.20 apresenta a curva obtida com o uso do CuSFM-SC, cuja abscissa representa o comprimento do perfil em milímetros (escala logarítmica) e a ordenada representa o fator de carregamento, $p$. Os seis pontos marcados representam o carregamento crítico para os comprimentos L, de $15 \mathrm{~cm}, 70 \mathrm{~cm}, 150 \mathrm{~cm}, 200 \mathrm{~cm}, 300 \mathrm{~cm}$ e 
$400 \mathrm{~cm}$. Os respectivos modos de instabilidade são apresentados na Figura 4.21 e os carregamentos críticos obtidos com os três graus de refinamento da seção transversal são apresentados na Tabela 4.5.

Tabela 4.5. Valores dos carregamentos críticos $(\mathrm{kN})$ obtidos com o CUFSM-SC para os graus de refinamento $(\mathrm{Gr})$ tipo 1, 2 e 3 da seção transversal.

\begin{tabular}{ccccccc}
\hline & \multicolumn{6}{c}{$\mathrm{L}(\mathrm{cm})$} \\
\cline { 2 - 7 } Gr. & 15,0 & 70,0 & 150,0 & 200,0 & 300,0 & 400,0 \\
\hline 1 & 82,06 & 152,80 & 249,53 & 177,37 & 82,96 & 47,04 \\
2 & 81,98 & 152,50 & 248,50 & 176,29 & 82,44 & 46,74 \\
3 & 81,95 & 151,54 & 248,24 & 176,07 & 82,33 & 46,68 \\
\hline
\end{tabular}

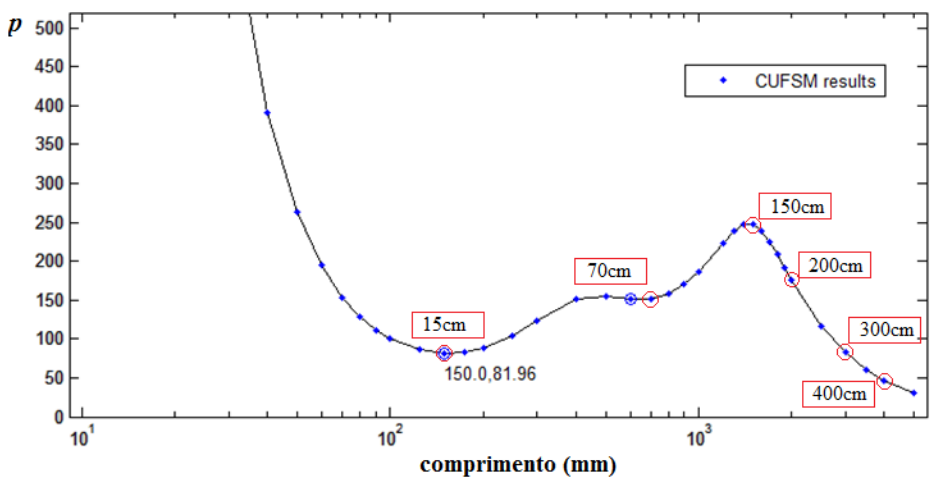

Figura 4.20 - Determinação da curva do fator de carregamento, $p$, em função do comprimento do perfil em mm, com o CUFSM-SC.

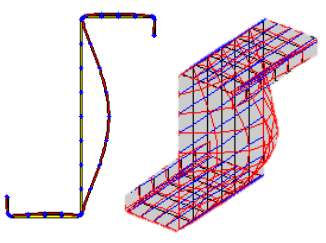

$\mathrm{L}=15 \mathrm{~cm}$

(a)

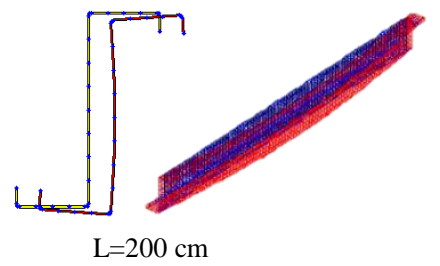

(d)

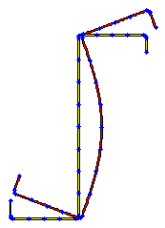

$\mathrm{L}=70 \mathrm{~cm}$

(b)

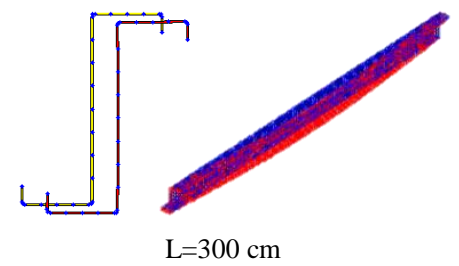

(e)

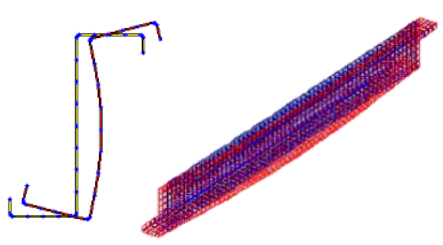

$\mathrm{L}=150 \mathrm{~cm}$

(c)

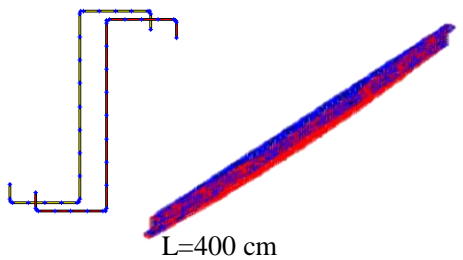

(f)

Figura 4.21 - Modos de instabilidade obtidos com o CUFSM-SC para a discretização tipo 3 da seção transversal para comprimento de (a) $15 \mathrm{~cm}$, (b) $70 \mathrm{~cm}$, (c) $150 \mathrm{~cm}$, , (d) $200 \mathrm{~cm}$, (e) $300 \mathrm{~cm}$ e (f) $400 \mathrm{~cm}$.

Utilizando a solução do tipo "general boundary condition", contudo, obtêm-se resultados diferentes para os comprimentos de 70 a $300 \mathrm{~cm}$, da mesma forma que ocorreu com o perfil Ue anterior: o carregamento crítico passa a ser aproximadamente $\mathrm{P}_{\mathrm{cr}}=82 \mathrm{kN}$ para todos os comprimentos indicados na figura abaixo e todos correspondem 
a um modo local de chapa (MLC) com mais de uma semionda longitudinal, conforme ilustrado na Figura 4.11. Nota-se que diferentemente do CUFSM-SC, o CUFSM-GBC não apresenta os resultados em forma de curvas.
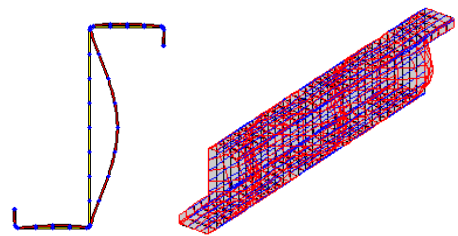

(a)

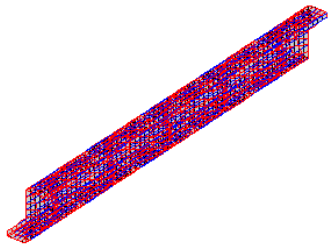

(b)

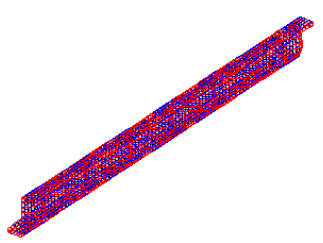

(c)

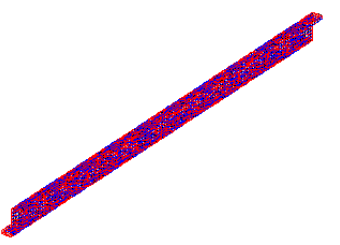

(d)

Figura 4.22 - Modo de instabilidade local de chapa obtido via CUSFM-GBC, para comprimentos de (a) $70 \mathrm{~cm}$, (b) $150 \mathrm{~cm}$, (c) $200 \mathrm{~cm}$ e (d) $300 \mathrm{~cm}$.

A mesma limitação identificada para os perfis Ue também pode ser observada para os perfis Ze: o CUFSM utilizando o signature curve não identifica os carregamentos críticos cujo modo crítico corresponde a um MLC com mais de uma semionda longitudinal.

Tanto para o CUFSM-SC quanto para o CUFSM-GBC, a barra de $400 \mathrm{~cm}$ de comprimento, apresenta resultados em boa concordância com a solução analítica de Vlasov.

\subsubsection{Análise com a teoria generalizada de viga via GBTUL}

A Figura 4.23 apresenta a curva obtida com o uso do programa computacional GBTUL, cujo eixo das abscissas representa o comprimento da barra em centímetros (escala logarítmica) e o eixo das ordenadas representa o carregamento crítico em $\mathrm{kN}$. Alterou-se o valor de "m" para 20 harmônicos longitudinais, de forma a garantir pontos de mínimos.

Os pontos destacados em vermelho representam as barras de comprimentos iguais a $15 \mathrm{~cm}, 70 \mathrm{~cm}, 200 \mathrm{~cm}, 300 \mathrm{~cm}$ e $400 \mathrm{~cm}$. Os modos de instabilidade referentes aos pontos destacados são apresentados na Figura 4.24, enquanto que os carregamentos críticos para os três graus de refinamento são apresentados na Tabela 4.6.

Tabela 4.6. Valores dos carregamentos críticos $(\mathrm{kN})$ obtidos com o GBTUL para os graus de refinamento $(\mathrm{Gr})$ tipo 1,2 e 3.

\begin{tabular}{ccccccc}
\hline & \multicolumn{6}{c}{$\mathrm{L}(\mathrm{cm})$} \\
\cline { 2 - 7 } Gr. & 15,0 & 70,0 & 150,0 & 200,0 & 300,0 & 400,0 \\
\hline 1 & 82,63 & 83,39 & 82,63 & 82,59 & 82,63 & 48,54 \\
2 & 82,54 & 83,23 & 82,54 & 82,49 & 82,54 & 48,54 \\
3 & 82,53 & 83,30 & 82,53 & 82,49 & 82,53 & 48,54 \\
\hline
\end{tabular}




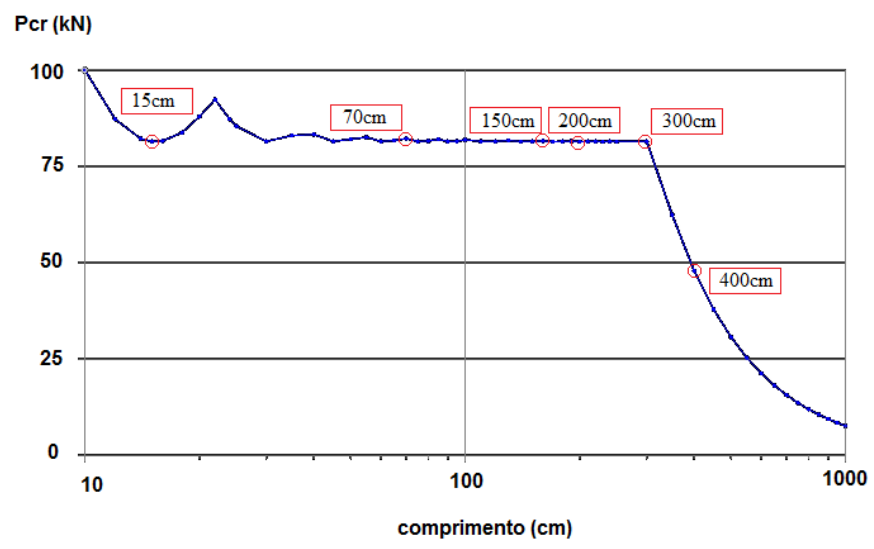

Figura 4.23 - Determinação da curva carregamento crítico, Pcr (kN) em função do comprimento (cm) com o GBTUL.

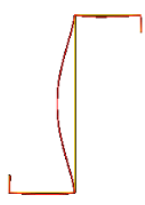

$\mathrm{L}=15 \mathrm{~cm}$

(a)

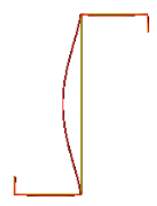

$\mathrm{L}=70 \mathrm{~cm}$

(b)

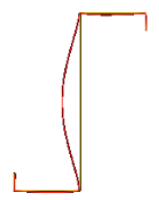

$\mathrm{L}=150 \mathrm{~cm}$

(c)

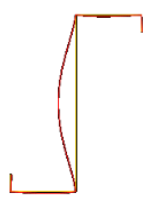

$\mathrm{L}=200 \mathrm{~cm}$

(d)

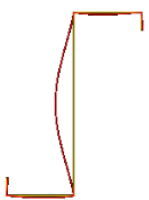

$\mathrm{L}=300 \mathrm{~cm}$

(e)

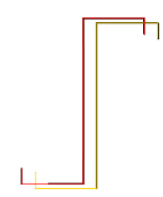

$\mathrm{L}=400 \mathrm{~cm}$

(f)

Figura 4.24 - Seção transversal no meio do vão obtida com o GBTUL para os modos de instabilidade de comprimento igual a: (a) $15 \mathrm{~cm}$, (b) $70 \mathrm{~cm}$, (c) $150 \mathrm{~cm}$, (d) $200 \mathrm{~cm}$, (d) $300 \mathrm{~cm}$ e (f) $400 \mathrm{~cm}$.

Os resultados para o comprimento de $15 \mathrm{~cm}$ estão em boa concordância com os do Cufsm. Porém, para os comprimentos de $70 \mathrm{~cm}, 150 \mathrm{~cm}, 200 \mathrm{~cm}$ e $300 \mathrm{~cm}$ o GBTUL fornece o modo local de chapa (MLC) como primeiro modo, sendo esse com a ocorrência de mais de um harmônico longitudinal (i.e., o número de semiondas longitudinais pode ser maior do que 1 e menor do que 20, conforme estipulado anteriormente), e com carregamento crítico da ordem de $83 \mathrm{kN}$.

Novamente, esse resultado é bastante diferente daquele obtido com o uso do CUFSM via signature curve, onde se obtém um modo distorcional (MD), por exemplo, com o triplo do valor do carregamento crítico obtido para o comprimento de $150 \mathrm{~cm}$.

Outra vez, nota-se que em uma determinada faixa de comprimentos, o carregamento crítico independe do comprimento do perfil. Ou seja, o carregamento crítico mínimo corresponderá, nessa faixa, sempre a modos de instabilidade de chapa, MLC, com carregamento crítico da ordem de $83 \mathrm{kN}$ para todos os comprimentos nesse intervalo. Além disso, esses resultados independem do perfil selecionado, isso ocorre porque a perda de estabilidade acontece na alma dos perfis e essa possui a mesma 
geometria, tanto para o Ue quanto para o Ze a largura da alma é 200mm e espessura da alma é $2 \mathrm{~mm}$.

Vale observar ainda que, para a barra de $400 \mathrm{~cm}$ de comprimento, os resultados estão em boa concordância com a solução analítica de Vlasov.

\subsubsection{Análise com o método dos elementos finitos via ABAQUS}

A Figura 4.25 e Figura 4.26 apresentam o primeiro modo de instabilidade obtido através do ABAQUS para os mesmos comprimentos analisados nos itens anteriores, considerando que as faixas de cores se referem ao valor do deslocamento normalizado: máximo na cor vermelha e nulo na cor azul escura. Os carregamentos críticos para os três graus de refinamento são apresentados na Tabela 4.7 .

Tabela 4.7. Valores dos carregamentos críticos $(\mathrm{kN})$ obtidos com o MEF-cascas para os graus de refinamento (Gr) tipo 1,2 e 3.

\begin{tabular}{ccccccc}
\hline & \multicolumn{6}{c}{$\mathrm{L}(\mathrm{cm})$} \\
\cline { 2 - 7 } Gr. & 15,0 & 70,0 & 150,0 & 200,0 & 300,0 & 400,0 \\
\hline 1 & 85,88 & 92,70 & 92,94 & 93,11 & 82,21 & 42,25 \\
2 & 16,50 & 82,24 & 82,16 & 82,21 & 80,39 & 45,56 \\
3 & 75,30 & 80,85 & 80,82 & 80,88 & 80,93 & 46,17 \\
\hline
\end{tabular}

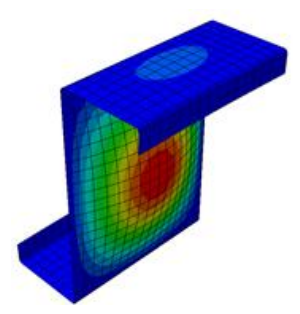

$\mathrm{L}=15 \mathrm{~cm}$

(a)

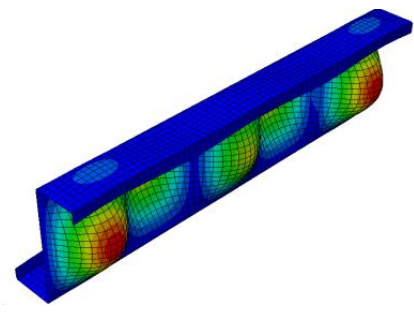

$\mathrm{L}=70 \mathrm{~cm}$

(b)

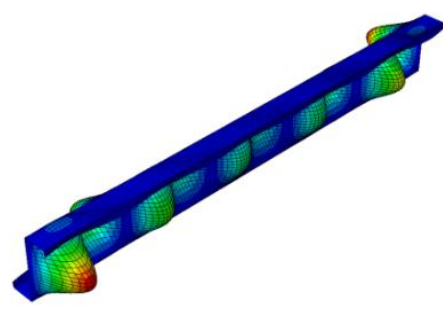

$\mathrm{L}=150 \mathrm{~cm}$

(c)

Figura 4.25 - Modos de instabilidade obtidos com o ABAQUS para a discretização tipo 3 da seção transversal para comprimento de (a) $15 \mathrm{~cm}$, (b) $70 \mathrm{~cm}$ e (c) $150 \mathrm{~cm}$

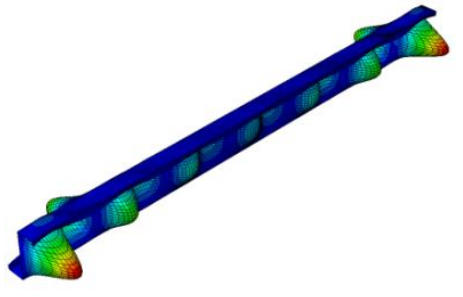

$\mathrm{L}=200 \mathrm{~cm}$

(a)

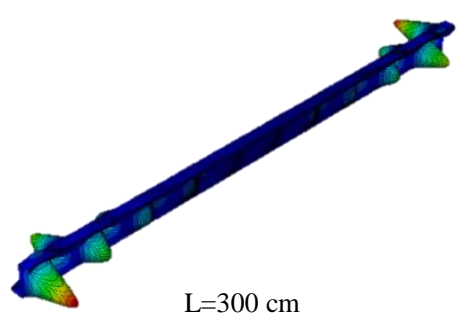

(b)

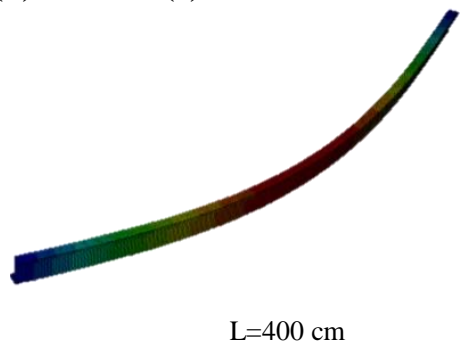

(c)

Figura 4.26 - Modos de instabilidade obtidos com o ABAQUS para a discretização tipo 3 da seção transversal para comprimento de (a) $200 \mathrm{~cm}$, (b) $300 \mathrm{~cm}$ e (c) $400 \mathrm{~cm}$. 
É importante observar que os casos para comprimentos de $15 \mathrm{~cm}, 70 \mathrm{~cm}, 150 \mathrm{~cm}$, $200 \mathrm{~cm}$ e $300 \mathrm{~cm}$ tratam de modos locais de chapa (MLC), o primeiro com uma onda longitudinal, o segundo com cinco semiondas longitudinais, o terceiro com dez semiondas longitudinais, o quarto com treze semiondas longitudinais e por fim, o quinto com vinte semiondas longitudinais. Para esses casos os resultados obtidos com o GBTUL (MEF-GBT) estão em ótima concordância com os resultados obtidos com o ABAQUS (MEF-cascas) se o número de semiondas permitido no GBTUL for suficientemente grande ( $\mathrm{m}=20$ ou maior), enquanto que os resultados do CUFSM-SC (signature curve) apresentam grande discrepância, pois conforme citado anteriormente o programa CUFSM tem fixo em sua formulação o número de semiondas longitudinais igual a 1 quando a solução é obtida pelo signature curve.

Para a barra de $400 \mathrm{~cm}$ de comprimento, todos os programas apresentaram o MGFT como o modo mínimo. Os carregamentos críticos obtidos com o CUFSM-SC $(\operatorname{Pcr}=46,7 \mathrm{kN})$ e com o ABAQus para a malha tipo $3(\operatorname{Pcr}=46,2 \mathrm{kN})$, estão em concordância com o valor teórico de Pcr=47,0kN obtido na Eq.(4.2). Devido as aproximações da geometria, o resultado obtido com o GBTUL (Pcr=48,5 kN) é levemente diferente do teórico, similar ao ocorrido com o perfil U enrijecido.

Em todos os casos estudados, nota-se que o nível de discretização no plano da seção transversal tem influência (embora não determinante) no valor dos carregamentos críticos. Esses diferem entre si de (i) $2 \%$ a $15 \%$ entre os tipos 1 e 3, (ii) $2 \%$ a $13 \%$ entre os tipos 1 e 2 , e (iii) $1 \%$ a $2 \%$ entre os tipos 2 e 3 .

\subsubsection{Resumo dos resultados}

Os resultados obtidos com o ABAQUS, e apresentados anteriormente, são comparados com os resultados obtidos com o CUFSM-SC, CUFSM-GBC e GBTUL graficamente na

Figura 4.27 para os perfis Ue e na Figura 4.28 para os Ze. As curvas abaixo representam os carregamentos críticos mínimos (i.e. o menor dos autovalores) obtidos para cada método em análise, em função do comprimento da barra, para o caso do tipo 3 de grau de refinamento da seção transversal. 


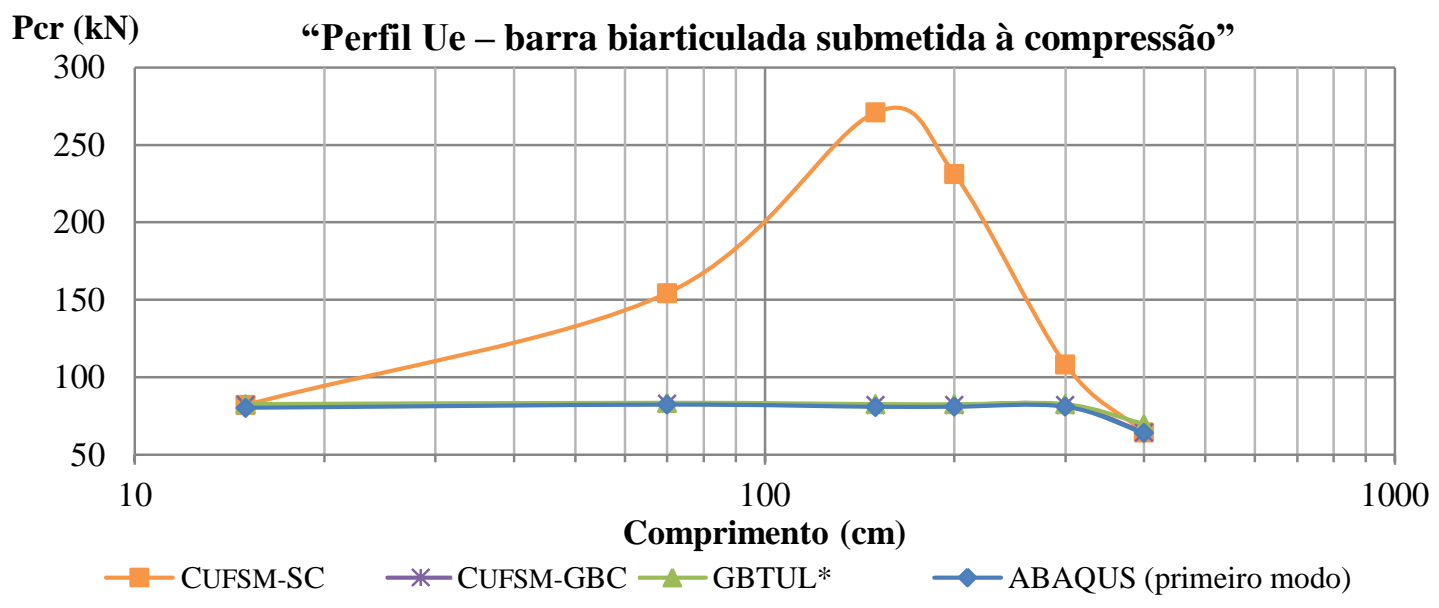

Figura 4.27 - Curvas dos carregamentos críticos em função dos comprimentos da barra para a seção transversal Ue, para as análises via (i) CUFSM-SC, (ii) CUFSM-GBC, (iii) GBTUL, considerando m $\geq 20$ e (iv) ABAQUS, considerando apenas o primeiro modo.

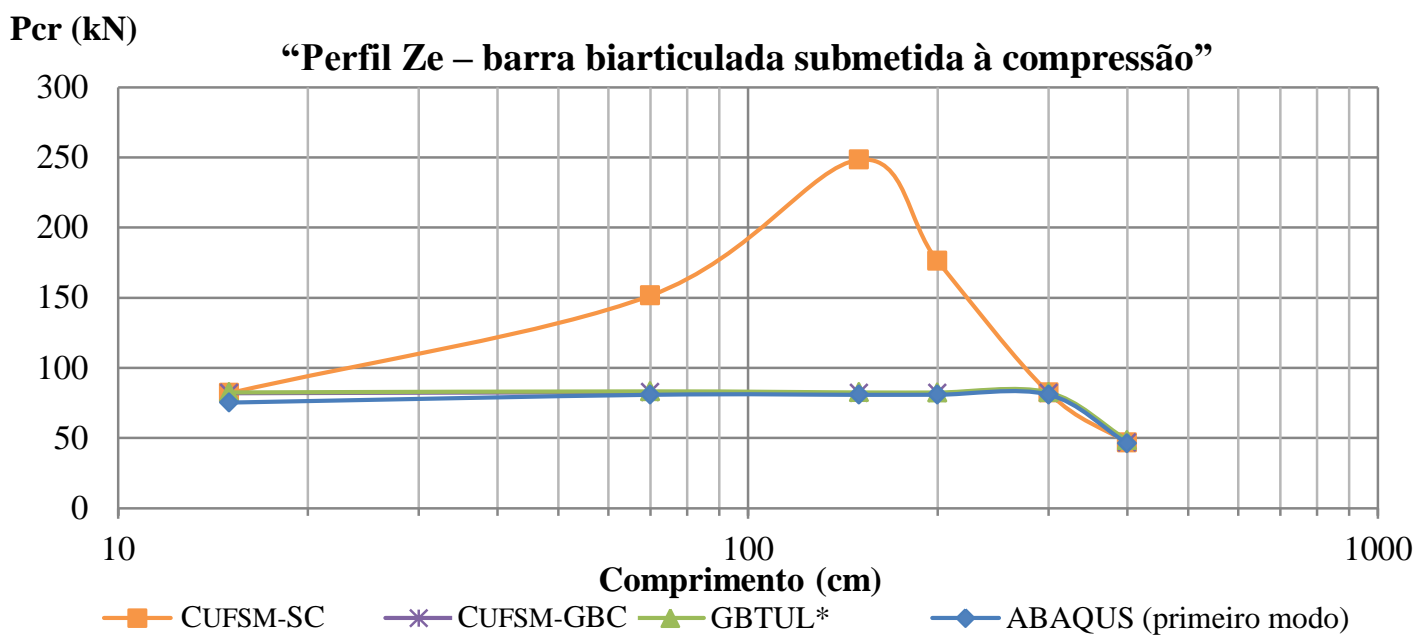

Figura 4.28 - Curvas dos carregamentos críticos em função dos comprimentos da barra para a seção transversal Ze , para as análises via (i) CUFSM-SC, (ii) CUFSM-GBC, (iii) GBTUL, considerando $m \geq 20$ e (iv) ABAQUS, considerando apenas o primeiros modo.

\subsection{Barra biarticulada submetida à flexão pura}

Conforme apresentado na Figura 4.1b, Figura 4.2 e Figura 4.3, nesse exemplo os perfis estão biarticulados e submetidos a flexão pura devido a um momento $\mathrm{M}$ de valor igual a 1 kN.cm, conforme indicado na Figura 4.29 e Figura 4.30. Os resultados obtidos nessa análise são para seções com o grau de refinamento tipo 3 em ambos os casos. 
No CUFSM e no GBUTL, o carregamento pode ser aplicado diretamente como um momento unitário $\mathrm{M}$ (ou $\mathrm{M}_{1}$ ), em torno do eixo principal de maior inércia. O CUFSM ainda possibilita aplicar o carregamento em forma de tensão uniforme, $\sigma$, ao longo de todo o perfil. Essa tensão é obtida para qualquer ponto da seção transversal distante de y (ou $\mathrm{d}_{1}$ ), dos eixos principais e considerando os momentos de inércia I (ou $\mathrm{I}_{1}$ ) em relação ao eixo principal de maior inércia.

No ABAQUS, aplicou-se um carregamento linear q, na linha média $l$ das seções transversais das extremidades, correspondente às forças normais induzidas pelo momento unitário. Foram aplicadas as mesmas condições de contorno de deslocamento do item anterior.

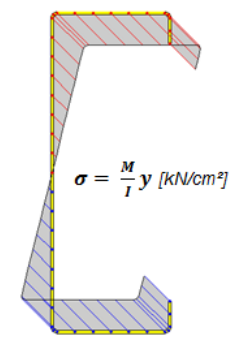

(a)

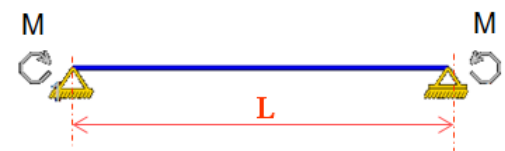

(b)

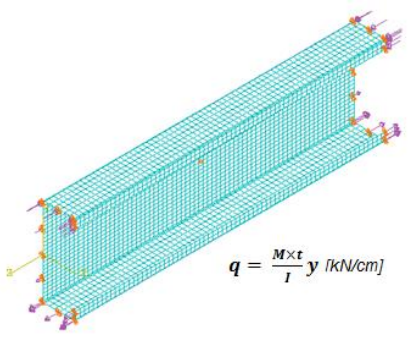

(c)

Figura 4.29 - Modelo estrutural do perfil Ue para (a) CufSM, (b) GbTUL e (c) AbaQus.

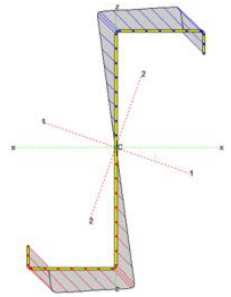

$\sigma= \pm \frac{M_{1}}{I_{1}} d_{1}\left[\mathrm{kN} / \mathrm{cm}^{2}\right]$

(a)

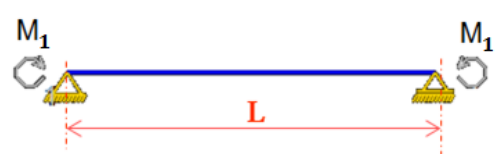

(b)

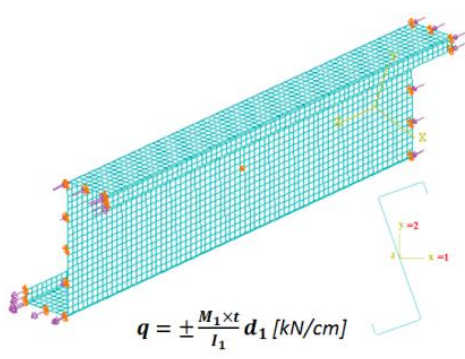

(c)

Figura 4.30 - Modelo estrutural do perfil Ze para (a) CuFSM, (b) GBTUL e (c) ABAQuS.

$\mathrm{Na}$ sequência são apresentados os modos de instabilidade e os carregamentos críticos obtidos nas análises numéricas para os perfis Ue e Ze via CUFSM (os resultados com a opção "signature curve" são denominados CUFSM-SC e os resultados com a opção "general boundary conditions" são denominadas CUFSM-GBC), GBTUL e ABAQUS. 


\subsubsection{Perfil U enrijecido}

\subsubsection{Análise com o método das faixas finitas via CUFSM}

A Figura 4.31 apresenta a curva obtida com o uso do CuSFM-SC, cuja abscissa representa o comprimento do perfil em milímetros (escala logarítmica) e a ordenada representa $\mathrm{o}$ fator de carregamento, $p$. Os seis pontos marcados representam o carregamento crítico para os comprimentos L, de $15 \mathrm{~cm}, 70 \mathrm{~cm}, 150 \mathrm{~cm}, 200 \mathrm{~cm}, 300 \mathrm{~cm}$ e $400 \mathrm{~cm}$. Os valores dos carregamentos críticos e os respectivos modos de instabilidade são apresentados na Figura 4.32.

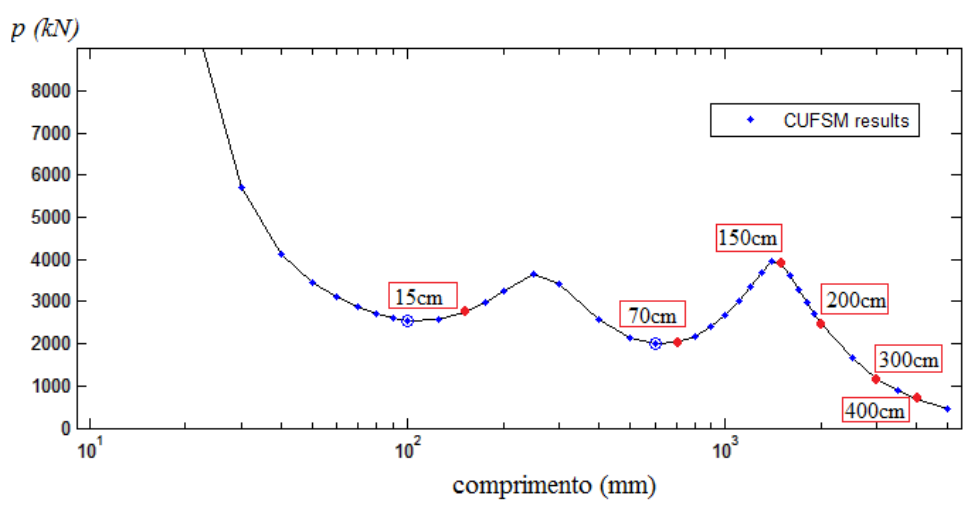

Figura 4.31 - Determinação da curva do fator de carregamento, $p$, em função do comprimento do perfil em mm, com o CUFSM-SC.

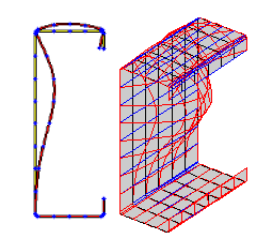

Mcr $=2736 \mathrm{kN} . \mathrm{cm}$ $\mathrm{L}=15 \mathrm{~cm}$

(a)

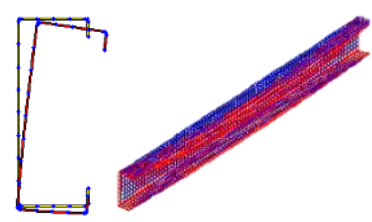

Mcr $=2493 \mathrm{kN} . \mathrm{cm}$ $\mathrm{L}=200 \mathrm{~cm}$

(d)

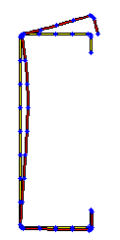

$\mathrm{Mcr}=2041 \mathrm{kN} . \mathrm{cm}$ $\mathrm{L}=70 \mathrm{~cm}$

(b)

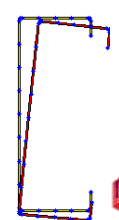

$\mathrm{Mcr}=1177 \mathrm{kN} . \mathrm{cm}$ $\mathrm{L}=300 \mathrm{~cm}$

(e)
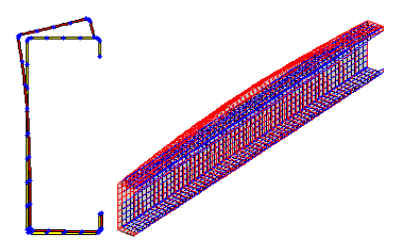

Mcr $=3908 \mathrm{kN} . \mathrm{cm}$ $\mathrm{L}=150 \mathrm{~cm}$

(c)
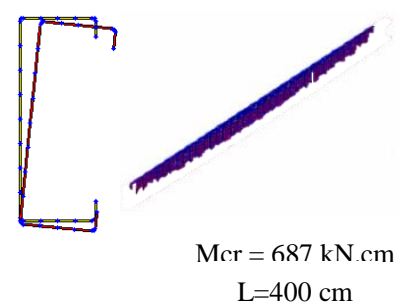

(f)

Figura 4.32 - Carregamentos críticos e modos de instabilidade obtidos com o CUFSM-SC (seção transversal no meio do vão) para L igual a: (a) $15 \mathrm{~cm}$, (b) $70 \mathrm{~cm},($ c) $150 \mathrm{~cm}$, (d) $200 \mathrm{~cm}$, (d) $300 \mathrm{~cm}$ e (f) $400 \mathrm{~cm}$.

Convém destacar que para os comprimentos $150 \mathrm{~cm}$ e $200 \mathrm{~cm}$ o CuFsM via "signature curve", mais uma vez, não fornece os menores carregamentos críticos 
possíveis. Utilizando o "general boundary conditions", obtêm-se resultados diferentes para esses comprimentos e os mesmos não são apresentados em curvas como no CUFSM-SC. Os carregamentos críticos mínimos e os modos correspondentes obtidos com o CUFSM-GBC são apresentados na Figura 4.33. Nota-se que ambos os casos correspondem a um MLC com mais de uma semionda longitudinal.

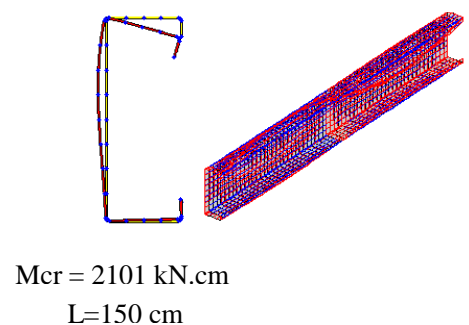

(a)

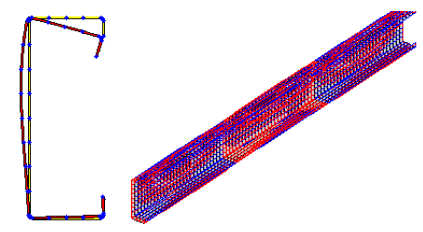

$\mathrm{Mcr}=2015 \mathrm{kN} . \mathrm{cm}$

$\mathrm{L}=200 \mathrm{~cm}$

(b)

Figura 4.33 - Carregamento crítico e modo de instabilidade obtido via CUFSM-GBC, para comprimentos de (a) $150 \mathrm{~cm}$ e (b) $200 \mathrm{~cm}$.

\subsubsection{Análise com a teoria generalizada de viga via GBTUL}

A Figura 4.34 apresenta a curva obtida com o uso do GBTUL, cujo eixo das abscissas representa o comprimento da barra em centímetros (escala logarítmica) e o eixo das ordenadas representa o carregamento crítico em kN.cm . Os pontos destacados em vermelho representam as barras de comprimentos iguais a $15 \mathrm{~cm}, 70 \mathrm{~cm}, 150 \mathrm{~cm}$, $200 \mathrm{~cm}, 300 \mathrm{~cm}$ e $400 \mathrm{~cm}$. Os modos de instabilidade e os carregamentos críticos referentes aos pontos destacados estão apresentados na Figura 4.35.

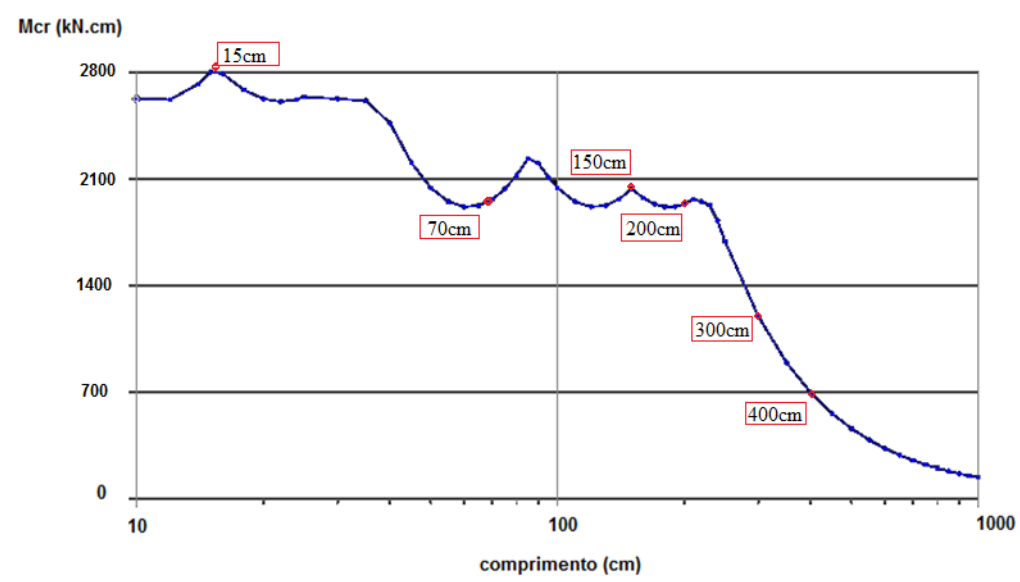

Figura 4.34 - Determinação da curva carregamento crítico, Pcr $(k N)$ em função do comprimento (cm) com o GBTUL.

Nota-se que nesse caso não ocorre um patamar no valor do carregamento crítico como nas barras biarticuladas submetidas à compressão uniforme. Os valores acima contemplam um número máximo de semiondas igual a 50. 


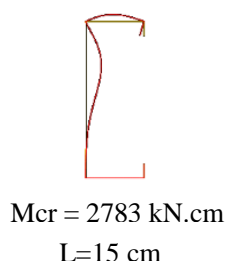

(a)

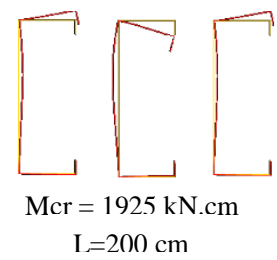

(d)

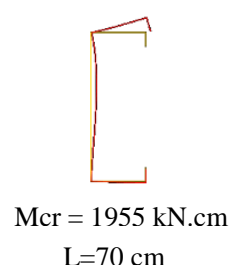

(b)

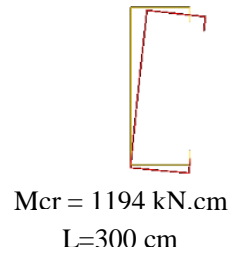

(e)

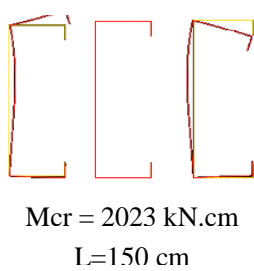

(c)

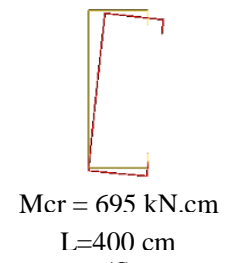

(f)

Figura 4.35 - Carregamentos críticos e modos de instabilidade obtidos com o GBTUL para $L$ igual a: (a) $15 \mathrm{~cm}$ - seção a $0,5 \mathrm{~L}$, (b) $70 \mathrm{~cm}$ - seção a $0,5 \mathrm{~L}$, (c) $150 \mathrm{~cm}$ - seção a $0,25 \mathrm{~L}, 0,5 \mathrm{~L}$ e $0,75 \mathrm{~L}$, (d) $200 \mathrm{~cm}$ - seção a 0,25L, 0,5L e 0,75L, (d) $300 \mathrm{~cm}$ - seção a 0,5L e (f) $400 \mathrm{~cm}$ - seção a 0,5L.

\subsubsection{Análise com o método dos elementos finitos via ABAQUS}

As figuras a seguir apresentam os primeiros modos de instabilidade e os respectivos carregamentos críticos obtidos através do ABAQUS para os mesmos comprimentos analisados nos itens anteriores, considerando a faixa do deslocamento normalizado, máximo na cor vermelha e nulo na cor azul escura.

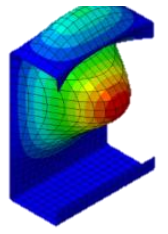

Mcr $=2741 \mathrm{kN} . \mathrm{cm}$ $\mathrm{L}=15 \mathrm{~cm}$

(a)

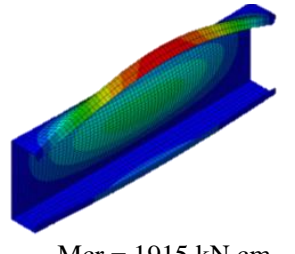

$\mathrm{L}=70 \mathrm{~cm}$

(b)

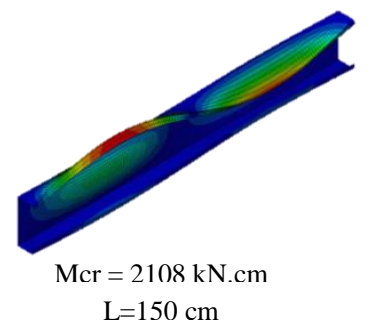

(c)

Figura 4.36 - Carregamentos críticos obtidos com o ABAQUS para o primeiro modo dos comprimentos de barra (a) $L=15 \mathrm{~cm}$, (b) $L=70 \mathrm{~cm}$ e (d) $L=150 \mathrm{~cm}$.

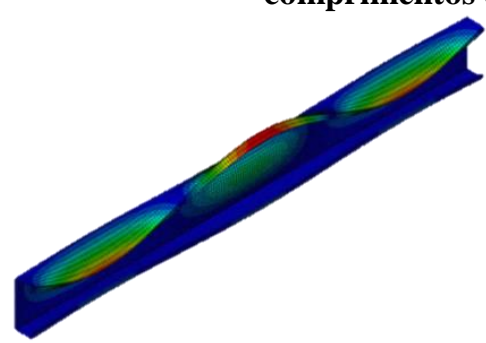

$\mathrm{Mcr}=2008 \mathrm{kN} . \mathrm{cm}$

$\mathrm{L}=200 \mathrm{~cm}$

(a)

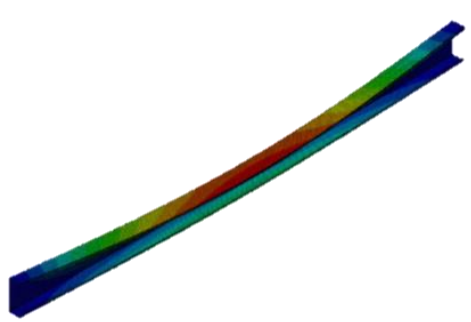

$\mathrm{Mcr}=1198 \mathrm{kN} \cdot \mathrm{cm}$

$\mathrm{L}=300 \mathrm{~cm}$

(b)

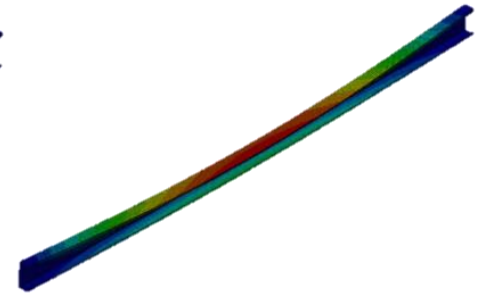

$\mathrm{Mcr}=698 \mathrm{kN} . \mathrm{cm}$

$\mathrm{L}=400 \mathrm{~cm}$

(c)

Figura 4.37 - Carregamentos críticos obtidos com o ABAQUS para o primeiro modo dos comprimentos de barra (a) $\mathrm{L}=200 \mathrm{~cm}$, (b) $\mathrm{L}=300 \mathrm{~cm}$ e (d) $\mathrm{L}=400 \mathrm{~cm}$.

Os casos para comprimentos de $150 \mathrm{~cm}$ e $200 \mathrm{~cm}$ tratam de modos locais (acoplamento do MLC e MD), o primeiro com duas semiondas longitudinais e o 
segundo com três semiondas longitudinais. Para esses casos os resultados obtidos com o GBTUL (MEF-GBT) estão em ótima concordância com os resultados obtidos com o ABAQus (MEF-cascas), enquanto que o CUFSM-SC ("signature curve") apresenta grande discrepância. Para esses casos a Figura 4.38a e Figura 4.38b apresentam os modos superiores obtidos com o ABAQUS e que são compatíveis com os modos que o CUFSMSC captura como sendo o primeiro modo de instabilidade para as barras de $150 \mathrm{~cm} \mathrm{e}$ $200 \mathrm{~cm}$ de comprimento, respectivamente.

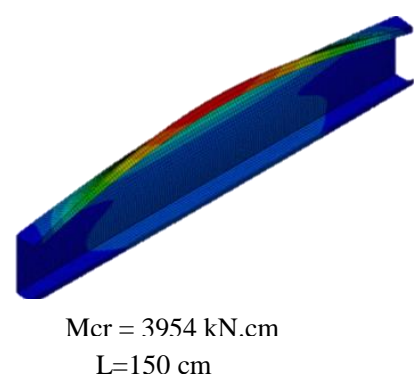

(a)

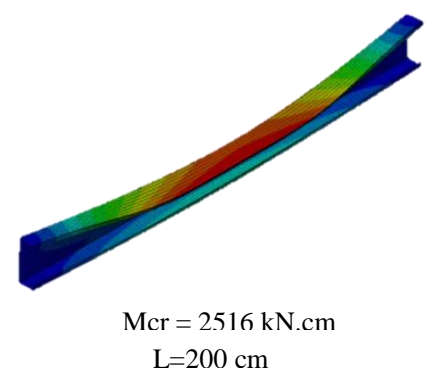

(b)

Figura 4.38 - Carregamentos críticos obtidos com o ABAQUS (a) sexagésimo sexto modo para $\mathrm{L}=150 \mathrm{~cm}$ e (b) quinto modo para $\mathrm{L}=200 \mathrm{~cm}$.

\subsubsection{Perfil $Z$ enrijecido}

\subsubsection{Análise com o método das faixas finitas via CUFSM}

A Figura 4.39 apresenta a curva obtida com o uso do CUSFM-SC, cuja abscissa representa o comprimento do perfil em milímetros (escala logarítmica) e a ordenada representa $\mathrm{o}$ fator de carregamento, $p$. Os seis pontos marcados representam o carregamento crítico para os comprimentos L, de $15 \mathrm{~cm}, 70 \mathrm{~cm}, 150 \mathrm{~cm}, 200 \mathrm{~cm}, 300$ $\mathrm{cm}$ e $400 \mathrm{~cm}$. Os valores dos carregamentos críticos e os respectivos modos de instabilidade são apresentados na Figura 4.40.

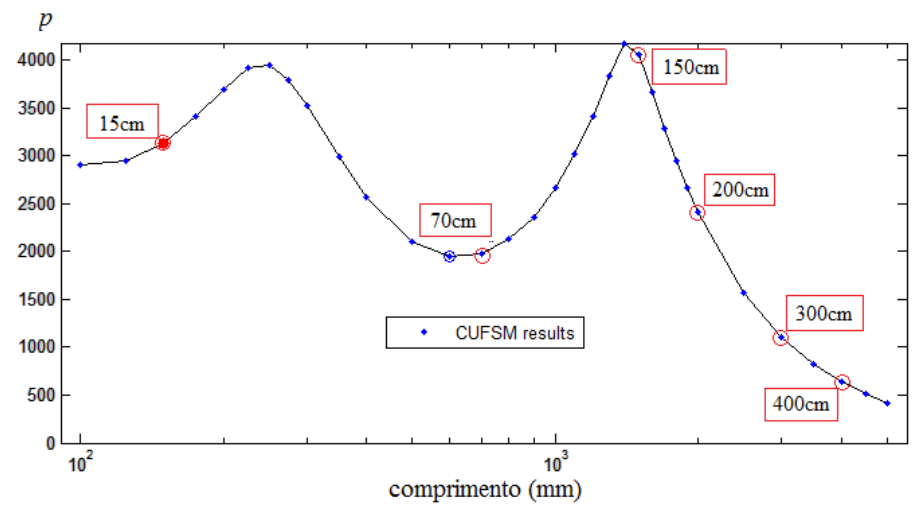

Figura 4.39 - Determinação da curva do fator de carregamento, $p$, em função do comprimento do perfil em mm, com o CUFSM-SC. 


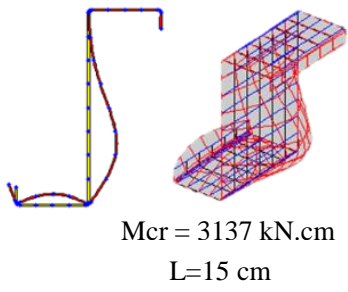

(a)

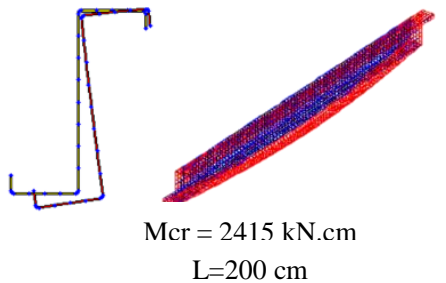

(d)

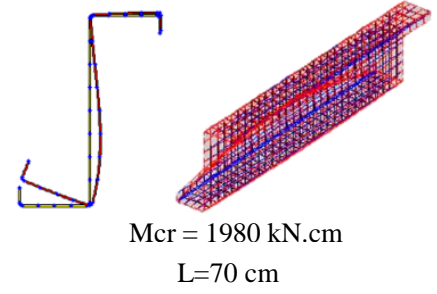

(b)

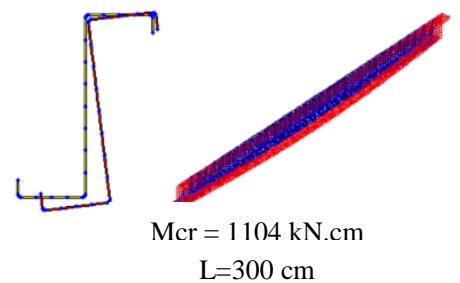

(e)

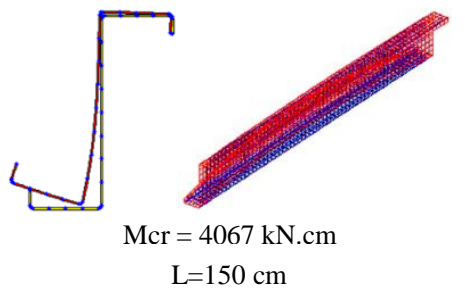

(c)

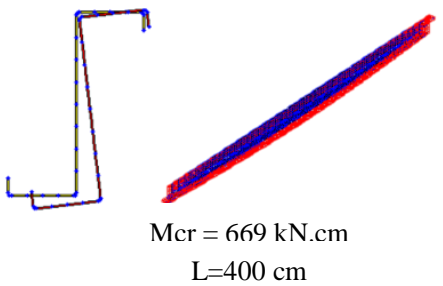

(f)

Figura 4.40 - Carregamentos críticos e modos de instabilidade obtidos com o CUFSM-SC (seção transversal no meio do vão) para L igual a: (a) $15 \mathrm{~cm}$, (b) $70 \mathrm{~cm}$, (c) $150 \mathrm{~cm}$, (d) $200 \mathrm{~cm}$, (d) $300 \mathrm{~cm}$ e (f) $400 \mathrm{~cm}$.

Novamente, para os comprimentos $15 \mathrm{~cm}, 150 \mathrm{~cm}$ e $200 \mathrm{~cm}$ o CUFSM não fornece os menores carregamentos críticos possíveis, quando se utiliza a solução do tipo "signature curve". Adotando a formulação do "general boundary conditions", obtêm-se resultados diferentes para esses comprimentos. Os carregamentos críticos mínimos e os modos correspondentes obtidos com o CUFSM-GBC são apresentados na Figura 4.41.

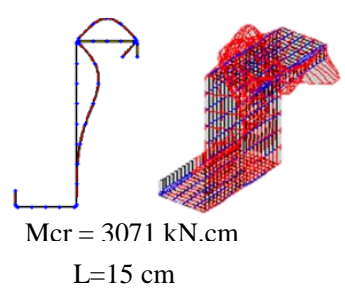

(a)

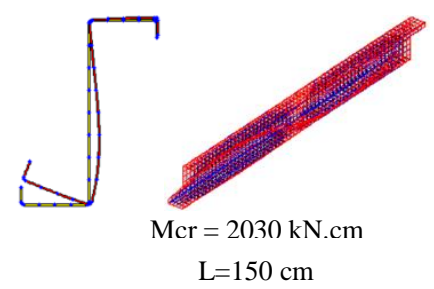

(b)
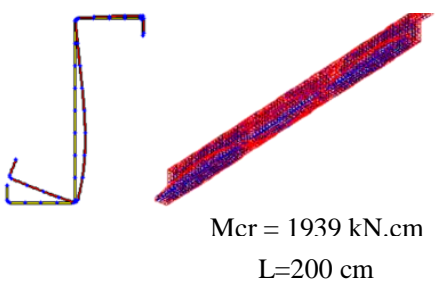

(c)

Figura 4.41 - Carregamento crítico e modo de instabilidade obtido via CUSFM-GBC para comprimentos de (a) $15 \mathrm{~cm}$, (b) $150 \mathrm{~cm}$ e (c) $200 \mathrm{~cm}$.

\subsubsection{Análise com a teoria generalizada de viga via GBTUL}

A Figura 4.42 apresenta a curva obtida com o uso do GBTUL, cujo eixo das abscissas representa o comprimento da barra em centímetros (escala logarítmica) e o eixo das ordenadas representa o carregamento crítico em $\mathrm{kN} . \mathrm{cm}$. Os pontos destacados em vermelho representam as barras de comprimentos iguais a $15 \mathrm{~cm}, 70 \mathrm{~cm}, 150 \mathrm{~cm}$, $200 \mathrm{~cm}, 300 \mathrm{~cm}$ e $400 \mathrm{~cm}$. Os modos de instabilidade e os carregamentos críticos referentes aos pontos destacados estão apresentados na Figura 4.43. 


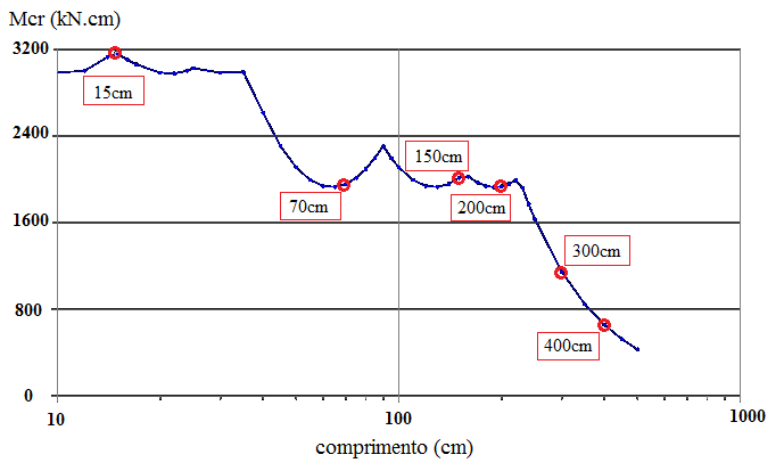

Figura 4.42 - Determinação da curva carregamento crítico, $\operatorname{Mcr}$ (kN.cm) em função do comprimento $(\mathbf{c m})$ com o GBTUL.

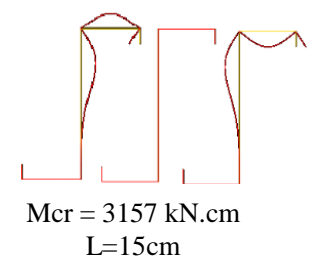

(a)

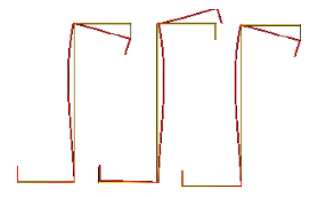

Mcr $=1936 \mathrm{kN} . \mathrm{cm}$ $\mathrm{L}=200 \mathrm{~cm}$

(d)

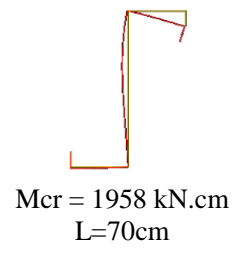

(b)

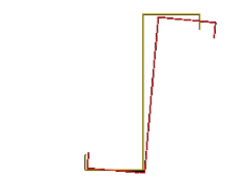

$\mathrm{Mcr}=1147 \mathrm{kN} . \mathrm{cm}$ $\mathrm{L}=300 \mathrm{~cm}$

(e)

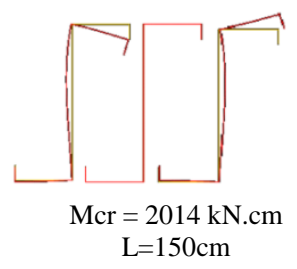

(c)

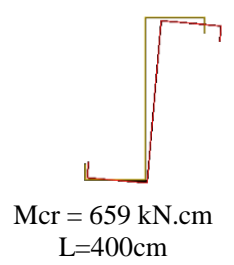

(f)

Figura 4.43 - Carregamentos críticos e modos de instabilidade obtidos com o GBTUL para $L$ igual a: (a) $15 \mathrm{~cm}$ - seção a $0,5 \mathrm{~L}$, (b) $70 \mathrm{~cm}$ - seção a $0,5 \mathrm{~L}$, (c) $150 \mathrm{~cm}$ - seção a $0,25 \mathrm{~L}, 0,5 \mathrm{~L}$ e $0,75 \mathrm{~L}$, (d) $200 \mathrm{~cm}$ - seção a $0,25 \mathrm{~L}, 0,5 \mathrm{~L}$ e $0,75 \mathrm{~L}$, (d) $300 \mathrm{~cm}$ - seção a $0,5 \mathrm{~L}$ e (f) $400 \mathrm{~cm}$ - seção a $0,5 \mathrm{~L}$.

Novamente, nota-se que não ocorre um patamar no valor do carregamento crítico. Para os comprimentos de $70 \mathrm{~cm}$ a $200 \mathrm{~cm}$ há uma combinação entre os MLC e os MD. Os valores acima contemplam um número máximo de semiondas igual a 50.

\subsubsection{Análise com o método dos elementos finitos via ABAQUS}

As figuras a seguir apresentam os primeiros modos de instabilidade e os respectivos carregamentos críticos obtidos através do ABAQUS para os mesmos comprimentos analisados nos itens anteriores, considerando a faixa de cores indicada (deslocamento normalizado máximo na cor vermelha e nulo na cor azul escura). 


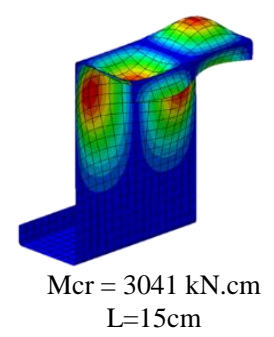

(a)

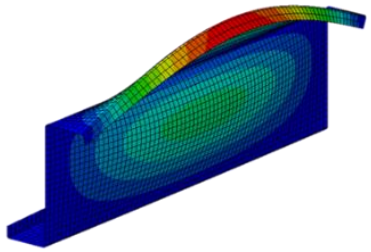

$\mathrm{Mcr}=1936 \mathrm{kN} \cdot \mathrm{cm}$ $\mathrm{L}=70 \mathrm{~cm}$

(b)

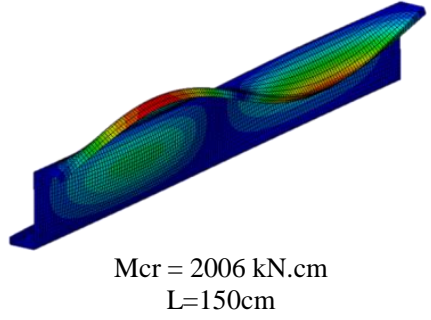

(c)

Figura 4.44 - Carregamentos críticos obtidos com o ABAQUS para o primeiro modo dos comprimentos de barra (a) $\mathrm{L}=15 \mathrm{~cm}$, (b) $\mathrm{L}=70 \mathrm{~cm}$ e (d) $\mathrm{L}=150 \mathrm{~cm}$.

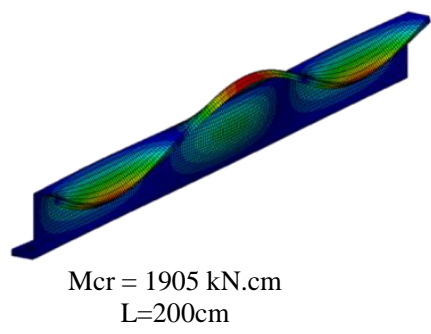

(a)

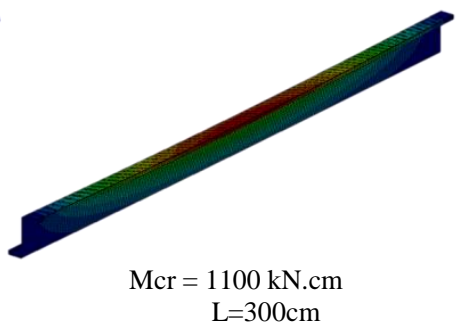

(b)

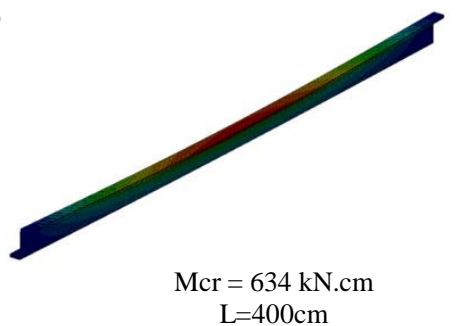

(c)

Figura 4.45 - Carregamentos críticos obtidos com o ABAQUS para o primeiro modo dos comprimentos de barra (a) $\mathrm{L}=200 \mathrm{~cm}$, (b) $\mathrm{L}=300 \mathrm{~cm}$ e (d) $\mathrm{L}=400 \mathrm{~cm}$.

Diferentemente do perfil Ue, o perfil Ze com comprimento igual a $15 \mathrm{~cm}$ possui carregamento critico mínimo correspondente a um modo crítico que combina o MLC na alma, na mesa e no enrijecedor, todos com duas semiondas longitudinais. Esse resultado difere daquele apresentado pelo CUFSM-SC ("signature curve"), uma vez que o programa limita $\mathrm{m}=1$.

As figuras acima ilustram bem o acoplamento entre os modos locais de placa e os modos distorcionais dos perfis com comprimento $70 \mathrm{~cm}, 150 \mathrm{~cm}$ e $200 \mathrm{~cm}$. Para os casos de $150 \mathrm{~cm}$ e $200 \mathrm{~cm}$ os resultados obtidos com o GBTUL (MEF-GBT) estão em ótima concordância com os resultados obtidos com o ABAQUS (MEF-cascas), enquanto que o CUFSM-SC ("signature curve") apresenta, mais uma vez, grande discrepância. Para esses casos a Figura 4.46a e Figura 4.38b apresentam os modos superiores obtidos com o ABAQUS e que são compatíveis com os modos que o CUFSM-SC captura como sendo o primeiro modo de instabilidade para as barras de $150 \mathrm{~cm}$ e $200 \mathrm{~cm}$ de comprimento, respectivamente.

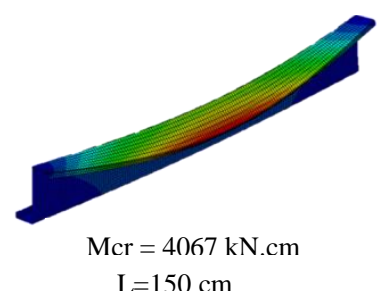

(a)

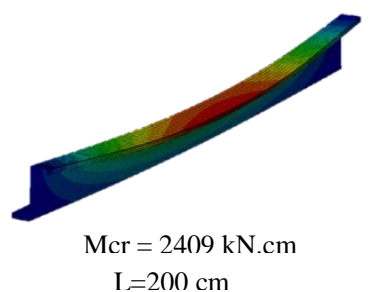

(b)

Figura 4.46 - Carregamentos críticos obtidos com o ABAQUS (a) sexagésimo sexto modo para $\mathrm{L}=150 \mathrm{~cm}$ e (b) sexto modo para $\mathrm{L}=200 \mathrm{~cm}$. 


\subsubsection{Resumo dos resultados}

Os resultados obtidos com o ABAQUS, e apresentados anteriormente, são comparados com os resultados obtidos com o CUFSM-SC, CUfSM-GBC e GBTUL graficamente na Figura 4.47 para os perfis U enrijecidos e na Figura 4.48 para os $\mathrm{Z}$ enrijecidos. As curvas abaixo representam os carregamentos críticos mínimos (i.e. o menor dos autovalores) obtidos para cada método em análise, em função do comprimento da barra, para o caso do tipo 3 de grau de refinamento da seção transversal.

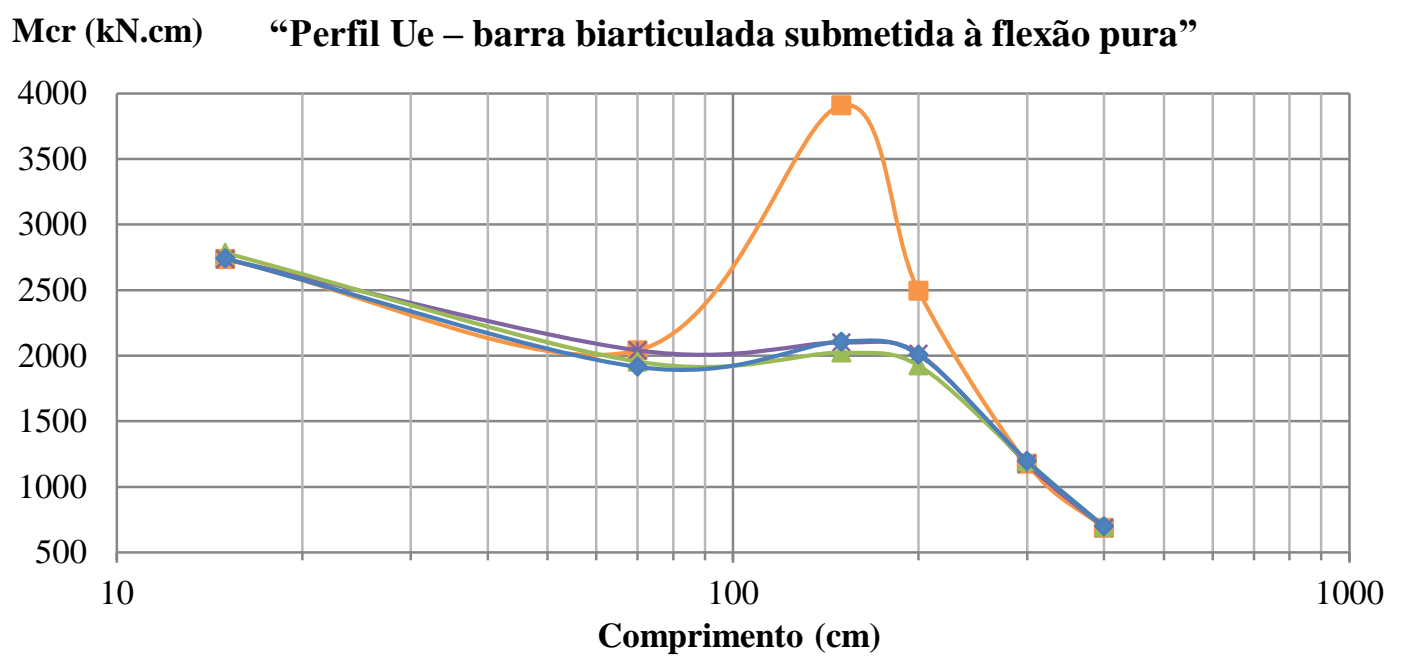

- CUFSM-SC $\rightarrow$ CUFSM-GBC $\multimap$ GBTUL $\multimap$ ABAQUS (primeiro modo)

Figura 4.47 - Curvas dos carregamentos críticos em função dos comprimentos da barra para a seção transversal Ue, para as análises via (i) CUFSM-SC, (ii) CUFSM-GBC, (iii) GBTUL, considerando $m \geq 50$ e (iv) ABAQUS, considerando apenas os primeiros modos.

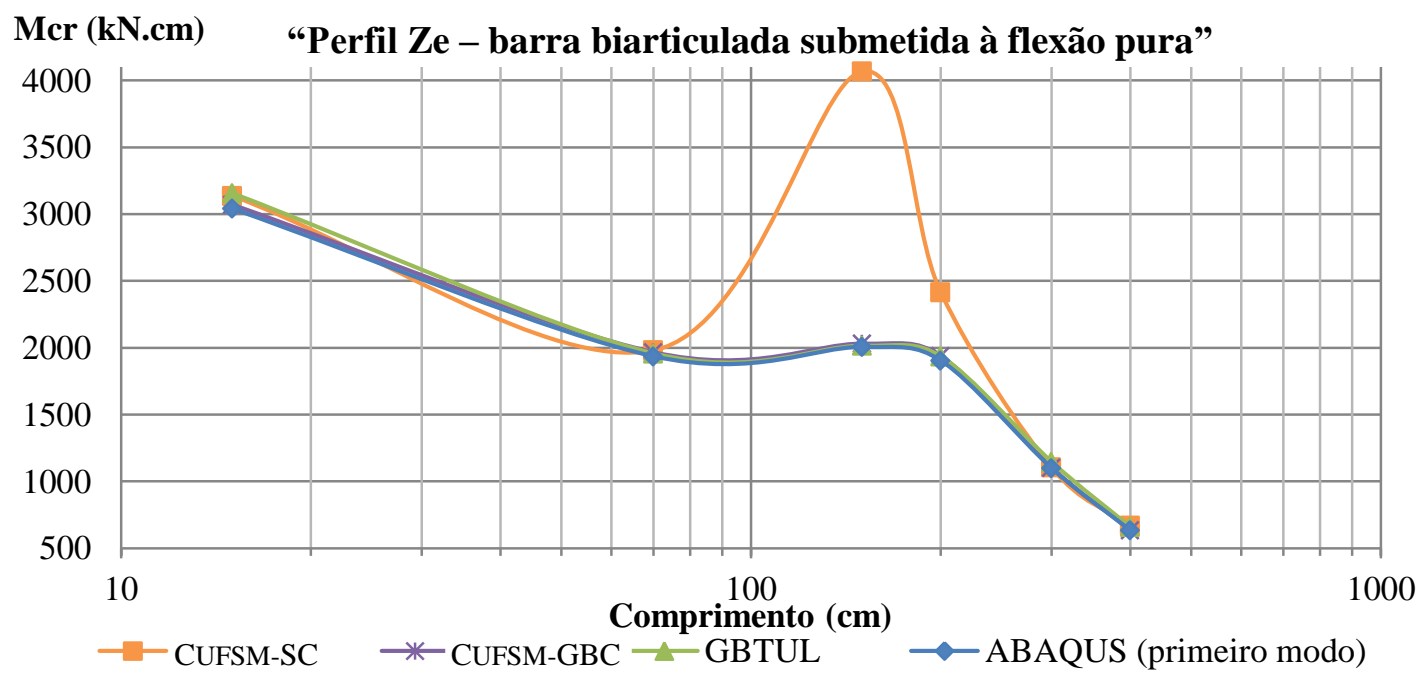

Figura 4.48 - Curvas dos carregamentos críticos em função dos comprimentos da barra para a seção transversal Ze, para as análises via (i) CUFSM-SC, (ii) CUFSM-GBC, (iii) GBTUL, considerando $\mathbf{m} \geq 20$ e (iv) ABAQUS, considerando apenas os primeiros modos. 


\subsection{Barra biarticulada submetida à flexão simples}

Conforme apresentado na Figura 4.1c, Figura 4.2 e Figura 4.3, os perfis em

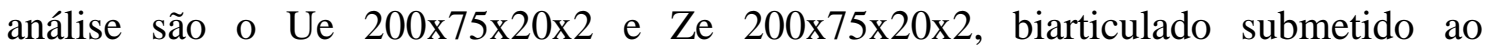
carregamento distribuído q igual a $1 \mathrm{kN} / \mathrm{cm}$. Os resultados obtidos nessa análise são para seções com o grau de refinamento tipo $3 \mathrm{em}$ ambos os casos.

Como os esforços internos não são uniformes ao longo da barra, o CUFSM não consegue simular esse problema e não será utilizado nessa análise. Aborda-se então a comparação das diferenças de modelagem e dos resultados entre o MEF-GBT e o MEFcascas através dos programas GBTUL (Figura 4.49a) e ABAQUs (Figura 4.49b e Figura $4.49 \mathrm{c})$.

No GBUTL, o carregamento distribuído q é aplicado diretamente no centro de torção da seção transversal e ao longo de todo comprimento $\mathrm{L}$ da barra.

No ABAQUS, aplicou-se o mesmo carregamento distribuído q, porém na forma de carregamento por superfície, considerando a área de duas faixas de elementos (uma acima e uma baixo da linha média da alma) ao longo de todo comprimento L. Foram aplicadas as mesmas condições de contorno de deslocamento do item anterior.

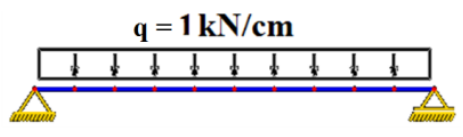

(a)

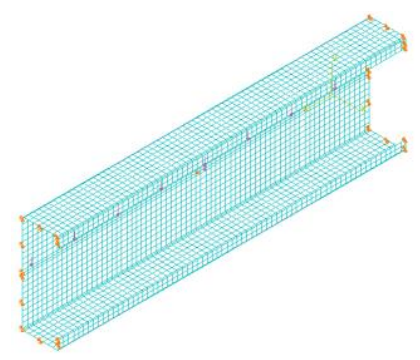

(b)

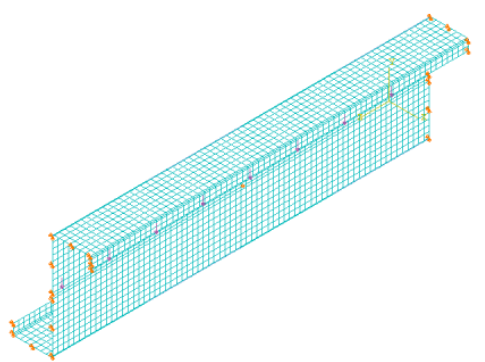

(c)

Figura 4.49 - Barra isolada de comprimento $L$, biarticulada e submetida a carregamento distribuído, (a) esquema estrutural no GBTUL; (b) esquema estrutural no ABAQUS para seção Ue e (c) esquema estrutural no ABAQUS para seção Ze.

$\mathrm{Na}$ sequência, são apresentados os modos de instabilidade e os carregamentos críticos obtidos nas análises numéricas para os perfis Ue e Ze via GBTUL e ABAQUS. 


\subsubsection{Perfil U enrijecido}

\subsubsection{Análise com a teoria generalizada de viga via GBTUL}

A Figura 4.50 apresenta a curva obtida com o uso do GBTUL, cujo eixo das abscissas representa o comprimento da barra em centímetros (escala logarítmica) e o eixo das ordenadas o carregamento crítico em $\mathrm{kN} / \mathrm{cm}$. Os modos de instabilidade e os carregamentos críticos referentes aos comprimentos $15 \mathrm{~cm}, 70 \mathrm{~cm}, 150 \mathrm{~cm}, 200 \mathrm{~cm}, 30 \mathrm{~cm}$ e $400 \mathrm{~cm}$ são apresentados na Figura 4.51.

Alterou-se o valor de "m" para 100 harmônicos longitudinais, de forma a tentar garantir os menores carregamentos críticos possíveis.

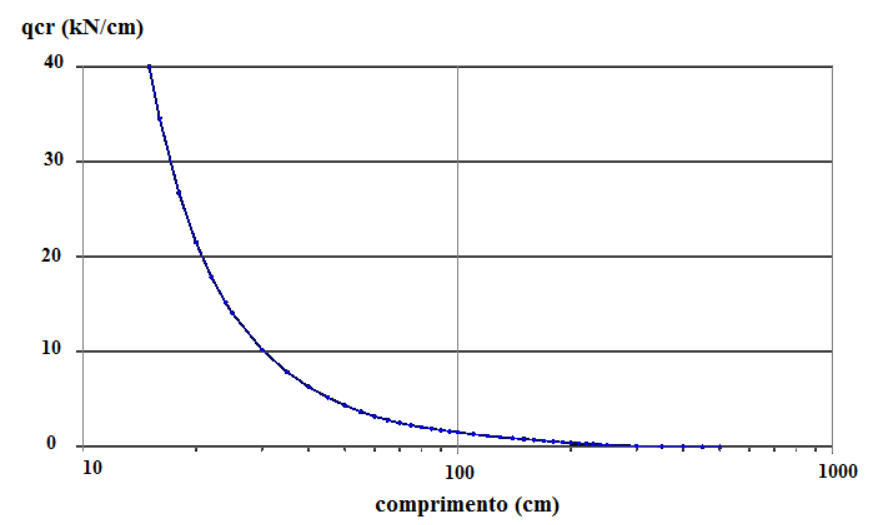

Figura 4.50 - Determinação da curva comprimento $(\mathrm{cm})$ vs. carga crítica, qcr $(\mathrm{kN} / \mathrm{cm})$.

$\mathrm{Na}$ Figura 4.51, os carregamentos críticos são apresentados na forma de carregamento distribuído ao longo do comprimento, qcr.

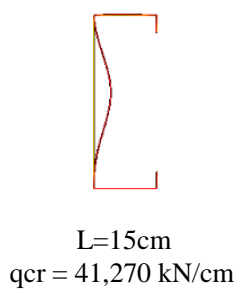

(a)

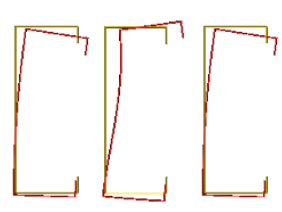

$\mathrm{L}=200 \mathrm{~cm}$ $\mathrm{qcr}=0,457 \mathrm{kN} / \mathrm{cm}$

(d)
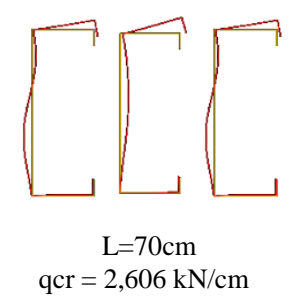

(b)

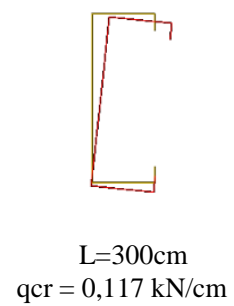

(e)

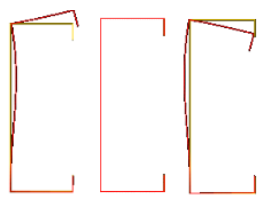

$\mathrm{L}=150 \mathrm{~cm}$ $\mathrm{qcr}=0,861 \mathrm{kN} / \mathrm{cm}$

(c)

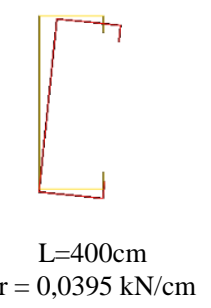

(f)

Figura 4.51 - Carregamentos críticos e modos de instabilidade obtidos com o GBTUL para $L$ igual a: (a) $15 \mathrm{~cm}$ - seção a $0,5 \mathrm{~L}$, (b) $70 \mathrm{~cm}$ - seção a $0,25 \mathrm{~L}, 0,5 \mathrm{~L}$ e $0,75 \mathrm{~L}$, (c) $150 \mathrm{~cm}$ - seção a $0,25 \mathrm{~L}, 0,5 \mathrm{~L}$ e $0,75 \mathrm{~L}$, (d) $200 \mathrm{~cm}$ - seção a $0,25 \mathrm{~L}, 0,5 \mathrm{~L}$ e $0,75 \mathrm{~L}$, (d) $300 \mathrm{~cm}$ - seção a $0,5 \mathrm{~L}$ e (f) $400 \mathrm{~cm}$ - seção a $0,5 \mathrm{~L}$ 


\subsubsection{Análise com o método dos elementos finitos via ABAQUS}

As figuras a seguir apresentam o primeiro modo de instabilidade e os respectivos carregamentos críticos (qcr em $\mathrm{kN} / \mathrm{cm}$ ) obtidos através do ABAQUS para os mesmos comprimentos analisados no item anterior, considerando a faixa de cores indicada (deslocamento normalizado máximo na cor vermelha e nulo na cor azul escura).

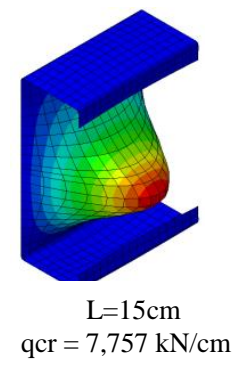

(a)

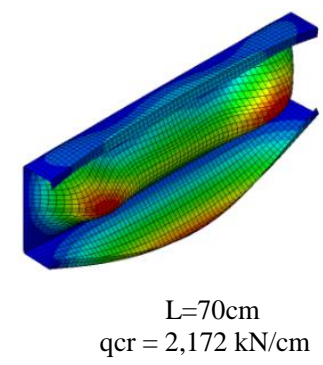

(b)

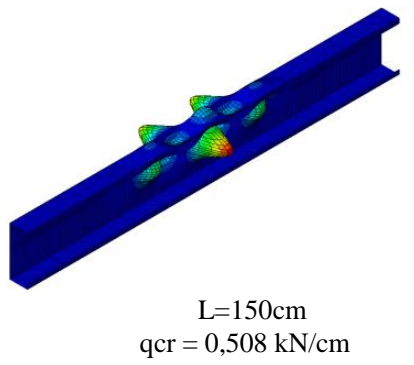

(c)

Figura 4.52 - Carregamentos críticos obtidos com o ABAQUS para o primeiro modo dos comprimentos de barra (a) $\mathrm{L}=15 \mathrm{~cm}$, (b) $\mathrm{L}=70 \mathrm{~cm}$ e (d) $\mathrm{L}=150 \mathrm{~cm}$.

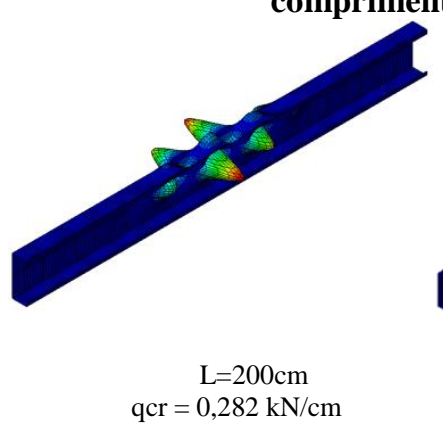

(a)

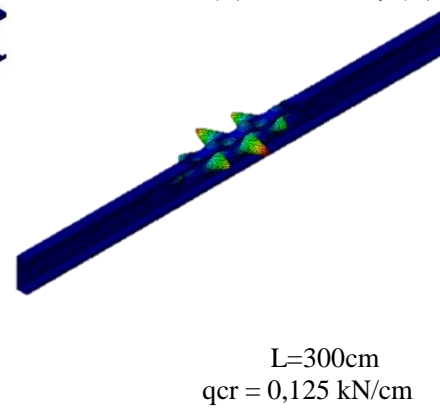

(b)

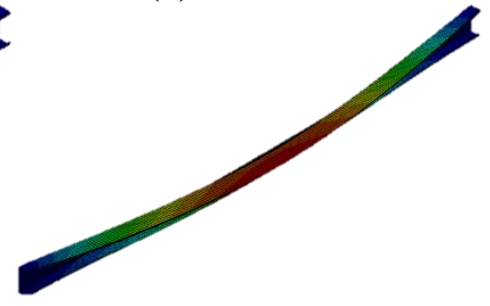

$$
\mathrm{qcr}=0,0621 \mathrm{kN} / \mathrm{cm}
$$

(c)

Figura 4.53 - Carregamentos críticos obtidos com o ABAQUS para o primeiro modo dos comprimentos de barra (a) $\mathrm{L}=200 \mathrm{~cm}$, (b) $\mathrm{L}=300 \mathrm{~cm}$ e (d) $\mathrm{L}=400 \mathrm{~cm}$.

Observa-se que para os comprimentos de $15 \mathrm{~cm}$ a $300 \mathrm{~cm}$ os resultados obtidos com o GBUTL apresentam grande discrepância em relação aos resultados obtidos com o ABAQUS. Embora para o perfil de $15 \mathrm{~cm}$ ambos apresentem o MLC na alma, o valor do carregamento crítico obtido pelo GBTUL é muito superior ao do ABAQUS. No caso da barra de $300 \mathrm{~cm}$, o valor dos carregamentos crítico é semelhante, mas os modos são totalmente diferentes nos dois modelos. Aparentemente, o GBTUL não consegue identificar um MLC localizado em uma região restrita da barra (nesse caso, a região do meio do vão, onde as tensões de compressão são mais elevadas); isso ocorre nas barras de comprimento igual a $150 \mathrm{~cm}, 200 \mathrm{~cm}$ e $300 \mathrm{~cm}$.

Nota-se ainda que, para o perfil de $400 \mathrm{~cm}$, a resposta entre os dois programas apresenta também grande discrepância; no entanto, isso era esperado devido ao fato de o carregamento ser aplicado de maneira diferente, tratando-se, pois de problemas distintos. 


\subsubsection{Perfil $Z$ enrijecido}

\subsubsection{Análise com a teoria generalizada de viga via GBTUL}

A Figura 4.54 apresenta a curva obtida com o uso do GBTUL, onde no eixo das abscissas tem-se o comprimento da barra em centímetros (escala logarítmica) e no eixo das ordenadas o carregamento crítico em $\mathrm{kN} / \mathrm{cm}$. Os modos de instabilidade e os carregamentos críticos (qcr em $\mathrm{kN} / \mathrm{cm}$ e Pcr em $\mathrm{kN}$ ) referentes aos comprimentos $15 \mathrm{~cm}$, $70 \mathrm{~cm}, 150 \mathrm{~cm}, 200 \mathrm{~cm}, 30 \mathrm{~cm}$ e $400 \mathrm{~cm}$ são apresentados na Figura 4.55.

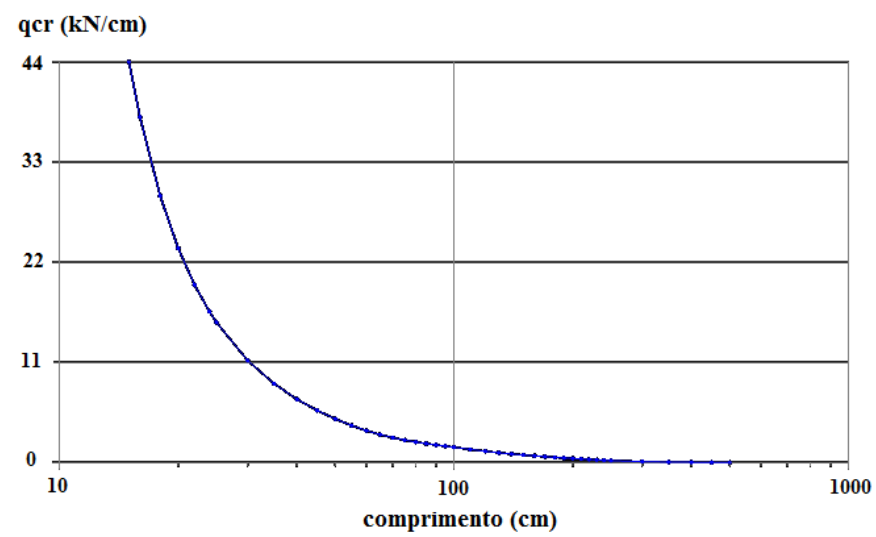

Figura 4.54 - Determinação da curva comprimento $(\mathrm{cm})$ vs. carga crítica, qcr $(\mathrm{kN} / \mathrm{cm})$.

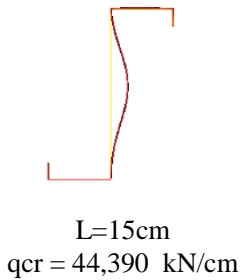

(a)

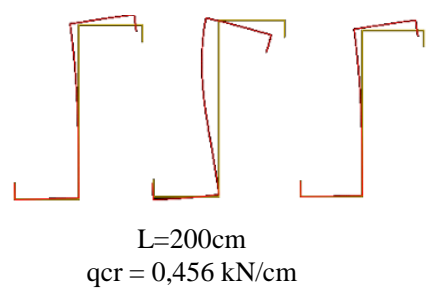

(d)
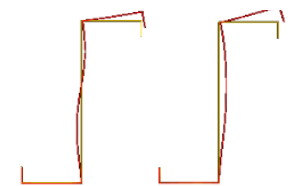

$\mathrm{L}=70 \mathrm{~cm}$ $\mathrm{qcr}=2,760 \mathrm{kN} / \mathrm{cm}$

(b)

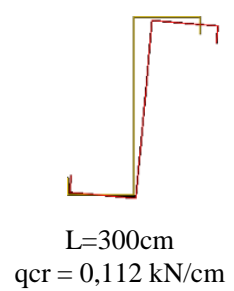

(e)

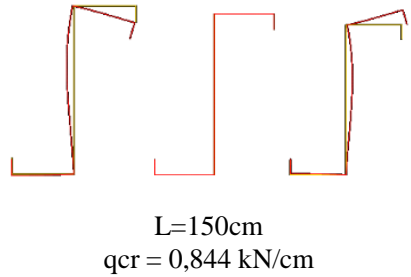

(c)

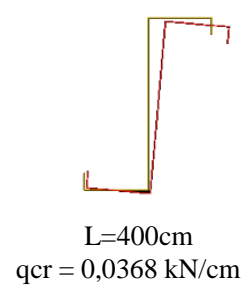

(f)

Figura 4.55 - Carregamentos críticos e modos de instabilidade obtidos com o GBTUL (seção transversal na extremidade carregada) para $L$ igual a: (a) $15 \mathrm{~cm}$ - seção a $0,5 \mathrm{~L}$, (b) $70 \mathrm{~cm}$ - seção a $0,25 \mathrm{~L}, 0,5 \mathrm{~L}$ e $0,75 \mathrm{~L}$, (c) $150 \mathrm{~cm}$ - seção a $0,25 \mathrm{~L}, 0,5 \mathrm{~L}$ e $0,75 \mathrm{~L}$, (d) $200 \mathrm{~cm}$ - seção a $0,25 \mathrm{~L}, 0,5 \mathrm{~L}$ e $0,75 \mathrm{~L}$, (d) $300 \mathrm{~cm}$ - seção a $0,5 \mathrm{~L}$ e (f) $400 \mathrm{~cm}$ - seção a $0,5 \mathrm{~L}$. 


\subsubsection{Análise com o método dos elementos finitos via ABAQUS}

As figuras a seguir apresentam o primeiro modo de instabilidade e os respectivos carregamentos críticos (qcr em kN/cm e Pcr em kN) obtidos através do ABAQUS para os mesmos comprimentos analisados no item anterior, considerando a faixa de cores indicada (deslocamento normalizado máximo na cor vermelha e nulo na cor azul escura).

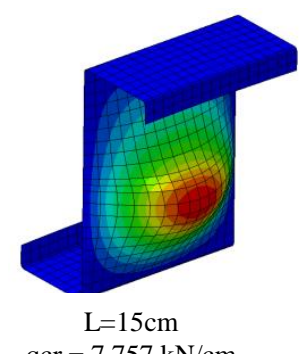

$\mathrm{qcr}=7,757 \mathrm{kN} / \mathrm{cm}$

(a)

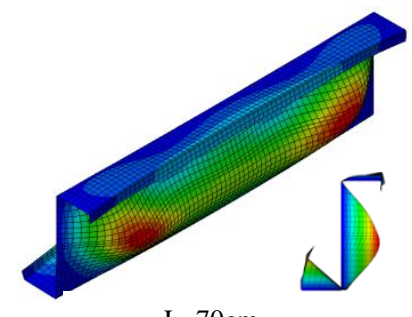

$\mathrm{L}=70 \mathrm{~cm}$ $\mathrm{qcr}=2,162 \mathrm{kN} / \mathrm{cm}$

(b)

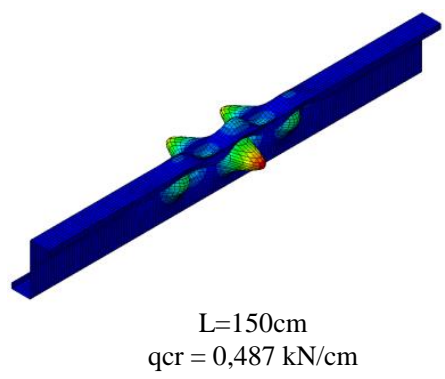

(c)

Figura 4.56 - Carregamentos críticos obtidos com o ABAQUS para o primeiro modo dos comprimentos de barra (a) $\mathrm{L}=15 \mathrm{~cm}$, (b) $\mathrm{L}=70 \mathrm{~cm}$ e (d) $\mathrm{L}=150 \mathrm{~cm}$.

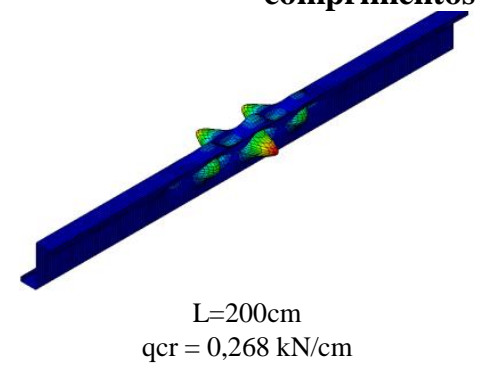

(a)

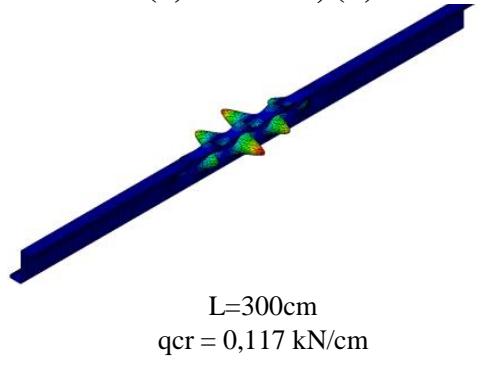

(b)

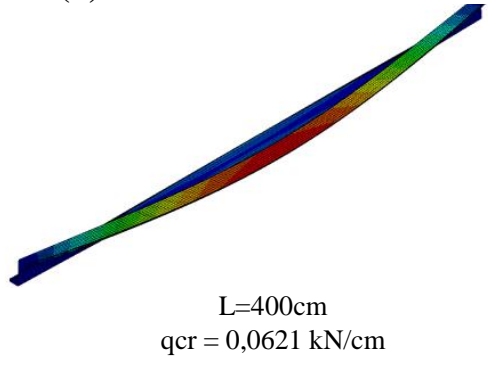

(c)

Figura 4.57 - Carregamentos críticos obtidos com o ABAQUS para o primeiro modo dos comprimentos de barra (a) $\mathrm{L}=200 \mathrm{~cm}$, (b) $\mathrm{L}=300 \mathrm{~cm}$ e (d) $\mathrm{L}=400 \mathrm{~cm}$

Aqui, embora o carregamento seja aplicado de maneira semelhante no GBTUL e no ABAQUS, observa-se que os resultados apresentam grande discrepância para todos os comprimentos.

\subsubsection{Resumo dos resultados}

Os resultados obtidos com o ABAQUS, e apresentados anteriormente, são comparados com os resultados obtidos com o GBTUL graficamente na Figura 4.58 para os perfis $U$ enrijecidos e na Figura 4.59 para os $\mathrm{Z}$ enrijecidos. As curvas abaixo representam os carregamentos críticos mínimos (i.e. o menor dos autovalores) obtidos para cada método em análise, em função do comprimento da barra. 


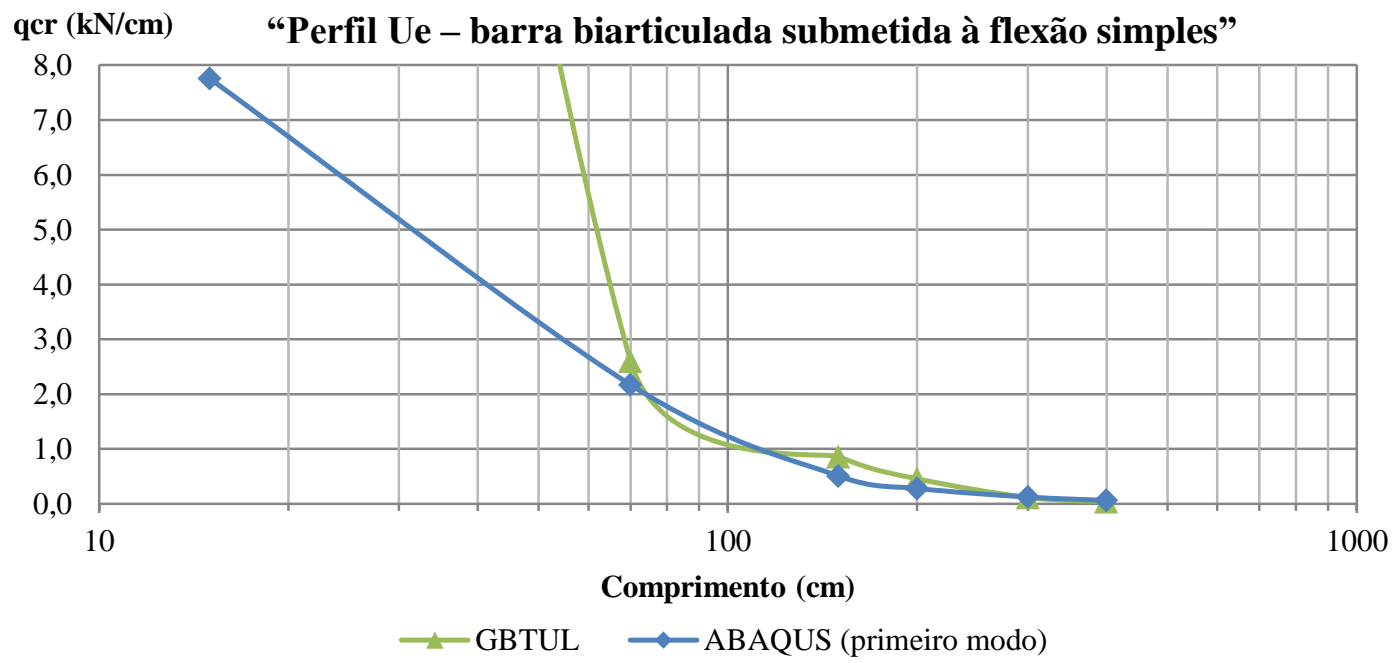

Figura 4.58 - Curvas dos carregamentos críticos em função dos comprimentos da barra para a seção transversal Ue, para as análises (i) via GBTUL e (ii) via ABAQUS.

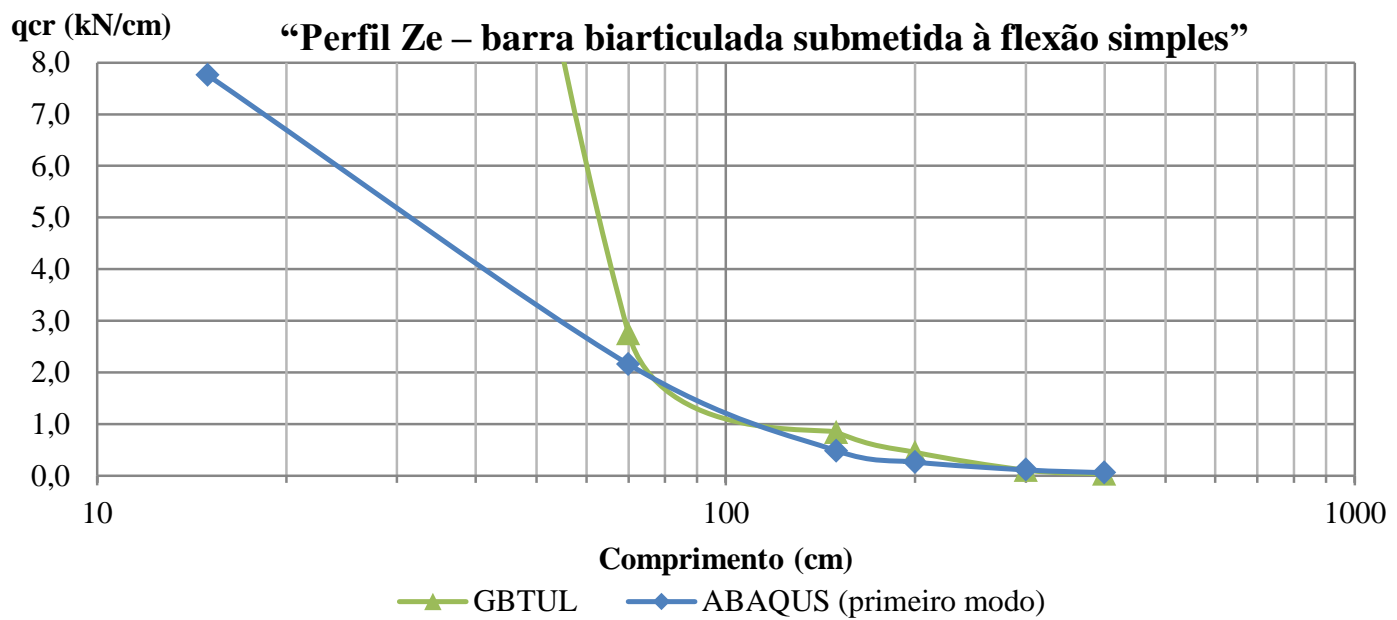

Figura 4.59 - Curvas dos carregamentos críticos em função dos comprimentos da barra para a seção transversal Ze, para as análises (i) via GBTUL e (ii) via ABAQUS.

\subsection{Barra engastada submetida à flexão simples}

Conforme apresentado na Figura 4.1d, Figura 4.2 e Figura 4.3, os perfis em análise são o Ue 200x75×20x2 e Ze 200x75×20x2, engastados em uma extremidade e livres na outra e submetidos a flexão devido a uma força transversal P de valor igual a 1 $\mathrm{kN}$ na extremidade livre.

Novamente, como os esforços não são uniformes ao longo da barra, o CUFSM não consegue simular esse problema e não será utilizado nessa análise. Aborda-se então a comparação das diferenças de modelagem e dos resultados entre o MEF-GBT e o MEF- 
cascas através dos programas GBTUL (Figura 4.60a) e ABAQus (Figura 4.60b e Figura 4.60c), sendo q, o carregamento linear aplicado ao longo da linha média $l$.

No GBUTL, o carregamento P é aplicado diretamente no ponto da extremidade da barra e a condição de engastamento é imposta no ponto da extremidade oposta.

No ABAQUS, aplicou-se o mesmo carregamento $\mathrm{P}$, porém na forma de carregamento linear q, ao longo da linha média $l$, da seção na extremidade. Na seção oposta à extremidade carregada, restringiu-se as três translações e três rotações ao longo de toda a linha média $l$.

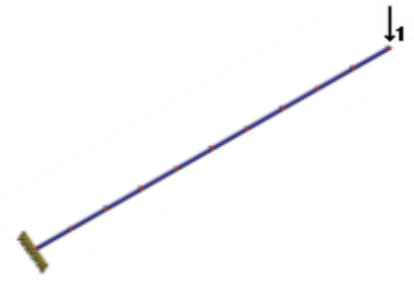

(a)

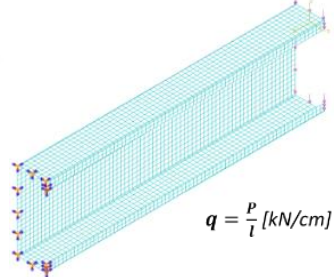

(b)

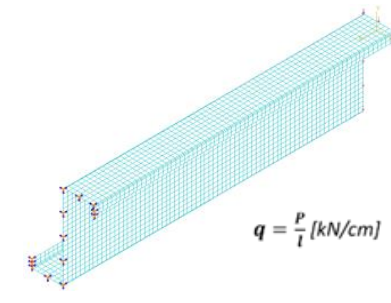

(c)

Figura 4.60 - Barra isolada de comprimento $L$, engastada e submetida ao carregamento $P$, (a) esquema estrutural no GBTUL; (b) esquema estrutural no ABAQUS para seção Ue e (c) esquema estrutural no ABAQUS para seção Ze.

Os resultados obtidos nessa análise são para seções com o grau de refinamento tipo 3 em ambos os casos.

Na sequência são apresentados os modos de instabilidade e os carregamentos críticos obtidos nas análises numéricas para os perfis Ue e Ze via GBTUL e ABAQUS.

\subsubsection{Perfil U enrijecido}

\subsubsection{Análise com a teoria generalizada de viga via GBTUL}

A Figura 4.61 apresenta a curva obtida com o uso do GBTUL, cujo eixo das abscissas representa o comprimento da barra em centímetros (escala logarítmica) e no eixo das ordenadas o carregamento crítico em $\mathrm{kN}$. Os pontos destacados em vermelho representam as barras de comprimentos iguais a $15 \mathrm{~cm}, 70 \mathrm{~cm}, 200 \mathrm{~cm}, 300 \mathrm{~cm}$ e 400 $\mathrm{cm}$. Os modos de instabilidade e os carregamentos críticos referentes aos pontos destacados estão apresentados na Figura 4.62.

Alterou-se o valor de "m" para 100 harmônicos longitudinais, de forma a tentar garantir os menores carregamentos críticos. 


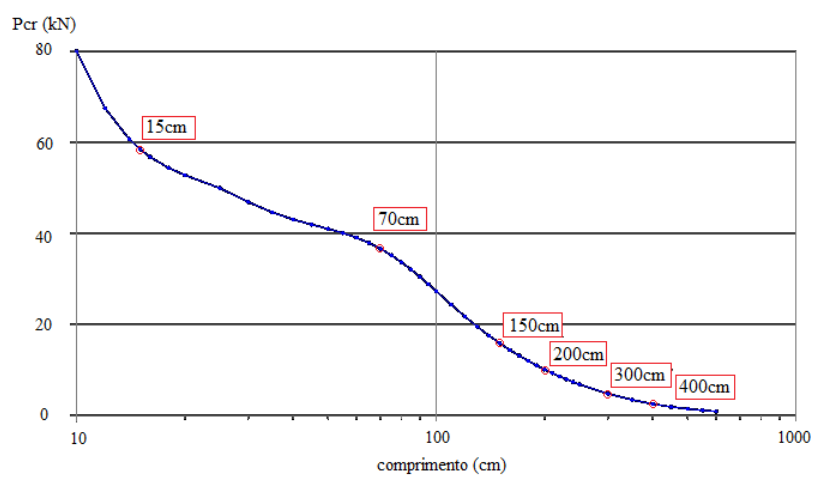

Figura 4.61 - Determinação da curva comprimento $(\mathrm{cm})$ vs. carga crítica, $\operatorname{Pcr}(\mathbf{k N})$.

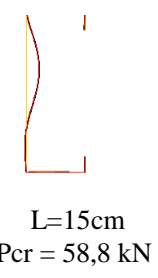

(a)

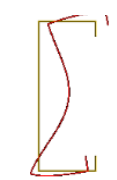

$$
\begin{aligned}
\mathrm{L} & =70 \mathrm{~cm} \\
\mathrm{Pcr} & =36,9 \mathrm{kN}
\end{aligned}
$$

(b)

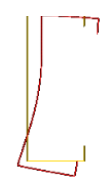

$\mathrm{L}=150 \mathrm{~cm}$ $\mathrm{Pcr}=16,0 \mathrm{kN}$

(c)

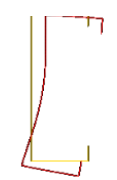
$\mathrm{L}=200 \mathrm{~cm}$ $\mathrm{Pcr}=10,2 \mathrm{kN}$

(d)

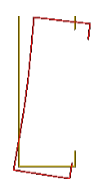
$\mathrm{L}=300 \mathrm{~cm}$ $\mathrm{Pcr}=4,9 \mathrm{kN}$

(e)

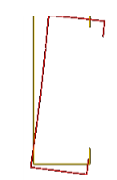

$\mathrm{L}=400 \mathrm{~cm}$ $\mathrm{Pcr}=2,6 \mathrm{kN}$

(f)

Figura 4.62 - Carregamentos críticos e modos de instabilidade obtidos com o GBTUL (seção transversal na extremidade carregada) para $L$ igual a: (a) $15 \mathrm{~cm}$ - meio do vão, (b) $70 \mathrm{~cm}$ extremidade carregada, (c) $150 \mathrm{~cm}$, (d) $200 \mathrm{~cm}$, (d) $300 \mathrm{~cm}$ e (f) $400 \mathrm{~cm}$.

\subsubsection{Análise com o método dos elementos finitos via ABAQUS}

As figuras a seguir apresentam o primeiro modo de instabilidade e os respectivos carregamentos críticos obtidos através do ABAQUS para os mesmos comprimentos analisados no item anterior, considerando a faixa de cores indicada (deslocamento normalizado máximo na cor vermelha e nulo na cor azul escura).

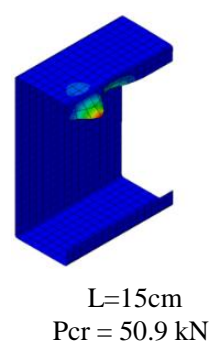

(a)

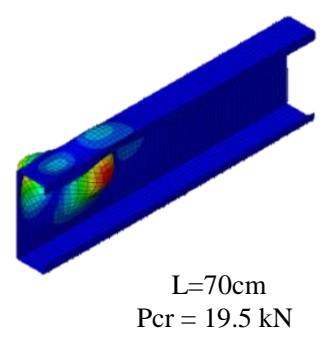

(b)

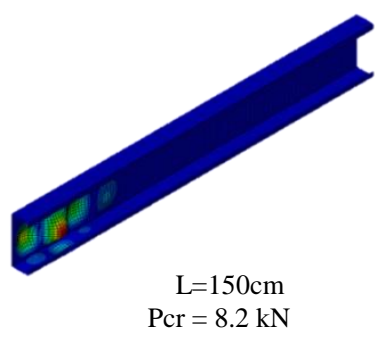

(c)

Figura 4.63 - Carregamentos críticos obtidos com o ABAQUS para o primeiro modo dos

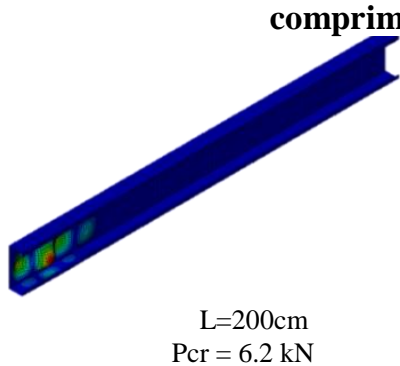

(a)

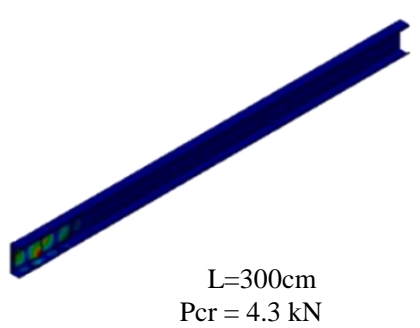

(b)

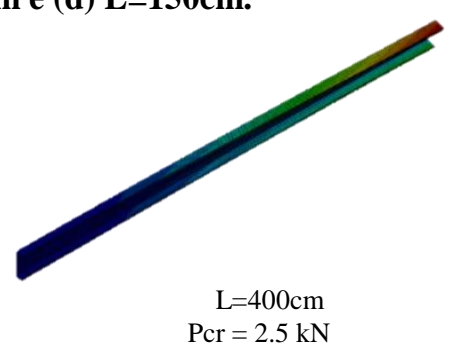

(c)

Figura 4.64 - Carregamentos críticos obtidos com o ABAQUS para o primeiro modo dos comprimentos de barra (a) $\mathrm{L}=200 \mathrm{~cm}$, (b) $\mathrm{L}=300 \mathrm{~cm}$ e (d) $\mathrm{L}=400 \mathrm{~cm}$. 
Os casos com comprimentos de $15 \mathrm{~cm}, 70 \mathrm{~cm}, 150 \mathrm{~cm}, 200 \mathrm{~cm}$ e $300 \mathrm{~cm}$ apresentam modos locais, seja no enrijecedor de borda, seja na mesa comprimida, seja na alma do perfil. Nesses casos, a instabilidade está restrita à região próxima ao engaste, que é onde as tensões de compressão são mais elevadas, e o GBTUL mais uma vez não consegue identificar os MLC's localizados, fornecendo resultados com grande discrepância.

Para esses casos a Figura 4.65 e Figura 4.66 apresentam os modos superiores obtidos com o ABAQUS que são compatíveis com os modos que o GBTUL captura como sendo o primeiro modo de instabilidade para as barras de $15 \mathrm{~cm}, 70 \mathrm{~cm}, 150 \mathrm{~cm}, 200$ $\mathrm{cm}$ e $300 \mathrm{~cm}$ de comprimento.

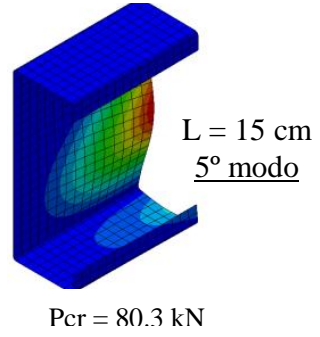

(a)

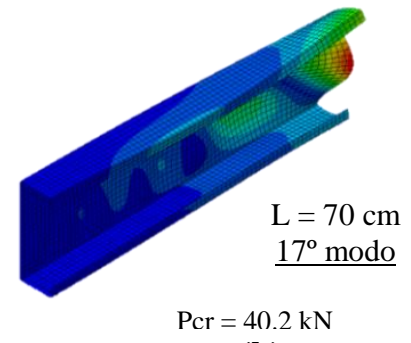

(b)

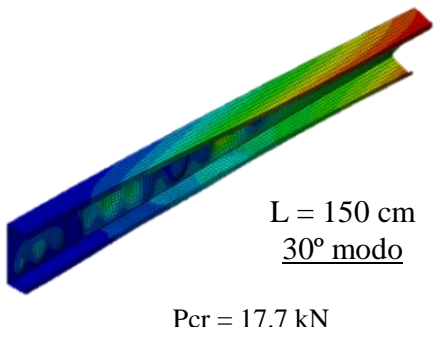

(c)

Figura 4.65 - Carregamentos críticos obtidos com o ABAQUS para o (a) quinto modo para $\mathrm{L}=15 \mathrm{~cm}$, (b) décimo sétimo modo para $\mathrm{L}=70 \mathrm{~cm}$ e (d) trigésimo modo para $\mathrm{L}=150 \mathrm{~cm}$.

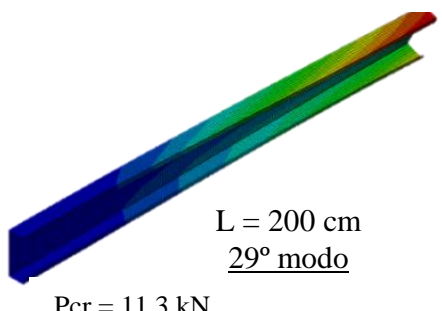

(a)

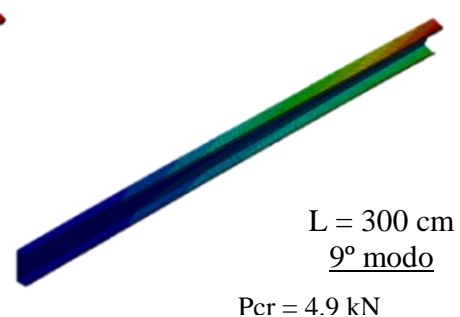

(b)

Figura 4.66 - Carregamentos críticos obtidos com o ABAQUS para o (a) vigésimo nono modo para $\mathrm{L}=200 \mathrm{~cm}$ e (b) nono modo para $\mathrm{L}=300 \mathrm{~cm}$.

Mesmo permitindo 100 semiondas longitudinais, o GBTUL não conseguiu identificar os mesmos modos críticos do ABAQUS. Isso ocorre, em parte, porque o GBTUL não possui na sua biblioteca esses modos de deformação (para o caso do perfil com $15 \mathrm{~cm}$, por exemplo, não há nenhum modo padrão que contenha a deformação somente do enrijecedor de borda, conforme a Figura 4.63a), e em parte porque o modelo com elementos de casca é, por natureza, capaz de melhor capturar efeitos localizados.

Curiosamente, embora o carregamento seja introduzido de maneira diferente no GBTUL e no ABAQUS, para o perfil de $400 \mathrm{~cm}$ os resultados do carregamento crítico são bem semelhantes. 


\subsubsection{Perfil $Z$ enrijecido}

\subsubsection{Análise com a teoria generalizada de viga via GBTUL}

A Figura 4.67 apresenta a curva obtida com o uso do GBTUL, o eixo das abscissas representa o comprimento da barra em centímetros (escala logarítmica) e o eixo das ordenadas representa o carregamento crítico em $\mathrm{kN}$. Os pontos destacados em vermelho representam as barras de comprimentos iguais a $15 \mathrm{~cm}, 70 \mathrm{~cm}, 200 \mathrm{~cm}, 300$ $\mathrm{cm}$ e $400 \mathrm{~cm}$. Os modos de instabilidade e os carregamentos críticos referentes aos pontos destacados estão apresentados na Figura 4.68.

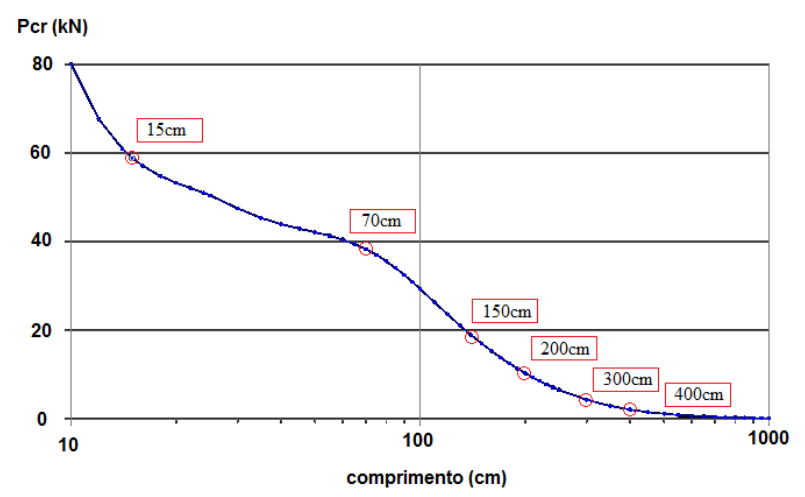

Figura 4.67 - Determinação da curva comprimento (cm) vs. carga crítica, $\operatorname{Pcr}(\mathrm{kN})$.

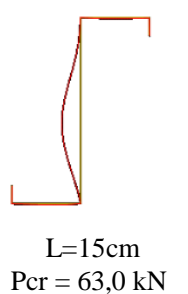

(a)

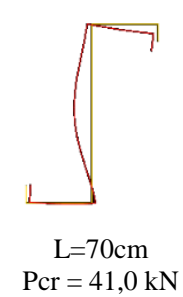

(b)

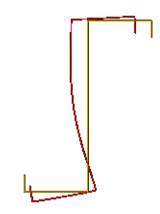

$$
\begin{aligned}
\mathrm{L} & =150 \mathrm{~cm} \\
\mathrm{Pcr} & =18,3 \mathrm{kN}
\end{aligned}
$$

(c)

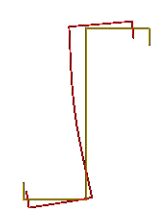

$\mathrm{L}=200 \mathrm{~cm}$ $\operatorname{Pcr}=11,1 \mathrm{kN}$

(d)

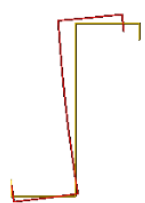

$\mathrm{L}=300 \mathrm{~cm}$ Pcr $=4,7 \mathrm{kN}$

(e)

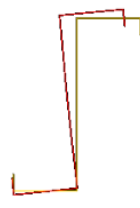

$\mathrm{L}=400 \mathrm{~cm}$ $\mathrm{Pcr}=2,3 \mathrm{kN}$

(f)

Figura 4.68 - Carregamentos críticos e modos de instabilidade obtidos com o GBTUL (seção transversal na extremidade carregada) para $L$ igual a: (a) $15 \mathrm{~cm}$ - meio do vão, (b) $70 \mathrm{~cm}$ extremidade carregada, (c) $150 \mathrm{~cm}$, (d) $200 \mathrm{~cm}$, (d) $300 \mathrm{~cm}$ e (f) $400 \mathrm{~cm}$.

\subsubsection{Análise com o método dos elementos finitos via ABAQUS}

As figuras a seguir apresentam o primeiro modo de instabilidade e os respectivos carregamentos críticos obtidos através do ABAQUS para os mesmos comprimentos analisados nos itens anteriores, considerando a faixa de cores indicada (deslocamento normalizado máximo na cor vermelha e nulo na cor azul escura). 


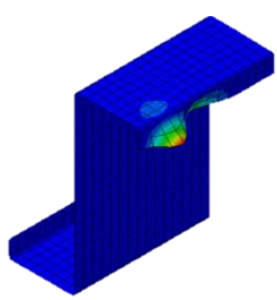

$\mathrm{L}=15 \mathrm{~cm}$ Pcr $=51.4 \mathrm{kN}$

(a)

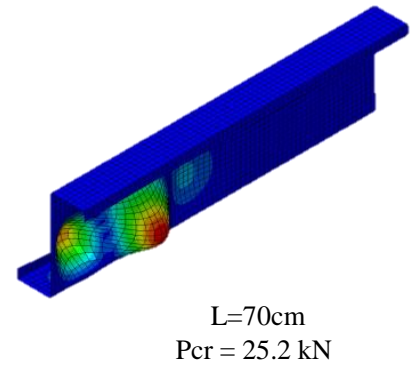

(b)

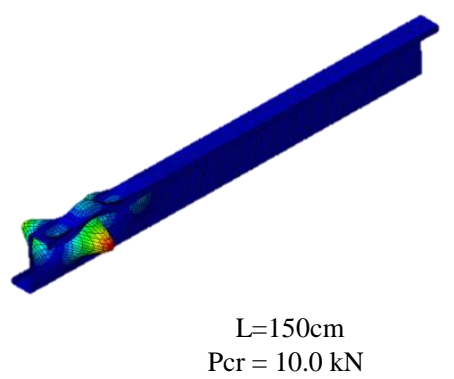

(c)

Figura 4.69 - Carregamentos críticos obtidos com o ABAQUS para o primeiro modo dos comprimentos de barra (a) $\mathrm{L}=15 \mathrm{~cm}$, (b) $\mathrm{L}=70 \mathrm{~cm}$ e (d) $\mathrm{L}=150 \mathrm{~cm}$.

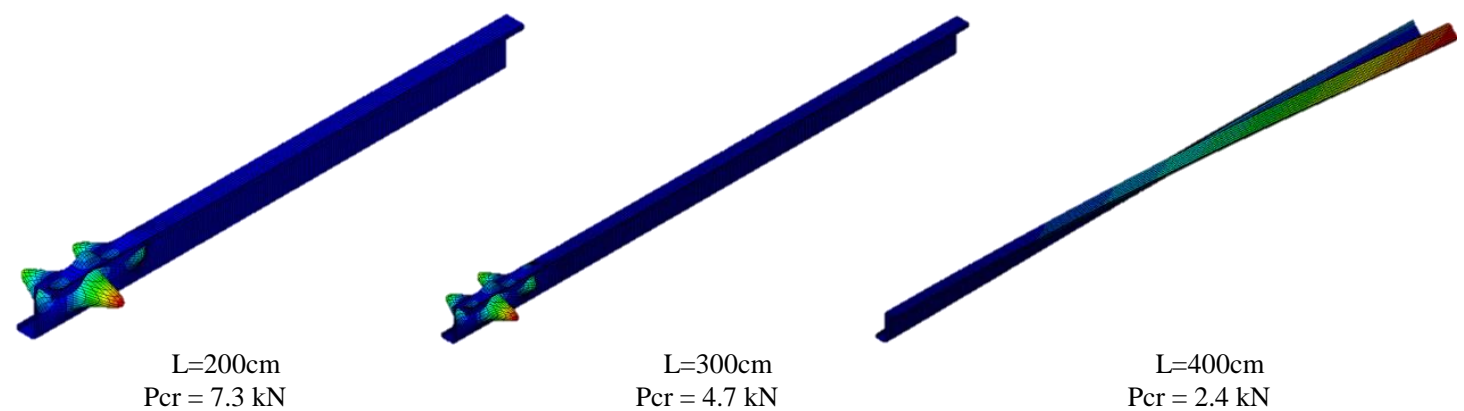

(a)

(b)

(c)

Figura 4.70 - Carregamentos críticos obtidos com o ABAQUS para o primeiro modo dos comprimentos de barra (a) $\mathrm{L}=200 \mathrm{~cm}$, (b) $\mathrm{L}=300 \mathrm{~cm}$ e (d) $\mathrm{L}=400 \mathrm{~cm}$.

Os casos para comprimentos de $15 \mathrm{~cm}, 70 \mathrm{~cm}, 150 \mathrm{~cm}, 200 \mathrm{~cm}$ e $300 \mathrm{~cm}$ tratam de modos locais, seja no enrijecedor da borda comprimida, seja na alma do perfil. Para esses casos, mais uma vez, os resultados obtidos com o GBTUL (MEF-GBT) apresentam grande discrepância.

A Figura 4.71 apresenta os modos superiores obtidos com o ABAQUs que são compatíveis com os modos que o GBTUL captura como sendo o primeiro modo de instabilidade para as barras de $70 \mathrm{~cm}, 150 \mathrm{~cm}, 200 \mathrm{~cm}$ e $300 \mathrm{~cm}$ de comprimento.

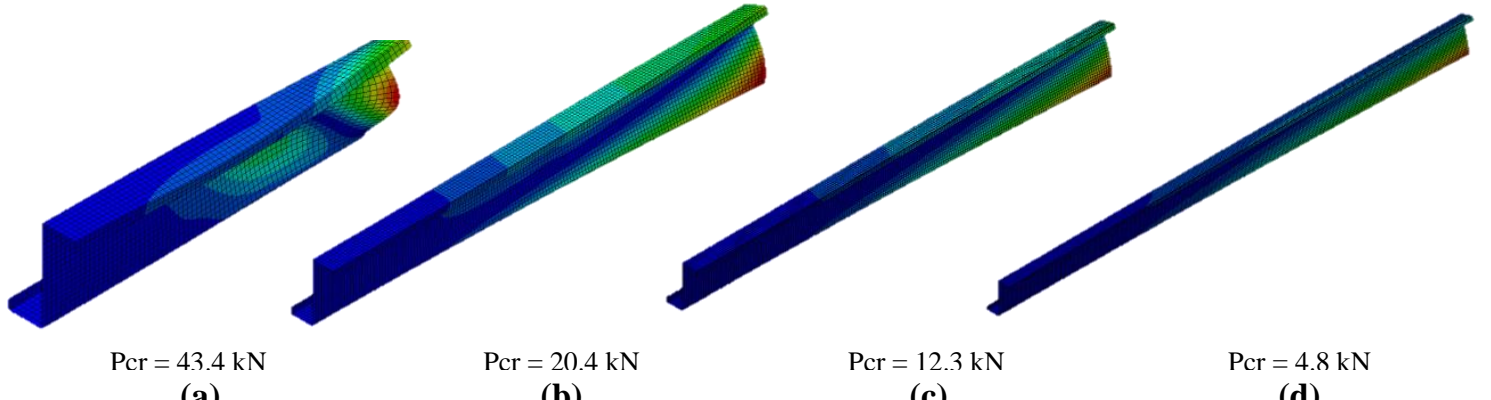

(a)

(b)

(c)

(d)

Figura 4.71 - Carregamentos críticos obtidos com o ABAQUS para o (a) décimo quarto modo para $\mathrm{L}=70 \mathrm{~cm}$, (b) vigésimo nono modo para $\mathrm{L}=150 \mathrm{~cm}$, (c) vigésimo quinta modo para $\mathrm{L}=200 \mathrm{~cm}$ e (d) sexto modo para $\mathrm{L}=300 \mathrm{~cm}$.

Para o perfil de $400 \mathrm{~cm}$, o GBTUL e o ABAQUS apresentaram modos globais de flexotorção com o mesmo carregamento crítico, uma vez que o carregamento está aplicado em ambos os casos no centro de torção. 


\subsubsection{Resumo dos resultados}

Os resultados obtidos com o ABAQUS, e apresentados anteriormente, são comparados com os resultados obtidos com o GBTUL graficamente na Figura 4.72 para os perfis $U$ enrijecidos e na Figura 4.73 para os $\mathrm{Z}$ enrijecidos. As curvas abaixo representam os carregamentos críticos mínimos (i.e. o menor dos autovalores) obtidos para cada método em análise, em função do comprimento da barra.

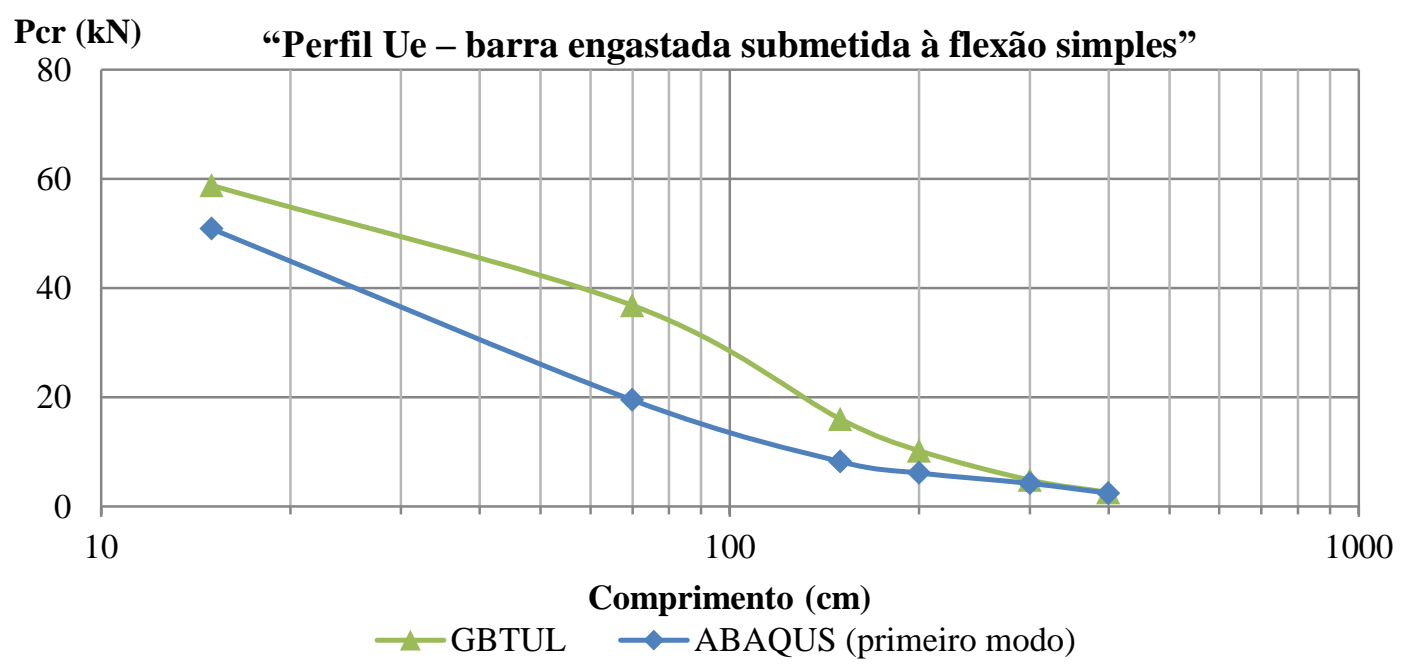

Figura 4.72 - Curvas dos carregamentos críticos em função dos comprimentos da barra para a seção transversal Ue, para as análises (i) via GBTUL e (ii) via ABAQUS.

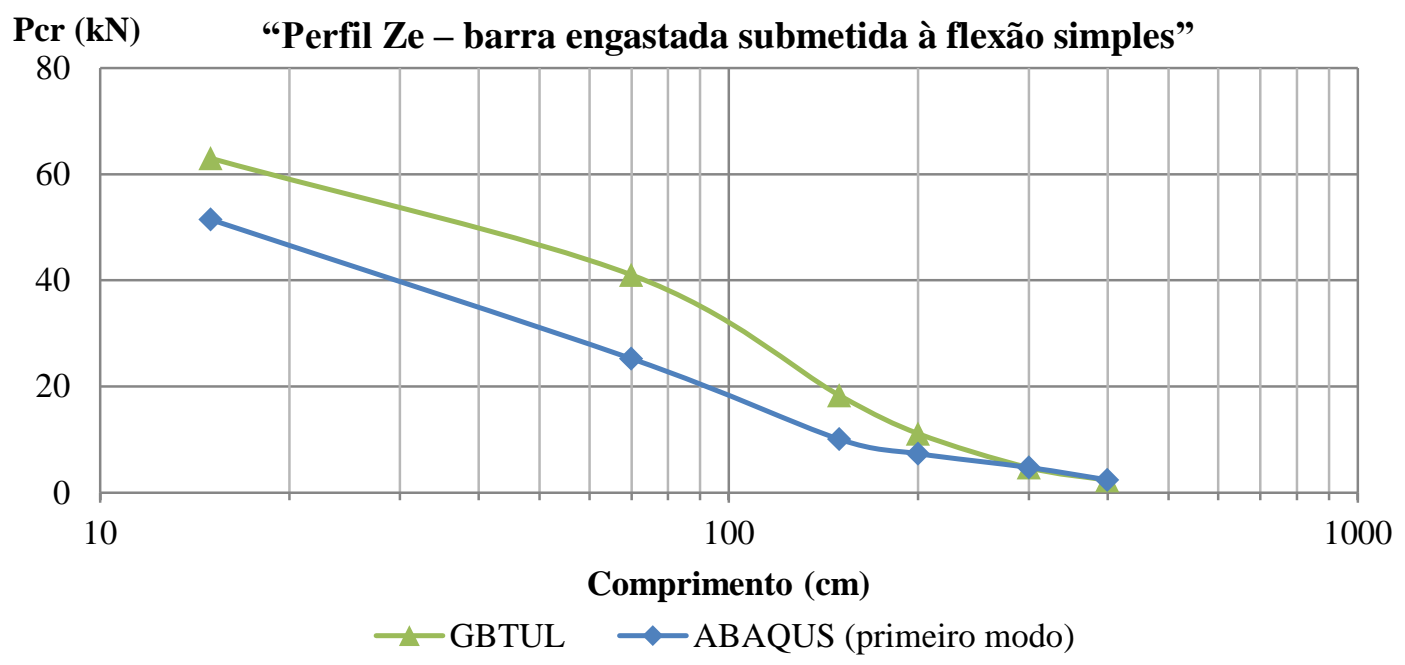

Figura 4.73 - Curvas dos carregamentos críticos em função dos comprimentos da barra para a seção transversal Ze, para as análises (i) via GBTUL e (ii) via ABAQUS.. 


\section{Capítulo 5}

\section{CONCLUSÕES}

Este trabalho ateve-se à instabilidade estática de perfis formados a frio e, dentro dessa, à instabilidade bifurcacional, também denominada de flambagem segundo definição concedida por Zagottis (1980). Foram realizadas análises lineares de estabilidade, ou análises de flambagem, que na literatura de língua inglesa são denominadas como linear buckling analysis.

Nesse contexto, avaliaram-se três métodos numéricos de análise aplicados a perfis de chapas dobradas de seção transversal U enrijecido e Z enrijecido, para barras isoladas de diversos comprimentos longitudinais, com empenamento livre, distorção restringida nas extremidades e nas condições de carregamento e vinculação (i) biarticulada submetida à compressão uniforme, (ii) biarticulada submetida à flexão pura, (iii) biarticulada submetida à flexão simples e (iv) engastada submetida à flexão simples.

\section{- SOBRE OS MÉTODOS NUMÉRICOS - VANTAGENS E DESVANTAGENS}

A análise com o Método das Faixas Finitas, apesar de ser uma alternativa de baixo custo computacional e gratuita, revela algumas limitações: (i) as seções transversais devem ser obrigatoriamente prismáticas; (ii) o método só permite barras isoladas; (iii) não há restrição ao empenamento; e (iv) como há somente nós nas seções das extremidades, o carregamento deve ser obrigatoriamente uniforme ao longo da barra, sendo essa última a mais severa das limitações tratando-se de perfis de aço formados a frio. 
A análise com a Teoria Generalizada de Vigas, por meio de elementos finitos de barra, inclui uma abordagem mais geral do que o MFF, embora também seja limitada a barras isoladas e prismáticas.

A análise com o Método dos Elementos Finitos utilizando elementos de casca, apesar de poder ser mais representativa das reais condições do problema, requer a imposição criteriosa das condições de contorno e dos carregamentos nas seções extremas. No caso da análise de estabilidade de perfis formados a frio, a incorreta modelagem desses aspectos pode acarretar em modos e carregamentos críticos completamente falseados. Por outro lado, o modelo de cascas permite simular condições de vinculação e carregamento muito mais próximas da realidade do que os modelos de barra. Por exemplo, para as barras biarticuladas, as condições de vinculação impostas simularam apoio simples com empenamento livre, lembrando-se que se optou por restringir a distorção nas extremidades, de forma a possibilitar a comparação dos resultados do ABAQUS com o uso dos outros programas. Liberar a distorção nas seções extremas implica, em alguns casos, carregamentos críticos menores. Desde que se tratem esses aspectos adequadamente, a análise com o MEF-cascas será sempre superior aos outros métodos, uma vez que o modelo representa mais fielmente o problema físico.

\section{- ANÁliSE COMPARATIVA DOS PROGRAMAS COMPUTACIONAIS}

O resultado das análises realizadas nos programas CUFSM-SC (utilizando a opção "signature curve") e GBTUL, é apresentado em forma de curvas que caracterizam o carregamento crítico em função do comprimento longitudinal do perfil. Essa forma de apresentação dos resultados gera uma visão geral do caso em estudo, porém possibilita uma má intepretação dos resultados quando o usuário não está familiarizado com a teoria da estabilidade de chapa e não se atenta ao número máximo de semiondas que o programa considera na análise.

Observou-se que, em determinadas situações, o CUFSM utilizando o "signature curve" não é capaz de fornecer os menores valores possíveis de carregamento crítico para os modos de instabilidade local (MLC e MD). Para esses casos, o primeiro modo de instabilidade fornecido pelo CUFSM-SC corresponde normalmente a um modo superior aos apresentados pelo GBTUL e o ABAQUS. Isto pode ser explicado pelo fato de as funções de forma para a solução "signature curve", considerarem apenas uma semionda "m" ao longo do comprimento longitudinal, de modo que o MD ou modos 
globais resultem em autovalores inferiores ao MLC fixado em apenas uma semionda. Esse problema pode ser contornado utilizando-se a solução do tipo "general boundary condition", disponível nas versões mais recentes do programa. A solução "signature curve" só deve ser utilizada quando há interesse em determinar os modos distorcionais ou modos globais (independentemente de eles corresponderem a modos superiores de instabilidade ou não). Quando for necessária a determinação dos carregamentos críticos mínimos, i.e. o menor valor de fator de carregamento seja por modos locais ou modos globais, deve-se utilizar sempre a opção "general boundary condition”, uma vez que o CUFSM-GBC não fixa o número de semiondas e não apresenta o resultado em forma de curvas.

O GBTUL oferece resultados satisfatórios para os casos de barras biarticuladas com carregamento uniforme ao longo do comprimento. Para barras com outras condições de vínculo e outros tipos de carregamento, como no caso da flexão simples, nem sempre os resultados são satisfatórios. Como visto em algumas situações, o GBTUL forneceu carregamentos críticos superiores aos apresentados pelo ABAQUS. Isso se deve, em parte, ao fato de o GBTUL trabalhar com modos de deformação da seção prédefinidos pelo programa. Esses, por sua vez, representam boa parte dos possíveis modos que podem se manifestar durante a instabilidade, porém não esgotam as possibilidades.

Embora o CUFSM e o GBTUL sejam ferramentas atrativas por serem gratuitas e de interface simples, deve-se utilizá-las com critério e cautela, para que a má interpretação dos resultados não influencie na determinação correta do carregamento crítico mínimo.

O ABAQUS se mostrou uma ferramenta muito poderosa e confiável, por apresentar de maneira clara e confiável tanto os carregamentos críticos mínimos e seus respectivos modos, quanto os carregamentos e modos superiores. Em relação ao grau de discretização da seção transversal, a análise com o MEF-cascas revelou-se a única que apresenta alguma sensibilidade, embora não significativa. De qualquer forma, aconselha-se o uso de malhas refinadas para a correta determinação dos autovalores e autovetores.

\section{- SUGESTÕES PARA TRABALHOS FUTUROS}

Como continuidade deste trabalho, citam-se duas sugestões para trabalhos futuros: (i) comparar os carregamentos críticos de bifurcação e os respectivos modos de flambagem obtidos nesse trabalho com a configuração pós-crítica e os respectivos 
carregamentos críticos obtidos através de análises não lineares, considerando o comportamento elastoplástico e o efeito das imperfeições geométricas e (ii) estudar a abordagem de diferentes procedimentos normativos a fim de relacionar os carregamentos críticos bifurcacionais com as expressões dos esforços resistentes últimos recomendados pelas normas. 


\section{LISTA DE SÍMBOLOS}

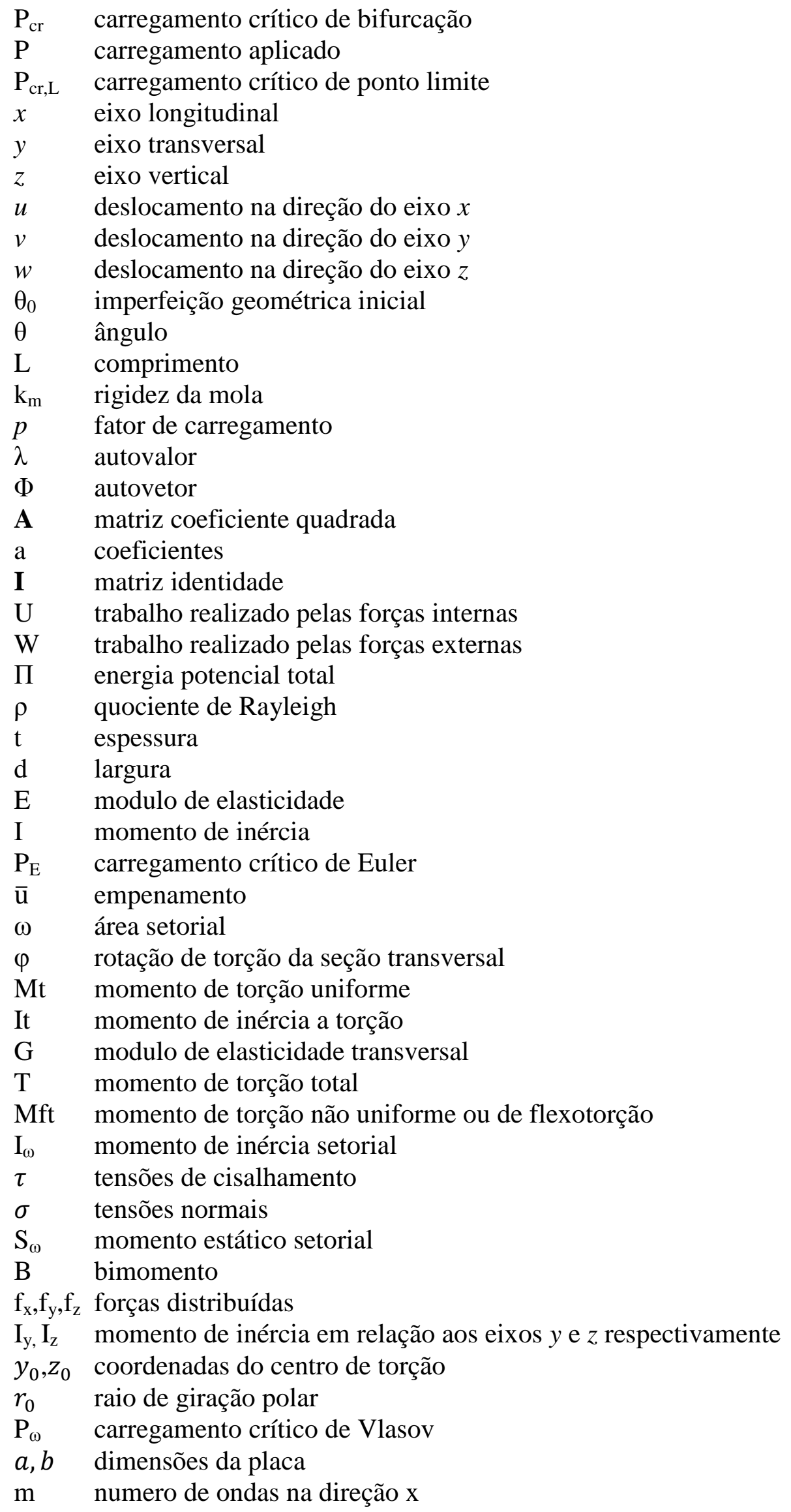


n numero de ondas na direção y

D rigidez a flexão da placa

$v \quad$ coeficiente de Poisson

$\mathbf{K}_{\mathbf{e}} \quad$ matriz de rigidez elástica

$\mathbf{K}_{\mathbf{g}} \quad$ matriz de rigidez geométrica

$\mathbf{K}_{\mathbf{t}} \quad$ matriz de rigidez tangente

$\sigma_{c r}$ tensão crítica

u campo dos deslocamentos

d vetor dos deslocamentos nodais

$\boldsymbol{\varepsilon} \quad$ vetor das deformações

$\Lambda$ matriz diagonal 


\section{LISTA DE FIGURAS}

Figura 1.1 - Contextualização da instabilidade de perfis formados a frio.

Figura 1.2 -Modos de instabilidade classificados em:(a) modo global por flexão, (b) modo global por flexotorção, (c) modo global por torção, (d) modo local de chapa e (e) modo distorcional.

Figura 1.1 - Condições de vinculação e carregamento: (a) barra biarticulada submetida a compressão uniforme, (b) barra biarticulada submetida a flexão pura, (c) barra biarticulada submetida a carregamento distribuído e (d) barra engastada submetida a flexão simples. 16

Figura 1.3 - Apresentação esquemática do (a) MFF, (b) MEF-GBT e (c) MEF-cascas 17

Figura 2.1 - Estados de equilíbrio (a) estável, (b) indiferente ou neutro e (c) instável.. 20

Figura 2.2 -Instabilidade bifurcacional de uma barra comprimida. Adaptado de (Gambhir, 2004).

Figura 2.3 -Instabilidade por Ponto Limite. Adaptado de (Reis, et al., 2012).

Figura 2.4 - Instabilidade bifurcacional do tipo (a) simétrica estável, (b) simétrica instável e (c) assimétrica de sistemas perfeitos e imperfeitos; identificação de pontos de

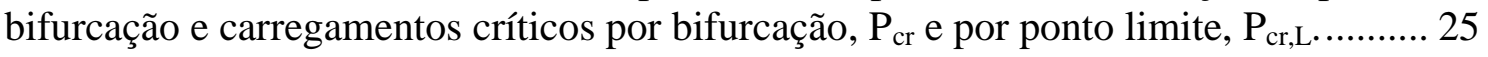

Figura 2.5 - Barras biarticuladas sob compressão.

Figura 2.6 - Razão de carregamento, $p$, versus rotação $\theta$. Adaptado de (Farshad, 1994).

Figura 2.7 - Variação da energia potencial total, П. Adaptado (Gambhir, 2004). 31

Figura 2.8 - Deflexão de uma barra comprimida simplesmente apoiada de comprimento L e produto de rigidez à flexão EI constante.

Figura 2.9 - Modos de instabilidade globais (a) por flexão, e (b) por flexotorção 34

Figura 2.10 - Carregamentos críticos e modos de instabilidade ( $\mathrm{n}=1,2$ e 3$)$ para barras comprimidas simplesmente apoiadas. Adaptado de (Galambos, et al., 2008).

Figura 2.11 - Casos fundamentais de barras comprimidas (Galambos, et al., 2008)..... 38

Figura 2.12 - Empenamento e rotação $\varphi$ da barra submetida ao momento de torção $\mathrm{T}$ e momento de torção distribuído m. Adaptado de (Mori, et al., 2009).

Figura 2.13 - (a) barra deformada e localização do centro de torção CT, (b) tensões de cisalhamento devido ao momento de torção uniforme $\mathrm{M}_{\mathrm{t}}$ e (c) tensões normais e de cisalhamento devido ao momento de flexotorção $\mathrm{M}_{\mathrm{ft}}$. Adaptado de (Fruchtengarten, 2003)

Figura 2.14 - Barra comprimida simplesmente apoiada. 
Figura 2.15 - Elementos estruturais bidimensionais (a) chapas (b) placas e (c) cascas. 44

Figura 2.16 - Chapa retangular simplesmente apoiada. 46

Figura 2.17 - Chapa retangular simplesmente apoiada sob compressão em uma direção (Timoshenko, et al., 1961). 50

Figura 2.18 - Tensões críticas em $\mathrm{MPa}$ e modos de instabilidade para (a) a=100cm, $\mathrm{m}=1$ e $\mathrm{n}=1$; (b) $\mathrm{a}=150 \mathrm{~cm}, \mathrm{~m}=2$ e $\mathrm{n}=1$; (c) $\mathrm{a}=300 \mathrm{~cm}, \mathrm{~m}=3$ e $\mathrm{n}=1$; (d) $\mathrm{a}=500 \mathrm{~cm}, \mathrm{~m}=5$ e $\mathrm{n}=1$.

Figura 3.1 - MFF utilizado no programa CUFSM. (a) Discretização do perfil (b) deslocamentos nodais de membrana (c) deslocamentos nodais de flexão e distribuição do carregamento longitudinal numa faixa Adaptado (Mezzomo, 2012)...................... 55

Figura 3.2 - Interface do CUFSM 4.03 para a condição "signature curve". 59

Figura 3.2 - Eixos locais e deslocamentos referenciados. Adaptado (Bebiano, et al., 2008).

Figura 3.3 - Modos de deformação no plano da seção transversal (Bebiano, et al., 2008). 61

Figura 3.4 - Pontos de integração dos elementos finitos de (a) integração reduzida: S4R e (b) integração completa: S4. Adaptado de (ABAQUS, 2010). 64

Figura 3.6 - Exemplo de malha de elementos finitos para o perfil U enrijecido de comprimento L. 65

Figura 4.1 - Condições de vinculação e carregamento: (a) barra biarticulada submetida a compressão uniforme, (b) barra biarticulada submetida a flexão pura, (c) barra biarticulada submetida a carregamento distribuído e (d) barra engastada submetida a flexão simples.

Figura 4.2 - Seção Ue200x75x20x2 e discretização da seção transversal (a) dimensões nominais em mm, (b) malha tipo 1, (c) malha tipo 2 e (d) malha tipo 3.

Figura 4.3 - Seção Ze200x75x20x2 e discretização da seção transversal (a) dimensões nominais em mm, (b) malha tipo 1, (c) malha tipo 2 e (d) malha tipo 3.

Figura 4.4 - (a) Ligação viga-pilar com tala simples de alma e (b) modelo estrutural para perfil Ue.

Figura 4.5 - Modelo estrutural do perfil Ue para (a) CUFSM, (b) GBTUL e (c) ABAQUS.

Figura 4.6 - Modelo estrutural do perfil Ze para (a) CUFSM, (b) GBTUL e (c) ABAQUS.

Figura 4.7 - Características geométricas da seção transversal U enrijecido. 70

Figura 4.8 - Características geométricas da seção transversal Z enrijecido. 70 
Figura 4.9 - Determinação da curva do fator de carregamento, $p$, em função do comprimento do perfil em mm, com o CUFSM-SC.

Figura 4.10 - Modos de instabilidade obtidos com o CUFSM-SC para a discretização tipo 1 da seção transversal para comprimento de (a) $15 \mathrm{~cm}$, (b) $70 \mathrm{~cm}$, (c) $150 \mathrm{~cm}$, (d) $200 \mathrm{~cm}$, (e) $300 \mathrm{~cm}$ e (f) $400 \mathrm{~cm}$.

Figura 4.11 - Modo de instabilidade local de chapa obtido via CUFSM-GBC, para comprimentos de (a) $70 \mathrm{~cm}$, (b) $150 \mathrm{~cm}$, (c) $200 \mathrm{~cm} \mathrm{e} \mathrm{(d)} 300 \mathrm{~cm}$.

Figura 4.12 - Determinação da curva carregamento crítico, Pcr $(\mathrm{kN})$ em função do comprimento $(\mathrm{cm})$ com o GBTUL.

Figura 4.13 - Seção transversal no meio do vão obtida com o GBTUL para os modos de instabilidade de comprimento igual a: (a) $15 \mathrm{~cm}$, (b) $70 \mathrm{~cm}$, (c) $150 \mathrm{~cm}$, (d) $200 \mathrm{~cm}$, (d) $300 \mathrm{~cm}$ e (f) $400 \mathrm{~cm}$.

Figura 4.14 - Determinação da curva comprimento $(\mathrm{cm})$ vs. carga crítica, Pcr $(\mathrm{kN}) \ldots . .74$

Figura 4.15 - Modos de instabilidade obtidos com o ABAQUS para a discretização tipo 3 da seção transversal para comprimento de (a) $15 \mathrm{~cm}$, (b) $70 \mathrm{~cm}$ e (c) $150 \mathrm{~cm}$ 75

Figura 4.16 - Modos de instabilidade obtidos com o ABAQUS para a discretização tipo 3 da seção transversal para comprimento de (a) $200 \mathrm{~cm}$, (b) $300 \mathrm{~cm}$ e (c) $400 \mathrm{~cm}$....... 75

Figura 4.17 - Primeiro dos modos de instabilidade distorcional, MD: (a) vigésimo modo de instabilidade para $\mathrm{L}=70 \mathrm{~cm}$ e (b) trigésimo primeiro modo de instabilidade para $\mathrm{L}=150 \mathrm{~cm}$ 76

Figura 4.18 - Carregamentos críticos e modos de instabilidade para $\mathrm{L}=200 \mathrm{~cm}$, considerando até: (a) uma semionda longitudinal e (b) dez semiondas longitudinais ... 76

Figura 4.19 - Modo global de flexotorção, MGFT para L= $300 \mathrm{~cm}$ : vigésimo segundo modo de instabilidade.

Figura 4.20 - Determinação da curva do fator de carregamento, $p$, em função do comprimento do perfil em mm, com o CUFSM-SC. 78

Figura 4.21 - Modos de instabilidade obtidos com o CUFSM-SC para a discretização tipo 3 da seção transversal para comprimento de (a) $15 \mathrm{~cm}$, (b) $70 \mathrm{~cm}$, (c) $150 \mathrm{~cm}$, (d) $200 \mathrm{~cm}$, (e) $300 \mathrm{~cm}$ e (f) $400 \mathrm{~cm}$.

Figura 4.22 - Modo de instabilidade local de chapa obtido via CUSFM-GBC, para comprimentos de (a) $70 \mathrm{~cm}$, (b) $150 \mathrm{~cm}$, (c) $200 \mathrm{~cm} \mathrm{e} \mathrm{(d)} 300 \mathrm{~cm}$.

Figura 4.23 - Determinação da curva carregamento crítico, Pcr $(\mathrm{kN})$ em função do comprimento $(\mathrm{cm})$ com o GBTUL. 80

Figura 4.24 - Seção transversal no meio do vão obtida com o GBTUL para os modos de instabilidade de comprimento igual a: (a) $15 \mathrm{~cm}$, (b) $70 \mathrm{~cm}$, (c) $150 \mathrm{~cm}$, (d) $200 \mathrm{~cm}$, (d) $300 \mathrm{~cm}$ e (f) $400 \mathrm{~cm}$. 
Figura 4.25 - Modos de instabilidade obtidos com o ABAQUS para a discretização tipo 3 da seção transversal para comprimento de (a) $15 \mathrm{~cm}$, (b) $70 \mathrm{~cm}$ e (c) $150 \mathrm{~cm}$ 81

Figura 4.26 - Modos de instabilidade obtidos com o ABAQUS para a discretização tipo 3 da seção transversal para comprimento de (a) $200 \mathrm{~cm}$, (b) $300 \mathrm{~cm}$ e (c) $400 \mathrm{~cm}$....... 81

Figura 4.27 - Curvas dos carregamentos críticos em função dos comprimentos da barra para a seção transversal Ue , para as análises via (i) CUFSM-SC, (ii) CUFSM-GBC, (iii) GBTUL, considerando $m \geq 20$ e (iv) ABAQUS, considerando apenas o primeiro modo.

Figura 4.28 - Curvas dos carregamentos críticos em função dos comprimentos da barra para a seção transversal Ze , para as análises via (i) CUFSM-SC, (ii) CUFSM-GBC, (iii) GBTUL, considerando $m \geq 20$ e (iv) ABAQUS, considerando apenas o primeiros modo.

Figura 4.29 - Modelo estrutural do perfil Ue para (a) CUFSM, (b) GBTUL e (c) ABAQUS.

Figura 4.30 - Modelo estrutural do perfil Ze para (a) CUFSM, (b) GBTUL e (c) ABAQUS.

Figura 4.31 - Determinação da curva do fator de carregamento, $p$, em função do comprimento do perfil em mm, com o CUFSM-SC.

Figura 4.32 - Carregamentos críticos e modos de instabilidade obtidos com o CUFSMSC (seção transversal no meio do vão) para L igual a: (a) $15 \mathrm{~cm}$, (b) $70 \mathrm{~cm}$, (c) $150 \mathrm{~cm}$, (d) $200 \mathrm{~cm}$, (d) $300 \mathrm{~cm}$ e (f) $400 \mathrm{~cm}$. 85

Figura 4.33 - Carregamento crítico e modo de instabilidade obtido via CUFSM-GBC, para comprimentos de (a) $150 \mathrm{~cm}$ e (b) $200 \mathrm{~cm}$. 86

Figura 4.34 - Determinação da curva carregamento crítico, $\operatorname{Pcr}(\mathrm{kN})$ em função do comprimento $(\mathrm{cm})$ com o GBTUL. 86

Figura 4.35 - Carregamentos críticos e modos de instabilidade obtidos com o GBTUL para L igual a: (a) $15 \mathrm{~cm}$ - seção a 0,5L, (b) $70 \mathrm{~cm}$ - seção a 0,5L, (c) $150 \mathrm{~cm}$ - seção a 0,25L, 0,5L e $0,75 \mathrm{~L}$, (d) $200 \mathrm{~cm}$ - seção a 0,25L, 0,5L e 0,75L, (d) $300 \mathrm{~cm}$ - seção a $0,5 \mathrm{~L}$ e (f) $400 \mathrm{~cm}-$ seção a $0,5 \mathrm{~L}$. 87

Figura 4.36 - Carregamentos críticos obtidos com o ABAQUS para o primeiro modo dos comprimentos de barra (a) $\mathrm{L}=15 \mathrm{~cm}$, (b) $\mathrm{L}=70 \mathrm{~cm}$ e (d) $\mathrm{L}=150 \mathrm{~cm}$. 87

Figura 4.37 - Carregamentos críticos obtidos com o ABAQUS para o primeiro modo dos comprimentos de barra (a) $\mathrm{L}=200 \mathrm{~cm}$, (b) $\mathrm{L}=300 \mathrm{~cm}$ e (d) $\mathrm{L}=400 \mathrm{~cm}$. 87

Figura 4.38 - Carregamentos críticos obtidos com o ABAQUS (a) sexagésimo sexto modo para $\mathrm{L}=150 \mathrm{~cm}$ e (b) quinto modo para $\mathrm{L}=200 \mathrm{~cm}$. 88

Figura 4.39 - Determinação da curva do fator de carregamento, $p$, em função do comprimento do perfil em mm, com o CUFSM-SC. 
Figura 4.40 - Carregamentos críticos e modos de instabilidade obtidos com o CUFSMSC (seção transversal no meio do vão) para L igual a: (a) $15 \mathrm{~cm}$, (b) $70 \mathrm{~cm}$, (c) $150 \mathrm{~cm}$, (d) $200 \mathrm{~cm}$, (d) $300 \mathrm{~cm}$ e (f) $400 \mathrm{~cm}$.

Figura 4.41 - Carregamento crítico e modo de instabilidade obtido via CUSFM-GBC para comprimentos de (a) $15 \mathrm{~cm}$, (b) $150 \mathrm{~cm}$ e (c) $200 \mathrm{~cm}$.

Figura 4.42 - Determinação da curva carregamento crítico, Mcr $(\mathrm{kN} . \mathrm{cm})$ em função do comprimento $(\mathrm{cm})$ com o GBTUL.

Figura 4.43 - Carregamentos críticos e modos de instabilidade obtidos com o GBTUL para L igual a: (a) $15 \mathrm{~cm}$ - seção a $0,5 \mathrm{~L}$, (b) $70 \mathrm{~cm}$ - seção a $0,5 \mathrm{~L}$, (c) $150 \mathrm{~cm}$ - seção a 0,25L, 0,5L e $0,75 \mathrm{~L}$, (d) $200 \mathrm{~cm}$ - seção a 0,25L, 0,5L e 0,75L, (d) $300 \mathrm{~cm}$ - seção a $0,5 \mathrm{~L}$ e (f) $400 \mathrm{~cm}-$ seção a $0,5 \mathrm{~L}$ 90

Figura 4.44 - Carregamentos críticos obtidos com o ABAQUS para o primeiro modo dos comprimentos de barra (a) $\mathrm{L}=15 \mathrm{~cm}$, (b) $\mathrm{L}=70 \mathrm{~cm}$ e (d) $\mathrm{L}=150 \mathrm{~cm}$. 91

Figura 4.45 - Carregamentos críticos obtidos com o ABAQUS para o primeiro modo dos comprimentos de barra (a) $\mathrm{L}=200 \mathrm{~cm}$, (b) $\mathrm{L}=300 \mathrm{~cm}$ e (d) $\mathrm{L}=400 \mathrm{~cm}$. 91

Figura 4.46 - Carregamentos críticos obtidos com o ABAQUS (a) sexagésimo sexto modo para $L=150 \mathrm{~cm}$ e (b) sexto modo para $L=200 \mathrm{~cm}$.

Figura 4.47 - Curvas dos carregamentos críticos em função dos comprimentos da barra para a seção transversal Ue, para as análises via (i) CUFSM-SC, (ii) CUFSM-GBC, (iii) GBTUL, considerando $m \geq 50$ e (iv) ABAQUS, considerando apenas os primeiros modos. 92

Figura 4.48 - Curvas dos carregamentos críticos em função dos comprimentos da barra para a seção transversal Ze, para as análises via (i) CUFSM-SC, (ii) CUFSM-GBC, (iii) GBTUL, considerando $\mathrm{m} \geq 20$ e (iv) ABAQUS, considerando apenas os primeiros modos.

Figura 4.49 - Barra isolada de comprimento L, biarticulada e submetida a carregamento distribuído, (a) esquema estrutural no GBTUL; (b) esquema estrutural no ABAQUS para seção Ue e (c) esquema estrutural no ABAQUS para seção Ze.

Figura 4.50 - Determinação da curva comprimento $(\mathrm{cm})$ vs. carga crítica, qcr $(\mathrm{kN} / \mathrm{cm})$.

Figura 4.51 - Carregamentos críticos e modos de instabilidade obtidos com o GBTUL para L igual a: (a) $15 \mathrm{~cm}$ - seção a $0,5 \mathrm{~L}$, (b) $70 \mathrm{~cm}$ - seção a $0,25 \mathrm{~L}, 0,5 \mathrm{~L}$ e $0,75 \mathrm{~L}$, (c) $150 \mathrm{~cm}$ - seção a $0,25 \mathrm{~L}, 0,5 \mathrm{~L}$ e $0,75 \mathrm{~L}$, (d) $200 \mathrm{~cm}$ - seção a $0,25 \mathrm{~L}, 0,5 \mathrm{~L}$ e $0,75 \mathrm{~L}$, (d) $300 \mathrm{~cm}$ - seção a $0,5 \mathrm{~L}$ e (f) $400 \mathrm{~cm}$ - seção a $0,5 \mathrm{~L}$.

Figura 4.52 - Carregamentos críticos obtidos com o ABAQUS para o primeiro modo dos comprimentos de barra (a) $\mathrm{L}=15 \mathrm{~cm}$, (b) $\mathrm{L}=70 \mathrm{~cm}$ e (d) $\mathrm{L}=150 \mathrm{~cm}$.

Figura 4.53 - Carregamentos críticos obtidos com o ABAQUS para o primeiro modo dos comprimentos de barra (a) $\mathrm{L}=200 \mathrm{~cm}$, (b) $\mathrm{L}=300 \mathrm{~cm}$ e (d) $\mathrm{L}=400 \mathrm{~cm}$. 95 
Figura 4.54 - Determinação da curva comprimento $(\mathrm{cm})$ vs. carga crítica, qcr $(\mathrm{kN} / \mathrm{cm})$.

Figura 4.55 - Carregamentos críticos e modos de instabilidade obtidos com o GBTUL (seção transversal na extremidade carregada) para L igual a: (a) $15 \mathrm{~cm}$ - seção a $0,5 \mathrm{~L}$, (b) $70 \mathrm{~cm}$ - seção a $0,25 \mathrm{~L}, 0,5 \mathrm{~L}$ e $0,75 \mathrm{~L}$, (c) $150 \mathrm{~cm}$ - seção a $0,25 \mathrm{~L}, 0,5 \mathrm{~L}$ e $0,75 \mathrm{~L}$, (d) $200 \mathrm{~cm}$ - seção a $0,25 \mathrm{~L}, 0,5 \mathrm{~L}$ e $0,75 \mathrm{~L}$, (d) $300 \mathrm{~cm}$ - seção a 0,5L e (f) $400 \mathrm{~cm}$ - seção a $0,5 \mathrm{~L}$

Figura 4.56 - Carregamentos críticos obtidos com o ABAQUS para o primeiro modo dos comprimentos de barra (a) $\mathrm{L}=15 \mathrm{~cm}$, (b) $\mathrm{L}=70 \mathrm{~cm}$ e (d) $\mathrm{L}=150 \mathrm{~cm}$. 97

Figura 4.57 - Carregamentos críticos obtidos com o ABAQUS para o primeiro modo dos comprimentos de barra (a) $\mathrm{L}=200 \mathrm{~cm}$, (b) $\mathrm{L}=300 \mathrm{~cm}$ e (d) $\mathrm{L}=400 \mathrm{~cm}$.

Figura 4.58 - Curvas dos carregamentos críticos em função dos comprimentos da barra para a seção transversal Ue, para as análises (i) via GBTUL e (ii) via ABAQUS......... 98

Figura 4.59 - Curvas dos carregamentos críticos em função dos comprimentos da barra para a seção transversal Ze, para as análises (i) via GBTUL e (ii) via ABAQUS. ........ 98

Figura 4.60 - Barra isolada de comprimento L, engastada e submetida ao carregamento P, (a) esquema estrutural no GBTUL; (b) esquema estrutural no ABAQUS para seção Ue e (c) esquema estrutural no ABAQUS para seção Ze. 99

Figura 4.61 - Determinação da curva comprimento (cm) vs. carga crítica, Pcr $(\mathrm{kN})$.. 100

Figura 4.62 - Carregamentos críticos e modos de instabilidade obtidos com o GBTUL (seção transversal na extremidade carregada) para L igual a: (a) $15 \mathrm{~cm}$ - meio do vão, (b) $70 \mathrm{~cm}$ - extremidade carregada, (c) $150 \mathrm{~cm}$, (d) $200 \mathrm{~cm}$, (d) $300 \mathrm{~cm}$ e (f) $400 \mathrm{~cm} .100$

Figura 4.63 - Carregamentos críticos obtidos com o ABAQUS para o primeiro modo dos comprimentos de barra (a) $\mathrm{L}=15 \mathrm{~cm}$, (b) $\mathrm{L}=70 \mathrm{~cm}$ e (d) $\mathrm{L}=150 \mathrm{~cm}$. 100

Figura 4.64 - Carregamentos críticos obtidos com o ABAQUS para o primeiro modo dos comprimentos de barra (a) $\mathrm{L}=200 \mathrm{~cm}$, (b) $\mathrm{L}=300 \mathrm{~cm}$ e (d) $\mathrm{L}=400 \mathrm{~cm}$. 100

Figura 4.65 - Carregamentos críticos obtidos com o ABAQUS para o (a) quinto modo para $\mathrm{L}=15 \mathrm{~cm}$, (b) décimo sétimo modo para $\mathrm{L}=70 \mathrm{~cm}$ e (d) trigésimo modo para $\mathrm{L}=150 \mathrm{~cm}$ 101

Figura 4.66 - Carregamentos críticos obtidos com o ABAQUS para o (a) vigésimo nono modo para $\mathrm{L}=200 \mathrm{~cm}$ e (b) nono modo para $\mathrm{L}=300 \mathrm{~cm}$. 101

Figura 4.67 - Determinação da curva comprimento $(\mathrm{cm})$ vs. carga crítica, Pcr $(\mathrm{kN}) . .102$

Figura 4.68 - Carregamentos críticos e modos de instabilidade obtidos com o GBTUL (seção transversal na extremidade carregada) para L igual a: (a) $15 \mathrm{~cm}$ - meio do vão, (b) $70 \mathrm{~cm}$ - extremidade carregada, (c) $150 \mathrm{~cm}$, (d) $200 \mathrm{~cm}$, (d) $300 \mathrm{~cm}$ e (f) $400 \mathrm{~cm} .102$

Figura 4.69 - Carregamentos críticos obtidos com o ABAQUS para o primeiro modo dos comprimentos de barra (a) $\mathrm{L}=15 \mathrm{~cm}$, (b) $\mathrm{L}=70 \mathrm{~cm}$ e (d) $\mathrm{L}=150 \mathrm{~cm}$. 103 
Figura 4.70 - Carregamentos críticos obtidos com o ABAQUS para o primeiro modo dos comprimentos de barra (a) $\mathrm{L}=200 \mathrm{~cm}$, (b) $\mathrm{L}=300 \mathrm{~cm}$ e (d) $\mathrm{L}=400 \mathrm{~cm}$.

Figura 4.71 - Carregamentos críticos obtidos com o ABAQUS para o (a) décimo quarto modo para $L=70 \mathrm{~cm}$, (b) vigésimo nono modo para $\mathrm{L}=150 \mathrm{~cm}$, (c) vigésimo quinta modo para $\mathrm{L}=200 \mathrm{~cm}$ e $(\mathrm{d})$ sexto modo para $\mathrm{L}=300 \mathrm{~cm}$. 103

Figura 4.72 - Curvas dos carregamentos críticos em função dos comprimentos da barra para a seção transversal Ue, para as análises (i) via GBTUL e (ii) via ABAQUS....... 104

Figura 4.73 - Curvas dos carregamentos críticos em função dos comprimentos da barra para a seção transversal Ze, para as análises (i) via GBTUL e (ii) via ABAQUS....... 104 


\section{REFERÊNCIAS}

ABAQUS. Abaqus 6.10 Documentation. Providence, RI, USA: Dassault Systèmes, 2010.

AMERICAN IRON STEEL INSTITUTE. North American specification for the design of cold-formed steel structural members. Washington DC: AISI, 2004.

ASSOCIAÇÃO BRASILEIRA DE NORMAS TECNICAS, A. NBR 14762: Dimensionamento de estruturas de aço constituídas por perfis formados a frio. Rio de Janeiro: ABNT, 2010.

BARRETA, C. E. A. S. Interacção entre instabilidade local-de-placa e distorcional em colunas de aço enformadas a frio de secção em $\mathbf{Z}$. Dissertação de Mestrado, Instituto Superior Tecnico, Universidade Tecnica de Lisboa, Lisboa, 2011.

BEBIANO, R. et al. GBTUL - Buckling and Vibration Analysis of Thin-Walled Members. 19th International Specialty Conference on Cold-Formed Steel Structures. October 14-5, St. Louis, Missouri, USA: DECivil/IST, Technical University of Lisbon. 2008. Disponível em: http://www.civil.ist.utl.pt/gbt.

CAMOTIM, D. et al. GBT - Based Analysis and design of thin-walled metal and FRP members: recent developments. Brasov, Romênia: APCMR, 2006.

CAMPELLO, E. M. B. Análise não-linear de peris metálicos conformados a frio. Dissertação de Mestrado, Departamento de Engenharia de Estruturas e Fundações da Escola Politécnica da Universidade de São Paulo, São Paulo, 2000.

CAMPELLO, E. M. B. Modelos não-lineares de casca em elasticidade e elastoplasticidade com grandes deformações: teoria e implementação em elementos finitos. Tese de Doutorado, Departamento de Engenharia de Estruturas e Fundações da Escola Politécnica da Universidade de São Paulo, São Paulo, 2005.

CAMPELLO, E. M. B.; PIMENTA, P. M. A fully nonlinear multi-parameter rod model incorporating general cross-sectional in-plane changes and out-of-plane warping. Latin American Journal of Solids and Structures. 1, n. 1, 2003. 118-140.

CAMPELLO, E. M. B.; PIMENTA, P. M.; WRIGGERS, P. A triangular finite shell element based on a fully nonlinear shell formulation. Computational Mechanics. v. 31, n. 6, p. 505-518, 2003.

CASTELANI, T. Otimização e dimensionamento de perfis formados a frio pelo Método da Resistência Direta. Dissertação de Mestrado, Universidade Federal do Rio Grande do Sul, Porto Alegre, 2012.

CHODRAUI, G. M. B. Flambagem por distorção da seção transversal em perfis de aço formados a frio submetidos à compressão centrada e à flexão. Dissertação de Mestrado, Escola de Engenharia de São Carlos da Universidade de São Paulo, São Carlos, 2003. 
CHODRAUI, G. M. B. Análise teórica e experimental de perfis de aço formados a frio submetidos à compressão. Tese de Doutorado, Escola de Engenharia de São Carlos da Universidade de São Paulo, São Carlos, 2006.

DAVIES, M.; LEACH, P. Some applications of generalized beam theory. Eleventh Internacional Specialty Conference on Cold-Formed Steel Structures. October 20-12, St. Louis, Missouri, USA: [s.n.]. October 20-12 1992.

FARSHAD, M. Stability of Structures. Dübendorf, Switzerland: Elsevier Science B. V., 1994.

FRUCHTENGARTEN, J. Sobre a Estabilidade de Perfis de Seção Aberta. Tese de Doutorado, Escola Politécnica da Universidade de São Paulo, São Paulo, 1995.

FRUCHTENGARTEN, J. Projeto de Estruturas Metálicas. Notas de Aula, Departamento de Engenharia de Estruturas e Fundações da Escola Politécnica da Universidade de São Paulo, São Paulo, 2003.

FRUCHTENGARTEN, J. Sobre o estudo da flambagem lateral de vigas de aço por meio da utilização de uma teoria não-linear geometricamnete exata. Dissertação de Mestrado, Escola Politécnica da Universidade de São Paulo, São Paulo, 2005.

GALAMBOS, T. V.; SUROVEK, A. E. Structural Stability of Steel: Concepts and Applications for Structural Engineers. New Jersey: John Wiley \& Sons, 2008.

GAMBHIR, M. L. Stability Analysis and Design of Structures. Berlim, Alemanha: Springer, 2004.

GAY NETO, A. Estabilidade estrutural da configuração estática de risers em catenária. Tese de Doutorado, Escola Politécnica da Universidade de São Paulo, São Paulo, 2012.

LI, Z.; SCHAFER, B. W. Buckling analysis of cold-formed steel members with general boundary conditions using CUFSM - conventional and constrained finite strip method. 20th International Specialty Conference on Cold-Formed Steel Structures. November 3-4, Saint Louis, Missouri, USA: [s.n.]. 2010.

MEZZOMO, G. P. Análise de flambagem de perfis formados a frio utilizando modos puros de deformação. Tese de Doutorado, Escola de Engenharia da Universidade Federal do Rio Grande do Sul, Porto Alegre, RS, 2012.

MORI, D. D.; NETO, J. M. Flexo torção: barras de seção delgada aberta. São Carlos, SP: EESC-USP, 2009.

MULLIGAN, G. P. A. M.; PEKOZ, T. M. Locally Buckled Thin-Walled Columns. Journal of Structural Engineering. v. 110, n. 11, p. 2635-2654, 1984.

NAGAHAMA, K. J. Análise de estabilidade local em perfis de seção aberta em aço e em resina reforçada com fibra de vidro. Tese de Doutorado, Universidade Federal do Rio de Janeiro, Rio de Janeiro, 2003. 
PIERIN, I. A instabilidade de perfis formados a frio em situação de incêndio. Tese de Doutorado, Escola Politécnica da Universidade de São Paulo, São Paulo, 2011.

PIMENTA, P. M. Fundamentos da Mecânica dos Sólidos e das Estruturas. Notas de Aula, Departamento de Estruturas e Fundações da Escola Politécnica da USP, São Paulo, 2006.

PIMENTA, P. M.; YOJO, T. Geometrically-exact analysis of spatial frames. Applied Mechanics Reviews. ASME, New York, 46, n. 11, 1993. 118-128.

PINTO, A. E. M. R. Estabilidade Local de Perfis de Aço Enformados a Frio. Dissertação de Mestrado, Instituto Superior Técnico da Universidade Técnica de Lisboa, Lisboa, 2010.

REIS, A.; DINAR, C. Estabilidade e dimensionamento de estruturas. Alfragide: Orion, 2012.

SARAWIT, A. T. et al. The finite element method for thin-walled membersapplications. Thin-Walled Structures. n. 41, p. 191-206, 2003.

SCHAFER, B. W.; ÁDÁNY, S. Buckling analysis of cold-formed steel members using CUFSM - conventional and constrained finite strip methods. 18th International Specialty Conference on Cold-Formed Steel Structures. October 26-27, Orlando, Florida, USA.: [s.n.]. 2006.

SCHAFER, B. W.; CAMOTIM, D. Special Issue on Cold-Formed Steel Structures. Journal os Structural Engineering (ASCE). v. 139, p. 637-639, 2013.

SCHAFER, B. W.; PEKOZ, T. Computational modeling of cold-formed steel: characterizing geometric imperfections and residual stresses. Journal of Constructional Steel Research, Elsevier Science Ltd. v. 47, p. 193-210, 1998.

SCHAFER, B. W.; PEKOZ, T. Laterally Braced Cold-Formed Steel Flexural Members with Edge Stiffened Flanges. Journal of Structural Engineering (ASCE). v. 125, n. 2, p. 118-127, 1999.

SILVA, E. L. Sobre os dimensionamentos de perfis de aço formados a frio. Dissertação de Mestrado, Escola Politécnica da Universidade de São Paulo, São Paulo, 2006.

SIMITSES, G. J. An introduction to the Elastic Stability of Structures. Englewood Cliffs, NJ: Prentice Hall, 1976.

THOMPSON, J. M. T. Instabilities and Catastrophes in Science and Engineering. London: John Wiley \& Sons, 1982.

THOMPSON, J. M. T.; HUNT, G. W. A General Theory of Elastic Stability. London: John Wiley \& Sons, 1973.

TIMOSHENKO, S. P.; GERE, J. M. Theory of elastic stability. 2. New York: McGraw-Hill, 1961. 
TIMOSHENKO, S. P.; WOINOWSKY-KRIEGER, S. Theory of plates and shells. New York: McGraw-Hill, 1959.

VLASOV, V. Z. Thin-walled elastic beams. Jerusalem: National Science Foundation, Washington D.C. by the Israel Program for Scientific Translations, 1961.

WASZCZYSZYN, Z.; CICHÓN, C.; RADWANSKA, M. Stability of Structures by Finite Element Methods. Cracow, Poland: Elsevier Science B. V., 1994.

ZAGOTTIS, D. Capítulo 10 - Introdução à teoria das estruturas. p. 10.1-10.81 Notas de Aula, Escola Politecnica da Universidade de São Paulo - Departamento de Engenharia de Estruturas e Fundações, São Paulo, 1980. 